\title{
Landscape-level assessment of ecological and socioeconomic functions of rainforest transformation systems in Sumatra (Indonesia)
}

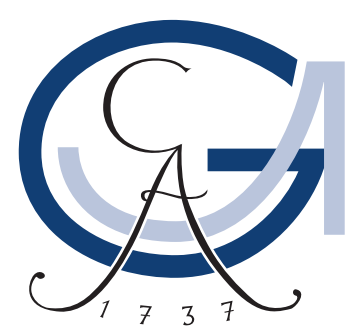

\author{
Dissertation \\ to attain the doctoral degree \\ "Doctor rerum naturalium" \\ of the Faculty of Forest Sciences and Forest Ecology \\ Georg-August-Universität Göttingen
}

Submitted by

Jan Salecker

born on March 4th, 1985 in Kassel

Göttingen, 2020 
1. Referee: Prof. Dr. Kerstin Wiegand, University of Goettingen

2. Referee: Prof. Dr. Holger Kreft, University of Goettingen

3. Referee: Prof. Dr. Volker Grimm, Helmholtz Centre for Environmental Research, UFZ

Additional committee member: Prof. Dr. Carola Paul, University of Goettingen

Date of oral examination: February 14, 2020 
Adopt the pace of nature: her secret is patience.

Ralph Waldo Emerson 


\section{Contents}

Index of Figures vii

Index of Tables viii

Glossary

Abstract $\quad x$

Zusammenfassung xi

$\begin{array}{lll}1 & \text { Introduction } & 1\end{array}$

1.1 Motivation . . . . . . . . . . . . . . . . . . . . . 1

1.2 Study area . . . . . . . . . . . . . . . . . . . . . 1

1.3 Research question . . . . . . . . . . . . . . . . . . . . . . . . . . . . . . . . . . . .

1.4 Methodology . . . . . . . . . . . . . . . . . . . 5

$1.4 .1 \quad$ Agent-based modelling . . . . . . . . . . . . . . . . 5

1.4 .2 Landscape Generators . . . . . . . . . . . . . . . . 5

1.4 .3 Software . . . . . . . . . . . . . . . . . . 6

$\begin{array}{lll}2 & \text { EFForTS-LGraf: A landscape generator } & 7\end{array}$

2.1 Introduction . . . . . . . . . . . . . . . . . . 8

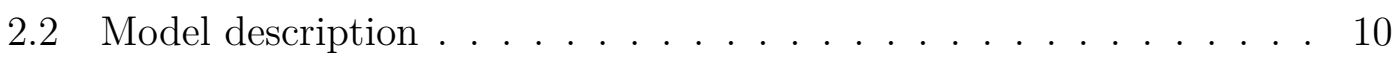

2.2 .1 Overview . . . . . . . . . . . . . . . . . . . . 10

2.2 .2 Design concepts . . . . . . . . . . . . . . . . . . . 14

$2.2 .3 \quad$ Details . . . . . . . . . . . . . . . . . . . . . . . 15

2.3 Scenarios and Parameterization . . . . . . . . . . . . . . 21

2.4 Results . . . . . . . . . . . . . . . . . . . . 26

2.4 .1 Approach 1: Sobol Sensitivity Analysis . . . . . . . . . . . . 26

2.4 .2 Approach 2: Validation . . . . . . . . . . . . . . 26

2.4.3 Approach 3: Applied case study . . . . . . . . . . . . . . . . 30

2.5 Discussion $\ldots \ldots \ldots \ldots \ldots \ldots$

2.6 Acknowledgments . . . . . . . . . . . . . . . . . . . . . . . . . 35

2.7 Author contributions . . . . . . . . . . . . . . . . . . . . . . 35

3 EFForTS-ABM: Land-use change in oil palm dominated tropical landscapes $\quad 36$ 3.1 Introduction . . . . . . . . . . . . . . . . . . . . . . . . . . . . . . . . . 37 
3.2 Methods . . . . . . . . . . . . . . . . . . . . . . . . . . . . 39

$3.2 .1 \quad$ Overview $\ldots \ldots \ldots \ldots$

3.2 .2 Design concepts . . . . . . . . . . . . . . . . . . . 43

3.2 .3 Model scenarios . . . . . . . . . . . . . . . . . . . 46

3.3 Results and Discussion . . . . . . . . . . . . . . . . . . . 47

3.4 Outlook $\ldots \ldots \ldots \ldots \ldots \ldots$

3.5 Acknowledgments . . . . . . . . . . . . . . . . . . 58

3.6 Author contributions . . . . . . . . . . . . . . . . . . 58

4 From bacteria to birds: tropical land-use change causes variable responses in species turnover $\quad 59$

$4.1 \quad$ Main . . . . . . . . . . . . . . . . . . . . . . . . . . 60

4.2 Conclusion $\ldots \ldots \ldots \ldots \ldots$

4.3 Acknowledgments . . . . . . . . . . . . . . . . . . 70

4.4 Funding $\ldots \ldots \ldots \ldots \ldots \ldots \ldots$

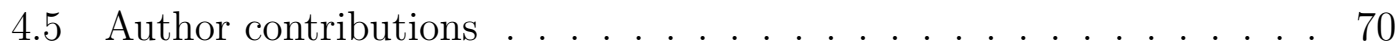

\begin{tabular}{|lll}
5 & The $n \operatorname{lr} x$ R package & 71
\end{tabular}

5.1 Introduction . . . . . . . . . . . . . . . . . . 72

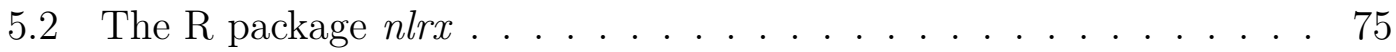

5.2 .1 nlrx workflow . . . . . . . . . . . . . . . 78

5.2 .2 Further functionality $\ldots \ldots \ldots \ldots$

5.3 Use case: Ants model . . . . . . . . . . . . . . . . . . . . . . 82

$5.3 .1 \quad$ Sensitivity Analysis with $n l r x \ldots \ldots \ldots$. . . . . . . . 82

5.3 .2 Genetic Algorithm with $n \operatorname{lrx} \ldots \ldots \ldots \ldots$. . . . . . 85

5.4 Conclusion and outlook . . . . . . . . . . . . . . . . . 88

5.5 Acknowledgments $\ldots \ldots \ldots \ldots \ldots$

5.6 Author Contribution $\ldots \ldots \ldots \ldots \ldots$

5.7 Data Accessibility $\ldots \ldots \ldots \ldots \ldots$

$\begin{array}{lll}6 & \text { Consolidated discussion } & 91\end{array}$

6.1 Discussion $\ldots \ldots \ldots \ldots \ldots$

6.2 Outlook $\ldots \ldots \ldots \ldots \ldots \ldots$

\begin{tabular}{ll}
\hline Appendices & 95
\end{tabular}

\begin{tabular}{|l|l|l|}
\hline A Supplementary Material: EFForTS-LGraf (Chapter 2 ) & 96
\end{tabular}

A.1 Model Details . . . . . . . . . . . . . . . . . . . . . . . 996

A.1.1 Details on road creation and household placement . . . . . . 96

A.1.2 Details on field establishment . . . . . . . . . . . . 97 
A.1.3 Details on EFForTS-LGraf spatial output . . . . . . . . . . 98

A.2 Analysis Details . . . . . . . . . . . . . . . 100

A.2.1 Approach 1: Sobol sensitivity analysis . . . . . . . . . . . . 100

A.2.2 $\quad$ Approach 2: Validation . . . . . . . . . . . . . . . . . . . . 101

A.2.3 $\quad$ Approach 3: Applied case study . . . . . . . . . . . . . . . . 105

\begin{tabular}{ll|l|l|}
\hline B Supplementary Material: EFForTS-ABM (Chapter & 3 ) & 108
\end{tabular}

B.1 EFForTS-ABM: Model details . . . . . . . . . . . . . . . . . 108

B.1.1 Initialization . . . . . . . . . . . . . . . . . . . . 108

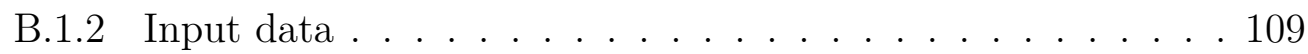

B.1.3 Submodels . . . . . . . . . . . . . . . . . . . . . . . 109

B.2 Parameterization of the household submodel . . . . . . . . . . . . 124

B.2.1 Production functions for oil palm and rubber. . . . . . . . . . 125

B.2.2 Costs, revenue \& Cash flow . . . . . . . . . . . . . . . . . . 134

B.2.3 Initial household inefficiency distribution . . . . . . . . . . . 138

B.2.4 Initial household wealth . . . . . . . . . . . . . . . . . . 139

B.2.5 Price dynamics . . . . . . . . . . . . . . . . . . . . . . . . . . 139

B.3 EFForTS-LGraf: Landscape generator . . . . . . . . . . . . . . . . 141

B.3.1 Parametrization of EFForTS-LGraf . . . . . . . . . . . . . . 142

B.4 Conversion of plantation plots under different land uses . . . . . . . 143

B.5 Additional model results . . . . . . . . . . . . . . . . . . . . . 144

\begin{tabular}{|ll|l|l|}
\hline C Supplementary Material: From bacteria to birds (Chapter & 448
\end{tabular}

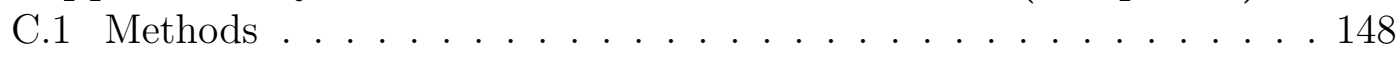

C.1.1 Study region and study design . . . . . . . . . . . . . . . . . 148

C.1.2 Species data . . . . . . . . . . . . . . . . . . . . . . . . . 148

C.1.3 Environmental data . . . . . . . . . . . . . . . . . . . . 151

C.1.4 Analysis . . . . . . . . . . . . . . . . . 153

\begin{tabular}{|l|l|l|}
\hline S Supplementary Material: $n l r x$ package (Chapter & 5 ) & 161
\end{tabular}

D.1 Benchmark details . . . . . . . . . . . . . . . . . . 161

D.2 Ants parallel . . . . . . . . . . . . . . . . . . . . . . . . . . . . . 162

D.3 nldoc . . . . . . . . . . . . . . . . . . . . . . . . . . . . . . . . . . 164

D.3.1 Documentation of NetLogo models with $n l r x$. . . . . . . . . 164

D.3.2 Generate procedure networks of NetLogo models with $n$ lrx .175

D.4 Ants spatial . . . . . . . . . . . . . . . . . . 175

\begin{tabular}{lr}
\hline References & 179
\end{tabular}

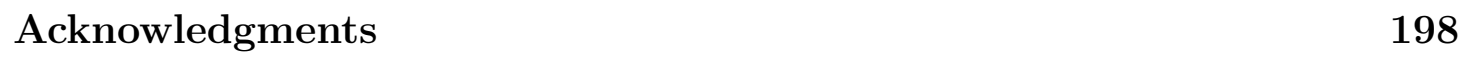

Doktoranden-Erklärung der Georg-August-Universität Göttingen 199 


\section{Index of Figures}

1.1 Study design of the EFForTS project . . . . . . . . . . . . . 2

1.2 Framework of models and tools . . . . . . . . . . . . . . . . 4

2.1 EFForTS-LGraf flowchart . . . . . . . . . . . . . . . . . . . . . . 12

2.2 Output map examples of EFForTS-LGraf. . . . . . . . . . . . . . . 13

2.3 Household size distributions $\ldots \ldots \ldots$. . . . . . . . . . . . . . . 22

2.4 Reclassified satellite image of Harapan landscape . . . . . . . . . . 23

$2.5 \quad$ Sensitivity analysis results $\ldots \ldots \ldots \ldots$. . . . . . . . . . . 27

2.6 Example maps of EFForTS-LGraf validation . . . . . . . . . . . . . 28

2.7 Landscape metrics analysis of EFForTS-LGraf validation . . . . . . 29

2.8 Example maps of applied case study with EFForTS-LGraf . . . . . 30

2.9 Regression results of applied case study with EFForTS-LGraf. . . . . 31

3.1 Initial land-use and household maps . . . . . . . . . . . . . . . . . . 41

3.2 Process overview of the whole model . . . . . . . . . . . . . . . . . 44

3.3 Process overview of the economic household model . . . . . . . . . 45

3.4 Snapshots of simulated landscape . . . . . . . . . . . . . . . . . . 49

3.5 Development of land use, consumption, and carbon over time. . . . 50

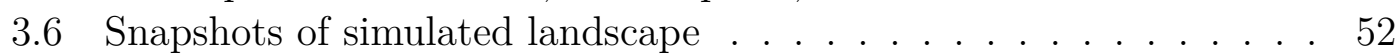

$3.7 \quad$ Development of land use, consumption, and carbon over time. . . . 53

3.8 Delevopment of yield gaps over time . . . . . . . . . . . . . 56

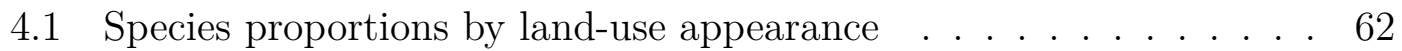

$4.2 \quad$ Effects of land-use change on alpha and beta diversity . . . . . . . . . 64

4.3 Correlations of species richness and community dissimilarity . . . . 66

$4.4 \quad$ Drivers of dissimilarity by category . . . . . . . . . . . . . . . 68

4.5 Drivers of dissimilarity by principal components . . . . . . . . . . . 69

$5.1 \quad$ Benchmarks of the $n l r x$ package . . . . . . . . . . . . . . . . . 74

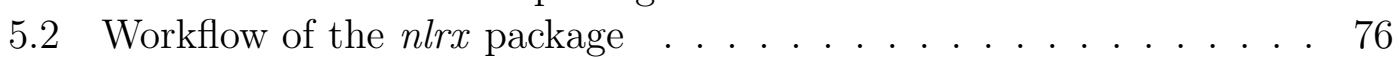

5.3 Spatial output of the ants model . . . . . . . . . . . . . . . . . . . 81

5.4 Sensitivity analysis of the ants model . . . . . . . . . . . . . . . . 85

5.5 Optimization results of the ants model . . . . . . . . . . . . . . 87

A.1 3D rendered snapshot of EFForTS-LGraf . . . . . . . . . . . . . . . 99

A.2 Landscape metrics comparison between generated landscapes and samples from reclassified satellite image . . . . . . . . . . . . . 102 
A.3 Comparison between generated landscape maps and map samples from reclassified satellite image . . . . . . . . . . . . . . . 104

A.4 Effect of land-use specialization and household area on selected landscape metrics . . . . . . . . . . . . . . . 107

B.1 Carbon stocks of different land-use types . . . . . . . . . . . . . . 123

B.2 Oil palm and rubber yield functions . . . . . . . . . . . . . . . . . . . 126

B.3 Oil palm and rubber labor functions . . . . . . . . . . . . . . . . 130

B.4 Oil palm and rubber technical input functions . . . . . . . . . . . . . 132

B.5 Oil palm and rubber investment costs and capital stocks . . . . . . 133

B.6 Oil palm cost functions . . . . . . . . . . . . . . . . . . . . 134

B.7 $\quad$ Rubber cost functions . . . . . . . . . . . . . . . . . . . . . . . . . . 135

B.8 Oil palm revenue, net cash flow, and expected net cash flows . . . . 136

B.9 $\quad$ Rubber revenue, net cash flow, and expected net cash flows . . . . . 137

B.10 Comparison of expected net cash flows for oil palm and rubber . . . 138

B.11 Efficiency distribution of survey households . . . . . . . . . . . . 138

B.12 Histogram of households purchased assets value with fit to data . . 140

B.13 Output price functions . . . . . . . . . . . . . . . 141

B.14 Histogram of household sizes with fit to data . . . . . . . . . . . . . 142

B.15 Histogram of field sizes with fit to data . . . . . . . . . . . . . . . . 143

B.16 Land-use change and replanting of fields under constant prices scenario 145

B.17 Land-use change and replanting of fields under historical price trends

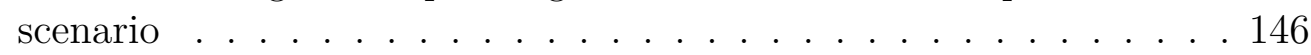

B.18 Correlation of land-use change and output prices under historical price trends scenario . . . . . . . . . . . . . . . . . . 147

C.1 Contributions of environmental variables to principal components . 154

C.2 Rarefaction curves for canopy ants, canopy parasitic wasps, butterflies, birds, and plants . . . . . . . . . . . . . 157

C.3 Rarefaction curves for leaf litter ants, spiders, fungi, oribatida, and

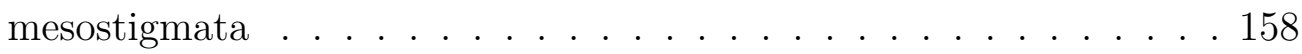

C.4 Rarefaction curves for testate amoeba, archaea, bacteria, and protists 159

C.5 Rarefaction curves for chilopoda, leaf litter beetles, and leaf litter

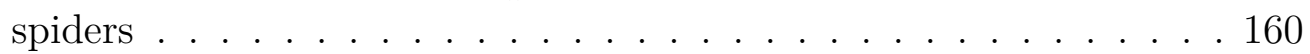

D.1 Procedure network of Wolf Sheep Predation model . . . . . . . . . 175

D.2 Results from bivariate point pattern analysis of the ants model . . . 178 


\section{Index of Tables}

2.1 EFForTS-LGraf model parameters . . . . . . . . . . . . . 16

2.2 Landscape metrics description $\ldots \ldots \ldots$. . . . . . . . . . . . . 22

$3.1 \quad$ Spatial units of the model . . . . . . . . . . . . . . . . . . 40

3.2 List of household variables $\ldots \ldots$. . . . . . . . . . . . . . . . . . . . . 42

3.3 List of cell variables . . . . . . . . . . . . . . . . . . . . . . . 43

3.4 Model scenarios $\ldots \ldots \ldots$. . . . . . . . . . . . . . . . . . 47

5.1 Main differences between NetLogo's BehaviorSpace, RNetLogo, and

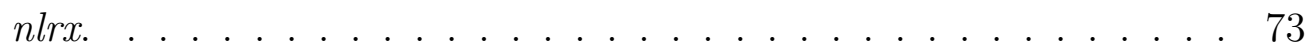

5.2 List of slots of an $\mathrm{nl}$ S4 class object. . . . . . . . . . . . . . . . 75

5.3 List of slots of an experiment S4 class object. . . . . . . . . . . . . . 77

5.4 List of slots of a simdesign S4 class object. . . . . . . . . . . . . . 78

A.1 Sobol sensitivity analysis parameter ranges . . . . . . . . . . . . . . 100

A.2 Applied case study parameter ranges . . . . . . . . . . . . . . . 105

B.1 Initial household parameter values . . . . . . . . . . . . . . . . . . . 110

B.2 $\quad$ Parameters of the production and cost functions . . . . . . . . . . . 127

B.3 Parameters of the economic household model . . . . . . . . . . . . . 128

B.4 Plantation conversions . . . . . . . . . . . . . . . . . . . 144

C.1 Summary of species data . . . . . . . . . . . . . . . . . . . . . . 149

C.2 Summary of environmental data . . . . . . . . . . . . . . . . . . 151

D.1 System specifications of machines running benchmark simulations. . 161 


\section{Glossary}

ABM Agent-based models.

EFForTS Ecological and Socioeconomic Functions of Tropical Lowland Rainforest Transformation Systems, Indonesia.

EFForTS-LGraf EFForTS-Landscape Generator Roads And Fields.

EFForTS-ABM EFForTS-agent-based model.

FFB fresh fruit bunches.

GDM Generalized dissimilarity models.

GLM Generalized linear models.

HPC High Performance Computing.

LPI largest-patch-index.

LSI landscape-shape-index.

MAS/LUCC Multi-agent system models of land-use/cover change.

nlrx Netlogo to R via XML.

ODD Overview, Design concepts and Details.

PCI patch-cohesion-index.

SESs Social-Ecological Systems.

SRC standardized regression coefficients. 


\section{Abstract}

Tropical landscapes have experienced drastic land-use change in recent decades. The transformation from natural vegetation to agricultural production systems has a variety of negative impacts on ecosystem functioning, but also increases the potential for economic benefits. Generating a mechanistic understanding of the processes driving these dynamics is an essential step in identifying potential synergies that can improve ecosystem functioning without drastically affecting economic prosperity.

Our study sites are located in the province of Jambi on the Island of Sumatra, Indonesia, which is a model region for smallholder-driven land-use change. We want to identify trade-offs and synergies between economic prosperity and ecosystem functioning in Jambi's smallholder landscapes. Further, we want to investigate how smallholder heterogeneity affects these trade-offs. We also want to investigate the temporal and spatial dynamics of these trade-offs.

In order to initialize our model landscapes we developed EFForTS-LGraf, a processbased, agent-based landscape generator for smallholder landscapes. In order to answer our main research questions, we have developed EFForTS-ABM a spatially-explicit, agentbased, coupled socio-economic and ecological simulation model. The economic submodel simulates smallholder land-use management decisions based on a profit maximization assumption. The ecological submodel includes a simple account of carbon sequestration in above-ground and below-ground vegetation. In order to cover more aspects of ecosystem functions in EFForTS-ABM, we have analyzed biodiversity patterns of 14 taxa which will inform our upcoming biodiversity submodel. We have also developed the $\mathrm{R}$ package nlrx, which allows us to connect our two main software environments $\mathrm{R}$ and NetLogo.

EFForTS-LGraf is able to generate realistic land-cover maps with properties that lie within the boundaries of landscapes from classified satellite images. The overall results of EFForTS-ABM reveal complex interactions between the economic and ecological spheres and strong effects of smallholder heterogeneity and market prices. Our analysis of biodiversity patterns of 14 taxa indicated strong differences in the composition of forest and agroforest communities versus rubber or oil palm plantations. However, the different taxonomic groups showed highly variable responses to land-use intensification. The nlrx package provides a valuable framework to run simulations with improved performance compared to previous approaches.

Our findings underline the utility of coupled ecological-economic models, to act as exploratory tools which can advance our understanding of the mechanisms underlying the trade-offs and synergies of ecological and economic functions in tropical landscapes. Such an understanding is highly needed in order to develop and guide policy recommendations that lead to a more sustainable land-use in smallholder dominated landscapes of Indonesia. 


\section{Zusammenfassung}

In den letzten Jahrzehnten unterlagen tropische Landschaften einem drastischen Wandel der Landnutzung. Die Transformation der natürlichen Vegetation, hin zu landwirtschaftlichen Produktionssystemen bedeutet negative Auswirkungen auf Ökosystemfunktionen, erhöht aber das Potenzial für wirtschaftliche Entwicklungen. Ein mechanistisches Verständnis der Prozesse, die diese Dynamik antreiben, ist ein wesentlicher Schritt bei der Identifizierung von Synergien, um Ökosystemfunktionen zu erhalten, ohne die wirtschaftliche Entwicklung zu beeinträchtigen.

Unsere Untersuchungsflächen befinden sich in der Provinz Jambi auf der Insel Sumatra, Indonesien, eine Modellregion für kleinbäuerliche Landnutzungsänderungen. Wir wollen Wechselwirkungen und Synergien zwischen wirtschaftlichem Wohlstand und Ökosystemfunktionen in Jambi identifizieren. Darüber hinaus wollen wir den Einfluss von Kleinbauernheterogenität auf diese Wechselwirkungen untersuchen. Dabei untersuchen wir auch die zeitliche und räumliche Dynamik dieser Wechselwirkungen.

Zur Initialisierung unserer Modelllandschaften haben wir EFForTS-LGraf entwickelt, einen prozess- und agentenbasierten Landschaftsgenerator für kleinbäuerliche Landschaften. Mit EFForTS-ABM haben wir ein räumlich-explizites, agentenbasiertes, gekoppeltes sozioökonomisches und ökologisches Simulationsmodell entwickelt. Das ökonomische Teilmodell simuliert Landnutzungsentscheidungen auf Grundlage einer Gewinnmaximierungsannahme. Das ökologische Teilmodell beinhaltet eine Schätzung der Kohlenstoffsequestrierung in der Vegetation. Weiterhin haben wir Analysen der Biodiversitätsmuster von 14 Taxa durchgeführt. Diese bilden die Grundlage für unser zukünftiges Biodiversitätsteilmodell. Wir haben außerdem das R-Paket nlrx entwickelt, mit dem wir unsere beiden Softwareumgebungen $\mathrm{R}$ und NetLogo verbinden können.

Ein Vergleich unserer Modelllandschaften mit klassifizierten Satellitenbildern zeigte, dass EFForTS-LGraf realistische Bodendeckungskarten erstellen kann. Die Gesamtergebnisse von EFForTS-ABM zeigen komplexe Wechselwirkungen zwischen Ökonomie und Ökologie und einen starken Einfluss der Kleinbauernheterogenität und Marktpreise. Unsere Analyse der Biodiversitätsmuster von 14 Taxa zeigte starke Unterschiede in der Zusammensetzung von Wald- und Agrowaldgemeinschaften im Vergleich zu Gummioder Ölpalmenplantagen. Die verschiedenen taxonomischen Gruppen zeigten jedoch sehr unterschiedliche Reaktionen auf die Intensivierung der Landnutzung. Das nlrx Paket bietet uns das Werkzeug für die Durchführung von Simulationen mit erhöhter Leistung im Vergleich zu bereits bestehenden Lösungen.

Unsere Ergebnisse unterstreichen den Nutzen ökologisch-ökonomischer Modelle als Instrumente, die unser Verständnis der Mechanismen, die den Wechselwirkungen und Synergien ökologischer und ökonomischer Funktionen zugrunde liegen, verbessern können. Ein solches Verständnis ist dringend erforderlich, um politische Empfehlungen zu entwickeln, die zu einer nachhaltigeren Landnutzung in den kleinbäuerlich dominierten Landschaften Indonesiens führen. 


\section{Chapter 1}

\section{Introduction}

\subsection{Motivation}

In past decades, land-use changes have transformed tropical landscapes dramatically. Ongoing deforestation and agricultural intensification are the most important processes driving this land-use change (Powell et al., 2015). Many studies have shown that agricultural intensification can lead to drastic losses in ecosystem services (ClOugh et al., 2016, Dislich et al., 2017). At the same time, economic development opportunities increase with the ongoing transformations (KLASEN et al., 2013, SAYER et al., 2012).

The transformation of natural systems into agricultural areas therefore implies a multitude of trade-offs between the provision of ecosystem services on the one hand and the creation of opportunities for economic benefit on the other. These trade-offs are likely to be complex, often non-linear, scale-dependent and not well understood. Generating a mechanistic understanding of the processes that drive these trade-offs is an essential step in identifying potential synergies that can improve the functioning of ecosystems on a landscape scale without drastically compromising economic prosperity.

This thesis presents a unique approach aiming at the landscape-level assessment of ecological and socio-economic functions of rainforest transformation systems in Sumatra. Our approach comprises the development and application of several novel modelling and analysis tools.

\section{$1.2 \quad$ Study area}

Our research is embedded within the interdisciplinary research project "Ecological and Socioeconomic Functions of Tropical Lowland Rainforest Transformation Systems, Indonesia (EFForTS)". The field research of the collaborative research centre EFForTS was conducted in Jambi province, Sumatra, Indonesia. This region faced severe land-use change during the last century and large areas are dominated by smallholder agriculture (CLOUGH et al., 2016). In the 1980s transmigration villages were introduced under the Suharto regime which led to a shift from shifting cultivation and subsistence farming to smallholder expansion by transmigration 
(Kunz et al., 2017). Many of the transmigrants that moved from the island of Java to Jambi province were contract farmers for oil palm production (KunZ et al., 2017). Subsequently, rainforests were transformed into agricultural plantations (mainly rubber and oil palm) (ClOUGH et al., 2016).

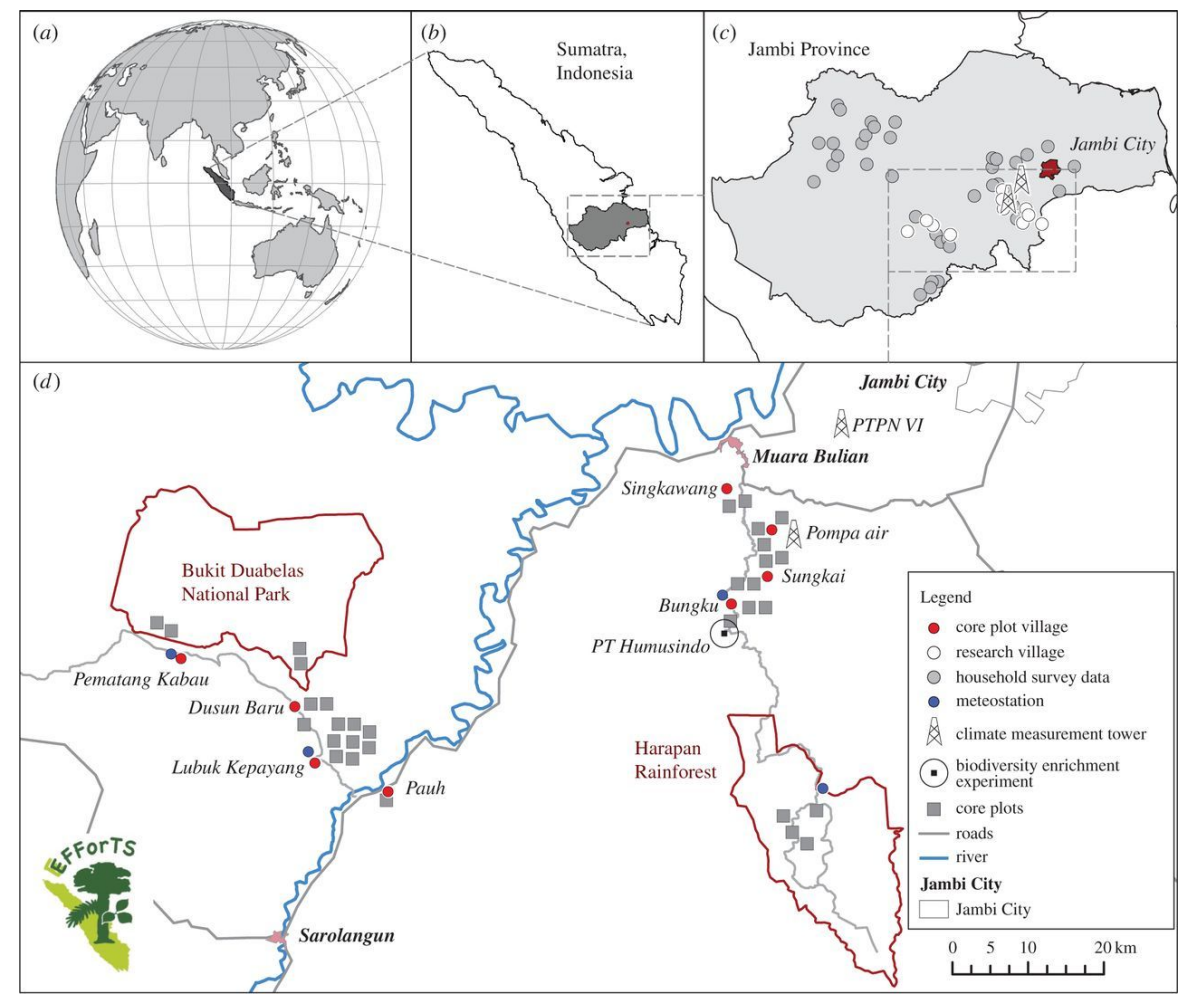

Figure 1.1: Location of EFForTS study sites in Sumatra (a,b) and Jambi Province $(\mathrm{c}, \mathrm{d})$. Socio-economic surveys are carried out all over Jambi Province (c), while the core plots are located in two landscapes near to Bukit Duabelas National Park and Harapan Rainforest (d). The map was originally published in DRESCHER et al., 2016

Field research was carried out in two selected areas of Jambi, Harapan and Bukit Duabelas (with loam and Acrisol soils, respectively) (see Fig. 1.1). In each of these areas four so-called core plots were established for each of the four dominating landuse types in Jambi, namely primary degraded lowland rainforest (MARGONO et al., 2014), jungle rubber (rubber agroforestry system), rubber monoculture plantation, and monoculture oil palm plantation. In sum, 32 core plots were established, each with an area of $50 \mathrm{~m} \times 50 \mathrm{~m}$. While forest plots were established in the Bukit Duabelas National Park and the Harapan Rainforest Restoration concession (PT REKI), all core plots with agricultural land uses were owned and managed by smallholders. Within each plot, five permanent $5 \mathrm{~m} \times 5 \mathrm{~m}$ subplots were established. 
On these core plots, data of various types, ranging from biodiversity surveys over soil sampling and productivity measurements to bioclimatic conditions have been collected by several sub-groups of the EFForTS project (DRESCHER et al., 2016).

In addition, several household and village surveys have been conducted in Jambi province by the EFForTS project. In our approach, we mainly draw on a household survey of 701 smallholder households, which include information such as households' land holdings, agricultural and non-agricultural activity, endowments, and household composition (for more details see EuLER et al., 2016b EuLER et al., 2017; Krishna et al., 2014; Krishna et al., 2015, and Section B.2 in Appendix B). Detailed information on the general study design of the EFForTS project were also published in Clough et al., 2016 and Drescher et al., 2016.

\subsection{Research question}

Due to the cultural, historical, and political background, smallholders in Jambi are found to be very heterogeneous in decision-making (crop selection, management), efficiency and wealth (EULER et al., 2016b; EulER et al., 2017). Studies could show that decision-making of smallholders in Jambi is strongly driven by individual households and village characteristics and rational economic considerations (EULER et al., 2017; Hetтig et al., 2016). These decisions are a main driver of the resulting landscape mosaic and thus of the potential for provisioning of ecosystem services and biodiversity (CLOUGH et al., 2016). We have developed the simulation model EFForTS-agent-based model (EFForTS-ABM), in order to understand the linkages between individual rational economic decision-making and ecological consequences on plot and landscape scale (see Chapter 3). Our main goal is first to identify potential trade-offs and synergies between economic benefit and ecosystem functioning, second to find landscape mosaics that optimize ecosystem functioning without drastic losses in economic welfare, and third to develop and to test policy schemes that can be implemented to reach such "optimal" landscape mosaics. Our main research questions can be summarized as:

- Which trade-offs and synergies exist between economic welfare and ecosystem functioning in smallholder landscapes in Jambi?

- How does heterogeneity in smallholder properties and management practices affect these trade-offs?

- How do trade-offs vary across time and space?

Development of several tools was needed to conduct our research (see Fig. 1.2). We developed the landscape generator EFForTS-Landscape Generator Roads And Fields (EFForTS-LGraf) to initialize EFForTS-ABM with realistic landscapes 


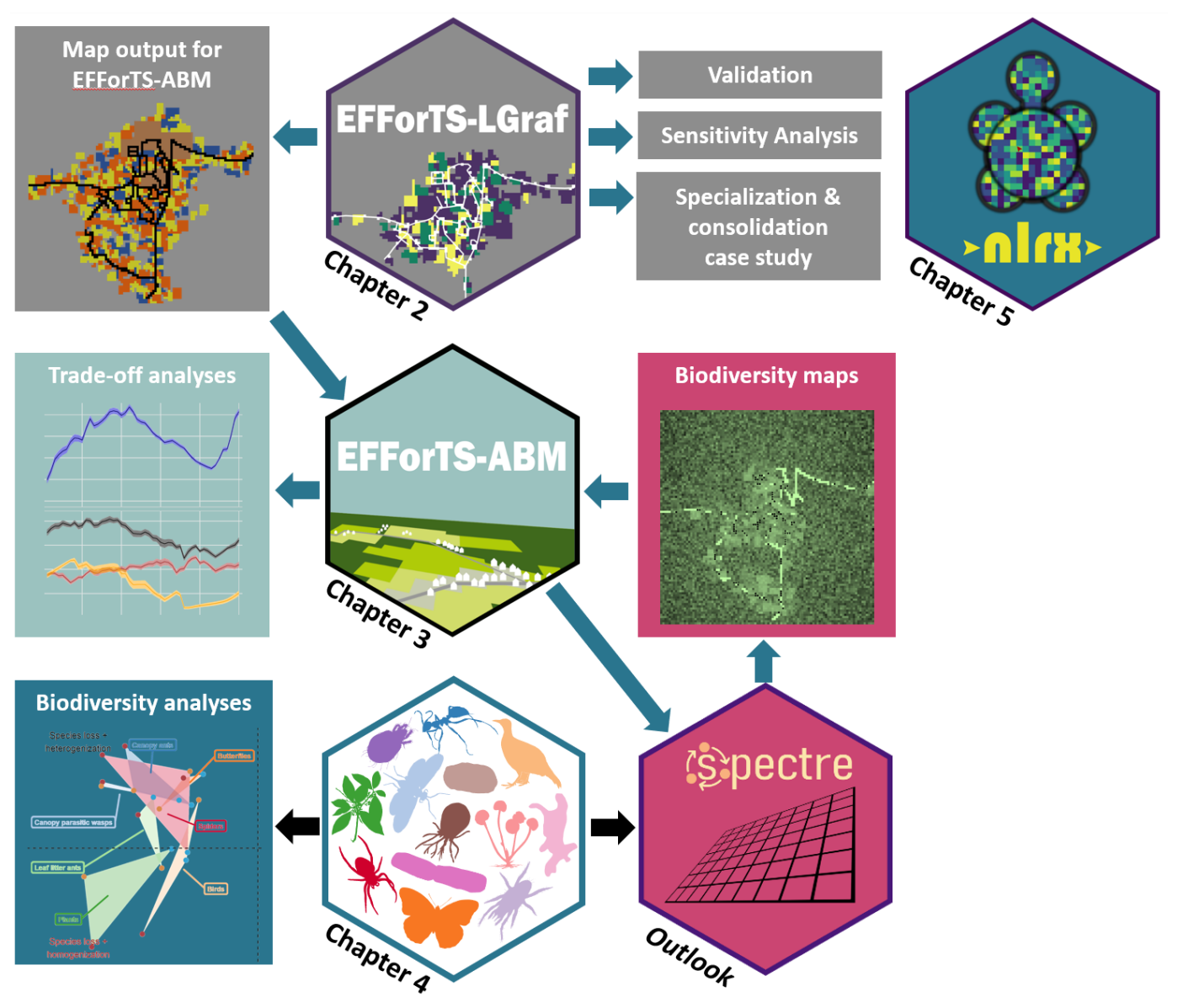

Figure 1.2: Framework of models and tools developed and used within this study. Hexagons indicate models (EFForTS-LGraf, EFForTS-ABM, biodiversity models) and $\mathrm{R}$ packages (nlrx, spectre). Square boxes indicate conducted analyses and results. Arrows indicate dependencies between tools and outputs. Blue arrows indicate dependencies that are enabled via the nlrx package.

(see Chapter 2). We developed EFForTS-ABM to simulate smallholder decisionmaking and assess trade-offs and synergies of ecosystem functioning and economic welfare in the smallholder landscapes of Jambi, Indonesia (see Chapter 3). We present a detailed study, looking into patterns of biodiversity across a multitude of taxa in Jambi, Indonesia (see Chapter 4). This study is an important step for implementation of the upcoming biodiversity module into EFForTS-ABM. Finally, we developed the $\mathrm{R}$ package Netlogo to $R$ via XML (nlrx) to connect our main modelling environment NetLogo with the statistics software $R$ and enable reproducable and repeatable simulations and access to High Performance Computing (HPC) resources (see Chapter 5). 


\subsection{Methodology}

\subsubsection{Agent-based modelling}

Agent-based, spatially explicit modelling offers some advantages over other model forms for the present research project. Agent-based models (ABM) are characterized by their mostly low degree of abstraction compared to mathematical equation models, for example (Grimm and RAILSBACK, 2005). The parameter values are therefore often easy to determine, since these values are based on the processes that exist in reality. Model rules can be implemented individually and are not dependent on an a priori comprehensive understanding of the entire system, but rather contribute to achieving such an understanding. The graphical and statistical evaluation possibilities of ABM $\$$ are very extensive and graphical representations facilitate communication with non-modelers (CARTWRIGHT et al., 2016).

While many agent-based modelling studies focus either on ecological or socioeconomic aspects and human decision-making, several modelling approaches combine both spheres in coupled ABMs (reviewed in AN, 2012). ABMs are especially well suited for such cases because they allow to capture the heterogeneity of agents, decision-making, and the landscape at various scales (AN et al., 2005; BRUCH and Atwell, 2015). Because the temporal dynamics are most often explicitly considered in $\overline{\mathrm{ABM}}$, it is further possible to incorporate feedback loops between natural and socio-economic processes across temporal scales (BRUCH and ATWELL, 2015).

Following the classification of AN, 2012, we developed a microeconomic ABM in order to synthesize our knowledge on ecological and socio-economic processes of smallholder agriculture in Jambi, Indonesia. The extensive EFForTS household survey (Euler et al., 2016b; Euler et al., 2017; Krishna et al., 2014; KrishnA et al., 2015) allows us to develop an economic smallholder submodel that takes heterogeneity between agents into account and drives the decision-making in our model landscapes. Furthermore, we utilize the broad range of ecological data from the EFForTS core plots (see Drescher et al., 2016) to implement and parameterize our ecological submodel that is affected by smallholder decisions and might potentially feed back into production decisions of smallholder agents in future periods.

\subsubsection{Landscape Generators}

Following a spatially-explicit modelling approach means that spatial information of smallholder positions, field dimensions, and field ownership needs to be available to set up the initial model landscapes of EFForTS-ABM. However, often such data is not available or can not be obtained at the necessary level of detail. Landscape 
generators are one solution to overcome such problems (LANGHAMMER et al., 2019). Landscape generators can be broadly classified into two categories: pattern-based generators that reproduce properties of real landscapes by application of purely mathematical algorithms (also known as neutral landscape generators, e.g. SCIAINI et al., 2018); and process-based generators that take into account the processes that led to the pattern (e.g. PE'ER et al., 2013). Another advantage of landscape generators is the possibility to run simulations on various different model landscapes and scenarios, such as representations close to reality, extreme case scenarios or scenarios including potential conservation areas. A recent review of landscape generator software showed that no other landscape generator was published that explicitly incorporates the human dimension of land-use change and provides detailed information on smallholder porperties and field ownership (LANGHAMMER et al., 2019). Thus, we developed the agent-based landscape generator EFForTSLGraf that generates input maps for our simulation model EFForTS-ABM and incorporates the relevant processes of land-use change in smallholder landscapes of Jambi province explicitly.

\subsubsection{Software}

The EFForTS-ABM and EFForTS-LGraf models were both implemented in the freely available open-source modelling environment NetLogo (WiLENSKY, 1999). Model analyses were conducted with the open-source statistics software R ( R CORE TEAm, 2018). In order to conduct efficient, reproducable, and repeatable model simulations it was necessary to link these two environments. While the R-package RNetLogo (THIELE et al., 2012) provides functions for linking $\mathrm{R}$ and NetLogo we found several stability issues and had difficulties in running large scale simulation experiments on remote HPC clusters. Thus, we developed the R-package nlrx in order to overcome these issues. 


\title{
Chapter 2
}

\section{EFForTS-LGraf: A landscape generator for creating smallholder-driven land-use mosaics}

This chapter was published as a research article:

Salecker, J., Dislich, C., Wiegand, K., Meyer, K. M., and Pe'er, G. (2019). "EFForTS-LGraf: A Landscape Generator for Creating Smallholder-Driven Land-Use Mosaics". PLOS ONE 14.9, 1-24. doi: 10.1371/journal.pone.0222949.

\begin{abstract}
Spatially-explicit simulation models are commonly used to study complex ecological and socio-economic research questions. Often these models depend on detailed input data, such as initial land-cover maps to set up model simulations. Here we present the landscape generator EFFortS-LGraf that provides artificially-generated land-use maps of agricultural landscapes shaped by small-scale farms. EFForTSLGraf is a process-based landscape generator that explicitly incorporates the human dimension of land-use change. The model generates roads and villages that consist of smallholder farming households. These smallholders use different establishment strategies to create fields in their close vicinity. Crop types are distributed to these fields based on crop fractions and specialization levels. EFForTS-LGraf model parameters such as household area or field size frequency distributions can be derived from household surveys or geospatial data. This can be an advantage over the abstract parameters of neutral landscape generators. We tested the model using oil palm and rubber farming in Indonesia as a case study and validated the artificially-generated maps against classified satellite images. Our results show that EFForTS-LGraf is able to generate realistic land-cover maps with properties that lie within the boundaries of landscapes from classified satellite images. An applied simulation experiment on landscape-level effects of increasing household area and crop specialization revealed that larger households with higher specialization levels led to spatially more homogeneous and less scattered crop type distributions and reduced edge area proportion. Thus, EFForTS-LGraf can be applied both to generate maps as inputs for simulation modelling and as a stand-alone tool for
\end{abstract}


specific landscape-scale analyses in the context of ecological-economic studies of smallholder farming systems.

\subsection{Introduction}

Land-use change was highlighted as one of the most important anthropogenic impacts on ecosystems (LAMBIN et al., 2001). Agent-based models (ABMs) are widely applied to study the human perspective of land-use change (Multi-agent system models of land-use/cover change (MAS/LUCC) and Social-Ecological Systems (SESs), addressing the tight inter-coupling between ecological and socioeconomic processes (Matthews et al., 2007; PARKer et al., 2003, Schulze et al., 2017). Recent spatially-explicit simulation models in land-use science typically incorporate environmental heterogeneity by modelling the spatio-temporal distribution and dynamics of land-cover types (e.g. AYllón et al., 2016. TietJen, 2016).

However, environmental data, such as land-cover maps, can often not be obtained at the necessary level of detail. This problem is especially prevalent in tropical regions, where constant cloud coverage limits remote sensing data usability. In such cases, as well as for systematic research analyses, it may be necessary to artificially generate land-cover maps that approximate reality. For this purpose, landscape generators (also called landscape simulators) have been developed (LANGHAMMER et al., 2019). A typical landscape generator creates landscapes consisting of a grid of cells, where each cell is assigned a given land-cover type. Landscape generators can also be used to systematically generate many similar land-cover maps and thereby allow for scenario-based control of landscape characteristics. Moreover, the option of producing a range of (also non-realistic) landscapes, e.g. by setting population density or field sizes to unrealistically high values, is an important tool for testing potential scenarios and improving the understanding of model processes.

Two approaches are known for landscape generators: pattern-based landscape generators and process-based landscape generators (LANGHAMMER et al., 2019). Many pattern-based landscape generators are based on artificial (e.g. fractal) algorithms with relatively low model complexity and only a small number of parameters. The resulting landscapes are often known as neutral landscapes (GARDNER et al., 1987; Wiтh, 1997). However, real world land-cover patterns are often the result of historical land-use change by human interaction with the landscape and as such a result of the processes that shape these landscape. Furthermore, the outcomes of these interactions often result in spatial patterns that differ substantial from those shaped by neutral processes. Thus, in contrast to pattern-based landscape generators, process-based generators try to simulate the processes that lead to the pattern (SCHRÖDER and SEPPELT, 2006). The process-based approach can be 
more costly regarding the number of parameters and model complexity. However, parameters often have an empirical meaning and can be measured with surveys allowing for creation of artificial landscapes that mimic properties of real world landscapes of a certain study area.

Two key processes driving anthropogenic land-use changes are the rapid expansion of roads (IBISCH et al., 2016 LAURANCE et al., 2009) and the related expansion and intensification of agricultural fields (LAURANCE et al., 2014). Models that incorporate these processes into models of landscape design, such as DYPAL (GAUCHEREL et al., 2006) and G-RaFFe (PE'ER et al., 2013), have been shown to successfully produce realistic ranges of landscape characteristics for anthropogenically-altered landscapes. However, for ABMs that explicitly incorporate the human dimension, a realistic land-cover map alone might not be sufficient. For example, EFForTS-ABM, an agent-based model studying land-use change in agricultural landscapes dominated by smallholders in Indonesia, requires additional information regarding fields (as agricultural units) and land ownership, because smallholder households are modelled as agents that own these fields (DISLICH et al., 2018). The determination of fields and allocation to specific households cannot be done using remote sensing data and is difficult to obtain using existing landscape generator approaches. In consequence, the human perspective is often lacking completely in landscapes used for ecological research (including modelling), and in fact, forming one of the key gaps between ecological and socio-economic research.

Thus, an extension of the process-based approach to landscape generation is needed that overcomes this mismatch and incorporates the human dimension of landscape ownership and management. Such an extension would not only provide spatially explicit land-use maps, but would also deliver information on properties of smallholder farmers and land ownership and thus enable users to inform agent-based models, to study decision-making, ecosystem functioning trade-offs, and evaluate agricultural policies in more detail.

Here, we present a new model, EFForTS-LGraf, for creating land-cover maps that represent agricultural areas dominated by smallholders. We focus on smallholders because they comprise a large proportion of farmers in most parts of the world. The model allows for flexible parameterization of the main processes shaping these landscapes, i.e. road creation and field establishment by smallholder farming households. The model algorithms follow the assumption that the creation and expansion of agricultural land is connected to road establishment, as has been reported in several case studies (e.g., GATTO et al., 2015; KIRBY et al., 2006 SoARES-Filho et al., 2001). We build upon G-Raffe, an existing landscape generator that simulates the process of field establishment along roads (PE'ER et al., 2013) but does not explicitly incorporate the household dimension. We extended the algorithms of G-Raffe by using an agent-based modelling approach 
and introducing smallholder farming households that have a specific home-base and a given household size.

We present a detailed model description of EFForTS-LGraf, using the Overview, Design concepts and Details (ODD) protocol for describing agent-based models (GRIMm et al., 2006a; GrImm et al., 2010) and the ODD+D (ODD + Decision) extension of the protocol for describing agent-based models that involve human decisions (MüLlER et al., 2013). We take smallholder farming in Jambi province, Indonesia, as an example to demonstrate model applications using three approaches (Details, see Section 2.3): (1) We use a sensitivity analysis to quantify effects of EFForTS-LGraf model parameters on properties of the landscapes generated. (2) We compare a classified land-use map from our study region to the landscapes generated with EFForTS-LGraf. (3) In an applied case study we investigate effects of household consolidation and specialization on landscape patterns. All approaches are based on quantification of landscape characteristics via landscape metrics.

\subsection{Model description}

EFForTS-LGraf was implemented in NetLogo 6.0.2. The EFForTS-LGraf model and a manual on parameterization and execution of EFForTS-LGraf is provided in a publicly available online repository (doi.org/10.5281/zenodo.2677496). This repository also includes $\mathrm{R}$ scripts to reproduce our model analyses, corresponding output files and plots.

\subsubsection{Overview}

\subsubsection{Purpose}

The general goal of the EFForTS-LGraf landscape generator is to create artificial maps of landscapes that are dominated, or strongly shaped, by agricultural activities. The grid-based maps include fields of various sizes and different crop types and other potential land-cover types as desired. These other potential land-cover types, such as forest, grassland, water bodies or degraded land are grouped into a single land-cover type (here, we used the general term 'others'). In addition to fields, the model considers land ownership by assigning each field to a farming household agent. Artificial land-cover maps produced by EFForTS-LGraf can be used as a template, or input, for other models which, for example, can simulate the effects of land-use types on ecological and/or economic functions. The resulting maps may also be used as a starting point to analyse how farmer decisions alter land-use and shape land-use changes. 


\subsubsection{Entities, state variables and scales}

The simulated landscape comprises several spatial units: cells, fields, households and the landscape. Roads are a non-spatial unit of EFForTS-LGraf as they are similar to polylines in a GIS context. Cells are the smallest spatial unit of EFForTSLGraf. The landscape consists of a regular grid of these cells. The cell size can be set by the user and should approximately correspond to the smallest size of fields in the landscape. The extent of the landscape can also be set by the user. Cell attributes include its land-cover type, e.g. 'others' or 'field', and the household the cell belongs to (if any). Moreover, each cell has the attribute of whether it contains an intersecting road or not. The fields are composed of one or several contiguous cells that have all the same crop type and belong to (or are managed by) the same household. Each household has a home-base cell and owns one or several fields that do not need to occur next to each other. The household is represented by an agent that is establishing fields close to the household's home-base cell during the simulation process.

\subsubsection{Process overview and scheduling}

EFForTS-LGraf is initialized with a landscape completely covered by cells of the general class 'others' (Fig. 2.1). Within the procedure "Road creation and household placement" a network of roads is established either artificially or taken as input from a realistic road map (see Road creation and household placement in Section 2.2.3.2). The number of households in the landscape is determined and households are placed onto the map by assigning home-base cells. All home-base cells belong to the road network, i.e. home-base cells always have a road intersecting them. The spatial distribution of households may be completely random or aggregated in villages, depending on the village size distribution. In the "Field establishment" procedure, the households establish fields close to their home-base cell. This procedure is designed such that the resulting frequency distribution of field sizes as well as the resulting frequency distribution of household areas approximate

the expected distributions set by the input parameters (see Field establishment in Section 2.2.3.2). Thereafter, the procedure "Crop type assignment" assigns crop types to the established fields based on input parameters such as fractions of crop types and specialization degree (see Crop type assignment in Section 2.2.3.2). Finally, different maps of the simulated landscape are produced as model output, such as land-cover map and land-ownership map (see Output data in Section 2.2.3.2 and Fig. 2.2. . 
EFForTS-LGraf: Flowchart

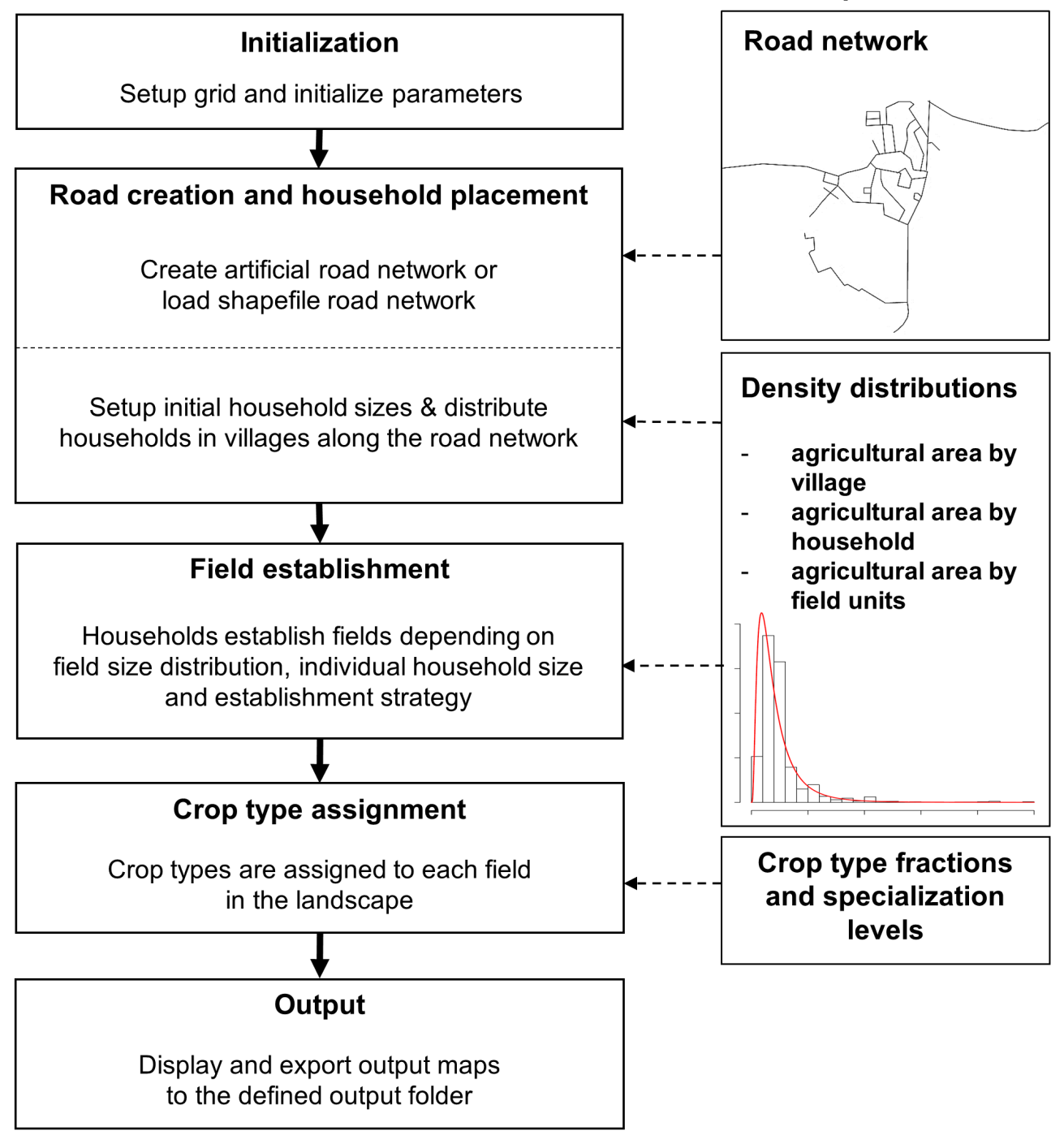

Figure 2.1: EFForTS-LGraf flowchart including process flow of main model processes and model inputs. 


\section{EFForTS-Lgraf: Output examples}

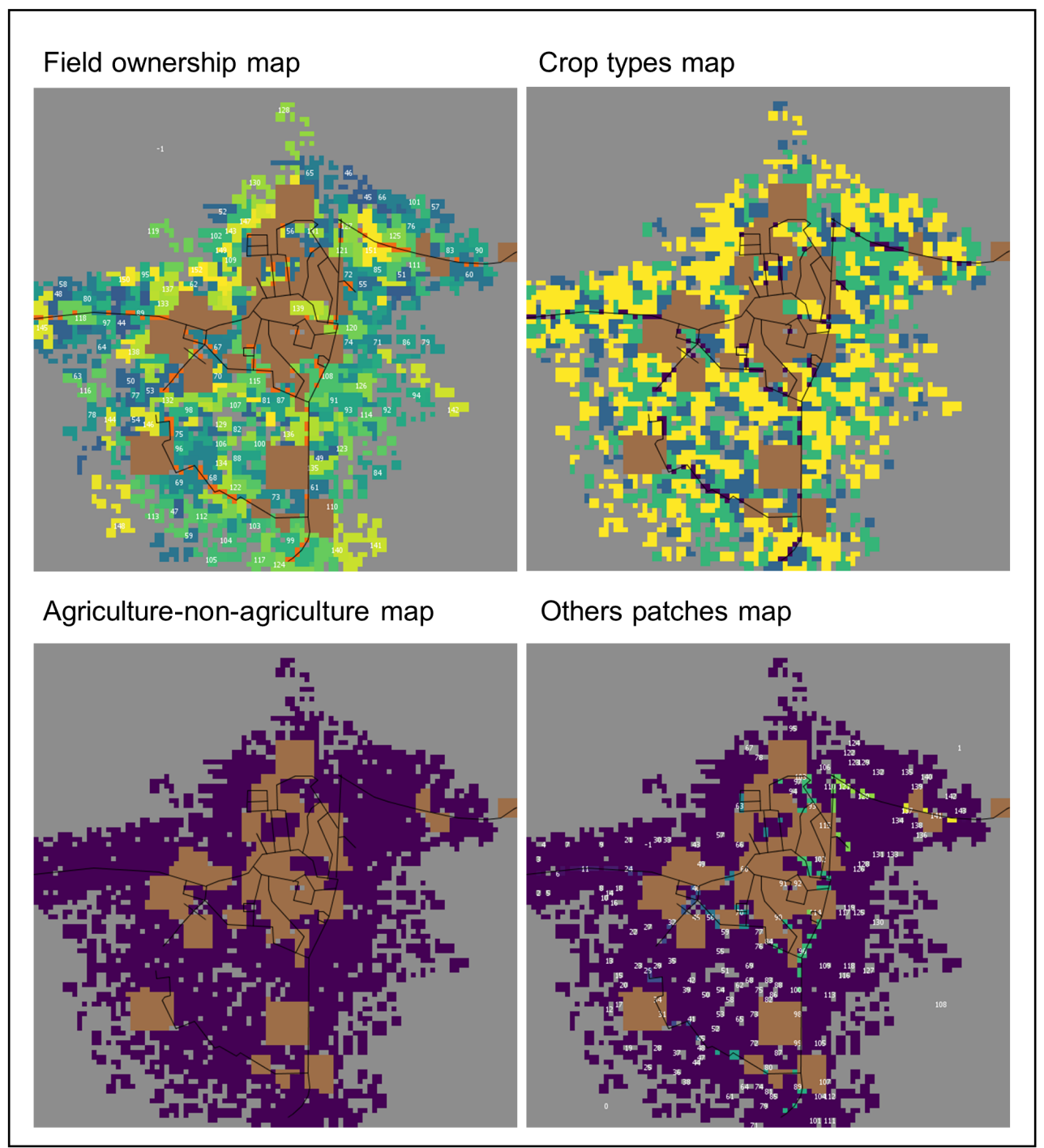

Figure 2.2: Output map examples of EFForTS-LGraf. All maps include patches of inaccessible area (brown color) and roads (black lines). In the field ownership map (upper left), hues indicate field owners. In the crop type map (upper right) colors indicate fields with different crops. The agriculture-non-agriculture map (lower left), is a binary map that differentiates agricultural cells (purple) from other cells (grey). The 'others' patches map (lower right) is similar to the agriculture-non-agriculture map but shows each separate patch of class 'other' in another color. 


\subsubsection{Design concepts}

\subsubsection{Theoretical and empirical background}

The main processes in EFForTS-LGraf build upon the assumption that households settle along roads and establish fields in close vicinity to their home. Such patterns have been reported in several case studies (e.g., GATTO et al., 2015 KIRBY et al., 2006 SOARES-FilHo et al., 2001) and have successfully been implemented in other landscape generators (PE'ER et al., 2013). EFForTS-LGraf does not incorporate any temporal dimension. Instead of simulating the process of land-use change over time explicitly, distributions of household and field sizes are used to create a landscape at one specific point in time. The model does not incorporate any environmental heterogeneity and all considered crop types are equally suitable throughout the landscape. However, the amount and distribution of crop types can be controlled by adjusting landscape proportions and household specialization levels for each crop type.

\subsubsection{Individual decision-making}

Households establish fields based on several decisions. They search for an unoccupied cell in the vicinity of their home-base and try to establish a field of a given size there. If this action is not successful, e.g. because the area between cells that are already occupied is too small, they continue to try in a different location. Finding an unoccupied cells depends on the current field establishment strategy (for Details see Field establishment in Section 2.2.3.2. If a household fails to establish a field for a given number of times under the current strategy, it switches the establishment strategy. Current establishment strategies include searching for unoccupied cells in vicinity of the home-base, in vicinity of already established fields, in neighboring cells of class 'others' with gradually increasing search radius, and searching for unoccupied cells that are surrounded only by unoccupied cells. If the attempt to establish a field of the given size fails for all potential strategies, a new field size is drawn from the field size distribution.

\subsubsection{Individual sensing}

As in reality, households are assumed to have full knowledge on land-use types and ownership of all cells in the landscape. A household cannot expand a new field into an already existing field, whether it is owned by a different household or by the same household. 


\subsubsection{Interaction}

Households interact indirectly by land ownership, e.g. one household cannot expand a new field into the field of a different household.

\subsubsection{Heterogeneity}

Household agents are heterogeneous in their expected and realized household area. Households also differ in number, size and shape of established fields. Additionally, households may cultivate different proportions of crop types and some households may also specialize on one specific crop type. Households are aggregated in villages and have different initial home-base positions. The initial size of the village and home-base position may affect field establishment by the household, which may for instance result in higher distances between home-base and fields (in densely populated areas). These aspects of heterogeneity are mostly imposed by external inputs that determine the overall distribution of field sizes, household areas and village areas.

\subsubsection{Stochasticity}

The location of household home-base cells along the road network is random. However, aggregation of households at certain locations can be controlled by providing a village size distribution (see Road creation and household placement in Section 2.2.3.2). Field sizes and household areas are drawn from a given probability distribution and are therefore also stochastic. In addition, in the case that the user chooses to create the road network within EFForTS-LGraf, the algorithm for road generation randomly assigns the location, direction and length of each road segment (see Section 2.2.3.2).

\subsubsection{Observation/Emergence}

The spatial arrangement of fields is an emergent property of the model and will thus differ between simulations. The emerging patterns can be compared to real maps or used to generate a set of virtual land-use maps. Aggregated model outputs that can be generated from the maps include spatially implicit data such as maximum distance between roads and fields.

\subsubsection{Details}

\subsubsection{Input data and Initialization}


Table 2.1: EFForTS-LGraf model parameters

\begin{tabular}{|c|c|c|c|}
\hline id & Name on GUI & Unit & Description \\
\hline$t_{\mathrm{s}}$ & setup-type & {$[-]$} & $\begin{array}{l}\text { households: number of villages and agricultural area } \\
\text { are approximated by providing a fixed number of } \\
\text { households; villages: number of households and agri- } \\
\text { cultural area are approximated by providing a fixed } \\
\text { number of villages; area: number of households and } \\
\text { villages are approximated by providing the total agri- } \\
\text { cultural area }\end{array}$ \\
\hline$n_{\mathrm{s}, \mathrm{h}}$ & number-of-farmers & {$[-]$} & number of farming households in landscape \\
\hline$n_{\mathrm{s}, \mathrm{v}}$ & number-of-villages & {$[-]$} & number of villages in landscape \\
\hline$n_{\mathrm{s}, \mathrm{a}}$ & prop-agricultural-area & {$[-]$} & proportion of agricultural area in landscape \\
\hline$n_{\mathrm{s}, \mathrm{c}}$ & households-per-cell & {$[-]$} & maximum number of household home-bases in one cell \\
\hline $\operatorname{seed}_{\mathrm{s}}$ & rnd-seed & {$[-]$} & $\begin{array}{l}\text { random seed of the simulation, only used when } r e p_{\mathrm{s}} \\
\text { is true }\end{array}$ \\
\hline$r e p_{\mathrm{s}}$ & reproducable? & {$[-]$} & if true, the user-set random seed seed $_{\mathrm{s}}$ is used \\
\hline$w_{\mathrm{s}}$ & width & cell & width of the landscape grid \\
\hline$h_{\mathrm{s}}$ & height & cell & height of the landscape grid \\
\hline$c_{\mathrm{s}}$ & cell-length-meter & cell & side length in meter of one cell of the landscape grid \\
\hline$t_{\mathrm{r}}$ & road-type & {$[-]$} & $\begin{array}{l}\text { type of road algorithm (shapefile, artificial.perlin or } \\
\text { artificial.graffe) }\end{array}$ \\
\hline$i_{\mathrm{r}, \mathrm{shp}}$ & road-map-nr & {$[-]$} & number of road map file (only used when $t_{\mathrm{r}}$ is shapefile) \\
\hline$n_{\mathrm{r}, \mathrm{art}}$ & total-road-length & cell & $\begin{array}{l}\text { total number of road cells in landscape (only used } \\
\text { when } t_{\mathrm{r}} \text { is artificial.perlin or artificial.graffe) }\end{array}$ \\
\hline$m_{\mathrm{r}, \text { art }}$ & min-dist-roads & cell & $\begin{array}{l}\text { minimum distance [cells] between two roads (only used } \\
\text { when } t_{\mathrm{r}} \text { is artificial.perlin or artificial.graffe) }\end{array}$ \\
\hline$p 1_{r, \text { per }}$ & perlin-octaves & cell & $\begin{array}{l}\text { octaves parameter for the perlin algorithm (only used } \\
\text { when } t_{\mathrm{r}} \text { is artificial.perlin) }\end{array}$ \\
\hline$p 2_{\mathrm{r}, \mathrm{per}}$ & perlin-persistence & cell & $\begin{array}{l}\text { persistence parameter for the perlin algorithm (only } \\
\text { used when } t_{\mathrm{r}} \text { is artificial.perlin) }\end{array}$ \\
\hline$p 3_{\mathrm{r}, \mathrm{per}}$ & cone-angle & cell & $\begin{array}{l}\text { cone-angle parameter for the perlin algorithm (only } \\
\text { used when } t_{\mathrm{r}} \text { is artificial.perlin) }\end{array}$ \\
\hline$p 4_{r, p e r}$ & dist-weight & cell & $\begin{array}{l}\text { distance versus elevation weighting for the perlin al- } \\
\text { gorithm (only used when } t_{\mathrm{r}} \text { is artificial.perlin) }\end{array}$ \\
\hline$d_{\mathrm{v}}$ & vlg-size-distribution & {$[-]$} & $\begin{array}{l}\text { type of distribution for village size (constant, uniform, } \\
\text { normal, log-normal) }\end{array}$ \\
\hline$\mu_{\mathrm{v}}$ & vlg-size-mean_ha & hhs & mean of village size distribution \\
\hline$\sigma_{\mathrm{v}}$ & vlg-size-sd_ha & hhs & standard deviation of village size distribution \\
\hline$d_{\mathrm{v}}$ & vlg-min-distance & cell & minimum distance between villages \\
\hline$d_{\mathrm{h}}$ & hh-area-distribution & {$[-]$} & $\begin{array}{l}\text { type of distribution for household area (normal, log- } \\
\text { normal) }\end{array}$ \\
\hline$\mu_{\mathrm{h}}$ & hh-area-mean_ha & ha & mean of household area distribution \\
\hline$\sigma_{\mathrm{h}}$ & hh-area-sd_ha & ha & standard deviation of household area distribution \\
\hline$n_{\mathrm{i}}$ & $\begin{array}{l}\text { inaccessible-area- } \\
\text { fraction }\end{array}$ & {$[-]$} & $\begin{array}{l}\text { fraction of landscape covered by inaccessible area (e.g. } \\
\text { large-scale plantations, protected area) }\end{array}$ \\
\hline$l_{\mathrm{i}}$ & $\begin{array}{l}\text { inaccessible-area- } \\
\text { location }\end{array}$ & {$[-]$} & $\begin{array}{l}\text { location of inaccessible areas (either random or road- } \\
\text { connected) }\end{array}$ \\
\hline
\end{tabular}




\begin{tabular}{|c|c|c|c|}
\hline$d_{\mathrm{i}}$ & $\begin{array}{l}\text { inaccessible-area- } \\
\text { distribution }\end{array}$ & {$[-]$} & $\begin{array}{l}\text { type of distribution for inaccessible area (constant, } \\
\text { uniform, normal) }\end{array}$ \\
\hline$\mu_{\mathrm{i}}$ & inaccessible-area-mean & ha & mean of inaccessible area distribution \\
\hline$\sigma_{\mathrm{i}}$ & inaccessible-area-sd & ha & standard deviation of inaccessible area distribution \\
\hline$t_{\mathrm{f}}$ & field-type & {$[-]$} & $\begin{array}{l}\text { distribution: field sizes are drawn from the provided } \\
\text { distribution; percentage: mean of the field size distri- } \\
\text { bution is adjusted to the percentage set by } \mu_{\mathrm{h}}\end{array}$ \\
\hline$d_{\mathrm{f}}$ & field-size-distribution & {$[-]$} & $\begin{array}{l}\text { type of distribution for field sizes (constant, uniform, } \\
\text { normal, log-normal) }\end{array}$ \\
\hline$\mu_{\mathrm{f}}$ & field_size_mean_ha & ha & mean of field size distribution \\
\hline$\sigma_{\mathrm{f}}$ & field_size_sd_ha & ha & standard deviation of field size distribution \\
\hline$p_{\mathrm{f}}$ & field-size-percentage & {$[-]$} & $\begin{array}{l}\text { sets percentage to adjust } \mu_{\mathrm{f}} \text { by multiplication with } \mu_{\mathrm{h}} \\
\text { (only used when } t_{\mathrm{f}} \text { is percentage) }\end{array}$ \\
\hline$s_{\mathrm{f}}$ & field-shape-factor & {$[-]$} & $\begin{array}{l}\text { controls if fields are mostly rectangular (value } 1 \text { ) or } \\
\text { narrow (higher values) }\end{array}$ \\
\hline$t_{\text {strat }}$ & strategies-type & {$[-]$} & $\begin{array}{l}\text { type of field strategies selection; manual: choose es- } \\
\text { tablishment strategies by manual selecting; } i d \text { : use a } \\
\text { predefined list of strategies }\end{array}$ \\
\hline$s 1_{\text {strat }}$ & s1.homebase & {$[-]$} & $\begin{array}{l}\text { field establishment strategy 1: establishment close to } \\
\text { own home-base (true/false) }\end{array}$ \\
\hline$s 2_{\text {strat }}$ & s2.fields & {$[-]$} & $\begin{array}{l}\text { field establishment strategy } 2 \text { : establishment close to } \\
\text { own fields (true/false) }\end{array}$ \\
\hline$s 3_{\text {strat }}$ & s3.nearby & {$[-]$} & $\begin{array}{l}\text { field establishment strategy } 3 \text { : establishment in nearby } \\
\text { 'others' cell (true/false) }\end{array}$ \\
\hline$s 4_{\text {strat }}$ & s4.avoid & {$[-]$} & $\begin{array}{l}\text { field establishment strategy 4: establishment in nearby } \\
\text { 'others' cell surrounded by 'others' cells (true/false) }\end{array}$ \\
\hline$n_{\text {strat }}$ & change-strategy & {$[-]$} & $\begin{array}{l}\text { number of unsuccessful tries for field establishment } \\
\text { after which search strategy is changed }\end{array}$ \\
\hline$i_{\text {strat }}$ & field-strategies-id & {$[-]$} & $\begin{array}{l}\text { overwrites manual strategies selection and determines } \\
\text { a pre-specified list of search strategies for field estab- } \\
\text { lishment (e.g. s1, s2, s4) }\end{array}$ \\
\hline$t_{1}$ & land-use-assignment & {$[-]$} & $\begin{array}{l}\text { crop type assignment algorithm; landscape-level- } \\
\text { fraction: approximate fractions of crop types; } \\
\text { landscape-level-specialization: approximate fractions } \\
\text { of crop types and fractions of household specialization }\end{array}$ \\
\hline$i d_{1}$ & $\begin{array}{l}\text { LUT-l-name } \\
(\mathrm{l}=1,2,3,4,5)\end{array}$ & {$[-]$} & name of crop types $l(l=1,2,3,4,5)$ \\
\hline$f r_{1}$ & $\begin{array}{l}\text { LUT-l-fraction } \\
(1=1,2,3,4,5)\end{array}$ & {$[-]$} & $\begin{array}{l}\text { fraction of agricultural area under crop type } l \\
(l=1,2,3,4,5) \text {; fractions must sum up to } 1\end{array}$ \\
\hline$f r_{1, \mathrm{spe}}$ & $\begin{array}{l}\text { LUT-l-specialize } \\
(\mathrm{l}=1,2,3,4,5)\end{array}$ & {$[-]$} & $\begin{array}{l}\text { minimum fraction of area under crop type } l \\
(l=1,2,3,4,5) \text {, which is farmed by specialist households }\end{array}$ \\
\hline$f_{1}$ & LUT-fill-up & {$[-]$} & $\begin{array}{l}\text { crop type (ID) to fill up fractions if sum of } f r_{1} \text { is } \\
\text { smaller than one }\end{array}$ \\
\hline
\end{tabular}

A potential external input for EFForTS-LGraf is a map of an existing road network (option real-road-map). Most of the model parameters (Table 2.1) can be estimated from empirical studies or remote sensing data. In addition to model parameters (numeric), switches (logical, categorical) allow turning on and off certain model 
processes (Table 2.1). Several distribution parameters affect model behaviour and outcomes: (1) A household size distribution, from which the total agricultural area of each household is sampled during model initialization. (2) A village size distribution, from which the village sizes (number of households per village) are sampled during model initialization. (3) A field size distribution, from which the areas of the single field units are sampled during field establishment. (4) Inaccessible area distribution, from which areas of each inaccessible area patch are sampled during model initialization. Different distribution types are possible and include constant, uniform, normal and log-normal shapes. Additionally, road parameters, crop type proportions, crop type specialization levels and field establishment strategies need to be set. Most of the model parameters can be estimated from empirical studies or remote sensing data.

The initialization procedure first updates world dimensions according to the parameters $w_{s}$ and $h_{s}$. All cells in the landscape are initialized as 'others' cells, with no household or fields. At that stage, cells are not owned by anybody. Global variables are set according to the user inputs and the output plots of the model are refreshed. Next, a sample of the household size distribution is drawn to initialize household properties. While the creation and placement of household agents is performed by the submodel "Road creation and Household placement" (see Section 2.2.3.2, the properties of the household agents are already determined during initialization. EFForTS-LGraf provides three options for household initialization via the parameter setup-type $\left(t_{s}\right)$. Depending on the chosen setup-type, the user provides either (1) a fixed number of households $n_{\mathrm{s}, \mathrm{h}}$ (option: households). The number of villages and the proportion of agricultural area are then approximated by using the defined village size and household size distributions; (2) the number of villages $n_{\mathrm{s}, \mathrm{v}}$ (option: villages). The number of households and the proportion of agricultural area are then approximated by using the defined household size distribution; (3) the proportion of agricultural area $n_{\mathrm{s}, \mathrm{a}}$ (option: area). The number of households and the number of villages are then approximated by using the defined household size and village size distributions.

Each of the above options generates a preliminary list of households. Each household has three properties: household-ID, household size and village-ID. The household sizes approximate the defined household size distribution, whereas the village-IDs are assigned in such a way that resulting village sizes approximate the defined village size distribution.

\subsubsection{Submodels}

Road creation and household placement. After initialization, first all roads are created and then households are placed along the established road network. Roads are treated as landscape items without a dimension, i.e. like polylines in 
GIS. Just as any other cell, cells with an intersecting road have a land-use type. There are three options for road creation: (1) a road network is created based on an existing road map in an input file (option: real.shapefile); (2) a road network is artificially created based on a random elevation model (option: artificial.perlin); or (3) a road network is artificially created based on the straight road creation algorithm of the G-Raffe landscape generator (option: artificial.graffe). For details on road creation and household placement see section A.1.1 in Appendix A.

Once the road network is established, households are created and placed along the road network. First, the algorithm determines the number of villages depending on the pre-generated list of households from the initialization procedure. Then, based on the number of villages and village-IDs, village centers are created on random road network cells complying with the minimum distance between village centers, $d_{\mathrm{v}}$. Then the households are placed randomly on road cells around village centers matching the corresponding village-IDs, i.e. each household establishes a home-base cell at the assigned cell. There is a cap to the number of household home-bases on one cell $n_{\mathrm{s}, \mathrm{c}}$.

Inaccessible areas are an optional landscape feature of EFForTS-LGraf, defining patches of areas that are not available for use by smallholder agriculture. This option allows defining either areas belonging to large-scale company plantations or protected (forest) areas. Given the overall fraction of the landscape covered by inaccessible area, $\mathrm{frac}_{p}$ (Table 2.1) and the inaccessible area size distribution, patch sizes are drawn from the distribution until the total size of inaccessible area patches matches the defined landscape fraction. From this list, each patch is then created by first selecting a starting location, which can be either a random cell in the landscape (option random for $l_{i}$ ) or a random road cell (option road-connected for $l_{i}$ ). From this starting location, a square-shaped field of the given size is created, following the basic field establishment rules (details see section A.1.2 in Appendix A).

Field establishment. The field establishment procedure determines the size and spatial location of fields, but does not yet determine the actual crop within fields. This is assigned in the next procedure (see "Land-use assignment" below). Fields are established by household agents and an attempt to establish a field comprises three steps: (1) deciding on the field size, (2) moving to a potential location, and (3) making sure there is enough space to establish a field of the desired size in this location (for details see section A.1.2 in Appendix A). In case of a successful attempt, the household gains ownership of these established field cells. By gaining ownership, the realized household area increases and field establishment continues until each household realizes its expected household size that was determined during initialization.

In other words, to realize the expected household size distribution, the procedure 
loops over all households that are marked as still growing, i.e. all households where the realized area of owned fields does not yet exceed the expected household size. At the first stage, these are all households because each household establishes at least one field. In every iteration, each relevant household draws a field size from the field-size distribution. If the projected household area, including the additional field, is below the expected household size, then the household attempts to establish a field of this size. If the projected area exceeds the expected household size, an attempt for establishment would take place only if the absolute difference between projected household area and expected household area is smaller after establishing the field. Otherwise, the household does not establish the field and becomes a non-growing household. After each establishment loop, households that have reached their final size become non-growing households, namely are excluded from the next iteration of field establishment. At the end of each loop, if the total realized agricultural area exceeds the expected cover of agricultural area, the field establishment procedure is halted.

Crop type assignment. After all fields are established, crop types are assigned to them. The current model version supports up to five different crop types and two alternative ways to distribute the crop types (parameter $t_{l}$ ). The first option (landscape-level-fraction) distributes crop types randomly among fields according to fractions of overall crop types. The second option (household-level-specialization) aims at additionally incorporating specialization for crop types at the household level. In this latter case, an additional input parameter is used for each crop type which describes the specialization by households for this particular crop type. The level of specialization is primarily a proportion ranging from 1 (all households that cultivate this crop type would cultivate this crop type exclusively) to zero (no preference for specialization in this crop type). For example, a specialization value of 0.7 for crop type 1 would mean that $70 \%$ of households that cultivate crop type 1 have only fields of crop type 1 and no field of any other crop type. The remaining $30 \%$ of households have fields of various crop types. Note that realized specialization levels can be higher than the input specialization levels, since the value determines a field-level outcome, and hence, all households with only one field are specialists by default.

Output data. The landscapes produced by EFForTS-LGraf contain information on various spatial scales (landscape level, household level, fields, cells) and can be visually inspected in different formats:

- Land-use maps: depict land uses in different colors (classes: agriculture, road, inaccessible, home-base, 'others') 
- Crop type maps: similar to land-use map with additional classification of crop types

- Agriculture-non-agriculture map: depicts the distinction between agricultural cells and cells of class 'others'

- Field-patches map: depicts the different fields on the map in different colors

- Household-patches map: differentiates fields based on the different households they belong to

- Habitat-patches map: depicts clusters of cells belonging to the same patch of class 'others' in different colors. Roads, fields and inaccessible areas function as separators for patches.

Maps are produced at the resolution cell-length-meter $c_{\mathrm{s}}$. Cell labels such as patch-IDs and owner-IDs, and spatial elements such as roads, home-bases and households can be selected to be drawn on top of these maps. All spatial outputs can also be stored as raster maps (ASCII) to allow using the generated landscapes for other model applications (Details on raster output see section A.1.3 in Appendix A). An additional feature ("create-3D-map" function) uses the NetLogo 3D functionality to create a 3D rendered map that displays trees, crops and buildings using 3D-shapes in realistic densities (Fig. A.1 in Appendix A).

\subsection{Scenarios and Parameterization}

We demonstrate the capabilities and potential uses of EFForTS-LGraf based on the example of smallholder-dominated agricultural areas in Jambi province in Sumatra, Indonesia. During the last decades, this region has faced severe land-use changes, mainly deforestation and agricultural expansion (e.g. KoH, 2011) and loss of ecosystem-functioning of the transformed landscapes (e.g., DisLICH et al., 2017). In order to provide agricultural maps that incorporate smallholder households and field ownership, we parameterized EFForTS-LGraf using household data from a smallholder survey of relatively large size (701 farming households) that was performed in Jambi province (Fig. 2.3) (EulER et al., 2017; Krishna et al., 2017). Jambi province is characterized by small villages with farming households that are mostly of relatively small size (median survey data 3.5 ha) and within these villages, small-scale fields with mostly oil palm and rubber. By parameterizing EFForTS-LGraf for a specific study region, the generated maps can be used to inform scenario-based studies such as the application of the agent-based simulation model EFForTS-ABM (DisLich et al., 2018). 

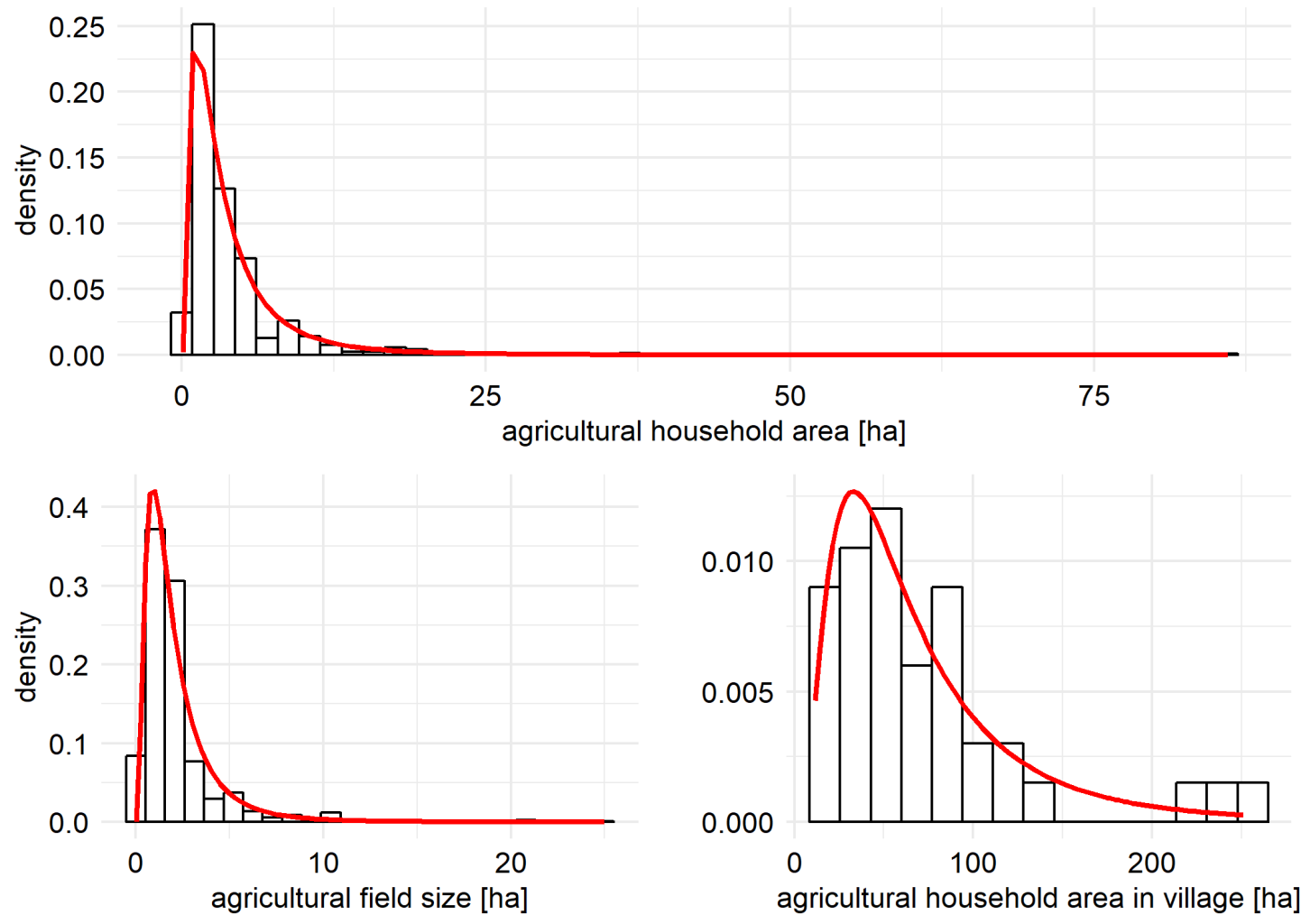

Figure 2.3: Distribution of household areas, village areas and field sizes, based on household surveys carried out in our study area in Jambi province, Sumatra, Indonesia.

Table 2.2: Landscape metrics description

\begin{tabular}{|c|c|c|c|}
\hline metric & short & range & description \\
\hline $\begin{array}{l}\text { landscape-shape- } \\
\text { index }\end{array}$ & LSI & $L S I \geq 1$, without limit & $\begin{array}{l}\text { measure of class aggregation or } \\
\text { clumping }\end{array}$ \\
\hline largest-patch-index & LPI & $0<L P I \leq 100$ & $\begin{array}{l}\text { percentage of total landscape area } \\
\text { comprised by the largest patch of } \\
\text { a class }\end{array}$ \\
\hline mean-patch-area & - & $\geq 0$, without limit & $\begin{array}{l}\text { mean patch area of all patches of } \\
\text { a class }\end{array}$ \\
\hline n-patches & - & $\geq 0$, without limit & total number of patches of a class \\
\hline $\begin{array}{l}\text { patch-cohesion- } \\
\text { index }\end{array}$ & PCI & $0 \leq P C I \leq 100$ & $\begin{array}{l}\text { physical connectedness of patches } \\
\text { of a class }\end{array}$ \\
\hline
\end{tabular}




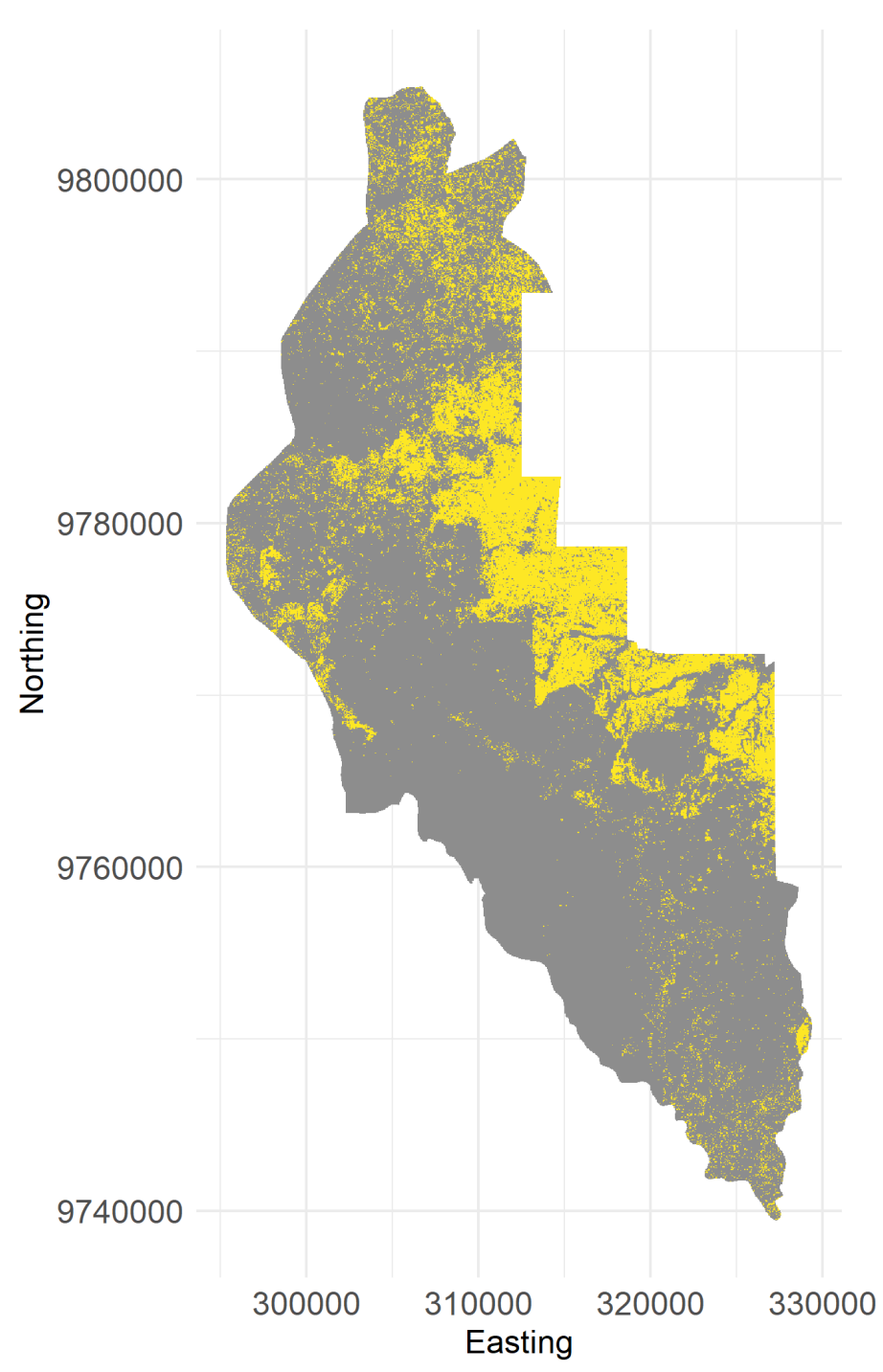

Figure 2.4: Snapshot of the reclassified satellite image of Harapan region in Jambi province. Grey cells indicate land-cover type 'others', which consist mostly of secondary forest but includes all other remaining non-agricultural land-cover classes, such as settlements and water bodies. Yellow cells indicate fields, which consist of oil palm and rubber plantations. 
To show EFForTS-LGraf's model and output capabilities, we followed three approaches. In approach 1 (Sobol sensitivity analysis), we determined how variability in the landscapes generated by EFForTS-LGraf can be apportioned to the different model parameters. In approach 2 (Validation), we assessed the characteristics of typical landscapes in the Harapan region in Jambi province and applied an optimization algorithm in order to generate artificial landscapes with similar characteristics. In approach 3 (Applied case study), we present an applied simulation scenario that investigates effects of household consolidation and crop specialization on landscape characteristics. For all approaches, we quantified the landscape characteristics using five landscape metrics that are either class-based or aggregated on class-level: landscape-shape-index (LSI), largest-patch-index (LPI), mean-patch-area, the number of patches (n-patches) and patch-cohesion-index (PCI) (Table 2.2, for a more detailed description see FRAGSTATS manual (MCGARIGAL et al., 2012)). We used the R-package SDMTools v1.1 to calculate landscape metrics of all landscapes (VANDERWAL et al., 2014).

For approach 1, we conducted a Sobol sensitivity analysis, i.e. a global variancebased sensitivity analysis for all model parameters including the parameters of the artificial road creation algorithm of EFForTS-LGraf (for parameterization details, see section A.2.1 in Appendix A. The Sobol method measures direct effects and interaction effects of model parameters on model output (here: landscape metrics) (Chan et al., 2000; JAnsen, 1999; SAltelli et al., 2010; Sobol, 1990). By applying a Sobol parameter sampling design, we generated 9500 different landscapes that cover a large parameter range of EFForTS-LGraf. Such analysis helps understand model processes and may be useful to reproduce certain landscape features. For instance, if one is interested in generating landscapes along a gradient of characteristics, the sensitivity analysis allows identifying which parameters can realize that gradient and how.

For approach 2 (Validation), we used a land-cover map (classified satellite image from 2013) from the Harapan region in Jambi province that features a large gradient of land-use intensities (Melati, 2017) (see Fig. 2.4). The original landcover map has a spatial resolution of $5 \times 5 \mathrm{~m}$ and an overall classification accuracy of $68.4 \%$ (MELATI, 2017). In order to allow for comparisons with our artificiallygenerated landscapes, we scaled the land-cover map to the same resolution as our generated EFForTS-LGraf landscapes, which is $50 \times 50 \mathrm{~m}$ cells. The original classified land-cover map consisted of 9 classes which we reclassified into two final land-cover types: fields and 'others' (fields consist of original classes rubber and oil palm; 'others' consist of original classes secondary dryland forest, shrub, bare land, settlement, water body, cloud, shadow). While we did not explicitly assess the overall classification accuracy of the final reclassified and rescaled map, overall classification accuracy is expected to improve trough reclassification into more 
general classes. From the reclassified land-cover map, we sampled 3 randomly placed landscapes, $100 \times 100$ cells in size (no overlaps) and calculated the five landscape metrics for each of these sampled landscapes and each land-cover type (fields and other). For each sample, we performed a genetic algorithm in order to recreate these samples with EFForTS-LGraf (KUMAR et al., 2010; WILlighAGEN and BALLings, 2015). The algorithm uses the proportion of agricultural area from the samples, but varies all road, household, village and field establishment parameters. For each generated landscape, a fitness value is calculated by comparing the landscape metrics of the generated landscape to the landscape metrics of the current sample. The algorithm then tries to minimize the total deviance by repeated creation of landscapes with adjusted parameters. The genetic algorithm was set up with 50 different initial parameterizations per sample (population size) and 25 iterations. In approach 2 (validation), we also compared the ranges of landscape metrics of the 9500 generated landscape from the Sobol sensitivity analysis (approach 1) to landscape metrics of 100 landscapes. These landscapes were randomly sampled (allowing overlaps) from the reclassified land-use map (results, see section A.2.2 in Appendix A).

EFForTS-LGraf not only allows us to generate land-cover maps, but also to conduct applied modelling studies (approach 3). Empirical data from Jambi, Indonesia indicates an increase over time in the area owned by households (EULER et al., 2016a). Smallholder households also tend to specialize on one specific crop type (KLASEN et al., 2016). Increasing household area and specialization on one crop may cause drastic changes in landscape composition and configuration. We analyzed whether EFForTS-LGraf can reproduce these changes by generating a set of landscapes with different levels of crop specialization and household area using a Latin hypercube sampling design with 500 samples (MCKAY et al., 1979). We randomly selected one village from the household survey in Jambi and cropped a road polyline shapefile based on a spatial layer covering the road network of Jambi. We used the classified satellite image of the village to estimate the proportions of oil palm and rubber in the agricultural landscape $($ oilpalm $=0.5$, rubber $=0.5)$. To mimic the increase in household area, we set the proportion of agricultural area in the landscape to a fixed value of $50 \%$ and varied the mean of the log-normal household area distribution from 1 ha to 3 ha within the Latin hypercube sampling design. The total number of households in the landscape was then estimated based on the proportion of agricultural land. With increasing mean values of the household area distribution, this yielded fewer households but the same total agricultural area in the landscape. We used two crop types (oil-palm and rubber) and varied the specialization levels for oil-palm from 0 (specialist by chance) to 1 (always specialists) within the Latin hypercube sampling design. For crop type 2 rubber we set the specialization level to 0 (for parameterization details, see 
section A.2.3 in Appendix A. We analyzed the resulting landscapes via the five selected landscape metrics from previous approaches (Table 2.2). We calculated linear regression models for each landscape metric and crop type combination and calculated standardized regression coefficients (SRC) to estimate parameter and interaction effects on landscape metrics of the generated landscapes.

Execution of NetLogo simulations and output post-processing where performed with R and the R-package nlrx (R Core Team, 2018; SAlecker and Sciaini, 2018).

\section{$2.4 \quad$ Results}

\subsubsection{Approach 1: Sobol Sensitivity Analysis}

Two parameters, total-agricultural-area, defining the resulting proportion of agricultural area in the generated landscapes and field-strategies-id, defining the set of field establishment strategies that is used by the households, had significant total (sum of direct and interaction effects) and main effects (direct effects without interaction) on a wide range of landscape metrics (Fig. 2.5). For some landscape metrics such as LPI or LSI these two parameters showed only main effects (indicated by dark tile and dot shading in Fig. 2.5). The largest patch index (LPI) was only affected by the parameter proportion-agricultural-area. The mean patch area was the only output landscape metric that was significantly affected by all model parameters. For some output metrics (LSI, n patches, PCI), the proportion-agricultural-area had a larger effect on 'others' class indices, whereas the field-strategies-id had a larger effect on the fields indices. Interestingly this pattern was reversed for the output metric mean patch area, where the proportion-agricultural-area had a larger effect on the mean patch area of field patches and the field-strategies-id had a larger effect on the mean patch area of 'others' class patches.

\subsubsection{Approach 2: Validation}

The re-classified satellite image of the Harapan region, Jambi, shows a large heterogeneity in the distribution of agricultural patches (Fig. 2.4). Large-scale clustered agricultural areas can be found in the North-East, whereas in the North, West and South, agricultural patches are more scattered. Harapan rainforest conservation area is located in the centre of the image and does not contain any agricultural fields at all.

The three landscapes that were sampled from this map reflect this gradient with agricultural proportions ranging from of 0.13 (sample A, Fig. 2.6) over 0.23 (sample B, Fig. 2.6) to 0.46 (sample C, Fig. 2.6). All three samples also show a 


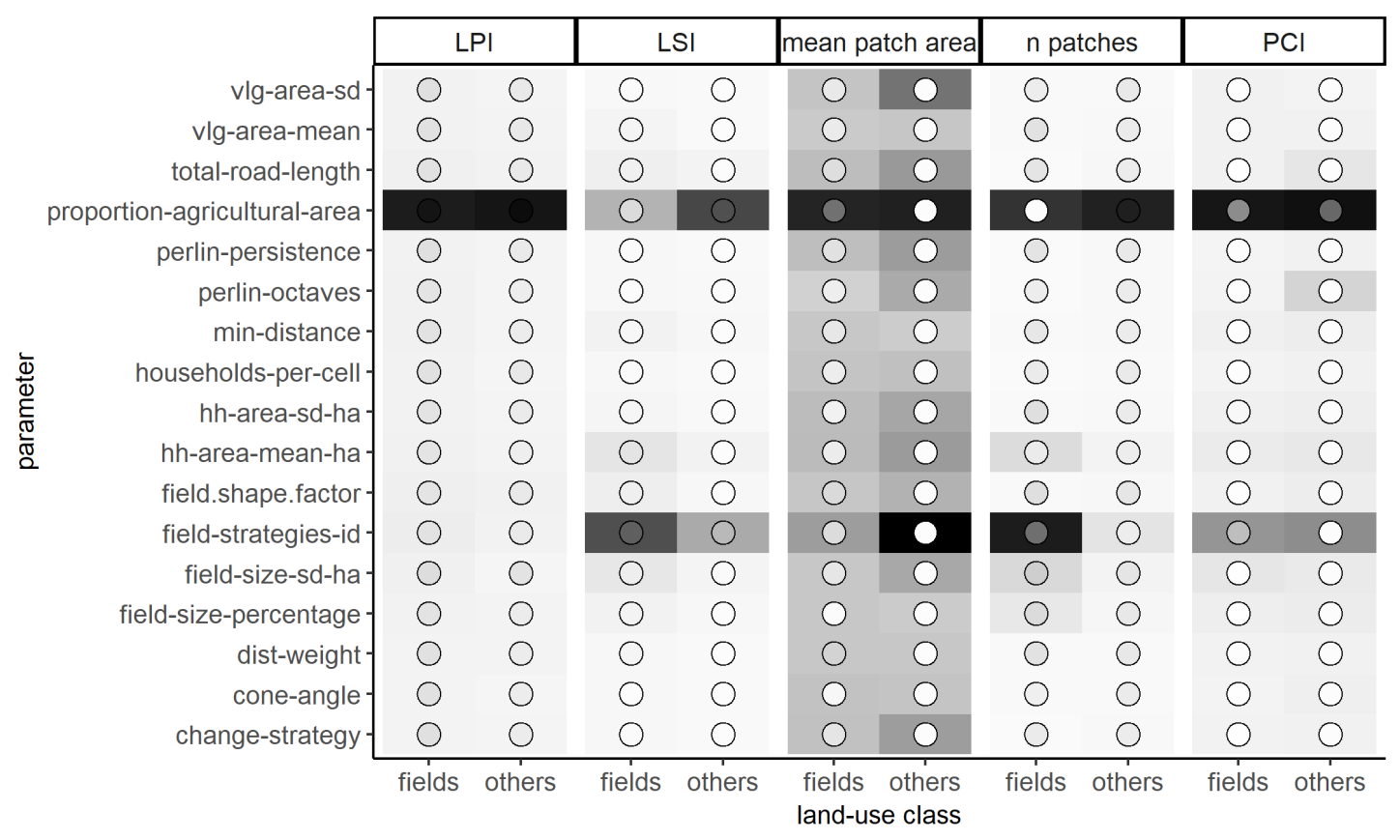

Figure 2.5: Approach 1, sensitivity analysis: Sobol total and main effects of EFForTS-LGraf model parameters on landscape metrics grouped by land-use classes fields and 'others'. Tile color of each parameter output combination indicates the total effect of parameter changes on the output metric. Colors of dots within each tile show the main effect of parameter changes on the output metric. Thus, tiles with dark color and a bright dot have a large total effect but a small main effect indicating strong interaction effects, whereas tiles with dark color and a dark dot indicate strong main effects. For abbreviations and model parameterizations, see section A.2.1 in Appendix A. 


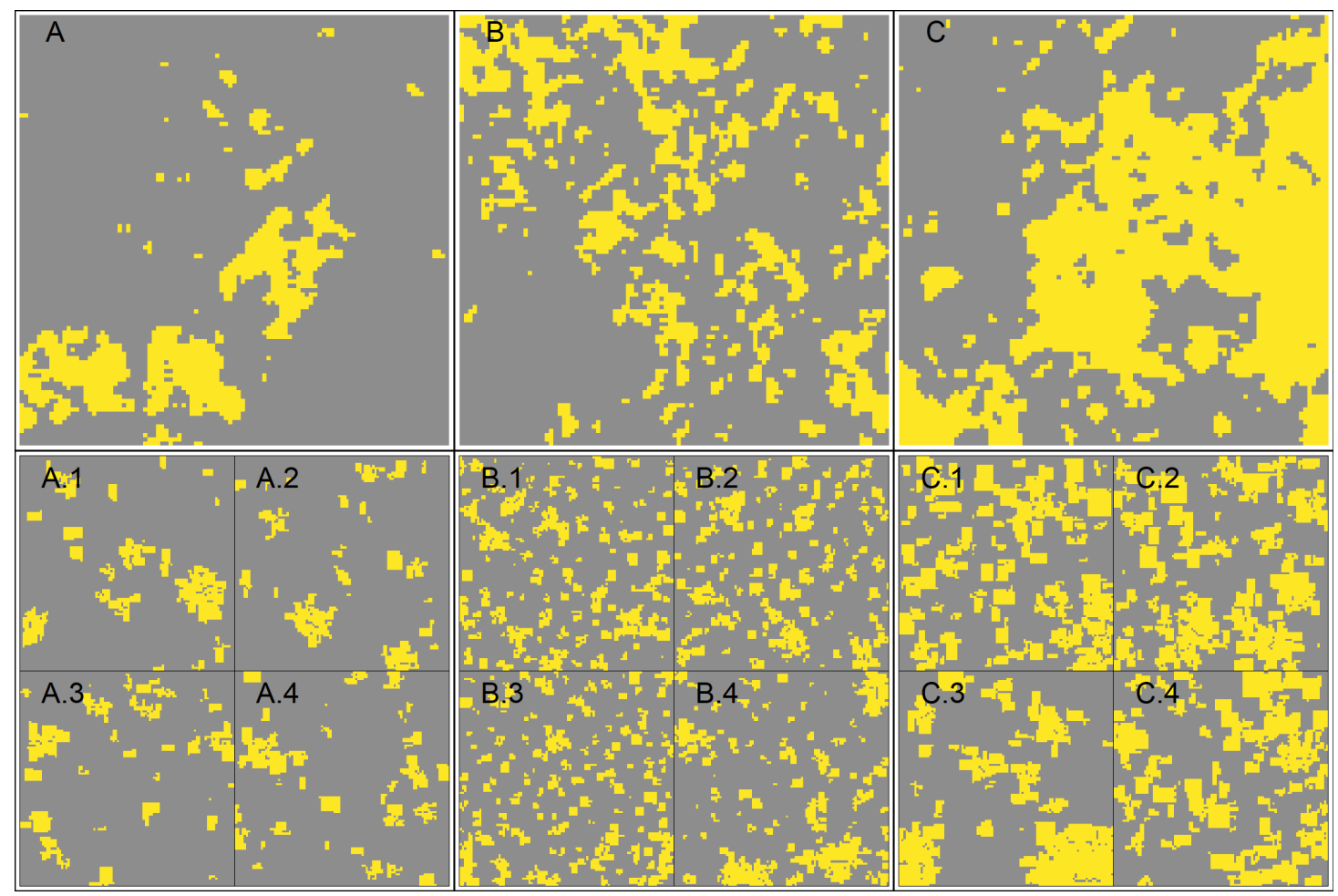

Figure 2.6: Approach 2, validation: A, B and C show sampled maps $(100 \times 100$ cells, $50 \mathrm{~m}$ resolution) from the reclassified satellite image of the Harapan region, Jambi province, Indonesia. Yellow cells indicate agricultural area, grey cells indicate land-use class 'others'. We applied genetic algorithm optimization to tweak EFForTS-LGraf model parameters in order to recreate these map samples. This was done by calculating deviances in landscape metrics between the sampled map and the generated map and minimizing this deviance with each generation of the algorithm. We ran the algorithm for each map sample (A, B, C) individually and stored the final parameterization with the lowest deviation. Using these final parameterizations we generated 4 maps for each map sample to account for stochasticity during the map creation process (A.1-A.4, B.1-B.4, C.1-C.4). The generated maps have the same resolution as the map samples $(100 \times 100$ cells, 50 $\mathrm{m}$ resolution) but are displayed at $1 / 4$ th size. 


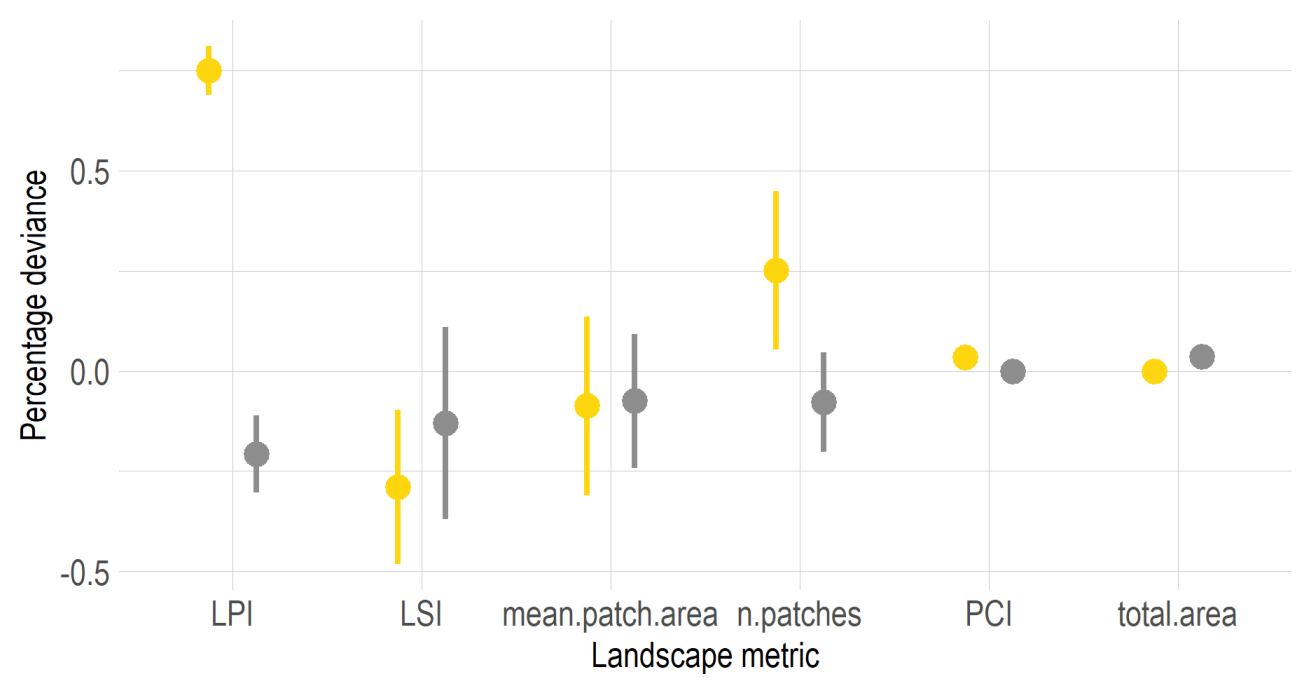

Figure 2.7: Approach 2, validation: Landscape metrics deviations of generated maps derived by application of a genetic algorithm (see maps A.1-A.4, B.1-B.4, C.1-C.4 in Fig. 2.6), to landscape metrics of original samples from the reclassified satellite image of the Harapan region, Jambi province (see maps A,B,C in Fig. 2.6). Yellow dots and line ranges represent landscape metrics of agricultural patches, grey dots and line ranges those of patches of class 'others'. 

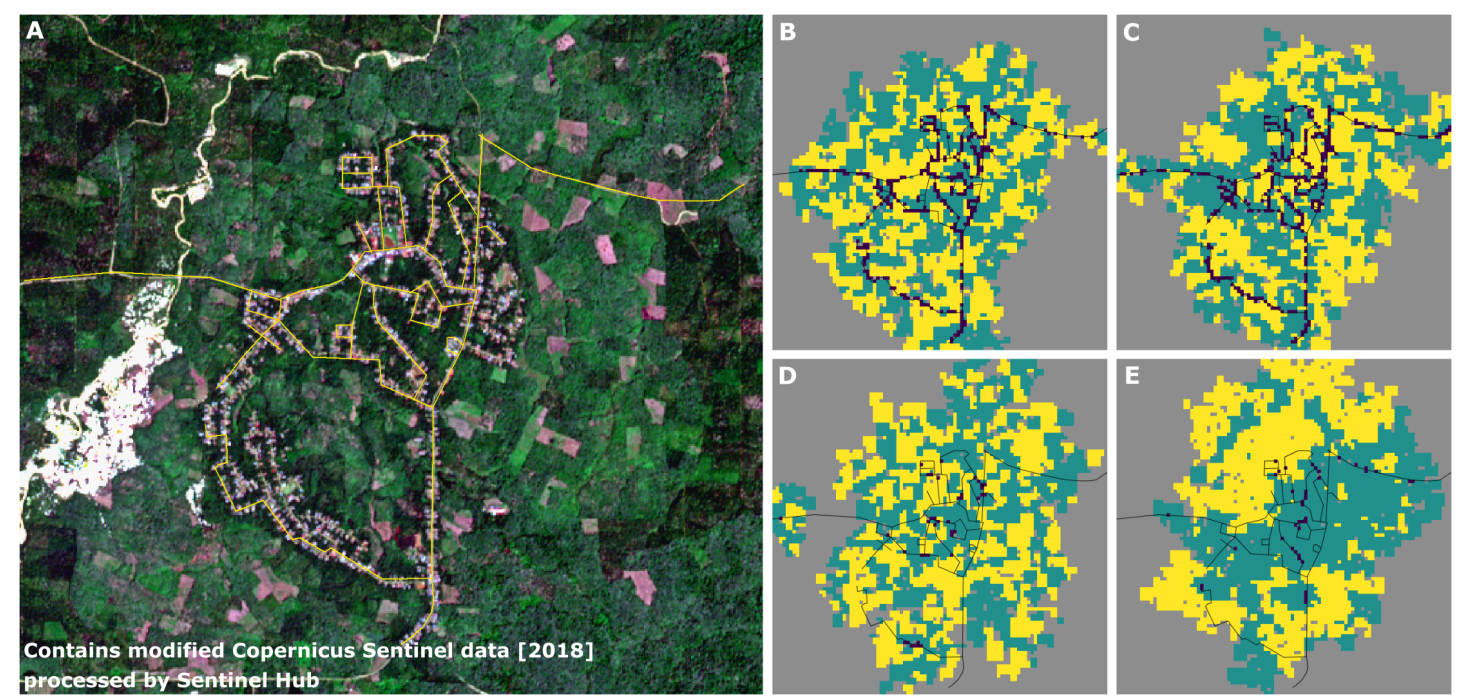

Figure 2.8: Approach 3, applied case study: (A) Satellite imagery showing the village Lantak Seribu in Renah Pamenang District, Merangin Regency, Jambi (contains modified Copernicus Sentinel data [2018] processed by Sentinel Hub). The road network of this village (yellow lines) was selected to generate examples of artificial agricultural smallholder landscape maps with EFForTS-LGraf for different household sizes and specialization levels. (B-E) Examples of artificial land-cover maps. Green cells indicate oil palm fields, yellow cells indicate rubber fields, grey cells indicate cells of class 'others', purple cells indicate household home-bases and black lines indicate roads. Examples $\mathrm{B}$ and $\mathrm{C}$ consist of smaller households that own only some fields whereas households in $\mathrm{D}$ and $\mathrm{E}$ are larger and own more fields. In $\mathrm{B}$ and $\mathrm{D}$, land uses are distributed to fields completely at random, whereas in $\mathrm{C}$ and E, households specialize completely on one land use.

large heterogeneity in patch sizes, field sizes and distribution of fields (see Fig. 2.6). While the genetic algorithm was able to find parameterizations that recreate many properties of the sampled landscapes, not every detail could be matched (see Fig. 2.7). Especially large patches of agricultural area could not be recreated accurately (yellow ranges for largest patch index (LPI) and n.patches, Fig. 2.7). However, even the highest deviation (LPI of agricultural patches) was still below $1 \%$.

\subsubsection{Approach 3: Applied case study}

In all generated landscapes, fields were distributed mainly along the road network that was used to set up the model (Fig. 2.8). We observed inter-linking effects of household area and specialization on aggregation of crop types in the landscape by visual comparison of resulting land-use maps (Fig. 2.8). High specialization on oil 


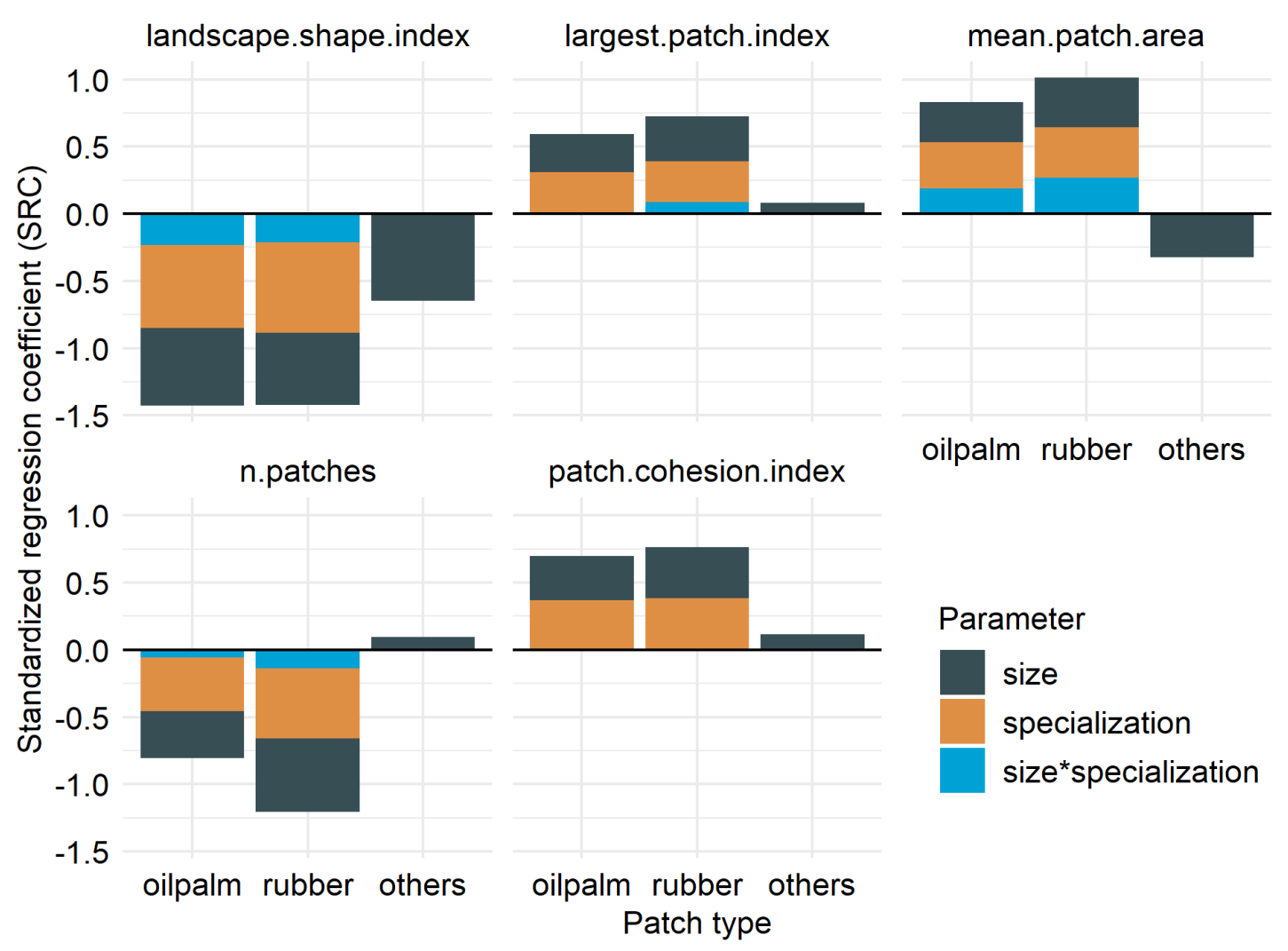

Figure 2.9: Approach 3, applied case study: We generated land-cover maps with varying household area and specialization levels for oil palm and calculated five selected landscape metrics for the two crop types (oil palm and rubber) and patches of class 'others'. The colored bars illustrate the corresponding standardized regression coefficients (SRC) from linear model regressions. Bars display significant importances of household size (size), specialization level (specialization) and the importance of interactions between these two parameters on the selected landscape metrics. Parameter names and values are described in section A.2.3 in Appendix A Landscape metrics are described in Section 2.3, Table 2.2. 
palm led to much higher spatial aggregation of crop types when household area was larger, compared to smaller household area (Fig. 2.8).

Within the boundaries of our assumptions we did not find any significant effects of oil palm specialization (specialization, orange bars in Fig. 2.9p or interaction effects (size*'specialization, blue bars in Fig. 2.9) on 'others' landscape metrics (see standardized regression coefficients for 'others' patches in Fig. 2.9). However, all metrics were significantly affected by the household size distributions (size, black bars in Fig. 2.9. For increasing household areas we found increased aggregation (negative landscape.shape.index coefficient), smaller patches (negative mean.patch.area coefficient), slightly higher total number of patches (positive n.patches coefficient) and fewer perimeter cells (positive patch.cohesion.index coefficient) of 'others' patches (Fig. 2.9).

The landscape metrics of agricultural patches of the two crop types where clearly affected by household area, specialization on oil palm and interaction effects of both parameters (see oil palm and rubber bars in Fig. 2.9p). In a system with two mono-cultural crop types, high specialization on one crop type indirectly affects the spatial distribution of the other crop type. Patch aggregation was higher for both crop types with increasing specialization and household area (negative landscape.shape.index coefficients). Mean patch area was higher for high specialization and larger households (positive mean.patch.area coefficients). Accordingly, the number of rubber and oil palm patches strongly decreased with increasing household area and oil palm specialization (negative n.patches coefficients). There were fewer perimeter cells for high specialization levels and larger household areas (positive patch.cohesion.index coefficients). Landscape shape index and mean patch area showed a considerable amount of interaction effects between both parameters suggesting non-linear relationships, which could also be observed from investigating raw data from the simulations (see Fig. A.2 in section A.2.2 in Appendix A).

\subsection{Discussion}

Although various landscape generator approaches have been developed in the past, only few of them are process-based, have a distinct focus on agricultural land or incorporate any human dimension (LANGHAMmER et al., 2019). The main goal of our study was to fill this gap by developing the landscape generator EFForTS-LGraf. The process-based algorithms of EFForTS-LGraf explicitly reflect the linkage of agricultural expansion and deforestation to road and infrastructure development (GAtto et al., 2015 Kirby et al., 2006; SoAres-Filho et al., 2001). This allows not only to generate realistic-looking landscapes, but also links the model to one of the world's central sources of environmental pressures, i.e. road expansion (IBISCH et al., 2016). Another key power of the model is explicit consideration 
of smallholder farming households and elements that characterize smallholder decisions and socio-economic patterns such as land ownership and farm economy and how these shape landscapes. In this, the model helps overcoming an important barrier between ecological and socio-economic research, allowing one to explore the behavior of agricultural-natural frontiers as a socio-ecological system (BERKES et al., 1998).

The process-based nature of the model algorithms and parameters allow to formulate and evaluate specific questions through adjustment of the model parameterization. Particularly the final analysis (approach 3) demonstrates how the model can be used to explore how factors that affect smallholder decisions and socio-economic processes shape landscape patterns and, thereby, biodiversity and ecosystem services. Notably, global processes of agricultural intensification comprise two elements that are captured by the model, namely a trend of specialization toward monocultures and an increase in field sizes and area owned by fewer smallholders (PE'ER et al., 2014), accompanied by an ongoing decline in rural employment (e.g. PE'ER et al., 2017 for the EU). Our simulation experiment revealed that household consolidation and crop specialization indeed had a large impact on various landscape characteristics. Although these effects were expected to some extent, our analysis showed that the inter-linkages between household-level processes and landscape characteristics were significantly affected by interaction effects of consolidation and specialization. Such identification of interactions and non-linear relationships may be important for a wide range of ecological studies.

We assessed the basic functionality, parameter sensitivity and validity of EFForTS-LGraf by performing a sensitivity analysis and a validation against real-world satellite imagery. The Sobol sensitivity analysis (approach 1) revealed that the proportion of agricultural area (proportion-agricultural-area) and the selection of establishment strategies (field-strategies-id) were the most important parameters across all landscape metrics. However, the effect of each parameter highly depended on the chosen landscape metric. For example, mean patch area was affected by nearly all model parameters, whereas the largest patch index was nearly exclusively affected by the proportion of agricultural area. We used the setup-type 'area' to initialize the households of each model simulation. Therefore, household area parameters by definition had little influence, since they were largely pre-set. This also means that we can expect larger household area parameter effects on landscape metrics when using the setup-type 'household'. The three different setup-types of EFForTS-LGraf allow for great flexibility in parameterizing the model. Depending on the application, it may be important to generate landscapes with the same proportion of agricultural area, but different household properties (approach 3). When the total number of households in the area is unknown but the typical village sizes and the number of villages in the area can be estimated, 
the setup-type village can be used to approximate the number of households.

Our artificially-generated landscapes showed high capacity to match various landscape metrics when compared to classified satellite images, and showed high flexibility to generate a broad range of maps along a gradient of spatial structures (see Fig. 2.6, 2.7 and section A.2.2 in Appendix A). Both are important features of landscape generators. Depending on the approach, it may be important to recreate specific maps trough pattern-based optimization approaches or to generate many different maps along a gradient of specific landscape characteristics.

Besides these technical approaches, EFForTS-LGraf can be applied for a wide range of potential applications. First of all, the generated maps can be used to inform other modelling studies, as has been successfully done with the simulation model EFForTS-ABM (Dislich et al., 2018). We are also planning to apply and validate EFForTS-LGraf to other agricultural regions where high quality remote sensing data are available, such as Central Europe. Additionally, EFForTS-LGraf may be required to perform policy-relevant applications, e.g., testing the future impacts of road expansion, especially in developing regions such as Indonesia and impacts of agricultural policies such as the CAP in the EU.

Currently, EFForTS-LGraf produces maps for one specific point in time. Considering the huge pressures of road expansion on natural habitats, particularly in developing countries including in Indonesia (LAURANCE et al., 2014), incorporating a temporal component explicitly might be a useful extension to the model. Such an extension would allow to create time series of maps with roads and fields occurring gradually. The assumption that at the beginning of map generation, each cell is equally suitable for field establishment is another limitation of EFForTS-LGraf. A potential model extension could add heterogeneous land-use types to the initial state of the landscape (e.g. forest, grassland, peatland, instead of assigning type 'others' to all cells). By consideration of differential pressure for land-use change depending on these land-use types, more complex landscape patterns could be created. We decided to develop EFForTS-LGraf with a clear focus on linking geospatial information, such as road polyline shapefiles and land-use fractions, with empirical data, such as household size and field size distributions.

When comparing model outcomes with reclassified land-cover maps from Harapan region (approach 2), we also revealed some systematic differences. Most prominently, the area of agricultural patches was underestimated in the generated landscapes, whereas the area of 'others' patches was overestimated. This mismatch may partly be explained by the homogeneous field establishment of model households. Although households are able to adjust their field establishment strategies if they are not successful, each household uses the same set of strategies and switches after the same number of unsuccessful tries. Adding household-level heterogeneity to field establishment strategies would allow for increased local field aggregation 
heterogeneity but would also add complexity to the model. In the current model version, crop types can be assigned to fields based on the user-set fractions and specialization levels. Future model extensions may also contain additional algorithms to control spatial clustering of certain crop types.

In conclusion, EFForTS-LGraf combines economic smallholder survey data and spatial information to generate landscapes featuring the characteristics of observed agricultural smallholder landscapes. EFForTS-LGraf is especially useful for applications where agricultural maps need to be provided in conjunction with corresponding economic household data which can not be obtained from remote sensing alone. Due to its flexibility, EFForTS-LGraf can be utilized for a wide range of applications, such as: (1) map generation by providing specific economic case study data, (2) application of pattern-matching approaches to match generated maps with realistic land-use maps, and (3) generating maps along gradients of properties on household or landscape-level. EFForTS-LGraf contributes to the set of already published landscape generators and fills an important gap through its application of process-based algorithms with a distinct focus on road expansion, agricultural land and explicit consideration of human dimensions of land-use change.

\subsection{Acknowledgments}

We thank Michael Euler, Vijesh Krishna, Matin Qaim and Stefan Schwarze for providing the household survey data and Dian Melati for providing the classified land-use map of the Harapan region of Jambi Province.

\subsection{Author contributions}

JS performed the formal analysis and investigation and created visualizations. JS and CD curated the data and implemented and validated the software. JS, CD and GP developed the methodology. CD, KW, KM and GP conceptualized the research. $\mathrm{KW}$ and KM acquired funding and were responsible for project administration, resources and supervision. JS and CD wrote the original draft and all authors contributed in the reviewing and editing process. 


\title{
Chapter 3
}

\section{Land-use change in oil palm dominated tropical landscapes - An agent-based model to explore ecological and socio-economic trade-offs}

This chapter was published as a research article:

Dislich, C., Hettig, E., Salecker, J., Heinonen, J., Lay, J., Meyer, K. M., Wiegand, K., and TARigan, S. (2018). "Land-use change in oil palm dominated tropical landscapes - An agent-based model to explore ecological and socio-economic trade-offs". PLOS ONE 13.1, e0190506. doi: 10.1371/journal.pone.0190506.

\begin{abstract}
Land-use changes have dramatically transformed tropical landscapes. We describe an ecological-economic land-use change model as an integrated, exploratory tool used to analyze how tropical land-use change affects ecological and socio-economic functions. The model analysis seeks to determine what kind of landscape mosaic can improve the ensemble of ecosystem functioning, biodiversity, and economic benefit based on the synergies and trade-offs that we have to account for. More specifically, (1) how do specific ecosystem functions, such as carbon storage, and economic functions, such as household consumption, relate to each other? (2) How do external factors, such as the output prices of crops, affect these relationships? (3) How do these relationships change when production inefficiency differs between smallholder farmers and learning is incorporated? We initialize the ecologicaleconomic model with artificially generated land-use maps parameterized to our study region. The economic sub-model simulates smallholder land-use management decisions based on a profit maximization assumption. Each household determines factor inputs for all household fields and decides on land-use change based on available wealth. The ecological sub-model includes a simple account of carbon sequestration in above-ground and below-ground vegetation. We demonstrate model capabilities with results on household consumption and carbon sequestration from different output price and farming efficiency scenarios. The overall results reveal complex interactions between the economic and ecological spheres. For
\end{abstract}


instance, model scenarios with heterogeneous crop-specific household productivity reveal a comparatively high inertia of land-use change. Our model analysis even shows such an increased temporal stability in landscape composition and carbon stocks of the agricultural area under dynamic price trends. These findings underline the utility of ecological-economic models, such as ours, to act as exploratory tools which can advance our understanding of the mechanisms underlying the trade-offs and synergies of ecological and economic functions in tropical landscapes.

\subsection{Introduction}

Land-use changes have dramatically transformed tropical landscapes throughout the past decades. Large stretches of pristine rainforests, grasslands, and peatlands have been replaced by agriculture (POWELL et al., 2015). This process continues, and even transformed landscapes are subject to continued human-induced land-use changes. Traditional smallholder agricultural systems are particularly turned into intensified monoculture cash crop plantations, for example, oil palm or rubber plantations (FEINTRENIE et al., 2010). It is well-documented that the replacement of previous forests, grasslands, traditional agricultural systems, or fallow lands by intensified agricultural systems can lead to losses in ecosystem functions (CLOUGH et al., 2016, Dislich et al., 2017, Prabowo et al., 2016). At the same time, agricultural intensification provides opportunities for economic development, especially in poor rural areas in developing countries (KLASEN et al., 2013; SAYER et al., 2012).

Interdependencies of ecosystem functions are present both within and between the ecological and socio-economic spheres. For example, the carbon storage ability of a landscape depends on ecological properties such as soil fertility, but may additionally be altered by human interaction and agricultural land use. Such interactions are likely to be complex, often non-linear, and not well-understood.

This paper presents an agent-based simulation model to analyze the ecological and economic drivers and consequences of land-use change in transformed landscapes in the Jambi Region of Sumatra, Indonesia. In these landscapes, oil palm and rubber represent the dominant land-use types. Our study focuses on how the decisions of smallholder farmers with typical field sizes of around two hectares shape the landscape mosaic and the corresponding economic and ecological functions. The model relies on detailed socio-economic and ecological data collected with an integrated design and provided by the interdisciplinary research project EFForTS (Ecological and Socioeconomic Functions of Tropical Lowland Rainforest Transformation Systems, Indonesia), which started in 2012 (see DrESCHER et al., 2016). We therefore refer to our model as EFForTS-ABM (Agent-Based Model).

Drawing on the comprehensive EFForTS database, our guiding research ques- 
tion is: What kind of landscape mosaic can improve the ensemble of ecosystem functioning, biodiversity, and economic benefit based on the synergies and trade-offs that we have to account for (cf., KoH et al., 2009)? This leads to more detailed questions: (1) How do specific ecosystem functions, such as carbon storage, and economic functions, such as household consumption, relate to each other? (2) How do external factors, such as the output prices of crops, affect these relationships? (3) How do these relationships change when production inefficiency differs between smallholder farmers and learning is incorporated?

Agent-based ecological-economic simulation models are suited to answer these questions (VILlAMOR et al., 2014). Agent-based simulation models (ABMs) are considered as "across-level models" (RAILSBACK and GRIMM, 2012, p. 10); that is, they can simulate the behavior of the system from that of individual agents and vice versa. They can thus incorporate the individual decisions of agents, for example, farming households, and evaluate the effects of these decisions on ecological and socio-economic functions at different scales (for example, local or landscape scales). These individual household decisions are themselves driven by social (adaption, learning) and environmental interactions (resources, yield). Such capacities of the often spatially explicit ABM approach have been used to tackle a variety of real-world situations (HOLDO et al., 2010; LE et al., 2008; LE et al., 2010) and many of the models are based on empirical data to the extent possible. Our model adds to this literature by highlighting the key role of smallholder behavior in the ecological-economic system under consideration. More specifically, we take into account the full extent of household farm production inefficiency and model social network learning processes based on spatial proximity (cf. BERGER, 2001; KiesLing et al., 2012; ZHANG and Vorobeychik, 2016). Our modelling of household behavior is based on a dataset of 701 farm households with information on land holdings, agricultural and non-agricultural activity, endowments, and other socio-demographic information (EULER et al., 2017; KRISHNA et al., 2017). High heterogeneity and high average yield gaps in cash crops are well-documented for our study region (for example, in oil palm, see EulER et al., 2016a). On the ecological side, we focus on carbon storage, again using original data from EFForTS. Considering other ecosystem functions, ongoing research will provide land-use-specific data covering the whole spectrum of ecological functions, such as species composition, or water availability and water quality.

EFForTS-ABM is complex enough to capture all factors and processes relevant to our questions (1)-(3), yet simple enough to make the model mechanisms and the forces that drive outcomes tractable (cf., Evans et al., 2013). We analyze the relationships between economic and ecological functions using a scenario-based approach. We highlight land-use decisions, changes in the landscape and the corresponding functions (household consumption and carbon sequestration) under 
(a) different output price scenarios, (b) different farming efficiency scenarios, and

(c) different assumptions on learning. This approach enables us to segregate the different mechanisms that drive ecological-economic trade-offs, such as price dynamics and household heterogeneity. EFForTS-ABM thereby enables us to gain a deeper understanding of the dynamic agricultural smallholder land-use system. This is an essential step for future research that will allow for the testing and devising of specific land-use and agricultural policies aimed at the improvement of the ecosystem functioning of transformed tropical landscapes.

\subsection{Methods}

The model description is structured according to the ODD $+\mathrm{D}$ protocol (MÜLLER et al., 2013), an extension to the ODD protocol for describing agent-based models (Grimm et al., 2006b; GrImm et al., 2010) which incorporates human decisionmaking.

\subsubsection{Overview}

\subsubsection{Purpose}

The purpose of our model is to provide an integrated, exploratory tool that can be used to analyze how land use affects ecological and socio-economic functions. Trade-offs or synergies between different functions on different spatial and functional scales will be investigated with the model.

As smallholders manage the majority of farm land in our study region, we focus on smallholder land management at this point. However, large company plantations will be added in future extensions of the model (see Section 3.4). Landuse and land-management decisions are modelled on the household level, based on household capital and external economic drivers like prices for inputs and products. Socio-economic functions in the model are development and welfare effects; on the ecological side, we focus on carbon storage. Further ecological functions, for example, species diversity, will be incorporated in the near future. We consider the perennial land-use types oil palm and rubber plantations, and use secondary forest (as a near-natural habitat) as a background in the landscape matrix, but we do not analyze secondary forest explicitly for the purposes of this paper.

We choose a spatially explicit approach by discretizing space into grid cells, since the location of the household and its farmland in the landscape might affect the decision-making process, as well as ecological functions. For example, the spatial distance between households influences whether households can learn from each other. Further, biodiversity can be affected by the degree of landscape fragmentation. A combined agent-based and grid-based approach provides the flexibility needed to 
model diverse ecological and socio-economic functions. Interactions between grid cells, as well as interactions between households, can be included explicitly in such a framework.

\subsubsection{Entities, scales, and state variables}

The model simulates ecological and socio-economic aspects of land use and landuse change and therefore comprises five different entities: (1) cells, (2) fields, (3) household area, (4) patches, and (5) the landscape (see Table 3.1). These spatial units capture the hierarchical structure of the system and facilitate the structurally realistic representation of the links between ecology (environment) and socio-economics (households).

Table 3.1: Spatial units of the model.

\begin{tabular}{ll}
\hline Spatial unit & Meaning \\
\hline cell & smallest spatial unit of the model $(50 \mathrm{~m} \times 50 \mathrm{~m})$ \\
field & $\begin{array}{l}\text { contiguous cells of the same land-use type and age belonging to the } \\
\text { same household (that is, an agricultural field) }\end{array}$ \\
household area & $\begin{array}{l}\text { cells belonging to the same household } \\
\text { patch }\end{array}$ \\
$\begin{array}{l}\text { contiguous cells of the same land-use type and same/similar age } \\
\text { (that is, same type of habitat, independent of ownership) }\end{array}$ \\
landscape & largest spatial unit of the model: set of all cells \\
\hline
\end{tabular}

The smallest spatial unit of the model is a square cell corresponding to the typical size of small fields $(50 \mathrm{~m} \times 50 \mathrm{~m}$; Fig. $3.1(\mathrm{~A}))$. Each cell is characterized by its position in the landscape, land-use type, and age, which is the time (number of years) since the current land-use was established. A field is defined as a number of contiguous cells under the same use for the same duration belonging to one household. Each household can own several fields and decide on their use and management (Fig. 3.1(B)). We do not consider expansion of household area or agricultural land and the size of existing fields remains constant throughout each simulation. Similar to fields, patches are contiguous cells of the same use and the same (or similar) age, but regardless of ownership. While fields are important units in the economic sub-model, patches define areas of similar habitat suitability and may thereby play an important ecological role for species diversity and distribution. The landscape comprises a regular grid of cells and is the highest-level entity of the model (here $100 \times 100$ cells, that is, $25 \mathrm{~km}^{2}$ ). All processes in the model, for example, vegetation growth, as well as household-related processes, work on an annual time step. Prices for yield are external and do not vary within the landscape. The temporal extent of one simulation is 50 years according to the external price data that was provided (historical prices scenario; see Section B.2.5 in Appendix B. 

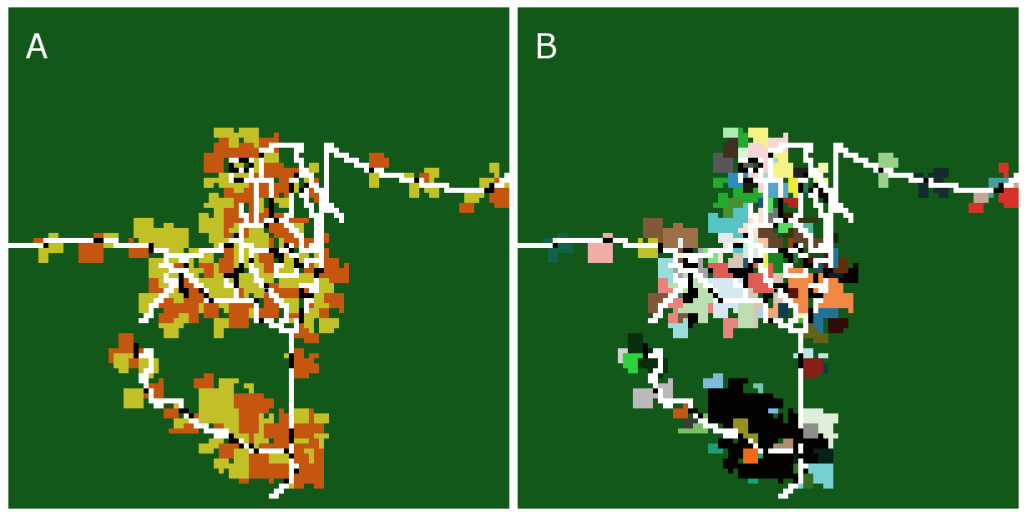

Figure 3.1: (A) Initial land-use map. Roads are marked in white, household home bases in black, oil palm plantations in orange, rubber plantations in dark yellow. Dark green is the area which is not used for agriculture. (B) Household map: different colors represent areas of different households.

Households are characterized by their location in the landscape, the sizes and locations of fields belonging to the household, and specific characteristics, such as wealth. Household variables describe the size and production of the owned land, as well as the financial resources of the household (details in Table 3.2). A detailed description of the household model is given in Appendix B.

Cell variables describe ecological and economic properties of the land use in that respective cell, such as type of use (for example, oil palm), age, technical input, production, and amount of carbon stored in the vegetation of that cell (details in Table 3.3. .

\subsubsection{Process overview and scheduling}

Each model run starts with the initialization procedure, with the loading of a pre-generated initial landscape that is parameterized to our study region and features household agents that are located on a road network, as well as agricultural fields which the agents have established (see Section B.3 in Appendix B). During initialization, crop-specific inefficiency values are also assigned to these households (see Section B.2.3 in Appendix B). After initialization, each grid cell has a certain land use (oil palm, rubber, or secondary forest). Each grid cell under agriculture (oil palm or rubber) has an owner and a certain age. Each household has a predefined initial wealth which is proportional to the area belonging to the household (see Section B.1.1 and B.2.4 in Appendix B). Within each time step (year), the following processes are scheduled (Fig. 3.2). At the beginning of each year, the economic household model is executed. If the optional learning is turned 
Table 3.2: List of household variables.

\begin{tabular}{|c|c|c|}
\hline Variable name & Unit & Meaning \\
\hline h_id & {$[-]$} & Household identifier \\
\hline h_area & [-] & Number of cells belonging to the household \\
\hline h_wealth & [USD] & Amount available for the household \\
\hline h_inefficiency_op & {$[-]$} & Inefficiency factor for oil palm $[0,1]$ \\
\hline h_inefficiency_rubber & {$[-]$} & Inefficiency factor for rubber $[0,1]$ \\
\hline h_debts & [USD] & Annual debts taken up for agricultural production \\
\hline h_capitalstock & [USD] & Amount of capital fixed in plantations \\
\hline h_exincome & [USD] & $\begin{array}{l}\text { Annual external income, i.e. income external to agri- } \\
\text { culture }\end{array}$ \\
\hline h_netcashflow & [USD] & Net cash flow from all household cells \\
\hline h_consumption & [USD] & $\begin{array}{l}\text { Annual consumption of household (fixed }+ \text { variable } \\
\text { consumption) }\end{array}$ \\
\hline h_cost_investment & [USD] & Annual investment costs from all household cells \\
\hline h_cost_labor & [USD] & Annual labor costs from all household cells \\
\hline h_cost_tinput & [USD] & Annual technical input costs from all household cells \\
\hline h_cost_capital & [USD] & Annual capital costs from all household cells \\
\hline h_cost_land & [USD] & Annual land rent costs from all household cells \\
\hline $\mathrm{h} \_$revenue & [USD] & Annual revenue from agriculture \\
\hline h_op_production & [ton] & $\begin{array}{l}\text { Annual production of oil palm fruit bunches from all } \\
\text { household cells }\end{array}$ \\
\hline h_rubber_production & [ton] & Annual production of rubber from all household cells \\
\hline h_debt_years & {$[-]$} & $\begin{array}{l}\text { Number of consecutive years in which the household } \\
\text { had debts }>0\end{array}$ \\
\hline h_connected_hhs & {$[-]$} & $\begin{array}{l}\mathrm{h} \text { _ids of connected households, representing the social } \\
\text { network }\end{array}$ \\
\hline
\end{tabular}

on, households adjust their inefficiency values by learning from their social network (see Paragraph Household inefficiency E learning in Section B.1.3.1 in Appendix B). Household consumption, which is subsistence and wealth-based, reduces the available resources for agriculture (Consumption I, for details, see Paragraph Decision on land-use change and production in Section B.1.3.1 in Appendix B).

Subsequently, households decide on land management and land-use change (Fig. 3.3). This decision is based on expected profits from different land-use options and available financial resources. The actual annual profit from agricultural land use is then calculated for all household cells according to age-specific yields and costs and prevailing commodity prices. At this point, the costs of land-use change, if applicable, are accounted for. These costs for land management include crop and age-specific maintenance and establishment costs (see Section B.2.1.4 in Appendix B . Household wealth is then updated by adding profits from agriculture and external income (if applicable) and deducting a profit-based household consumption (Consumption II). Households may temporarily take up debts to cover consumption or unavoidable costs (see Paragraph Implementation of the land 
Table 3.3: List of cell variables.

\begin{tabular}{|c|c|c|}
\hline Variable name & Unit & Meaning \\
\hline p_landuse & {$[-]$} & $\begin{array}{l}\text { Land use of the cell (oil palm, rubber, secondary } \\
\text { forest) }\end{array}$ \\
\hline p_age & [year] & Age of the plantation in the cell \\
\hline $\mathrm{p}$ _fieldsize & {$[-]$} & $\begin{array}{l}\text { Total number of cells belonging to the same field as } \\
\text { this cell }\end{array}$ \\
\hline p_carbon & [ton] & Carbon stored in the vegetation of this cell \\
\hline p_owner & {$[-]$} & $\mathrm{h}_{-1} \mathrm{id}$, if this cell is owned by a household, otherwise \\
\hline p_homebase & {$[-]$} & $\begin{array}{l}\mathrm{h} \text { _id, if this cell is the homebase of a household, } \\
\text { otherwise }-1\end{array}$ \\
\hline p_production & [ton] & Annual production from this cell \\
\hline p_id & {$[-]$} & $\begin{array}{l}\text { Field identity; all cells belonging to the same field } \\
\text { have the same field identity }\end{array}$ \\
\hline p_labor & [h] & Labor hours invested in this cell in one year \\
\hline p_tinput & {$[\mathrm{kg}]$} & Technical input invested in this cell in one year \\
\hline p_capitalstock & [USD] & Capital stock of this cell \\
\hline
\end{tabular}

management decision in Section B.1.3.1 in Appendix B). Households that do not manage to pay back debts within a certain period are assumed to be incapable of acting and become frozen in the model. Home bases and fields of frozen households disappear from the visual output and are not considered for any upcoming output calculations.

The updated household wealth serves as a basis for the land-use decision module in the next time step. When the calculation of the economic household model is finished, new carbon stocks are calculated for all cells.

\subsubsection{Design concepts}

\subsubsection{Theoretical and empirical background}

Economic household model. The economic household model is based on the concept of "agricultural household models" (SingH et al., 1986). In this type of model, a rural household simultaneously decides on production and consumption under given constraints, for example, initial endowments with land or access to credit. The land management decision includes land-use change and production, as well as the use of factor inputs.

Ecological sub-models. The currently applied carbon sub-model describes carbon stored in the vegetation and utilizes simple age-dependent stock equations for the oil palm and rubber plantation land-use types, and constant stock values for 


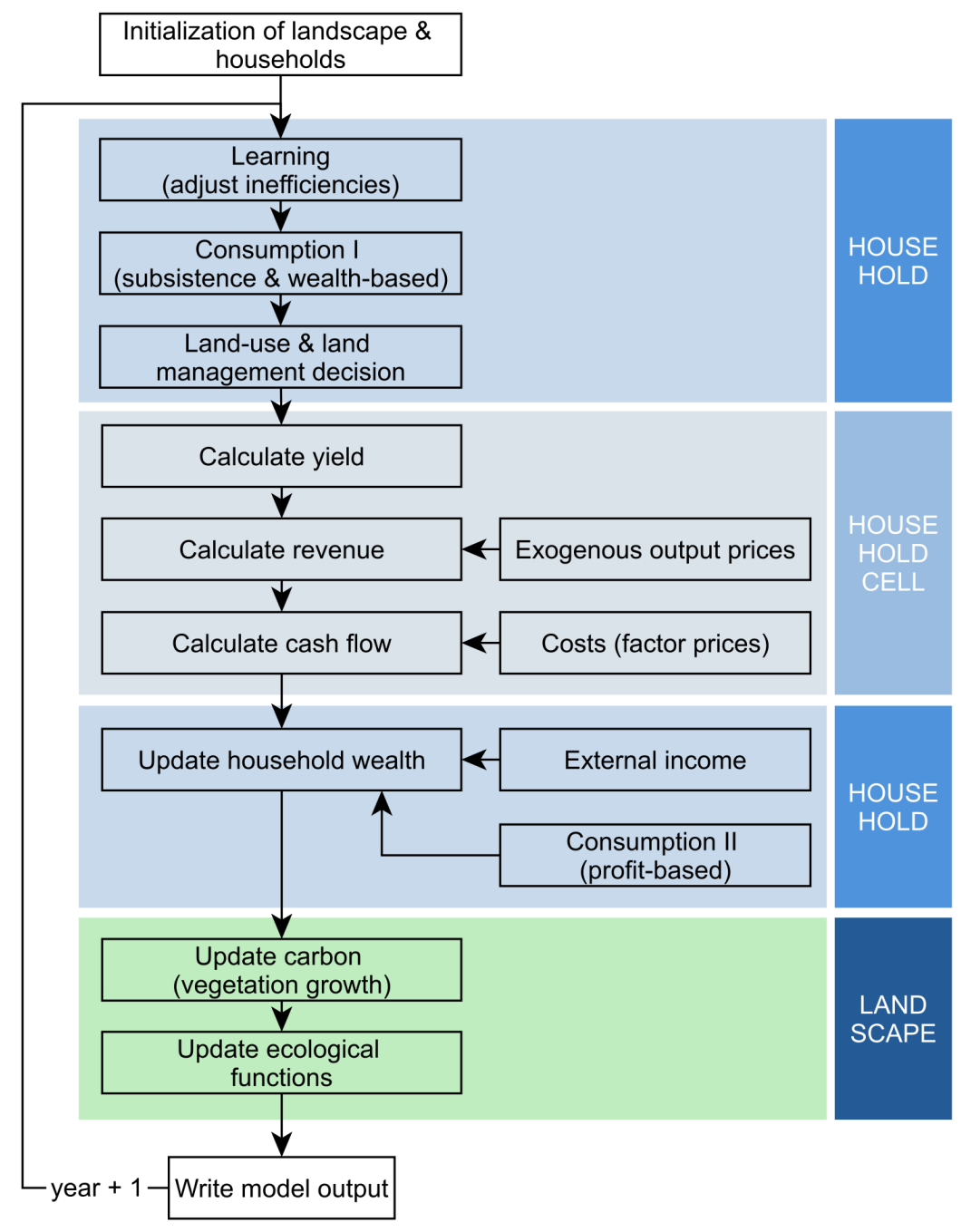

Figure 3.2: Process overview of the whole model.

forest cells. Other factors that might influence carbon stocks, for example, edaphic conditions, fertilizer management, etc., are not considered in this model version.

\subsubsection{Individual decision-making}

Every year, households decide on the land management and land-use change of owned fields. These decisions are driven by their agricultural choices, which, in turn, are determined by production technologies, initial conditions, and household endowments. Households attempt to maximize profits and decide between different land uses according to the expected relative profitability of different options over a 


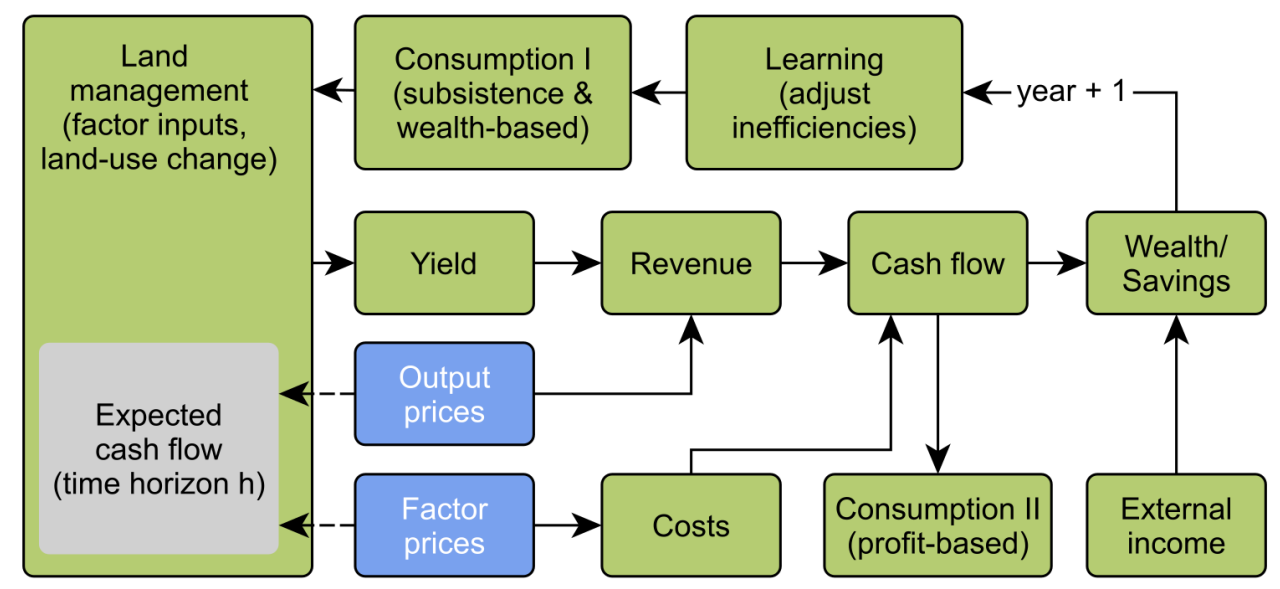

Figure 3.3: Process overview of the economic household model.

certain time horizon. Constraints are taken into account, for example, with regard to the availability of investment capital via proceeds from agricultural production.

\subsubsection{Individual learning, sensing, and prediction}

When learning is turned off, each agent makes its decision independently; that is no neighbor effects are incorporated. When learning is turned on, agents are able to learn from more efficient ones within their individual social network. These social networks are created during model initialization, based on the spatial proximity of agents using road distances. Households are only able to improve the inefficiency of a crop they currently cultivate ("learning by doing") and if their inefficiency is above the current network's mean inefficiency level. By learning, households continuously adjust their inefficiency values to the network's mean inefficiency level (see Paragraph Household inefficiency E learning in Section B.1.3.1 in Appendix B).

Agents' knowledge of prices is restricted to current commodities. Therefore, they forecast future prices using current prices and anticipate zero change. This is also true for inefficiencies; agents do not anticipate their own learning.

\subsubsection{Interaction, collectives, and heterogeneity}

When learning is turned on, the model incorporates interactions between agents. Irrespective of learning, agents differ in their land and capital endowments, as well as their initial land uses and the ages of their fields. Additional factors that introduce heterogeneity are the inefficiency parameters (one for each crop type; see Table 3.2 that affect a household's production function (see Paragraph Production function, cash flows and capital accumulation in Section B.1.3.1 in Appendix (B). 


\subsubsection{Stochasticity}

The initial wealth of households is drawn from a log-normal distribution and resulting values are assigned according to household areas (see Sections B.1.1 and B.2.4 in Appendix B. Parameters for crop and household-specific inefficiency are drawn from gamma distributions and either stay constant or vary through learning. Both wealth and inefficiency parameters are drawn from distributions using observed data. The social networks used by the learning procedure can be created either deterministically or stochastically by using a negative exponential probability function.

Different options of stochastic price dynamics are implemented (for example, Gaussian random walk; see Section B.2.5 in Appendix B). However, this option can be turned off to use constant prices.

\subsubsection{Observation}

Observed household patterns include land-use changes and dynamic yield development, predicted and actual cash flows, and household wealth. On the landscape level, we observe the fractions of different land-use types, mean consumption, survival of households, and carbon stocks.

\subsubsection{Model scenarios}

In order to address our research questions (1)-(3), and to explore underlying model mechanisms, we run six different model scenarios (see Table 3.4). We analyze the spatial patterns and economic and ecological trade-offs that emerged from the land-use decisions of households. We look at two different price scenarios: (i) constant prices for oil palm and rubber, set to values derived from the household survey data, collected in the Jambi region in 2012; (ii) historical price trends, which illustrate actual price fluctuations in world commodity markets, derived from World Bank data (see Section B.2.5 in Appendix B). For each price scenario, we look at three different household inefficiency scenarios: (i) all farmers have zero inefficiency for both crops (that is, all are perfectly efficient); (ii) farmers have heterogeneous inefficiency values drawn from gamma distributions. Inefficiencies stay constant throughout the simulation (that is, learning is turned off); (iii) farmers have heterogeneous inefficiency values and are allowed to improve productivity through learning from their social network (that is, learning is turned on). The social networks are created by using the distance kernel function combined with a maximum distance cap (see Paragraph Household inefficiency ES learning in Section B.1.3.1 in Appendix B). The temporal extent of all scenarios is 50 years, based on the extent of the external price data. In order to capture model stochasticity 
we simulate 20 replications for each scenario.

Table 3.4: Model scenarios

\begin{tabular}{lll}
\hline Scenario & Prices & Inefficiency \\
\hline C0 & Constant prices (C) & No inefficiencies (0) \\
CI & Constant prices (C) & Heterogeneous inefficient households and no learning (I) \\
CIL & Constant prices (C) & Heterogeneous inefficient households and learning (IL) \\
H0 & Historical trends (H) & No inefficiencies (0) \\
HI & Historical trends (H) & Heterogeneous inefficient households and no learning (I) \\
HIL & Historical trends (H) & Heterogeneous inefficient households and learning (IL) \\
\hline
\end{tabular}

\subsection{Results and Discussion}

The main result of this study is an integrated ecological-socio-economic land-use model, called EFForTS-ABM. EFForTS-ABM is an integrated model in terms of disciplines, processes, and scales (for spatial scales, see Table 3.1). Thereby, it covers key features of integration in environmental modelling (KELLY (LETCHER) et al., 2013).

The purpose of the model is to develop system understanding rather than prediction or forecasting (KELLY (LETCHER) et al., 2013). We chose an agentbased modelling approach because it incorporates complexity and details at the individual level (KELLY (LETCHER) et al., 2013), including heterogeneity between agents, as well as interactions between agents and scaling up from the agent to the landscape level (FISCHER et al., 2016). We have both quantitative and qualitative data available on social, economic, and ecological functions of the system (BARNES et al., 2014. GATTO et al., 2015). Both the qualitative purpose and the agent-based approach of the model facilitate incorporating different types of data. Moreover, we are in the unique situation that data collection follows an integrated scheme that has jointly been developed by modelers and empiricists (DRESCHER et al., 2016. FAUst et al., 2013; JELTSCH et al., 2013). Thus, the relationship between the data collection and monitoring in the field and the modelling can resemble an integrated environmental process, with feedbacks between different stages of the two procedures, providing a more holistic approach (LANIAK et al., 2013).

Our approach is distinct from previous agent-based models of land-use change that have been developed for Jambi, Sumatra, (LB-LUDAS, Villamor et al., 2014) and for other study regions and other land uses (e.g. KELLEY and Evans, 2011: Valbuena et al., 2010). This holds in particular for the decision-making process of the smallholders. We concentrate on (i) an appropriate representation of the intertemporal nature of the land-use change decisions implied by investment costs (related to switching crops or replanting) and the respective yield cycles, and 
(ii) an incorporation of the heterogeneity of smallholders in key determinants of land-use change decisions, most notably their endowments with land, capital, and labor, as well as crop-specific productivity (HETTig et al., 2016). We especially consider the incorporation of productivity heterogeneity, i.e. in production parameters, which is an innovation of our study. Further, we (iii) let farm households decide simultaneously on production and consumption, as is well-established in the literature on decision-making in agricultural households (TAYLOR and ADELMAN, 2003). Data from a smallholder survey of relatively large size (701 farm households) allows us to quantify all these household and farm-level variables (EULER et al., 2017; Krishna et al., 2017). We follow previous models (for example, KELLEY and Evans, 2011) and the literature on agricultural household models by assuming a rational "portfolio" choice that is constrained by household endowments and, in fact, subsistence needs. Note that the context that we are modeling is characterized by smallholder cash-croppers who are relatively undiversified in terms of agricultural production. All these modeling choices keep our model and the effects of smallholder heterogeneity tractable. We acknowledge, however, that this simplicity puts limitations to our analysis. The representation of the smallholder decision-making and their heterogeneity emphasizes the relative profitability of the two cash crops as a key driver of land-use change. The model does not explicitly account for socio-demographic household characteristics, such as education or ethnicity. Another important omission is the non-consideration of risk and risk aversion, as in the heterogeneous-agent portfolio-theory model by Kelley and Evans (KELley and Evans, 2011). This limitation may not be too severe as the risks related to the two considered crop options may be similar. Thus, our model has less probabilistic elements than, for example, VALBUEnA et al., 2010. While we do not explicitly model differences in preferences (as LB-LUDAS, VILLAMOR et al., 2014), the fact that the crop-specific productivity at the farm-level is parameterized in line with observed crop choices can be seen as an equivalent model feature.

Unlike previous applications of ABMs (e.g. KELLEY and Evans, 2011; VALBUENA et al., 2010), the focus of EFForTS-ABM is on the human-environment interactions of transformed landscapes. It is thus not on the expansion of agricultural land because most of the forested area in our study region has already been converted to monoculture plantations over the past decades. In contrast to other applications, we therefore do not consider land expansion. In addition, land-use options have been more differentiated in other models. Kelley and Evans, 2011. for example, include fallow land as an option, as farmers might want to reduce labor costs if output prices are low. In the EFForTS-ABM model, neighborhood effects work through learning effects, which indirectly influence land-use change decisions. Admittedly, direct neighborhood effects, i.e. where land conversion by one farmer directly affects the conversion decision of the neighbor, may be 


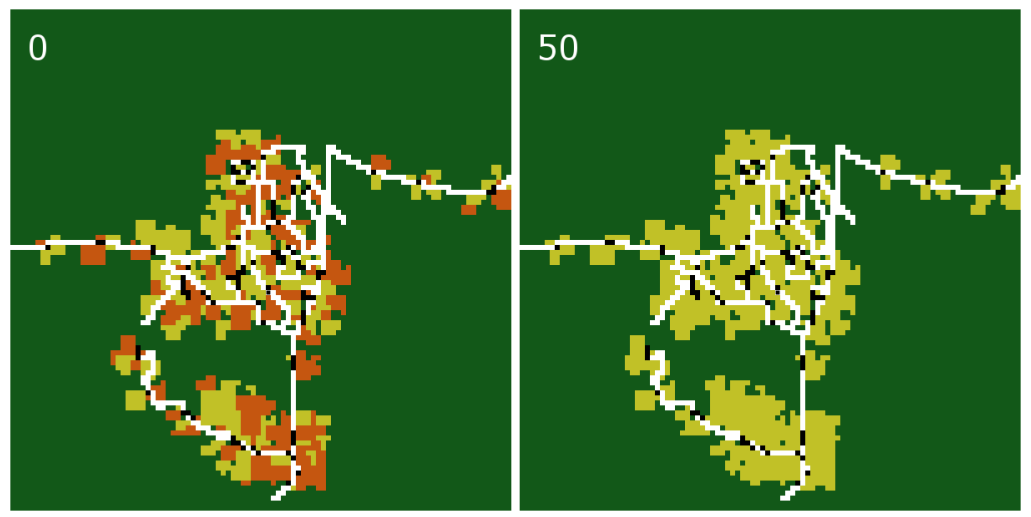

Figure 3.4: Snapshots of the initial (year 0) and final (year 50) simulated landscape of an exemplary simulation run with constant prices and no inefficiencies (scenario $\mathrm{C} 0$ ). Roads are marked in white, household home bases in black, oil palm plantations in orange, and rubber plantations in dark yellow. Dark green is the area which is not used for agriculture. An animated representation of this example simulation can be found in the Supplementary Materials of the published article DisLICH et al., 2018.

an important mechanism that EFForTS-ABM does not yet capture - this is also because we lack data on such conversion patterns. Further, other spatial aspects, including the composition of the surrounding landscape and transaction costs, such as the distance to roads (or processing facilities), are not yet accounted for.

The key mechanism of the EFForTS-ABM in its current form is the household's land management decision. Farmers will tend towards the more profitable land use and will convert land with some time lag conditional on the current land use. For instance, the household's capital endowment needs to be sufficient enough to cover the investment costs of conversion. This implies that the model should produce convergence towards the more profitable land use, at least if productivity is homogeneous and input and output prices are constant and common to all farmers. Indeed, we observe this behavior in the model. For example, at the farm-gate prices of the last quarter of 2012 with rubber at US $\$ 1,100$ per ton and oil palm at US $\$ 90$ per ton of fresh fruit bunches (FFB), rubber turns out to be more profitable than oil palm regardless of the time horizon used for how far into the future the household calculates expected net cash flows (time horizon tested up to 20 years, see Section B.2.2 in Appendix B. In such a scenario and with default settings, the proportion of fields planted with rubber increases to 1.0 (Fig. 3.4 and Fig. 3.5 (A, a)). The transition phase from a proportion around 0.5 for both crops in the initial situation to a complete dominance of rubber is about 20 years under the current model specification and parameterization. 


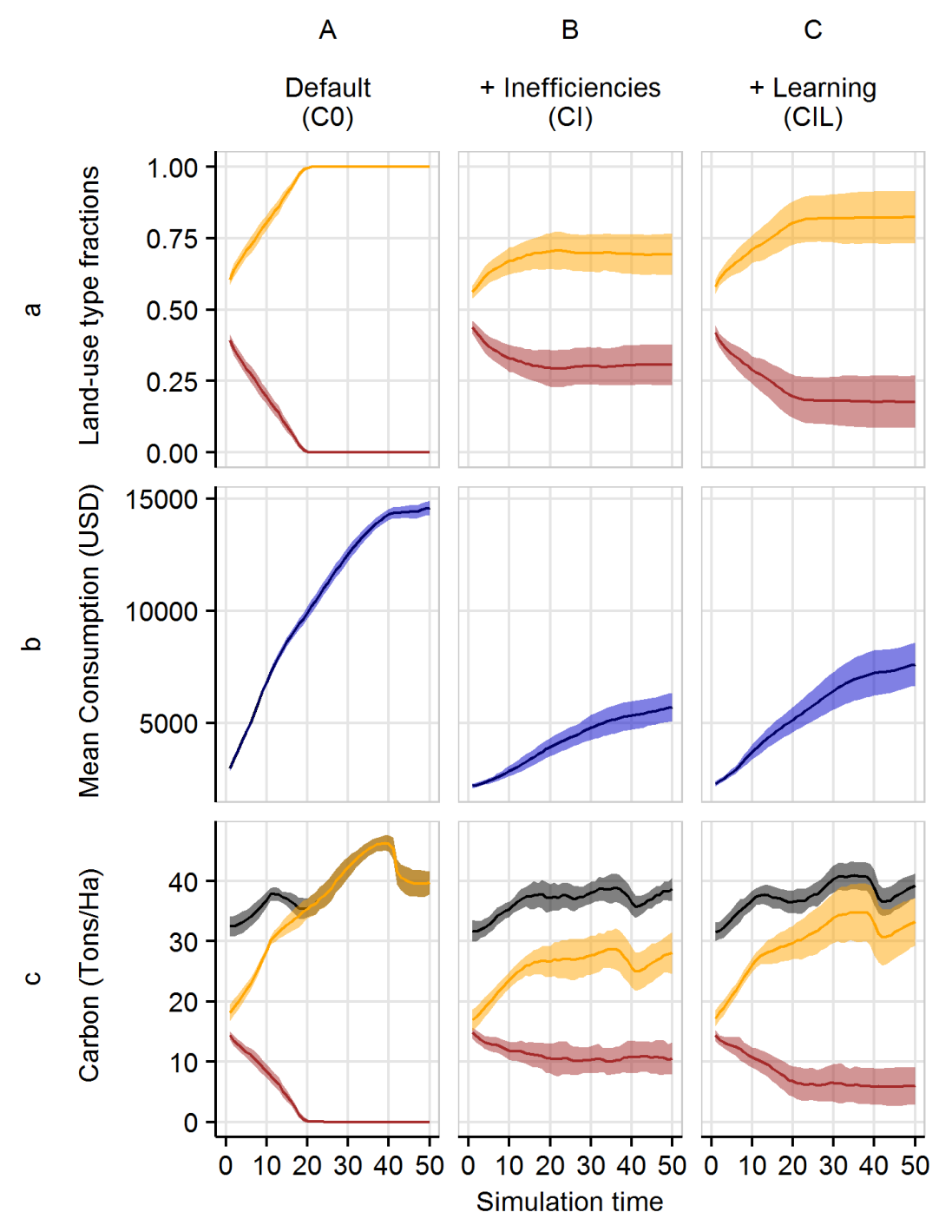

Figure 3.5: Temporal dynamics under constant price scenarios. Fractions of different land-use types within the agricultural area (a), mean household consumption (b), and vegetation carbon stocks over time (c), with constant output prices; for agents with no inefficiencies and no learning (A), heterogeneous inefficiencies and no learning (B), and heterogeneous inefficiencies and learning (C). In (a) and (c), the light orange color denotes rubber monoculture, while red denotes oil palm. In (c), black refers to the total carbon of land under agriculture. The dark lines represent mean values of the 20 model replications and the shaded polygon surrounding each line represents the respective standard deviations. 
The model produces more diverse land-use patterns if we introduce heterogeneity in productivity, that is, differences in household inefficiencies (Fig. 3.5 (B, a)). In this case, the relative profitability of rubber and oil palm differs between households and therefore also their choice. For some households, oil palm is more profitable than rubber, despite low output prices; this is due to these households having a substantially higher inefficiency for rubber than for oil palm. When learning is added, land-use change patterns are still inert, but they move closer to the scenario without inefficiencies (Fig. 3.5 (C, a)). Learning enables farmers to improve productivity over time and they become more homogeneous.

The simulated land-use change scenarios under constant prices are associated with considerable increases in household consumption (Fig. 3.5 (b)). In general, and in the absence of learning, two forces are at work in the model that can increase profits and thus consumption over time. One is the "natural" yield growth of both crops over time (see Section B.2.1 in Appendix B); the second force is the option to switch to a more profitable crop. However, the investment costs of switching will cut into consumption and may temporarily decrease household welfare. The model results show the average implications of these consumption-level mechanisms (Fig. 3.5 (A, b)). Overall, consumption more than doubles within about 20 years. This is driven by both switching to more profitable rubber, as well as increasing yields with plantation age. An increase in yields clearly drives the observed consumption increase after year 15, because most of the households already switched all their fields to rubber. After year 40, the growth of consumption slows down again as the necessary replanting of rubber plantations involves new investments. Rubber plantation productivity drops significantly when it reaches an age of 30 years, which promotes replanting. Because many households switched their fields from oil palm to rubber plantations in the beginning of the simulation, these plantations need to be replanted at around year 40 (see Section B.5 in Appendix B). With inefficiencies present, mean consumption is more than $50 \%$ lower than under efficient production (Fig. $3.5(\mathrm{~B}, \mathrm{~b})$ ). This is partly a direct implication of lower yields due to inefficient production. The heterogeneous inefficiencies also indirectly reduce the number of households who can profit from converting to rubber. When learning is introduced, consumption lies in between the outcome under the efficient and inefficient (without learning) scenarios (Fig. 3.5 (C, b)).

The fairly steady improvement of average household welfare is accompanied by relatively constant vegetation carbon dynamics (Fig. $3.5(\mathrm{~A}, \mathrm{c})$ ). The amount of carbon in the agriculturally used area fluctuates around 35-40 tons per hectare within the first 20 simulation years, that is, as long as there is a mixture of oil palm and rubber plantations. During this time, the reduction of vegetation carbon stock due to land-use change is roughly balanced by vegetation growth on those plots where land use does not change. Once all oil palm plantations are replaced 

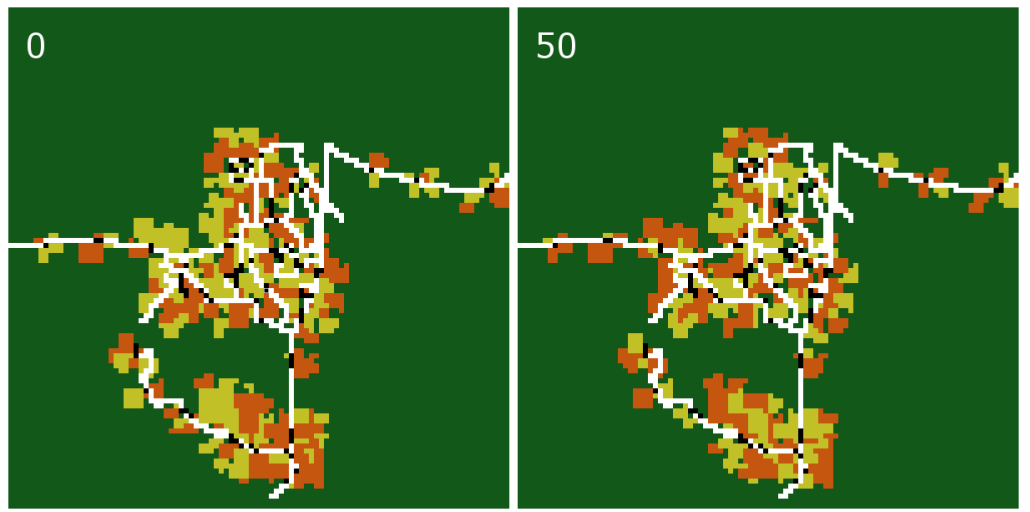

Figure 3.6: Snapshots of the initial (year 0) and final (year 50) simulated landscape of an exemplary simulation run with historical price trends and no inefficiencies (scenario H0). Roads are marked in white, household home bases in black, oil palm plantations in orange, and rubber plantations in dark yellow. Dark green is the area which is not used for agriculture. An animated representation of this example simulation can be found in the Supplementary Materials of the published article DisLiCH et al., 2018.

by rubber plantations, the vegetation carbon stock increases up to more than 45 tons per hectare, and then slightly decreases again. The decrease in carbon after year 40 is caused by the replanting of old rubber plantations (see Section B.5 in Appendix B). This means that with the applied land-use decision criterion and at the spatial scale and number of households of the model, we observe a tendency towards synchronization, not only of land-use types, but also of plantation ages. This can have both socio-economic and ecological consequences, such as a possible reduction in inequality and amplified cycling in landscape-scale carbon stocks. With the introduction of heterogeneity in inefficiency, carbon stock fluctuations are dampened further, as changes in land use are less dramatic (Fig. 3.5 (B, a and $\mathrm{B}, \mathrm{c})$ ). When learning is present, trends are again more similar to those under efficient production, albeit with a slower general rate of change (Fig. 3.5 (C, c)).

When the oil palm and rubber prices fluctuate as with past outputs, the choice of land use no longer settles to a stable state (Fig. 3.6). Instead, when households have no inefficiency, the dominant land-use type varies with the relative changes in the output prices (see Section B.2.5 in Appendix B). However, not all households are able to switch immediately to the more profitable crop. Households differ in the wealth and size of fields cultivated that originate from initial model conditions. Households with greater wealth and smaller fields (that is, higher investment capacity and lower required investment costs) can be more reactive to price changes 


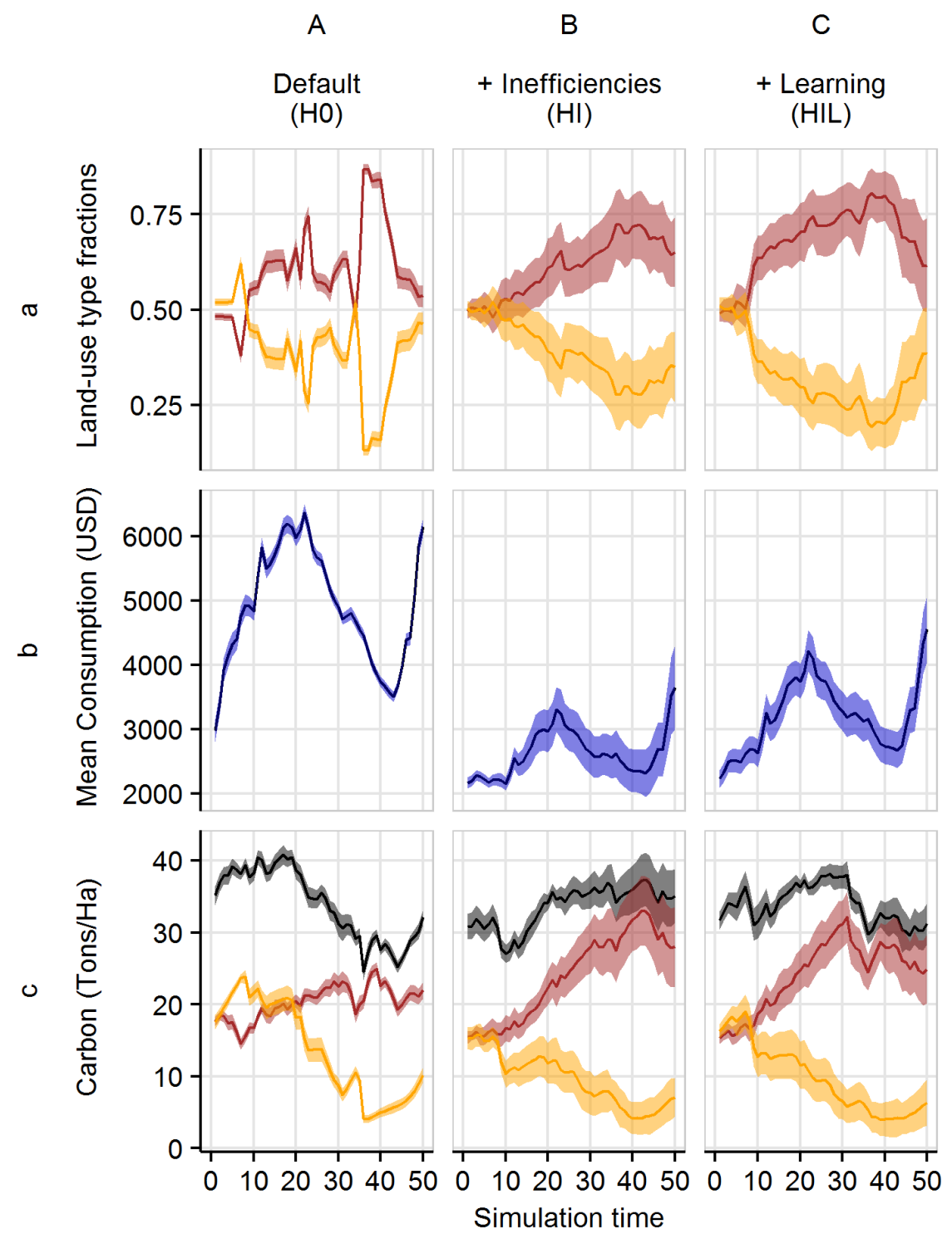

Figure 3.7: Temporal dynamics under historical price scenarios. Fractions of different land-use types within the agricultural area (a), mean household consumption (b), and vegetation carbon stocks over time (c), with historical price trends; for agents with no inefficiencies and no learning (A), heterogeneous inefficiencies and no learning (B), and heterogeneous inefficiencies and learning (C). In (a) and (c), the light orange color denotes rubber monoculture, while red denotes oil palm. In (c), black refers to the total carbon of land under agriculture. The dark lines represent mean values of the 20 model replications and the shaded polygon surrounding each line represents the respective standard deviations. 
and can more easily switch to a new, more profitable land use. Because of the continuous switching, mean household consumption never reaches the levels seen in the scenario with constant output prices (Fig. 3.5); however, similar levels of carbon accumulation under agriculture are reached compared to the constant prices scenarios (Fig. 3.5 and Fig. 3.7). When heterogeneity in inefficiency is included with or without learning, fluctuations in land-use fractions still occur with changing prices, but the overall trend is more stable (Fig. 3.7 (B, a and C, a)). Mean consumption is lower, but peaks occur at similar times as in the scenario with no inefficiencies (Fig. 3.7 (B, b and C, b)). Carbon stored under oil palm and rubber follows trends similar to those of the corresponding land-use fractions (Fig. 3.7 (B, c and C, c)). Interestingly, out of the three historical price trend scenarios, inefficiency without learning resulted in the most stable total carbon stocks at around 35 tons per hectare from year 25 onwards (Fig. 3.7 (B, c)).

In order to understand such ecological-economic trade-off dynamics, it is essential to look at the model drivers of carbon stock dynamics. Carbon stocks are driven by land-use change decisions, and land-use change towards the more profitable crop is mainly driven by price dynamics. In the no-inefficiency scenario (Fig. 3.7(A)), households react immediately to changing prices more or less synchronously. In these highly reactive systems, land-use change is quite frequent. The carbon accumulation rates following land-use change (that is, replanting or switching land use of fields) are very low compared to the rates of older plantations (see Section B.1.3.2 in Appendix B). Thus, the frequent switching of land-uses results in decreased total carbon stocks. When the efficient production assumption is relaxed and replaced by crop-specific heterogeneous inefficiencies, three types of households appear in the model: those with a lower inefficiency for oil palm than for rubber, those with a lower inefficiency for rubber than for oil palm, and those with similar inefficiencies for both crop types. Households with significant differences in crop inefficiencies focus on the crop type with which they have less inefficiency and only change land use under drastic price changes (see Section B.5 in Appendix B). Additionally, households with high inefficiencies have lower overall yields and are able to generate less capital needed for investment. This makes switching less affordable. The heterogeneity in households and their decision-making reduces synchronization and increases system inertia, which results in a more stable distribution of land-use fractions and thus more stable agricultural carbon stocks (Fig. 3.7 (B, c)).

To better understand the dynamics at the household level, it is instructive to look at actual yield as a percentage of potential yields. The yield gaps in both crops tend to decline even in scenarios without learning (Fig. 3.8 (A, a and A, b)). The two main reasons for this are: (i) farmers that are very inefficient producers of one crop type tend to switch to the type with which they are relatively more efficient. As very inefficient farmers thus tend to switch first, this reduces the average yield 
gap for all households active in the production of this crop; (ii) farmers that are inefficient in both crop types tend to take up debts and become frozen early during the simulation.

For example, in the historical price trend scenario (see Section B.2.5 in Appendix $B$, the declining initial prices make rubber farming the least profitable to smallholders with high rubber inefficiencies. This lowers the overall yield gap of the remaining rubber farming households down to a minimum at around year 39 . Rising rubber prices enables profitability even for households with high inefficiencies, which increases the overall yield gap from year 39 onwards. One might expect to see an inverse trend in oil palm yield gaps, especially in year 39, where we observe an increase in oil palm farming (see Fig. 3.7 (B, a and C, a)). However, oil palm yield gaps show a more or less linear decreasing trend over the entire simulation time. This is because only households that are relatively efficient oil palm producers will switch from rubber to palm oil, while others will take up debts and become frozen if rubber prices are at their minimum (see Section B.5 in Appendix B).

The overall results illustrate the complex interactions between economic and ecological functions, in particular when household heterogeneity is considered. This underlines the need for exploratory tools like EFForTS-ABM. The spatially explicit agent-based approach enabled us to investigate the detailed questions we proposed in the introduction. (1) In most scenarios, and especially in the constant prices scenarios, we do not see clear patterns of trade-offs between household consumption and agricultural carbon stocks. However, smallholder decisions on switching crops and replanting have important impacts on carbon stocks. (2) These decisions are influenced by fluctuating prices. Thus, price dynamics increase heterogeneity in land-use patterns with strong effects on both economic and ecological functions. (3) Productivity heterogeneity among smallholders can have important impacts of ecological-economic trade-offs. Because of the selection processes of more productive farmers (and/or learning), economic benefit can be improved with no harm to carbon storage. However, productivity and heterogeneity also affect the responsiveness of the households to price changes, which, in turn, may not always be beneficial from an ecological perspective.

Regarding our guiding question: "what kind of landscape mosaic can improve the ensemble of ecosystem functioning, biodiversity, and economic benefit based on the synergies and trade-offs that we have to account for?", we can say that, although carbon storage in oil palm and rubber fields is lower than in primary or secondary forests, the relationships between carbon accumulation/storage and economic benefit are not straightforward when household heterogeneity and switching between crops is taken into account. Rational decisions driven by household characteristics may, for example, lead to ecologically harmful switching that may be avoided by setting up appropriate pooling or compensation mechanisms among households. 
A

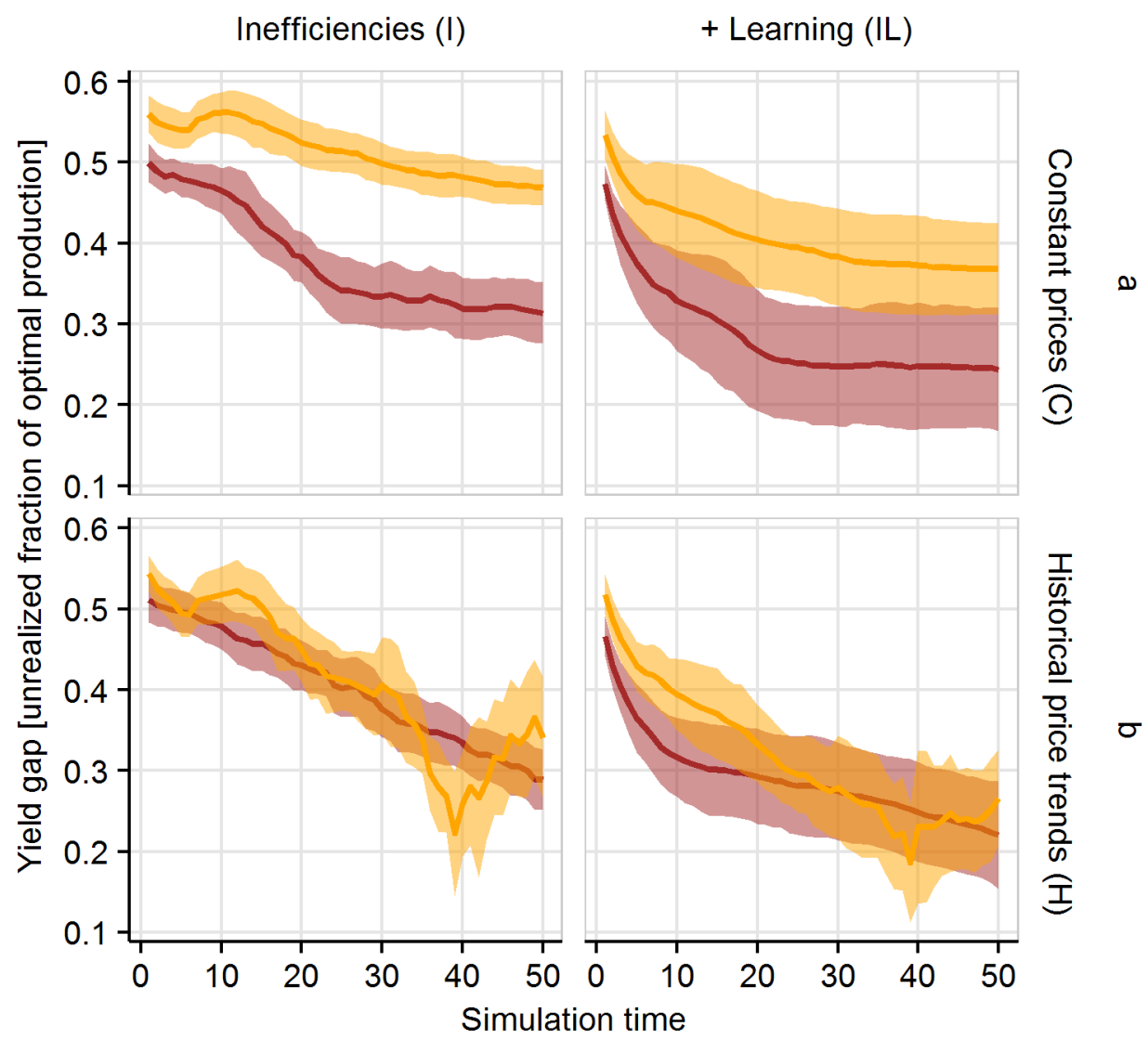

Figure 3.8: Yield gaps for the scenarios with heterogeneous inefficiencies for constant (CI, CIL) and historical price trends (HI, HIL). Yield gaps are calculated as an unrealized fraction of potential production of all households at each time step for each crop type (yellow: rubber, red: oil palm). Yellow denotes rubber monoculture, while red denotes oil palm. The dark lines represent mean values of the 20 model replications and the shaded polygon surrounding each line represents the respective standard deviations. 


\subsection{Outlook}

The results demonstrate our model's ability to simulate ecological and economic functions on the basis of a subtle representation of economic decision-making by farmers in a system of two intensified monocultures. At the same time, they demonstrate potentially missing features in the model, such as the lack of leaving land (and plantations) temporarily fallow. Field observations show that farmers are unlikely to immediately switch individual fields from rubber to oil palm production while the rubber is still of a (potentially) profitable age (V. Krishna, personal communication; see also Section B.4 in Appendix B). Furthermore, and along similar lines, observations from the field indicate more inertia in land-use changes than our model suggests. Credit constraints may be more binding than our model assumes or other factors, such as risk (and risk aversion), may prevent farmers from investing in new crops.

More comprehensive treatment of the socio-ecological complexity requires further expansion of the model. Future additions to the model could include large companyowned plantations which might affect knowledge transfer and social networks in our study system. In addition, demographic and land-use dynamics (farm consolidation processes, land markets, migration) need consideration (see GATTO et al., 2015).

In terms of the ecological sub-model, further extensions can include soil carbon dynamics (as opposed to just carbon stocks), hydrological functions, and biodiversity of soil microbial communities, plants, insects (including, for example, ants), birds, and possibly mammals (BARNES et al., 2014 KRAshevska et al., 2015, Mumme et al., 2015) (for study designs, see also DrESCHER et al., 2016; FAUst et al., 2013).

With these additional details, the model will be a flexible tool to examine trade-offs and possible synergies between a multitude of economic benefits and ecosystem services and biodiversity (cf. InVEST modelling tool NELSON et al., 2009). For example, similar to POLASKY et al., 2008, we may then investigate efficiency frontiers, that is, use landscape mosaics where economic benefit is high as starting points to search for alternatives that increase ecosystem services and biodiversity markedly, while having minimal impact on the economic benefits (Clough et al., 2011; POlasky et al., 2008).

In summary, Efforts-ABM in its current state serves well as a general tool for exploring the complex interactions and trade-offs between economic smallholder household decisions and ecological functions. Our next steps will include a sensitivity analysis (e.g. Schouten et al., 2014), further model refinement, and a validation against observed landscape patterns that will enable us to further increase model usability and reliability. 


\subsection{Acknowledgments}

We thank Michael Euler, Vijesh Krishna, Matin Qaim, and Stefan Schwarze for providing the household survey data, and Martyna Kotowska, Christoph Leuschner, and Dietrich Hertel for providing tree biomass data. We thank Vijesh Krishna and Michael Euler for comments and advice during model development and data analysis, and two anonymous reviewers for comments on an earlier version of this manuscript.

\subsection{Author contributions}

$\mathrm{CD}$ and EH curated the data and performed the formal analysis. CD, JS and JH implemented the software. CD, EH, JS and JH developed the methodology. JS and JH created visualizations. JL, KM and KW acquired funding. JL, KM, KW and ST were responsible for supervision. CD, EH, JS, JH, JL and KW wrote the original draft and all authors contributed in the investigation of research and the reviewing and editing process of the manuscript. 


\title{
Chapter 4
}

\section{From bacteria to birds: tropical land-use change causes variable responses in species turnover}

This chapter presents a manuscript that is intended to be submitted as a research letter: Salecker, J., Simpkins, C. E., Brambach, F., Corre, M. D., Drescher, J., Grass, I., Koenig, C., Barnes, A., Brinkmann, N., Brose, U., Daniel, R., Darras, K., Hertel, D., Jochum, M., Knohl, A., Kotowska, M., Krashevska, V., Leuschner, C., Polle, A., Potapov, A., Rembold, K., Sandmann, D., Scheu, S., Schneider, D., Stiegler, C., Tuitrosoedirdjo, S. S., TuoA, A., Tscharntke, T., Veldkamp, E., Wiegand, K., and Kreft, H. (in prep). "From bacteria to birds: tropical land-use change causes variable responses in species turnover".

\begin{abstract}
Land-use change in the tropics has converted vast areas of rainforest into agricultural landscapes. These changes pose a major threat to biodiversity and are likely to have a negative impact on the diversity and composition of species assemblages. Our knowledge on the conservation value of tropical land-use systems is often limited to few taxonomic groups. However, to design and manage landscapes with less dramatic effects on biodiversity, we need to understand the effects of land-use change on local diversity and spatial organization of species assemblages across a broad range of taxa. Here, we analyzed patterns and drivers of changes in the composition of local species assemblages (i.e. spatial species turnover) due to land-use change in an Indonesian smallholder landscape for 14 taxonomic groups. We studied a land-use intensity gradient from near-pristine rainforests, over low intensity rubber agroforests, to smallholder rubber plantations and intensively managed oil palm plantations in the Jambi Province of Sumatra. We found strong differences in the composition of forest and agroforest communities versus rubber or oil palm plantations. However, the different taxonomic groups showed highly variable responses to land-use intensification. In four groups, spatial species turnover within land-use systems (measured as pairwise Morisita-Horn-Index) was highest within forests and consistently decreased with land-use intensity towards
\end{abstract}


the plantations, indicating a trend of homogenization in species composition in intensively managed land uses. Five groups showed an opposite trend, with higher species turnover in the intensively managed plantation systems compared to forest, indicating heterogenization. Another five taxonomic groups did not show any consistent trend. Furthermore, spatial species turnover was strongly correlated among soil bacteria, protists, fungi, and plants, but surprisingly weakly correlated among the other taxa, making it generally difficult to predict the community composition of one group based on another and questioning the utility of indicator taxa. Environmental variables reflecting vegetation structure, soil attributes and microclimate emerged as strong predictors of species turnover but their relative importance varied considerably among taxa. Our results suggest land-use intensification does not consistently lead to homogenization of species assemblages in tropical smallholder landscapes, as we found divergent effects of land-use change on species turnover for different taxonomic groups. Our results highlight the need to consider multiple taxonomic groups in assessing the effects of land-use change on tropical biodiversity at broader spatial scales.

\subsection{Main}

Land-use change towards monocultural agricultural production has drastically altered landscapes in Indonesia in recent decades (LAURAnCE et al., 2014). Such drastic changes have a multitude of impacts on ecosystem functioning and biodiversity (DISLICH et al., 2017; FLYNN et al., 2009, FOLEY et al., 2005). Multi-taxa biodiversity studies have been conducted to understand the effects of land-use change and showed a strong decline in alpha biodiversity for most taxa (e.g. Mendenhall et al., 2016, Newbold et al., 2015).

Although the drivers of these effects are not yet well understood (TABARELLI et al., 2012), many studies analyze aggregated community patterns up to global scales (e.g. BARLOW et al., 2018) or only study effects of a single taxon (e.g. FrishKOFF et al., 2019, KARP et al., 2012 SOLAR et al., 2015). However, land-use change effects may be highly taxon-specific and scale-dependent, for example, (ClougH et al., 2016) reported higher species richness for some taxa in intensive agriculture. Other studies reported taxon-specific responses in tropical forests, agroforestry and annual culture (EDWARDS et al., 2014; LAWTON et al., 1998; SCHULzE et al., 2004). Previous assessments of local land-use change effects on multi-taxa species richness and turnover in the Brazilian Amazon reported mainly homogenization of species communities in deforested tropical landscapes (SolAR et al., 2015).

Here we analyze community patterns of 14 taxa, gathered across a land-use intensity gradient reaching from forest, over low-intensity rubber agroforestry (Jungle rubber) up to intensively managed rubber and oil palm plantations in 
Jambi, Indonesia. Across all taxa, we noticed substantially different community composition in agricultural land uses compared to forest sites. In line with most previous studies, the forest sites were the most diverse, and the largest group of species across all taxa were forest-dependent species that did not appear in any other land use and thus are especially threatened by ongoing deforestation. In many taxa, we observed a large fraction of species that only appeared in intensive agriculture, most likely including non-native species, indicating a strong shift in community composition. Although community composition was clearly affected by land-use change at broader spatial scales, we could not identify general patterns across all taxa, suggesting that biodiversity assessments in the tropics should always consider multiple taxa.

Species occurences. The island of Sumatra is part of the Sunda Islands which were identified as a global biodiversity hotspot (MYERS et al., 2000). Our study region on Sumatra, Jambi province, faced severe land-use change during the last century that mainly comprises deforestation and expansion of the smallholder farming area (ClOUGH et al., 2016). At present, however, there is no extensive study for these typical smallholder landscapes on the island of Sumatra that covers the alpha- and beta-biodiversity of several above-ground and below-ground taxa along a land use intensity gradient. Biodiversity and environmental data were collected in a standardized, plot-based sampling scheme and represent a uniquely comprehensive assessment of the community composition for 14 taxonomic groups covering all domains of life, different trophic levels, and above- and below-ground biodiversity.

When aggregating over all taxa considered, the majority of species were found to be forest-dependent species $(366 \%, 1$ st bar in Fig. 4.1 theoretical maximum $1400 \%)$. These are all species that were not found in any agricultural land use and thus are likely to be lost completely if a landscape would become devoid of forest habitat. The second largest group were species that appear in forest and at least two agricultural land uses (314\%, 2nd bar in Fig. 4.1) and can be considered as generalist species. The third largest group were agricultural generalists that appeared in at least two agricultural land uses but not in forest sites $(185 \%$, 3rd bar in Fig. 4.1). Species of this group are likely to be non-indigenous or even invasive species, as they do not appear in any observed forest site. The proportion of species that were dependent on one specific agricultural land use did not differ substantially between the land uses (rubber $120 \%$; oil palm $118 \%$; jungle rubber $112 \%)$. We only found a small number of species that were present in forest and one agricultural land use, except for jungle rubber (104\%). This suggests that jungle rubber may be better suited as habitat for certain forest species, than the more intensively managed land uses rubber and oil palm. However, the group of 


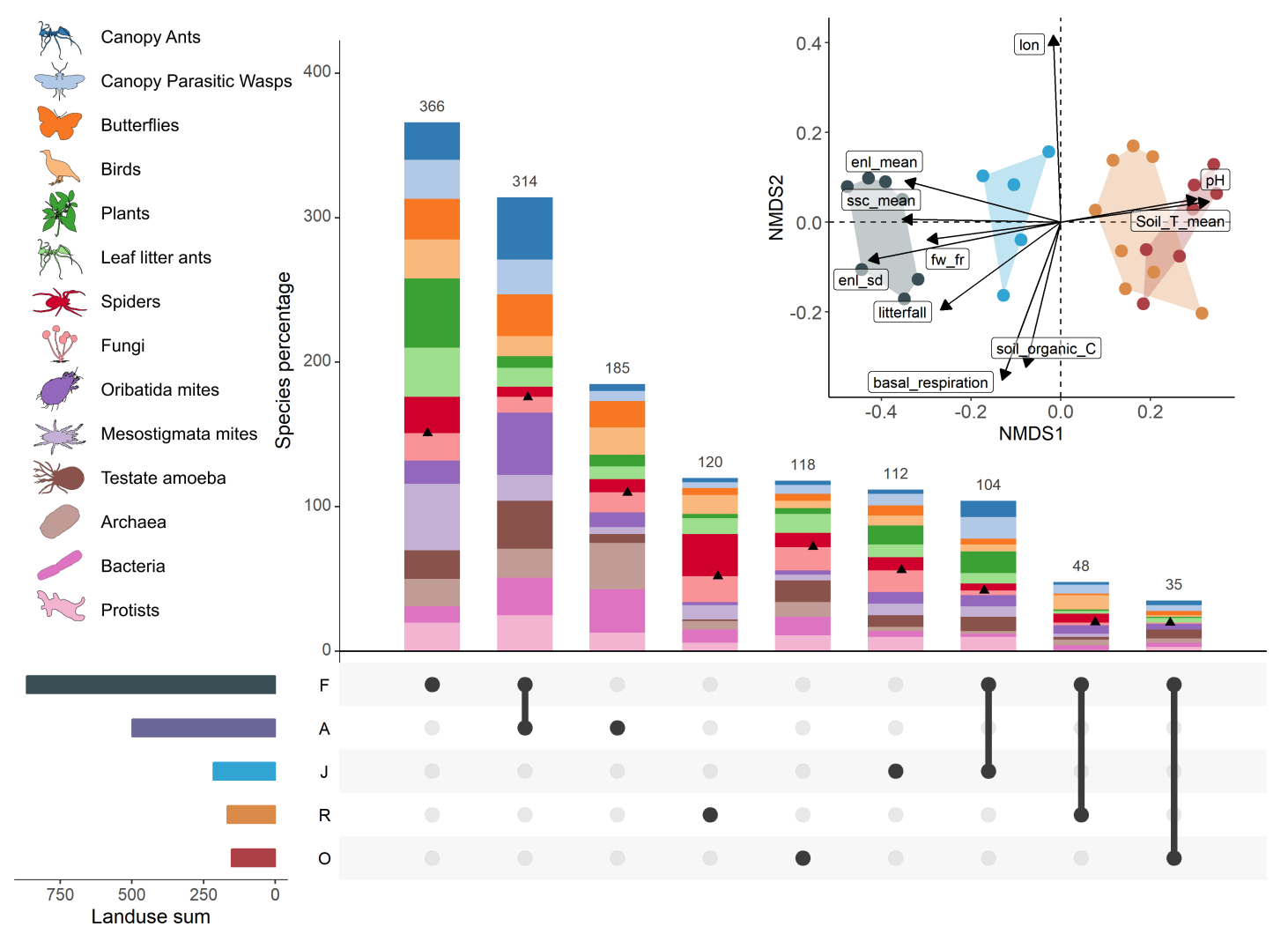

Figure 4.1: The main barplot panel illustrates species proportions by land-use appearance. For each taxon, each species has been categorized by observed presence in each land use. For instance, group $\mathrm{F}$ contains species that have been found in forest sites only $(\mathrm{J}=$ jungle rubber sites, $\mathrm{R}=$ rubber sites, $\mathrm{O}=$ oil palm sites, $\mathrm{A}=$ present in more than one agricultural land use). Group F-A contains species that occur in forest and more than one agricultural land use. Group appearance percentages have then been calculated for each taxon (bars of one color add up to 100\%; all taxa add up to 1400\%). Black triangles indicate switch from above-ground taxa (above triangle) to below-ground taxa (below triangle). Percentage sums of land-use groups are indicated by colored bars in the lower left. For example the forest land use sum (F) contains all species occurrences in forest sites (F), forest and agricultural sites (F-A), forest and jungle rubber sites (F-J), forest and rubber sites (F-R) and forest and oil palm sites (F-O). The upper right panel illustrates results of an NMDS ordination of observed pairwise dissimilarities between sites, grouped by land use and aggregated over all taxa. Arrows show the 10 most correlated environmental variables with $l o n=$ longitude, Soil_T_mean=mean soil temperature, enl_mean/enl_sd=mean and standard deviation of effective number of vegetation layers, ssc_mean $=$ mean stand structural complexity, $f w \_f r=$ freshwater in fine roots and $p H=\mathrm{pH}$ in soil. 
species occurring in forests and in at least two agricultural land uses is quite large (2nd bar in Fig. 4.1), suggesting that many species are generally adapted to the conditions of extensive agriculture and not to a specific agricultural land use in particular.

If we only consider below-ground taxa (colored bars below black triangle in Fig. 4.1) the observed pattern changes slightly with most species occurencing in agricultural land uses and forest-dependent species as second largest group. However, our estimation of forest-dependent species is quite conservative because our sampling design only included eight forest plots, whereas 24 agricultural plots entered our analysis.

Looking at differences between taxa, we observed a higher proportion of forestdependent species (1st bar in Fig. 4.1) for plants, leaf litter ants and mesostigmata, whereas archaea and bacteria were most present in the agricultural generalists group (3rd bar in Fig. 4.1). We observed a relatively high proportion of rubber-dependent spiders species (4th bar, dark red group, in Fig. 4.1) and a considerable overlap of forest and jungle rubber plants and canopy parasitic wasp species (7th bar, dark green and light blue group, in Fig. 4.1).

The ordination of aggregated pairwise dissimilarities between all sites indicated strong shifts of turnover between sites of different land-uses (see Fig. 4.1). Turnover between forest and oil palm plantations was found to be largest and showed strong correlation with vegetation structure, soil temperature and soil $\mathrm{pH}$. In order to gain deeper insights into linkages of environmental variables to community dissimilarity we additionally applied a generalized dissimilarity model to our data (see Section Drivers of species turnover).

Similar to previous studies in other tropical regions (e.g. EDWARDS et al., 2014 Lawton et al., 1998; Mendenhall et al., 2016; Newbold et al., 2015, Schulze et al., 2004, SoLAR et al., 2015), our result show that large-scale deforestation leads to a shift from a species-rich pool of forest-dependent species to a smaller pool of generalist and agriculture-dependent species. Protecting this large group of forest-dependent species is only possible by providing forest habitat through creation of conservation areas that are protected from further agricultural expansion (see, e.g. Phalan et al., 2011; Watson et al., 2014).

Community composition. Investigating biodiversity patterns across taxa via aggregated incidence measures may not be sufficient to understand larger-scale species distribution patterns at a landscape level (SOLAR et al., 2015; TABARELLI et al., 2012). Although different sites of the same land use may be very diverse and provide a large number of different species, they may be completely homogeneous when compared at broader spatial scales (Solar et al., 2015). We calculated pairwise dissimilarities to investigate the turnover effects of various taxa for specific 


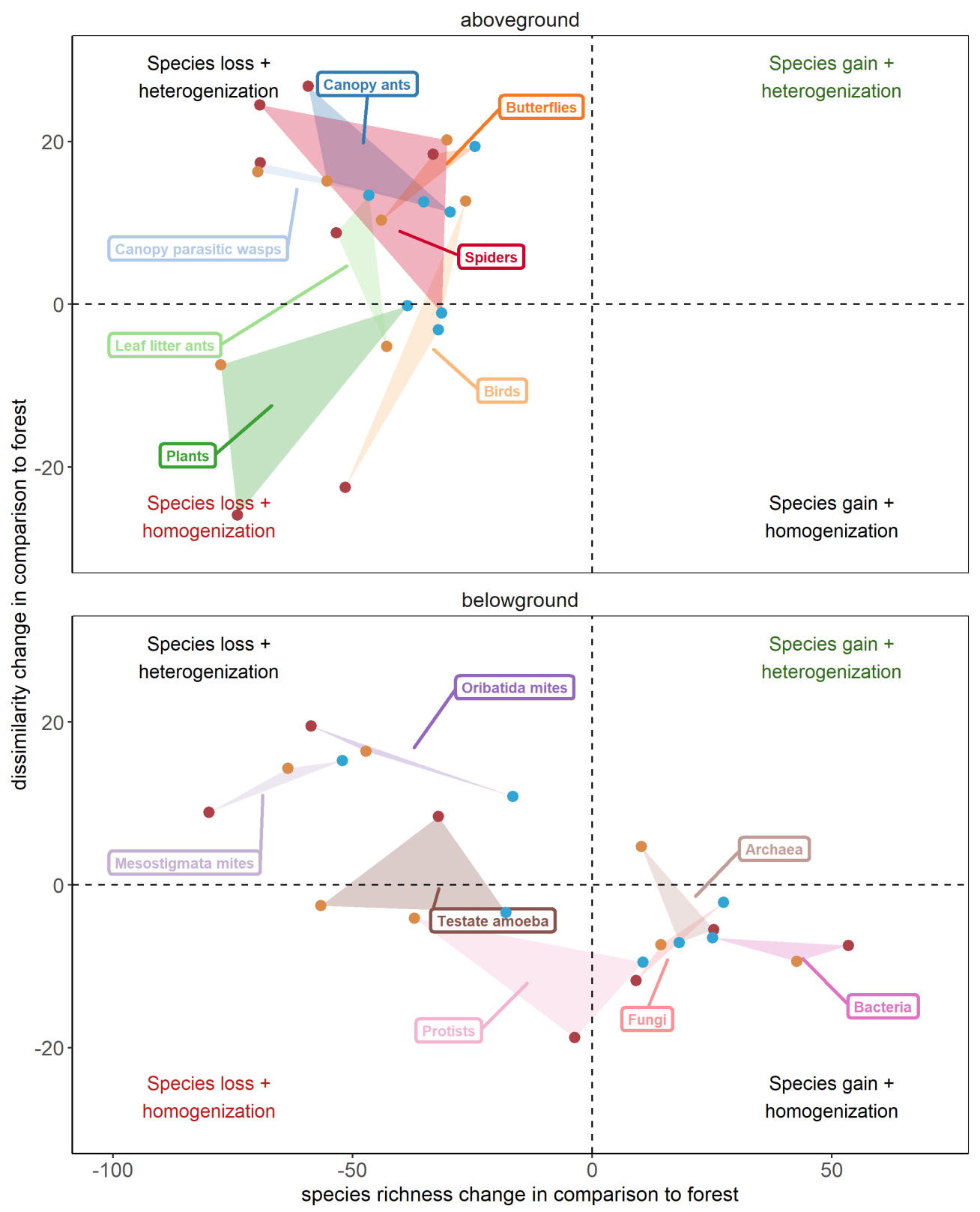

Figure 4.2: Effects of land-use change on alpha (species richness) and beta diversity (Morisita-Horn dissimilarity) of above-ground and below-ground taxa. Effects are summarized as percentage change relative to forest values, where all assemblages consist only of forest sites. Colors of data points indicate particular land-use types with blue indicating jungle rubber, orange indicating rubber monoculture and red indicating oil palm plantation. To illustrate the range of changes for specific taxa, points have been grouped by shaded polygons. 
land uses. For assessing dissimilarities, we used the Morisita-Horn index, which was found to be relatively robust towards undersampling (BECK et al., 2013). In order to assess effects of land-use transformations, we calculated percentage changes of turnover and species richness of the three agricultural land uses jungle rubber, rubber and oil palm in comparison to forest.

All of the seven above-ground taxa show a considerable amount of species loss in agricultural land uses, when compared to forest sites (see Fig. 4.2). For many taxa, jungle rubber sites showed the lowest (or 2nd lowest) species loss in comparison to forest (blue dots in Fig. 4.2). Turnover effects were more diverse between taxa. Plants showed homogenization between sites in all agricultural land uses. Four out of seven above-ground taxa showed homogenization in at least one agricultural land use, but we could also observe three taxa, namely butterflies, canopy ants, and canopy parasitic wasps that were more heterogeneously distributed in all agricultural land uses.

For below-ground taxa we could observe a different pattern with many observations indicating species gain in combination with homogenization or species loss in combination with heterogenization. Bacteria, archaea and fungi showed a considerable amount of species gain but also a clear trend of homogenization in all agricultural land uses, except archaea in rubber monoculture plantations. Protists showed a variable response for each land use with species gain and homogenization in jungle rubber, and species loss and homogenization in rubber and oil palm. Testate amoebae showed species loss in all agricultural land uses with homogenization in rubber and jungle rubber. The remaining two taxa, mesostigmata and oribatida showed species loss and heterogenzation in all agricultural land uses.

Our results indicate large changes of species composition and turnover between agricultural productive systems and natural forest in Jambi, Indonesia. The variability of responses in above-ground and below-ground taxa indicates that processes that lead to homogenization of plant and bird communities in agricultural land uses (as also reported by KARP et al., 2012 SOLAR et al., 2015) do not seem to be a general trend that equally affects all taxa. This also suggests that studying biodiversity patterns across different scales should not be done on highly aggregated levels, but instead should consider the differences between land uses and taxa and incorporate those factors explicitly.

Correlation of patterns between taxa. Studies on congruence between alphaand beta-diversity of different taxa in tropical forests and agricultural productive systems showed mixed results. While some studies found quite high correlations between some taxa (EDWARDS et al., 2014; SCHulzE et al., 2004), other studies did not recommend to predict patterns of biodiversity change through observed patterns of another taxon (LAWTON et al., 1998). While our analysis of community 


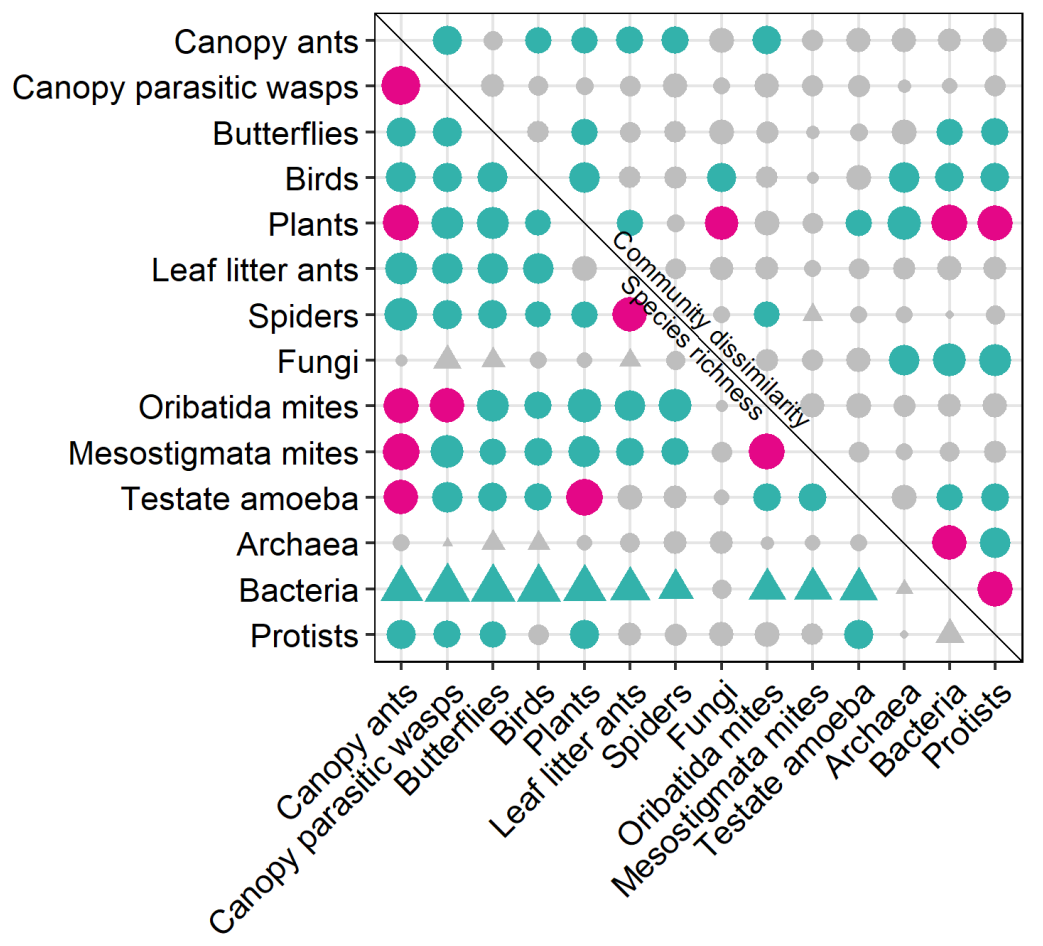

Figure 4.3: Correlations (Kendall's tau) of species richness (lower triangle) and community dissimilarity (upper triangle) between all 14 taxa. The direction of correlation is indicated by the shape ( $\operatorname{dot}=$ positive, triangle $=$ negative $)$ and the strength of correlation is indicated by shape size with larger shapes indicating stronger correlation. Colors indicate correlation effects at three distinct levels with magenta indicating correlations above 0.5 , turquoise indicating correlations of at least 0.25 and grey indicating correlations lower than 0.25 . 
dissimilarity already revealed variable patterns between taxa and land uses, we were interested if the taxon specific patterns are correlated to some extent. For species richness, we found 9 taxa combinations with correlations (Kendall's tau) above 0.5 , with a maximum value of 0.71 , between canopy parasitic wasps and canopy ants (see Fig. 4.3). However, for community dissimilarity, we only found 5 taxa combinations above 0.5 , with a maximum value of 0.57 , between plants and bacteria.

Species richness of bacteria was negatively correlated with all other taxa except fungi (see lower triangle in Fig. 4.3). Species richness of canopy ants was positively correlated to species richness of canopy parasitic wasps, plants, oribatida mites, mesostigmata mites and testate amoeba at relatively high levels $(>0.5)$. Species richness correlations of fungi and archaea were below 0.25 for all taxa combinations.

Positive correlations of community dissimilarity above 0.5 were found between plants and bacteria, plants and fungi, plants and protists, bacteria and archaea and bacteria and protists (see upper triangle in Fig. 4.3). We observed only weak correlations between the dissimilarity of most of the remaining taxa combinations.

While we observed a considerable amount of correlation between species richness of all taxa except for fungi and archaea, the surprisingly weak correlations among many taxa in turnover underlines the variability in responses (see also LAWTON et al., 1998). We also observed strong differences in correlation of taxa between alpha and beta diversity. Therefore, when considering alpha and beta diversity, it is difficult to predict the community composition of one group on the basis of another, which calls into question the usefulness of indicator taxa for our study region.

Drivers of species turnover. Generalized dissimilarity modelling (GDM) is a widely applied tool to measure the contribution of the environment and geographic distance to species turnover (FERRIER et al., 2007). While high contributions of distance are an indicator of neutral processes, high environmental contribution suggests habitat filtering processes (LEGENDRE et al., 2005). Many studies investigated beta diversity with a view to understanding the importance of neutral versus niche-based processes (BALDECK et al., 2013. CONDIT et al., 2002).

Turnover between our study sites in Jambi province, Sumatra was mostly driven by environmental and thus habitat filtering processes for all 14 taxa (see Fig. 4.4 Contribution of geographic distance above $10 \%$ were only observed for plants and fungi. Not all taxa could be modelled at the same level of explanatory power. Variation in bacteria could be explained by over 70\%. GDM models for plants, protists and archaea were explaining more than $50 \%$ of turnover variation (Fig. 4.4). While geographic distance had a considerable effect on turnover across many taxa, the main drivers of turnover were vegetation related variables, such as stand 


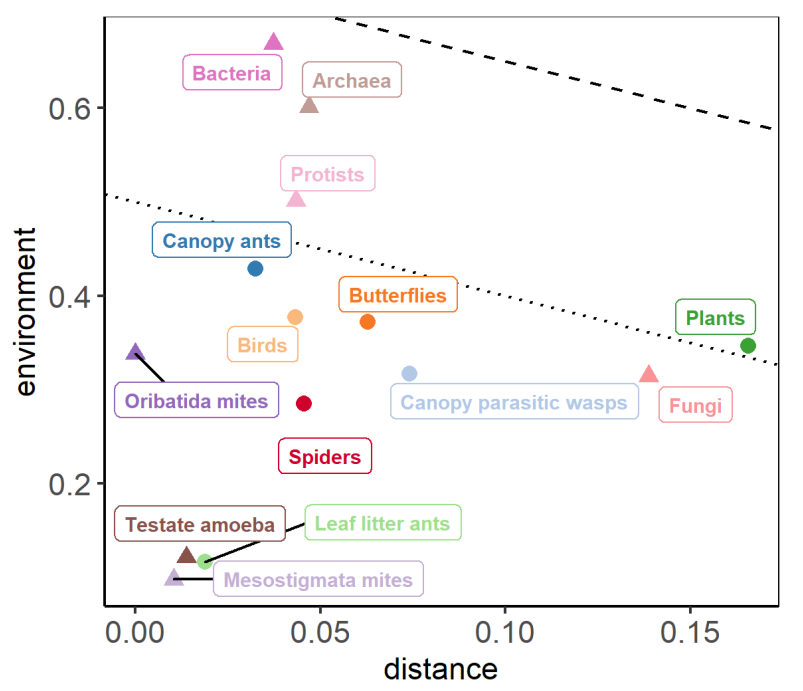

Figure 4.4: Drivers of dissimilarity according to generalized dissimilarity models. The dotted line indicates a threshold of $50 \%$ explained variance, whereas the dashed line indicates a threshold of $75 \%$ explained variance. Dots represent above-ground taxa, whereas triangles represent below-ground taxa.

structual complexity (see Fig. 4.5). Variables derived from the litter layer could explain turnover variations across many taxa except for canopy parasitic wasps, birds and plants. The second principal component of the litter variables group, which was driven by the amount of collected litter, had a much stronger effect than the first principal component, which was driven by the carbon and nitrogen content of the collected litter. The third largest group of drivers were soil related variables. The first principal component of soil variables showed the largest explanatory power and was mostly driven by nitrogen and carbon content and cation exchange capacity. These variables are clearly related to management practices that might explain differences in species community between our sampled sites. Climate variables, such as air temperatures, soil temperatures and humidity could only explain little of turnover variations. We could not observe strong differences in drivers of turnover between above-ground and below-ground taxa. The second and third soil principal components had a slightly stronger impact on below-ground taxa. The second climate principal component, which is driven by moisture measurements, could only explain turnover variations of below-ground taxa.

The GDM models for plants, bacteria, archaea and protists performed relatively well and were mostly driven by vegetation related variables, litter and geographic distance. These models could for example be used to predict species distributions on broader spatial scales using remote sensing data and application of scaling-up techniques (e.g. MokANy et al., 2011). 


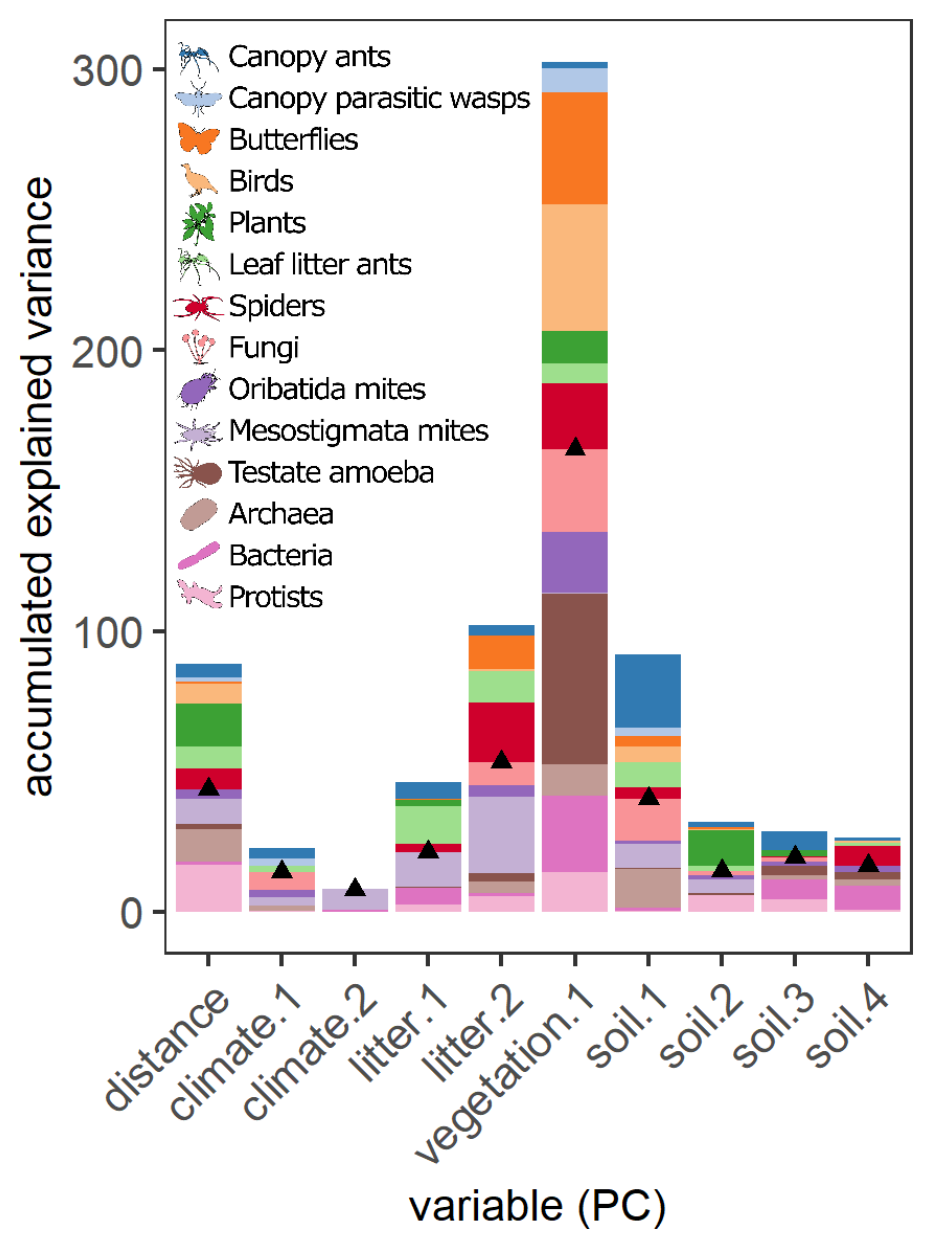

Figure 4.5: Drivers of dissimilarity according to generalized dissimilarity models. Variables were grouped and aggregated by application of a principal component analysis. For each group, principal components were selected until an cumulative explained variance of $70 \%$ was reached. Contributions of variables to each principal component are displayed in Fig. C.1 in Appendix C. Black triangles indicate switch from above-ground taxa (above triangle) to below-ground taxa (below triangle). 


\subsection{Conclusion}

Opposed to previous studies, for example in the Brazilian Amazon (SolAR et al., 2015), our study of species richness and turnover of 14 taxonomic groups along a land-use intensity gradient revealed various responses. We observed strong species loss in agricultural land areas for all above-ground taxonomic and four below-ground taxonomic groups. However, we did not find a general trend of homogenization for all taxa. Instead, turnover responses were taxon-specific. The various responses between 14 taxonomic groups are questioning the utility of indicator taxa in tropical regions, because correlations of turnover between taxonomic groups were not strong. We could not identify general trends in turnover that would suggest general conclusions that are applicable to all considered taxonomic groups. At least for tropical regions, this underlines the need of joint studies, applying a unified sampling strategy to cover a large range of taxonomic groups.

\subsection{Acknowledgments}

We thank the village leaders, respondents, farmers, PT REKI and Bukit Duabelas National Park for granting us access to sites and information, and Ristekdikti for the research permits. Rizky Nazarreta, Herry Marta Saputra and Azru Azhar (all IPB Bogor) assisted with identification of canopy ants, Anik Larasati, Cici Indriani, Nurul Novianti, Iqbal Tawakkal (all IPB Bogor) with identification of canopy parasitoid wasps, Peggie Djunijanti (LIPI Cibinong) with the identification of butterflies.

\subsection{Funding}

This study was financed by the Deutsche Forschungsgemeinschaft (DFG), project number 192626868, in the framework of the collaborative German-Indonesian research center CRC990.

\subsection{Author contributions}

JS and CES conducted the analysis. JS, CES, FB, MC, JD, IG, KD and HK designed the study. JS and IG assembled the data sets. AB to KW (in alphabetical order) contributed data and participated in discussions on study design, analysis and interpretation. CK assisted in analysis coding. JS, CES, KW, HK wrote the manuscript with contribution from all authors. 


\title{
Chapter 5
}

\section{The $n l r x \mathrm{R}$ package: A next-generation framework for reproducible NetLogo model analyses}

This chapter was published as a research article:

Salecker, J., Sciaini, M., Meyer, K. M., and Wiegand, K. (2019). "The nlrx r package: A next-generation framework for reproducible NetLogo model analyses". Methods in Ecology and Evolution 10, 1854-1863. doi: 10.1111/2041-210X.13286.

\begin{abstract}
Agent-based models find wide application in all fields of science where large-scale patterns emerge from properties of individuals. Due to increasing capacities of computing resources it was possible to improve the level of detail and structural realism of next-generation models in recent years. However, this is at the expense of increased model complexity, which requires more efficient tools for model exploration, analysis and documentation that enable reproducibility, repeatability and parallelisation. NetLogo is a widely used environment for agent-based model development, but it does not provide sufficient built-in tools for extensive model exploration, such as sensitivity analyses. One tool for controlling NetLogo externally is the R-package RNetLogo. However, this package is not suited for efficient, reproducible research as it has stability and resource allocation issues, is not straightforward to be setup and used on high performance computing clusters and does not provide utilities, such as storing and exchanging metadata, in an easy way. We present the R-package nlrx, which overcomes stability and resource allocation issues by running NetLogo simulations via dynamically created XML experiment files. Class objects make setting up experiments more convenient and helper functions provide many parameter exploration approaches, such as Latin Hypercube designs, Sobol sensitivity analyses or optimization approaches. Output is automatically collected in user-friendly formats and can be post-processed with provided utility functions. nlrx enables reproducibility by storing all relevant information and simulation output of experiments in one $\mathrm{R}$ object which can conveniently be archived and shared. We provide a detailed description of the nlrx package functions and the
\end{abstract}


overall workflow. We also present a use case scenario using a NetLogo model, for which we performed a sensitivity analysis and a genetic algorithm optimization. The nlrx package is the first framework for documentation and application of reproducible NetLogo simulation model analysis.

\subsection{Introduction}

Agent-based models are an increasingly popular method for understanding complex systems (DEAngelis and Grimm, 2014). They are developed and applied across many different research disciplines from natural sciences over archeology to socio-economic sciences (e.g., Dislich et al., 2018, Vincenot, 2018). Agent-based models incorporate the heterogeneity of entities at the individual level in order to observe patterns emerging on broader scales (GRImm and RAILSBACK, 2005). Due to the release from computing power constraints in recent years, next-generation agent-based models have evolved that are structurally realistic, powerful and detailed enough to address real-world problems (CABRAL et al., 2017; Grimm and BERGER, 2016). However, next-generation agent-based models require reproducability, repeatability and parallelisation of model analyses. Access to scripts, runs and results of statistical analyses is a key criterion for reproducible research (PENG, 2011: SANDVE et al., 2013). Yet, incentives for sharing code of agent-based models and model analyses alongside publications are still lacking (JANSSEN, 2017).

A widely used programming language to develop agent-based models in ecological and socio-economic sciences is NetLogo (ABAR et al., 2017; VinCENOT, 2018; Wilensky, 1999). NetLogo is a Java-based modelling environment that features a very comprehensible syntax, which allows for fast prototyping of agent-based models but also offers capabilities to formulate and implement complex agent-based models efficiently (RAILSBACK et al., 2017). With rising complexity of NetLogo models, increasing efforts need to be spent on model analyses and documentation of such analyses. Model analysis is a crucial part of the modelling cycle, not only for understanding model processes but also during model refinement and development (GRIMM and RAILSBACK, 2005). Often sensitivity analyses are the central part of such refinements, because they give access to detailed information on the relative importance of model parameters for model outputs (SALTELLI et al., 2008). Sensitivity analyses requires the simulation thousands of different parameter value combinations to gain a better understanding of the modelled systems. Unfortunately, the capabilities of the built-in tool of NetLogo to run such analyses, the NetLogo BehaviorSpace, are limited. If more than one parameter is changed within one experiment, BehaviorSpace automatically creates a full-factorial parameter matrix including all possible combinations of parameter values. This might be generally suitable for simple models, but with rising model complexity 
Table 5.1: Main differences between NetLogo's BehaviorSpace, RNetLogo, and nlrx.

\begin{tabular}{|c|c|c|c|}
\hline $\begin{array}{l}\text { Feature \& } \\
\text { Description }\end{array}$ & $\begin{array}{l}\text { Behavior } \\
\text { Space }\end{array}$ & RNetLogo & $n \operatorname{lr} x$ \\
\hline \multicolumn{4}{|l|}{ High-performance computing (HPC) } \\
\hline $\begin{array}{l}\text { Straightforward setup of HPC machines to submit } \\
\text { and run large NetLogo simulation jobs. }\end{array}$ & - & - & $\checkmark$ \\
\hline \multicolumn{4}{|l|}{ Controllable Java environment } \\
\hline $\begin{array}{l}\text { Possibility to open a new Java virtual machine for } \\
\text { each model simulation. }\end{array}$ & - & - & $\checkmark$ \\
\hline \multicolumn{4}{|l|}{ Interactive Java environment } \\
\hline $\begin{array}{l}\text { Possibility to control model parameters during } \\
\text { model run. }\end{array}$ & - & $\checkmark$ & - \\
\hline \multicolumn{4}{|l|}{ Reproducible research tools } \\
\hline $\begin{array}{l}\text { Possibility to perform model analyses in a non- } \\
\text { interactive, reproducible way. Means to control for } \\
\text { random number generator seeds and exchange of } \\
\text { model files. }\end{array}$ & - & - & $\checkmark$ \\
\hline \multicolumn{4}{|l|}{ Spatial integration of agent metrics } \\
\hline $\begin{array}{l}\text { Coerce NetLogo agent metrics to geospatial data } \\
\text { objects (vector and raster data). }\end{array}$ & - & - & $\checkmark$ \\
\hline \multicolumn{4}{|l|}{ Tidy data format } \\
\hline $\begin{array}{l}\text { Data format in which each observation is a unique } \\
\text { cell and each variable a unique column } \\
\text { (WICKHAM, 2014). }\end{array}$ & - & - & $\checkmark$ \\
\hline \multicolumn{4}{|l|}{ Utility functionality } \\
\hline $\begin{array}{l}\text { Functionality to perform pre- and post-processing } \\
\text { of simulation data. }\end{array}$ & - & - & $\checkmark$ \\
\hline
\end{tabular}

more efficient ways of scanning the parameter space and a better control of the design of parameter matrices are required. Additionally, post-processing of NetLogo model output is mostly done within statistical software, such as $\mathrm{R}$ (the most prominent programming language for ecologists; LAI et al., 2019). Transfer of the output data from NetLogo into R may not be straightforward, especially when dealing with spatially-explicit model output. This is because spatial NetLogo output is mostly reported in nested lists which need to be parsed and split to convert the data into a usable format.

The $\mathrm{R}$ package $R$ NetLogo currently is the only $\mathrm{R}$ package available to set up NetLogo model simulations directly from $R$ (THIELE et al., 2012, THIELE et al., 2014). However, the package establishes an interactive connection between the $\mathrm{R}$ session and the Java virtual machine that runs the NetLogo model application, which has two main drawbacks: (1) RNetLogo establishes the interactive connection via the rJava package, which may be cumbersome to set up, especially on remote systems, and requires access to system-wide environmental variables. (2) Resource 
Simulation runtime

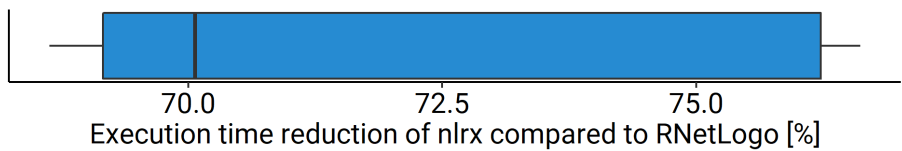

Memory usage

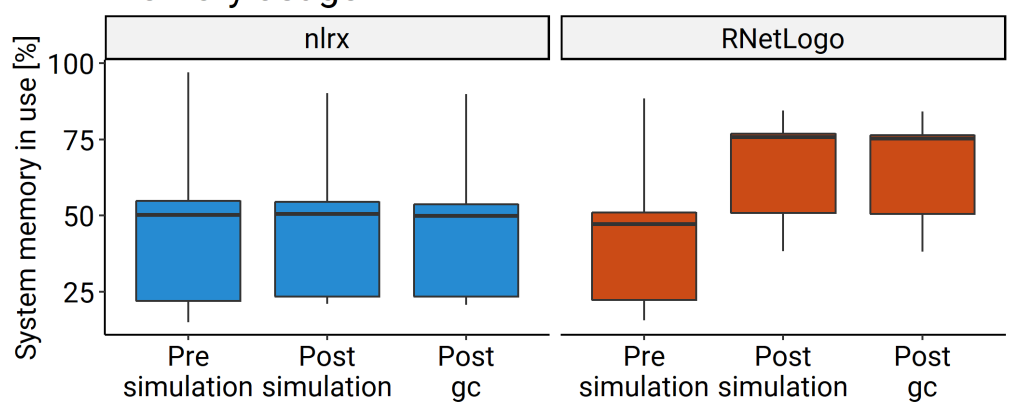

Figure 5.1: Comparison of execution time (top panel) and memory usage (bottom panel) of nlrx (blue) and RNetLogo (red). Benchmarks were calculated on different machines with various processor types, available memory and operating systems (details see Section D.1 in Appendix D, boxplots show variation between systems). Both packages were used to execute NetLogo model simulations with the Wolf Sheep Model from the NetLogo Models Library. With each package we simulated 8 replications of a Latin-Hypercube Sampling design with 100 samples and a run time of 500 ticks of each simulation. Available memory was measured before starting simulations (Pre simulation) and after simulations have finished (Post simulation). A third measurement of available memory was taken after manually executing the $\mathrm{R}$ garbage collection function $g c$ (Post gc).

allocation of rJava and RNetLogo may be problematic when running large jobs with many simulations. Memory may not be cleared efficiently between runs and Java virtual machines may freeze due to memory constraints. Furthermore, RNetLogo does not provide a convenient workflow to set up experiments with minimal coding, utility functions to generate simulations, or features to enable reproducible research (see a full comparison in Tab. 5.1).

We have, therefore, developed the $\mathrm{R}$ package $n l r x$ to provide a flexible framework for self-contained and reproducible analysis of NetLogo models from R, while also delivering performance gains (see Fig. 5.1 and Section D.1 in Appendix D). The nlrx framework serves four main needs for next-generation NetLogo modellers: (1) it provides an interface between $\mathrm{R}$ and NetLogo. Simulations are completely defined and stored within $\mathrm{R}$ objects. This allows the application of a huge toolbox of statistical methods to create simulation experiments and corresponding param- 
eter input matrices. The nlrx package utilizes the controlling API of NetLogo's BehaviorSpace to set up and run experiments. Thus, in contrast to RNetLogo, the connection between $\mathrm{R}$ and NetLogo is not interactive and does not rely on the rJava package. (2) it enables reproducible research (SANDVE et al., 2013) by storing a simulation experiment in one single $\mathrm{R}$ object (including parameter input matrix, applied simulation method and simulation results) and allows easy sharing of code and results among colleagues, with students and for publication. (3) nlrx enables utilization of high performance computing clusters (HPCs) in a very convenient way (see Section D.2 in Appendix D). (4) nlrx provides post-processing analysis functions of NetLogo model output for several applications, such as sensitivity analyses and calculation of descriptive statistics. nlrx also enables gathering spatial output from models, such as coordinates and properties of individuals and patches and provides functions to convert the output into spatial $\mathrm{R}$ objects (raster and vector data).

\subsection{The R package $n l r x$}

The nlrx package utilizes the NetLogo BehaviorSpace interface by calling NetLogo from the command line via a bash script (*.sh, linux) or a batch file (*.bat, windows). By default, NetLogo BehaviorSpace experiments are stored in XML format within the ${ }^{*}$.nlogo model file. However, when NetLogo is started in headless mode from command line, it is also possible to commit XML BehaviorSpace experiment files to setup and run experiments. The nlrx package creates such XML BehaviorSpace experiment files dynamically in order to run simulation experiments from $\mathrm{R}$.

Table 5.2: List of slots of an nl S4 class object.

\begin{tabular}{|c|c|c|}
\hline Slot & Example & Description \\
\hline nlversion & "6.0.4" & Version number of the NetLogo version \\
\hline nlpath & "/home/NetLogo 6.0.4" & Path to a NetLogo installation \\
\hline modelpath & $\begin{array}{l}\text { "/home/NetLogo 6.0.4/app/ } \\
\text { models/SampleModels/Biology/ } \\
\text { Wolf Sheep Predation.nlogo" }\end{array}$ & Path to a ${ }^{*}$.nlogo model file \\
\hline jvmmem & 1024 & $\begin{array}{l}\text { Java virtual machine memory in } \\
\text { megabytes }\end{array}$ \\
\hline experiment & & Stores an experiment S4 class object \\
\hline simdesign & & Stores a simdesign $\mathrm{S} 4$ class object \\
\hline
\end{tabular}




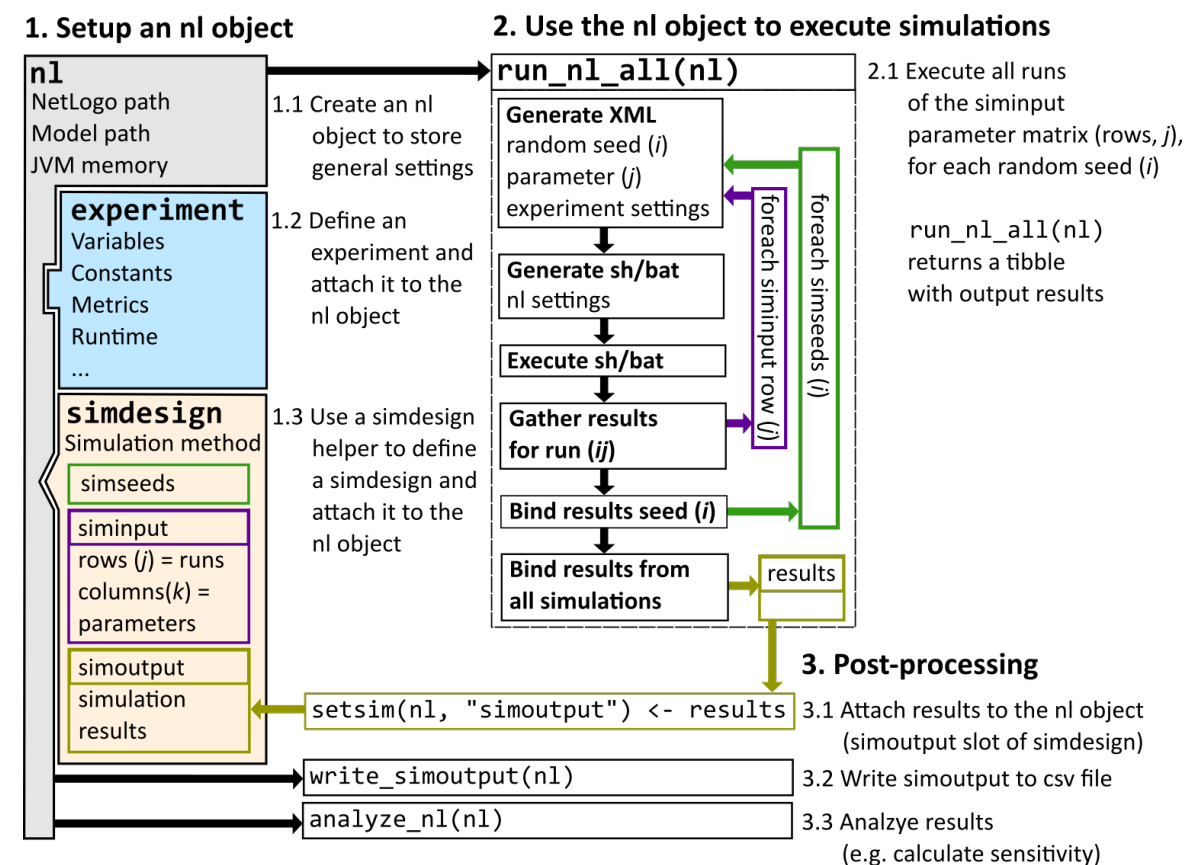

Figure 5.2: Workflow of the nlrx package. The nl object stores all the information needed to run NetLogo models. The experiment object, which contains all modelspecific information, such as names of setup and go procedures, runtime, variable range and metrics and the simdesign object, which contains all simulation-related information, such as input parameter matrix, simulation method and simulation output, are nested within this $\mathrm{nl}$ object. Abbreviations: JVM=java virtual machine; $\mathrm{XML}=$ Extensible Markup Language; $\mathrm{sh}=$ bash script; bat=batch file 
Table 5.3: List of slots of an experiment S4 class object.

\begin{tabular}{|c|c|c|}
\hline Slot & Example & Description \\
\hline expname & "nlrx-example" & Name of the BehaviorSpace experiment \\
\hline outpath & "/home/nlrxout" & Path to an output directory \\
\hline repetition & 1 & Number of repetitions \\
\hline tickmetrics & "true" & $\begin{array}{l}\text { If true, metrics are collected on each model } \\
\text { tick, otherwise only on the last tick }\end{array}$ \\
\hline idsetup & "setup" & $\begin{array}{l}\text { Name or vector of names containing NetL- } \\
\text { ogo procedures that are called to setup the } \\
\text { model }\end{array}$ \\
\hline idgo & "go" & $\begin{array}{l}\text { Name or vector of names containing NetL- } \\
\text { ogo procedures that are called to run the } \\
\text { model }\end{array}$ \\
\hline idfinal & "final" & $\begin{array}{l}\text { Name or vector of names containing NetL- } \\
\text { ogo procedures that are called at the end } \\
\text { of one run }\end{array}$ \\
\hline idrunnum & "id-input" & $\begin{array}{l}\text { Name of a NetLogo numeric widget to trans- } \\
\text { fer the current nlrx run number to NetLogo }\end{array}$ \\
\hline runtime & 100 & $\begin{array}{l}\text { Maximum runtime of model simulations } \\
\text { (number of ticks) }\end{array}$ \\
\hline evalticks & $\operatorname{seq}(90,100)$ & $\begin{array}{l}\text { Number or vector of ticks indicating when } \\
\text { metrics should be collected }\end{array}$ \\
\hline stopcond & "notany?turtles" & $\begin{array}{l}\text { A NetLogo reporter that reports TRUE/- } \\
\text { FALSE. If it reports TRUE the current } \\
\text { simulation run is stopped }\end{array}$ \\
\hline metrics & c("countturtles") & $\begin{array}{l}\text { Valid NetLogo reporters that are used to } \\
\text { collect output data }\end{array}$ \\
\hline metrics.turtles & $\begin{array}{l}\text { list ("turtles"=c ("who", } \\
\text { "pxcor", "pycor", "color") } \\
\text { ) }\end{array}$ & $\begin{array}{l}\text { A list with named vectors of strings defining } \\
\text { valid turtles-own variables that are taken } \\
\text { as output measurements }\end{array}$ \\
\hline metrics.patches & $\begin{array}{l}\text { c("pxcor", "pycor", } \\
\text { "pcolor") }\end{array}$ & $\begin{array}{l}\text { A vector of strings defining valid patches- } \\
\text { own variables that are taken as output mea- } \\
\text { surements }\end{array}$ \\
\hline metrics.links & $\begin{array}{l}\text { list("links"=c ("end1", } \\
\text { "end2")) }\end{array}$ & $\begin{array}{l}\text { A list with named vectors of strings defining } \\
\text { valid links-own variables that are taken as } \\
\text { output measurements }\end{array}$ \\
\hline variables & $\begin{array}{l}\text { list ("variable.parameter } \\
\text { 1"=list (min=50, max=150, } \\
\text { step=10, qfun="qunif")) }\end{array}$ & $\begin{array}{l}\text { A list with NetLogo globals that should be } \\
\text { varied in a simdesign }\end{array}$ \\
\hline constants & $\begin{array}{l}\text { list ("constant.parameter. } \\
1 "=4, \text { "constant.parameter } \\
2 "=0.1)\end{array}$ & $\begin{array}{l}\text { A list with NetLogo globals that should } \\
\text { stay constant in a simdesign }\end{array}$ \\
\hline
\end{tabular}


Table 5.4: List of slots of a simdesign S4 class object.

\begin{tabular}{ll}
\hline Slot & Description \\
\hline simmethod & $\begin{array}{l}\text { Name of the simdesign method (e.g. "ff"=full factorial, "lhs"=latin hyper- } \\
\text { cube sampling) }\end{array}$ \\
siminput & $\begin{array}{l}\text { tibble providing input parameterisations for the NetLogo model } \\
\text { (cols=parameter, rows=runs) }\end{array}$ \\
simobject & $\begin{array}{l}\text { List containing a simdesign object with further details on the simmethod } \\
\text { that may be needed for output analysis }\end{array}$ \\
simseeds & $\begin{array}{l}\text { Vector containing model seeds } \\
\text { simoutput }\end{array}$ \\
\hline
\end{tabular}

\subsection{1 nlrx workflow}

The typical workflow of the nlrx package starts with creation of an nl object, which is an S4 class object that stores basic information on NetLogo (see Fig. 5.2, and Tab. 5.2). The nl object contains information on the NetLogo version (nlversion), the path to the NetLogo directory (nlpath), the path to the NetLogo model file (modelpath) and the amount of reserved memory for each Java virtual machine (jvmmem).

Next, an experiment needs to be created and attached to the nl object (see Fig. 5.2, and Tab. 5.3). The experiment object stores all information that would be entered into a typical BehaviorSpace experiment (see Tab. 5.3). The experiment object contains the name of the experiment (expname), the directory where output is written to (outpath), the number of repeated runs within BehaviorSpace (repetition), a logical variable whether output should be measured on each tick or on the final tick only (tickmetrics), names of setup and go procedures (idsetup, idgo), the maximum number of ticks that should be simulated (runtime, $0=$ infinite), a vector of ticks for which output is reported (evalticks), a stop condition (stopcond), output metrics (metrics, metrics.turtles, metrics.patches, metrics.links), variable parameters and corresponding value ranges (variables), and constant parameters (constants).

Finally, a simdesign needs to be attached to the nl object (see Fig. 5.2 , and Tab. 5.4). The nlrx package provides many helper functions to create predefined simdesigns for simple parameter screenings (simple, distinct, full-factorial), sensitivity analyses (Morris (Morris, 1991), Sobol (Sobol, 1990), eFast (SAltelli et al., 1999)) or parameter optimizations (simulated annealing (KIRKPATRICK et al., 1983), genetic algorithm (Holland, 1992)). These helper functions take information from the experiment (variables, constants) to create a simdesign object that contains the name of the simulation design method (simmethod), a vector of random seeds (simseeds), the generated parameter matrix (siminput) and an empty tibble slot to attach output results after simulations have been 
finished (simoutput). The siminput and simoutput slots store tibble data, a modern representation of rectangular data in R (MÜLLER and WiCKHAM, 2018). The sensitivity analyses and optimization simdesign helper functions also create a simulation object (simobject) that contains further information needed for postprocessing, such as calculation of sensitivity indices. The optimization algorithms do not generate a parameter matrix in advance, because the parameterization of later runs depends on the results of previous runs. It is also possible to write user-defined helper functions to create simdesign objects.

After initialization of the $\mathrm{nl}$ object, simulations can be run by calling one of the run_nl_*() functions that come with nlrx. For simdesigns that generate a parameter matrix, run_nl_one() can be used to execute one specific row of the simdesign parameter matrix siminput by specifying the row ID and a model seed. This can be useful for testing specific parameterizations. The function run_nl_all() executes all simulations from the parameter matrix siminput across all seeds. run_nl_all() uses the future_map_dfr() function (furrr package) to loop over random seeds and rows of the siminput parameter matrix (see Fig. 5.2). This allows users to run the function sequentially or in parallel, on local machines and remote HPC machines. Parallelisation options can be easily adjusted by using different future plans before calling the function (for more details see documentation of $\mathrm{R}$ package future). For optimization simdesigns that do not come with a pre-generated parameter input matrix, run_nl_dyn() can be used to execute model simulations with dynamically generated parameter settings.

The connection between $\mathrm{R}$ and NetLogo is realized within these three run_nl_*() functions. First, a BehaviorSpace experiment XML file is created from the information that is stored within the provided nl object. This XML file contains the random seed, parameter settings and experiment settings. Next, depending on the operating system, a bash script or batch file is generated that is used to execute NetLogo via the command line in headless mode. The file contains information that is stored within the nl object (such as NetLogo path, model path, Java virtual machine memory and the path to the previously generated XML file). Afterwards, the script is executed to run the NetLogo simulations. When the simulation is finished, the NetLogo model output data is read into R. In the case of multiple simulations, results are bound together and reported as one large tibble.

After simulations are finished, the resulting output table can be attached to the $\mathrm{nl}$ object by using the provided setter function setsim. This stores a complete experiment setup, including output results, in one $\mathrm{R}$ object. After outputs have been attached to the $\mathrm{nl}$ object, the output results can also be written to a *.csv file by calling write_simoutput(). The output can also be further analyzed by calling analyze_nl(). For example, for an nl object with a Morris simdesign and attached simulation output results running analyze_nl(), lists Morris sensitivity 
indices for each parameter and each measured model output. For reproducible research, it is important to attach the output to the nl object even if one does not want to conduct further analyses. By attaching the output to the nl object, all information of the simulation experiment, including parameter inputs and simulation output, is stored within an nl object, which can be easily stored as *.rds file for documentation purposes.

\subsubsection{Further functionality}

nlrx offers a function unnest_simoutput () to turn agent-specific metrics that were collected during the simulation into a wide-format table that splits every type of agent, patch and link in a unique column and nests all measured variables in this column. To be able to derive this information, the nl object offers slots to specify agent, patch and link metrics. The unnested spatial data can easily be visualized to illustrate model behavior (Fig. 5.3). Furthermore, the functions nl_to_points(), nl_to_raster() and nl_to_graph() coerce the nl object directly into a spatial data type (e.g. spatial points and raster data for agents and patches, as well as undirected network graphs for links). To be able to use nlrx as a fully reproducible framework, the functions export_nl() and import_nl() store R and corresponding NetLogo model scripts in a zip file, which uses relative paths and thus enables easy collaboration. Furthermore, nlrx provides functions to generate documentation files as ${ }^{*}$.html, ${ }^{*}$.pdf and *.docx files from NetLogo model files containing specific documentation comment sections. nlrx also provides a function to generate a network of NetLogo model procedures (for details see Section D.3 in Appendix D). nlrx will thus enable ecologists to make use of agent-based NetLogo models in their research while permitting a workflow that follows modern scientific standards. 

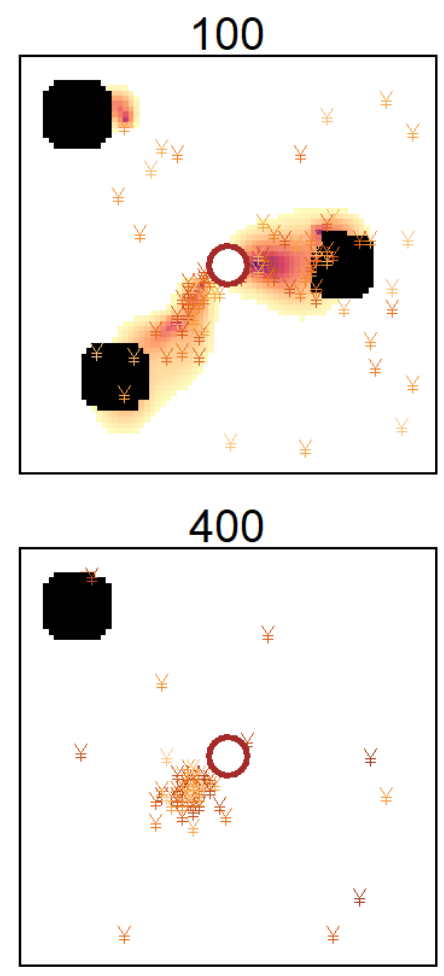

700

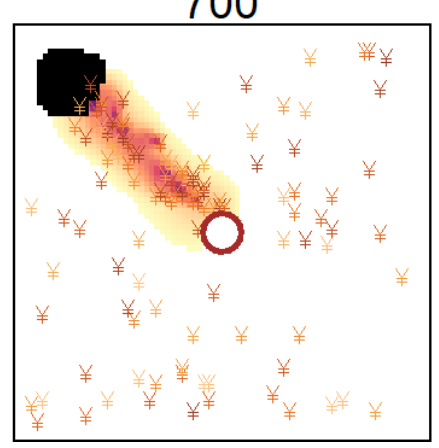

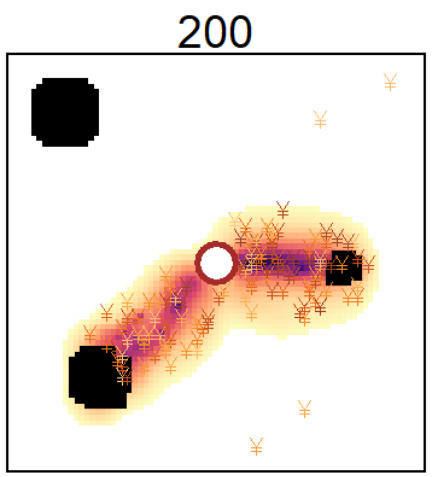

500

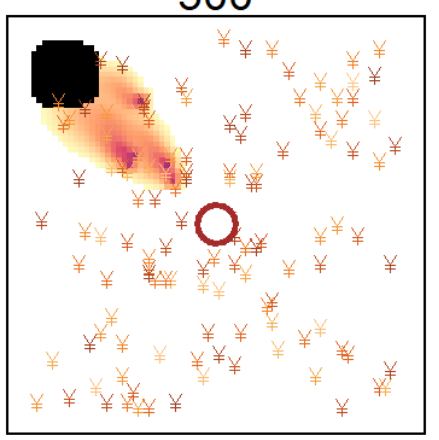

800

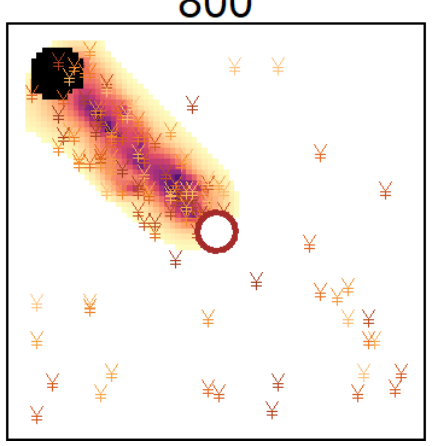

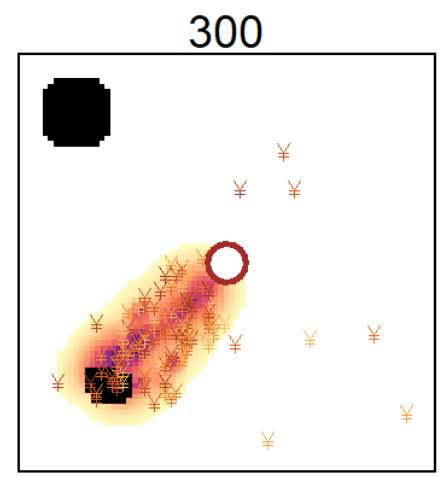

600

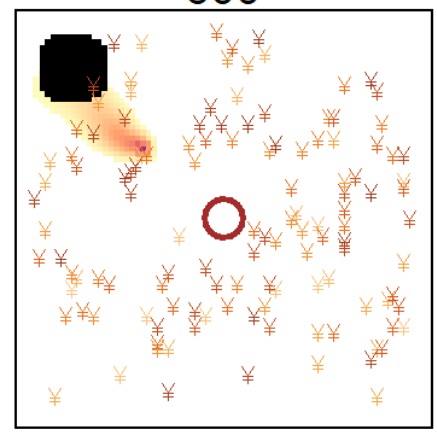

900

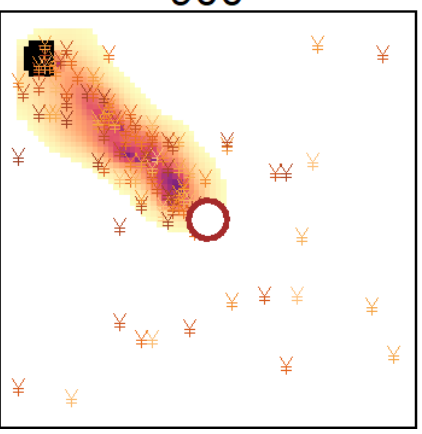

Figure 5.3: Visualization of spatial output gathered from the Ants model (see section Use case: Ants model for a description of the model) via the nlrx package. Ants positions (brown yen signs), position of food cells (black), position of the nest cell (brown circle), and amount of chemicals on all cells (heat shading, with darker colors indicating higher amount of chemicals) were measured using the metrics.turtles and metrics.patches slots of the nlrx experiment. Panels show output for every 100th tick of a model simulation. 


\subsection{Use case: Ants model}

This section describes two example use cases of nlrx using the Ants simulation model from the NetLogo Models Library: (i) a Sobol sensitivity analysis based on R's advanced statistical packages, (ii) a genetic algorithm optimization approach to optimize foraging speed.

The Ants model is a spatially-explicit model of an ant colony foraging for food. The landscape is set up as a patch lattice. The center cell of the landscape is the nest of the ant colony and all ants (number depending on parameter population) are created within this nest cell on initialization. Additionally, there are three clusters of food source cells created within the landscape. Food source clusters are created at different distances from the ant nest, with food source 1 being closest to the nest and food source 3 being furthest away from the nest. During a model run, ants move randomly in order to find food. If any ant finds a food source cell, a certain amount of food is transferred from that cell to the ant, which carries the food back to the nest. Each food cell only supplies a certain amount of food and is reset to a non-food cell once all food from this cell has been gathered. Any ant carrying food releases chemicals at its current position. Chemicals also diffuse to neighboring cells, depending on the parameter difussion-rate and evaporate depending on the parameter evaporation-rate. If ants sense chemicals on their current or neighboring patch, they change their movement pattern from random walk to directed walk following the trail of chemicals by moving into the direction which contains the most chemicals. The main output of the model simulation is the time needed to gather all food from all food sources. We also measure the time that is needed to completely deplete specific food source clusters. Furthermore, we are interested in the spatial distribution of ants under different parameterizations of the model (for details see Section D.4 in Appendix D.

\subsubsection{Sensitivity Analysis with $n l r x$}

In order to demonstrate the usability and workflow of the nlrx package, we performed a global sensitivity analysis of the Ants model (SoboL, 1990). We varied the three model parameters population, diffusion-rate and evaporation-rate by applying a Sobol parameter variation approach. As main output we measured the simulation time (ticks) until all food sources were completely depleted by the ants.

To set up the sensitivity analysis with nlrx, we first defined an nl object (List. 1). 


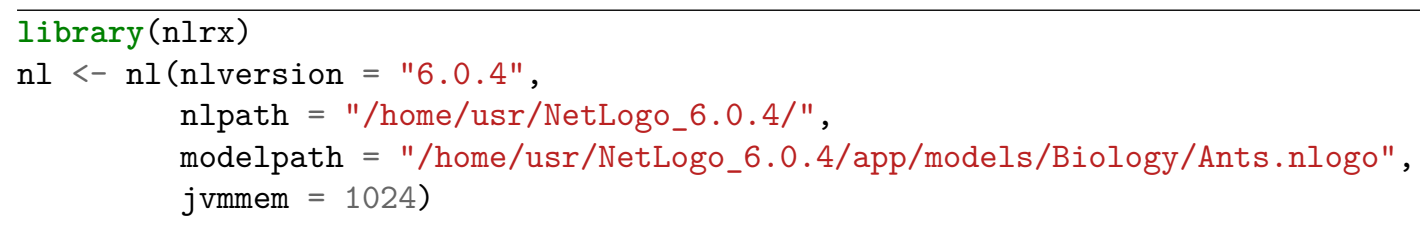

Listing 1: Defining an nl object.

In the next step, we attached an experiment to the previously generated $\mathrm{nl}$ object (List. 2). We defined that output should be measured only on the final tick (tickmetrics $=$ "false"). We set the runtime to infinite (runtime, $0=$ infinite) and defined a stop condition to stop model execution once no food cell is left in the model landscape (stopcond). As output metrics we measured the number of ticks simulated when the model run finishes (metrics).

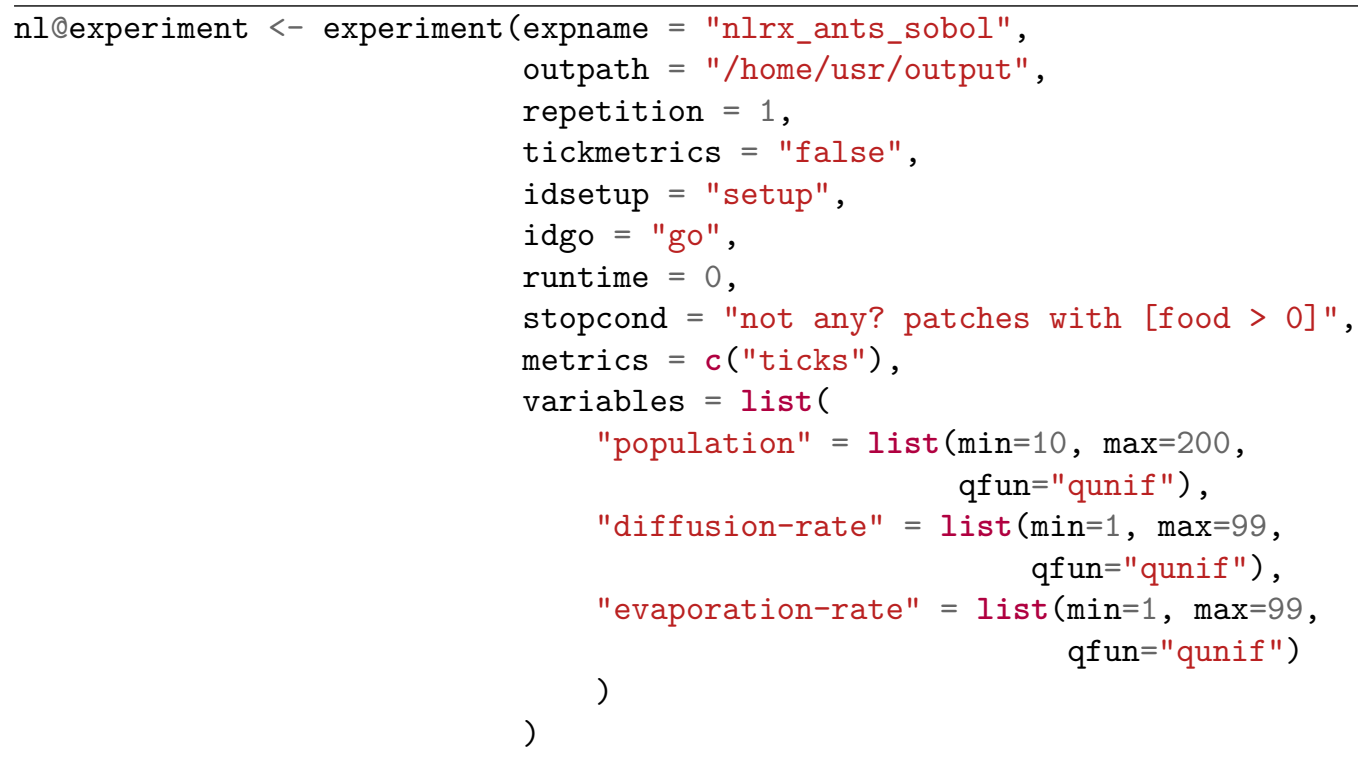

Listing 2: Attaching an experiment to an nl object.

To construct an input parameter matrix from the defined experiment and variable ranges, a simdesign needs to be attached to the nl object (List. 3). For our Sobol sensitivity analysis, we used the simdesign helper function simdesign_sobol(). We defined the number of samples (samples), the order of interaction effects (sobolorder), the number of bootstrapping replicates (sobolnboot), the confidence interval (sobolconf), the number of Sobol analysis repetitions (nseeds) and the precision level of values within the parameter matrix (number of decimal digits, precision). 


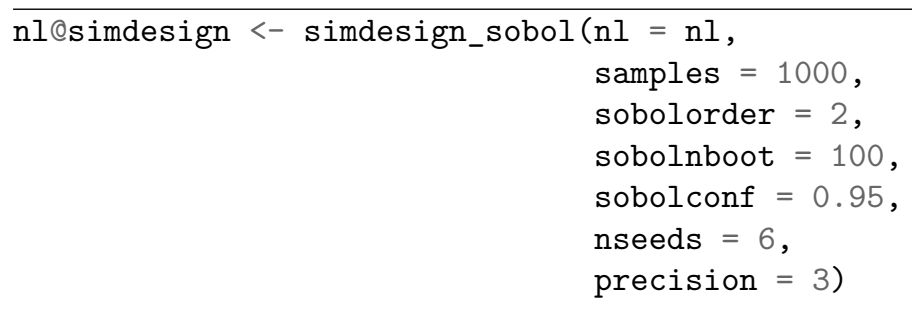

Listing 3: Attaching a Sobol simdesign to an nl object.

This $\mathrm{nl}$ object stores all information needed to run the sensitivity analysis. We can execute all simulations by calling run_nl_all() (List. 4). Because in our experiment we set tickmetrics to "false", output will only be reported for the final simulation step.

results <- run_nl_all(nl)

Listing 4: Executing all simulations of an $\mathrm{nl}$ object.

In order to execute the analyze nl () function, the results tibble first needs to be attached to the $\mathrm{nl}$ object (List. $\overline{5}$ ).

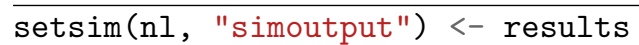

Listing 5: Attaching simulation results to an $\mathrm{nl}$ object and calculating sensitivity indices.

The Sobol sensitivity analysis revealed a very large main effect of the population parameter on the effectiveness of food collection (measured as number of ticks until all food sources are depleted) by the ant colony (see Fig. 5.4). The more ants were present, the faster the colony depleted all food sources. The two chemical-related parameters evaporation-rate and diffusion-rate showed only small main effects (see Fig. 5.4). However, we found some interaction effects between population and evaporation-rate, albeit at a very low level. There were no interactions between population and diffusion-rate and between diffusion-rate and evaporation-rate.

write_simoutput(nl)

export_nl(nl, nl@modelpath, <path-to-disk>)

Listing 6: Export simulation output and model files.

After running all simulations with nlrx, we store the simulation output as a *.csv file using the write_simoutput() function (see List. 6). Additionally, we 


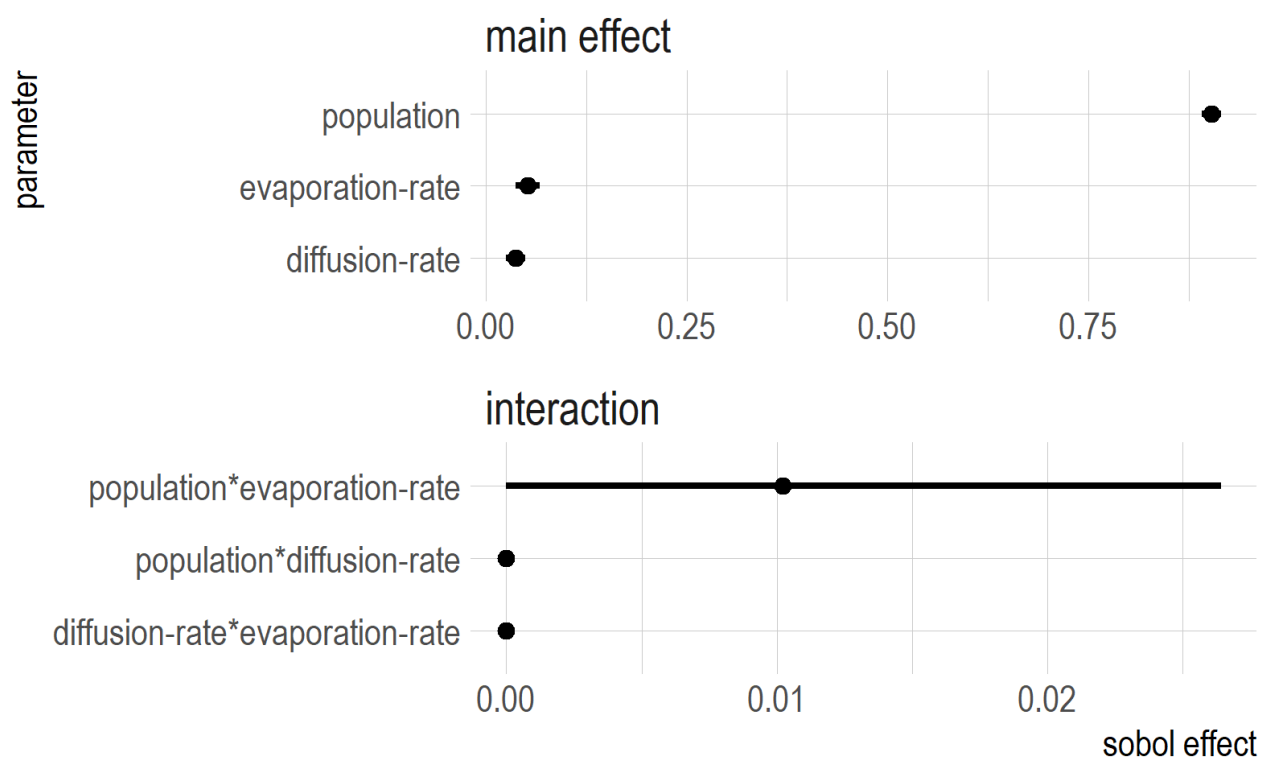

Figure 5.4: Main effects (upper panel) and interaction effects (lower panel) of each parameter of the Ants model on the total number of simulation steps that were simulated until all food sources were depleted by the ant individuals. Parameter effects were derived by applying a Sobol sensitivity analysis approach. Points indicate parameter mean sensitivity (Sobol effect) of 6 model simulation replicates, linebars indicate the corresponding standard deviation.

store the nl object, together with underlying model files as a zip folder using the export_nl() function.

\subsubsection{Genetic Algorithm with nlrx}

In order to demonstrate the optimization functions of $n l r x$, we applied a genetic algorithm to the Ants model. The genetic algorithm varies parameters of the model within defined ranges, in order to minimize a defined fitness criterion. In our case, we want to minimize the number of time steps needed by the ant colony to deplete all food sources completely.

For this analysis, we do not need to make any changes to the nl object and experiment that we used in the Sobol sensitivity analysis example, thus we can reuse the $\mathrm{nl}$ object and just add a different simdesign. In order to set up a 
genetic algorithm optimization simdesign, we used the simdesign helper function simdesign_GenAlg() (List. 7). We defined the number of initial parameterizations (popSize), the number of iterations (iters), the index of a defined output metric (see metrics slot in experiment) that is used as evaluation criterion (evalcrit), the elitism rate (elitism), the mutation probability (mutationChance) and the number of random seeds for replications of the algorithm (nseeds).

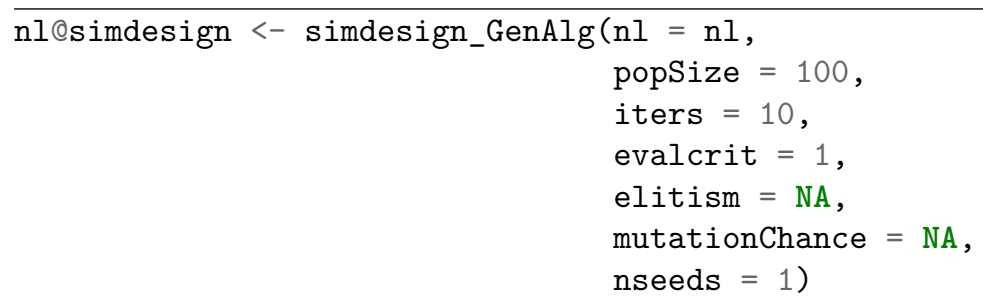

Listing 7: Attaching a genetic algorithm simdesign to an nl object.

In contrast to sensitivity analysis simdesigns, for optimization simdesigns there is no parameter input matrix set up in advance. Instead, random starting values are chosen within the defined parameter ranges. The parameterization of the next simulation run is dynamically created, depending on the output of the previous simulation. Thus, for optimization simdesigns, the nlrx function run_nl_dyn() needs to be used to execute the simulations (instead of run_nl_all() which iterates over a pre-generated parameter matrix)(List. 8).

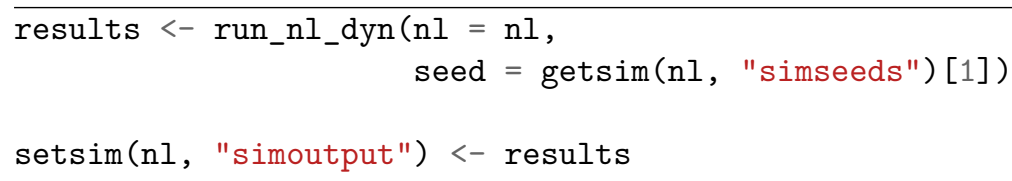

Listing 8: Executing dynamic simulations of an nl object with an optimization approach.

The results from the genetic algorithm simdesign are reported as a list which contains information of parameterizations and the evaluation criterion of each population of the genetic algorithm. We can also identify the best found parameterization, i.e. the parameterization that resulted in the smallest fitness value.

The genetic algorithm was able to decrease the time to deplete all food sources from more than 3000 ticks to below 500 ticks over 100 iterations (see Fig. 5.5, upper left). The parameterization of the best found solution had a moderately large population (166), a medium diffusion-rate (18.28), and a low evaporation-rate (8.41) (see Fig. 5.5, upper right).

To evaluate the stability of the optimization result under different random seeds, we simulated an additional 10 replicates (each with a different random seed) of the 


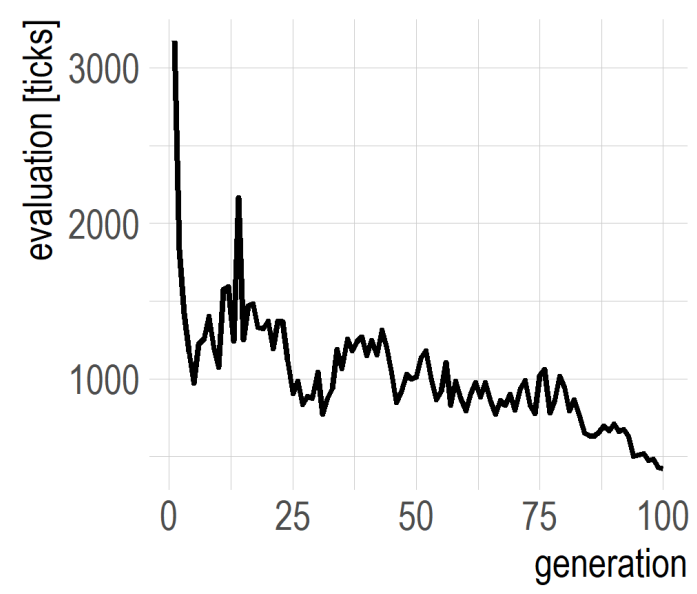

\begin{tabular}{|c|c|}
\hline parameter & value \\
\hline population & 166.00 \\
\hline diffusion-rate & 18.28 \\
\hline evaporation-rate & 8.41 \\
\hline
\end{tabular}
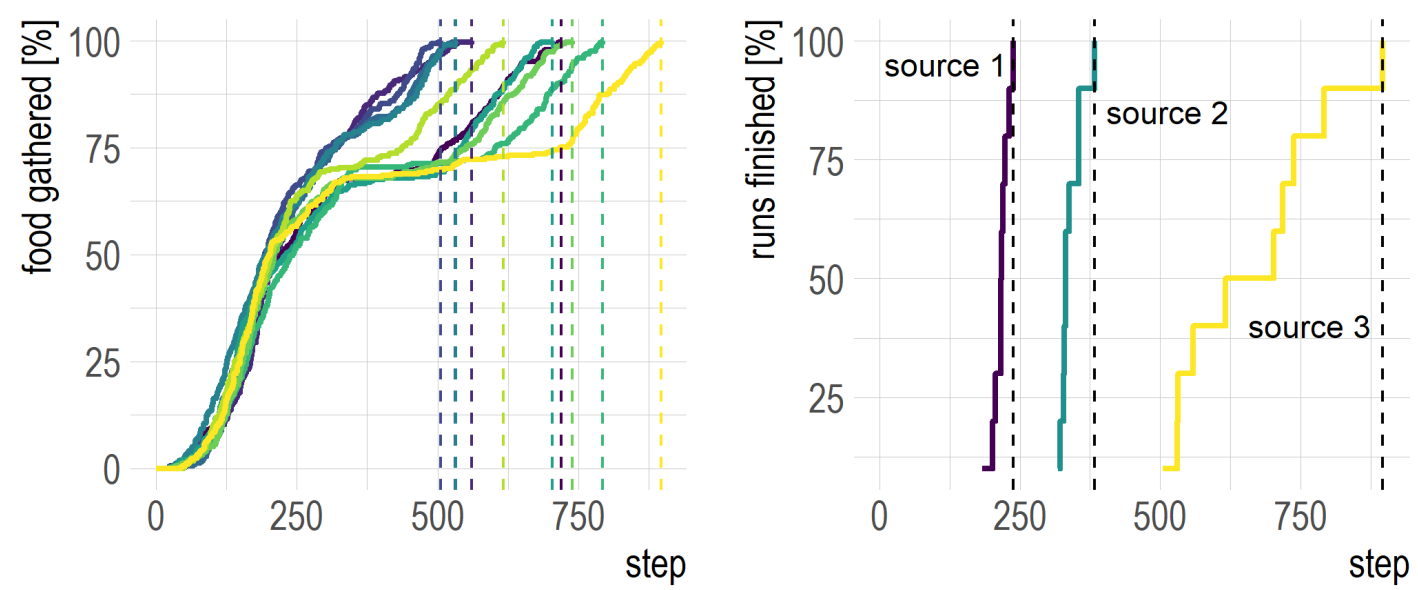

Figure 5.5: A genetic algorithm was applied to minimize simulation time until all food sources were depleted. The figure illustrates the minimization process over iterations of the algorithm (upper left) and the best found parameterization in terms of minimum simulation time (upper right). This best found parameterization was used to run the Ants model with 10 replicates and measuring the percentage of food gathered at each tick (lower left, colors indicate individual simulations). We also aggregated these 10 runs to measure at which time steps the three individual food source clusters were completely depleted (lower right). Dashed lines illustrate final time step of each curve.

best parameterization. In order to run a specific parameterization, the $n l r x$ package provides the simdesign helper function simdesign_simple(), which creates a parameter table for one single simulation that uses only defined values of constant parameters (constants slot of experiment). We removed all variable parameters from the experiment and defined those parameters as constants instead (List. 9). 
We also added counts of food sources as output metrics to the metrics slot of the experiment. Finally, we used the simdesign_simple() function to attach a simdesign containing a siminput matrix with only one parameterization and a simseeds vector with 10 random seeds (nseeds $=10$ ).

Again, we used the run_nl_all() function to execute the simulations and calculated the percentage of food gathered at each tick and identified the tick at which specific food source clusters were depleted completely. We observed some variation in total simulation time between these replicates, but all runs lay between 500 and 800 ticks (see Fig. 5.5, lower left). While the first two food sources were depleted very fast in all replicates, depletion times were more variable for the third food source, which had the largest distance from the ant nest (see Fig. 5.5, lower right).

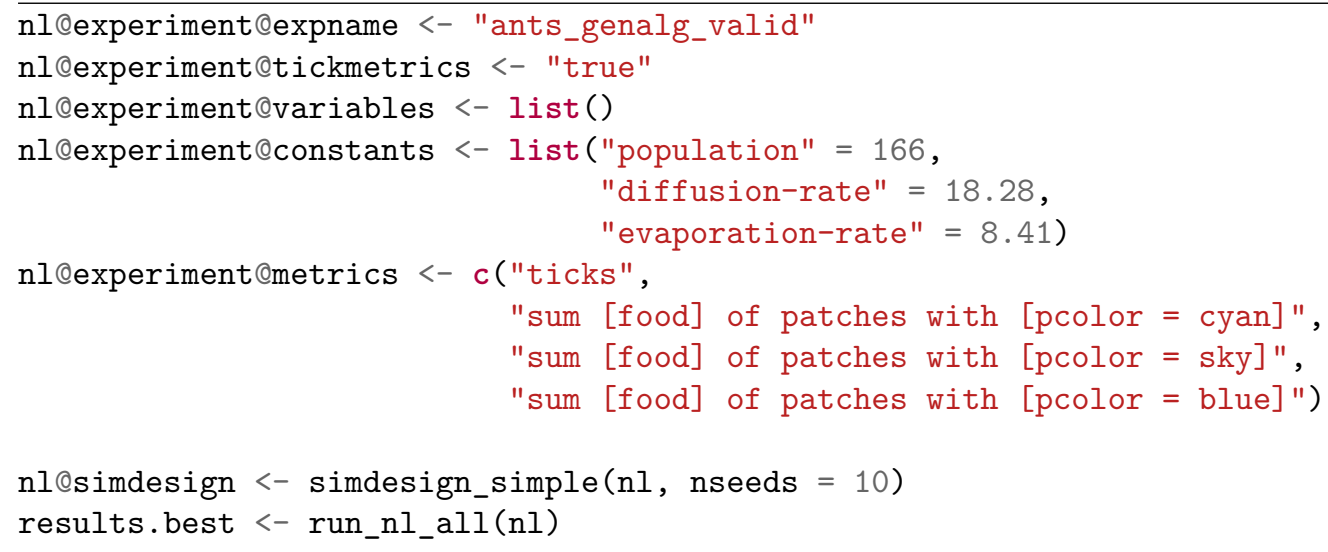

Listing 9: Setting specific slots of the experiment within an nl object and attaching a simple simdesign.

\subsection{Conclusion and outlook}

Next-generation agent-based models must be reproducible and repeatable. The new nlrx R-package fulfills the need for an efficient tool for running reproducible and repeatable analyses for the popular programming language NetLogo. nlrx has several advantages in comparison to previous approaches that connect $\mathrm{R}$ and NetLogo: (1) the package does not rely on the rJava package which is known to be unstable and causes many problems especially when working on machines with different configurations; (2) setup of model experiments is very similar to NetLogo BehaviorSpace. Thus, NetLogo users who do not have much experience with $\mathrm{R}$ will feel familiar with the workflow of nlrx. (3) multiprocessing and execution of large model simulations on remote HPC machines can be easily done with nlrx 
by adjusting the future plan of the $\mathrm{R}$ session. (4) all information on the model version, simulation experiment definitions and simulation design definitions are stored within one single $\mathrm{R}$ object. By using the nlrx export and import functions, these objects can be archived and shared, together with all required NetLogo model files. This functionality enables a reproducible workflow and easy collaboration.

In contrast to RNetLogo, NetLogo instances of nlrx are not interactive. There is no direct connection from $\mathrm{R}$ to NetLogo and thus, it is not possible to manipulate the NetLogo model from within $\mathrm{R}$ while the model is running. However, for most use cases it is sufficient to set up and run model simulations in a convenient way because manual exploration of NetLogo models can also be done directly in NetLogo.

The presented use cases of the Ants model highlight the flexibility and convenient workflow of the nlrx framework. With the nested class layout the same $\mathrm{nl}$ object and experiment can be reused for several simulation design approaches (as demonstrated in the genetic algorithm use case). Thus, research questions can be tackled from very different angles with minimal code adjustments. Because reported output from model simulations is reported in a tidy data format (see section 5.7 Data Accessibility for additional R code examples), post-processing, data analysis and result visualization can benefit from the well-established tool set provided by the tidyverse framework (e.g. dplyr, ggplot2 packages). Collecting agent metrics and coercing them to spatial objects is now possible with nlrx in two lines of code, thus enabling ecologists to use advanced statistical methods on the individual level of their simulation models (see Section D.4 in Appendix D).

Increasing model complexity across many disciplines increases the need of standardized tools and open standards for model documentation, application and analysis. For example, the ODD (Overview, Design concepts, and Details) protocol and the TRACE (TRAnsparent and Comprehensive Ecological modelling documentation) framework are such standards for documentation of agent-based models that are widely accepted and applied within the field of agent-based modelling (GRImm et al., 2006a; GRIMm et al., 2010; Grimm et al., 2014; MüLleR et al., 2013). However, given the rising importance of reproducible research as a standard in academia, standards for documentation and reproducibility of applied model analysis and corresponding code are still lacking. nlrx is a first step to provide a framework for documentation and application of reproducible NetLogo simulation model analysis. While nlrx mainly provides tools that enable reproducible research, future work might also give recommendations on a best practice approach that also incorporates data management, collaboration and version control.

nlrx has been officially released on CRAN (current version 0.2.0) and peerreviewed by rOpenSci (github.com/ropensci/onboarding/issues/188). 


\subsection{Acknowledgments}

JS and KW were funded by the Deutsche Forschungsgemeinschaft (DFG, German Research Foundation) - project number 192626868 - SFB 990 in the framework of the collaborative German - Indonesian research project CRC 990. MS and KW were supported by the DFG through grant number WI 1816/18-1 (FOR2432) and DFG-GRK 1644/3. We thank rOpenSci for their extensive code review and three reviewers for their helpful and constructive comments on an earlier version of this manuscript.

\subsection{Author Contribution}

JS and MS developed the R package. The case study was designed by JS. JS and MS drafted the manuscript and all authors contributed critically to the manuscript and gave final approval for publication.

\subsection{Data Accessibility}

The nlrx package is hosted at doi.org/10.5281/zenodo.3367095. All the code for the figures and use cases in this manuscript can be found at doi.org/10.5281/ zenodo.2650853. 


\section{Chapter 6}

\section{Consolidated discussion}

\subsection{Discussion}

We developed a framework of multiple modelling tools for coupled socio-economic ecological agent-based modelling in Jambi, Sumatra. Although our models are explicitly parameterized for our study region, each of our tools can be easily parameterized and applied to other study regions, underlining the general value of our research for studying coupled socio-economic ecological systems.

The landscape generator EFForTS-LGraf fills a main gap in spatially-explicit modelling by providing maps that explicitly incorporate the human dimension of land-use change and provide additional information on smallholders in the landscape. The validation of EFForTS-LGraf could show that our parameterization with household survey data from Jambi resulted in generated maps with realistic properties, when compared to classified land-use maps. Besides generation of input maps for EFForTS-ABM, we used EFForTS-LGraf to conduct analyses to assess landscape scale effects of consolidation and smallholder crop specialization. We could show that both processes have an impact on various landscape metrics and that some metrics were affected by considerable interaction effects. Landscapes with large farm sizes and high specialization resulted in more homogeneous landscapes with large, less complex shaped patches that were highly connected. This study demonstrates one advantage of agent-based and thereby process-based modelling compared to pattern-based landscape generators. The implementation of processes and dynamics that actually exist in reality allowed us to tweak model parameters in a meaningful way to study relevant hypothesis on interactions between properties of smallholders and the properties of landscape mosaics.

While EFForTS-LGraf provides us with maps for one specific point in time, it is essential to incorporate the temporal dimension of land-use change to answer our main research questions. EFForTS-ABM allows us to assess landscape dynamics and smallholder properties over time in a spatially-explicit way. With our first application scenarios, we investigated effects of smallholder heterogeneity and learning on economic welfare and above-ground carbon stocks in the landscape. Incorporating smallholder heterogeneity in wealth and farming efficiency yielded very different results compared to our baseline scenarios with homogeneous farming efficiency. These results confirmed our choice of the agent-based modelling approach 
where we can explicitly incorporate heterogeneity at various levels. While the EFForTS-ABM is already published and available for download, we still develop the model further, especially to incorporate more facets of ecosystem functioning (see Section 6.2).

The assessment of biodiversity samples from 14 different taxonomic groups allowed us to identify general patterns of land-use change on biodiversity and to understand important differences between the taxonomic groups. While species richness was decreasing from natural forest to intesively managed agricultural systems in nearly all taxonomic groups ( $\alpha$-diversity), we could not identify such general patterns on broader spatial scales ( $\beta$-diversity). We also found considerable differences between above-ground and below-ground taxonomic groups. The biodiversity assessment will enable us to develop statistical models Generalized linear models (GLM), Generalized dissimilarity models (GDM) to predict $\alpha$ and $\beta$ diversity within our model landscapes in EFForTS-LGraf and EFForTS-ABM.

The $n l r x$ package allows modellers to link the powerful statistical software $\mathrm{R}$ to the widely applied agent-based modelling software NetLogo. It has several advantages in comparison to previous approaches that connect $\mathrm{R}$ and NetLogo, such as reduced runtime, improved memory management and minimal coding requirements. It also enables fully reproducable and repeatable model analyses, which is especially valuable in a large research project such as EFForTS, where sharing of data and code between researchers is indispensable. The nlrx package enabled us to run large simulation projects with EFForTS-LGraf and EFForTS$\mathrm{ABM}$ and allowed us to link those tools in one environment. All analyses presented in the respective modelling chapters (see Chapter 2 and 3 ) have been conducted using the nlrx package.

While further investigation is still needed to gain a universal understanding of synergies and trade-offs between economic welfare and ecosystem functioning in Jambi, Indonesia, we found answers on some aspects of our main research questions:

- Which trade-offs and synergies exist between economic welfare and ecosystem functioning in smallholder landscapes in Jambi?

- We could show that above ground carbon stocks are highly affected by decision-making of smallholders in the landscape.

- These decisions were mainly driven by the output prices of different crops.

- Strong shifts in prices led to increased synchronized switching of landuses which resulted in low carbon stocks and inefficient utilization of resources.

- How does heterogeneity in smallholder properties and management practices affect these trade-offs? 
- Our inefficiency and learning scenarios could show that trade-offs between economic welfare and above-ground carbon stocks are highly affected by smallholder properties.

- Heterogeneity in wealth and farming inefficiency led to higher inertia of decision-making, less synchronization, and less dramatic switching of crops.

- How do trade-offs vary across time and space?

- Temporal dynamics of trade-offs were mainly driven by output prices. However, incorporating smallholder heterogeneity weakened this effect considerably.

- Our learning scenario could show that spatial structures of social networks might affect the spatial distribution of trade-offs.

\subsection{Outlook}

Our modelling tools EFForTS-ABM, EFForTS-LGraf and nlrx are already published and freely available under open-source licenses. However, these tools will be further developed and additional analyses will be carried out in order to investigate our main research questions further.

While our first trade-off analyses already revealed important insights, we want to consider more facets of ecosystem functioning in EFForTS-ABM in the future. We are currently working on the implementation of a biodiversity submodel into EFForTS-ABM that utilizes the statistical biodiversity models from our extensive analysis (see Chapter 4). We will use these models to scale plot based biodiversity observations to continuous layers of species communities. Remote sensing data and continuous layers of geographic and climatic variables will be used to relate plot observations to larger extents. Our scaling algorithms are inspired by the work of MOKANY et al., 2011 and will be published as a freely available $\mathrm{R}$ package (spectre). This approach will allow us to estimate species communities in our model landscapes at a detailed level and opens up a large suite of potential analyses from calculating general biodiversity indicators for landscapes or certain landscape elements up to detailed studies on identification of conservation priority areas. Besides biodiversity, we will draw on the extensive database of the EFForTS project to incorporate additional ecosystem functions into EFForTS-ABM. We are currently in the progress of adding a water runoff submodel and a biological control submodel. These additional submodels will enable us to conduct trade-off analyses even more comprehensively. We will further incorporate heterogeneous management practices 
that will also include tree enrichment plantings within oil palm plantations (ZEMP et al., 2019b).

Once these additional submodels are implemented, we will design optimal landscapes by investigating "frontiers of maximum economic benefit". We will use baseline landscapes and apply optimization techniques in order to search for landscape mosaics with specific trade-off dynamics. For example, we may search for landscapes that increase ecosystem functioning while having minimal impact on the economic benefits of smallholders. These optimal landscapes may then be used as a target for evaluating policy scenarios, such as price premia or agglomeration payments (BELL et al., 2016).

In order to communicate our results to the public, we also created an education version of EFForTS-ABM. This simplified model version will be further refined and used for lectures and teaching purposes, also in Indonesia.

We plan to extend our documentation of the EFForTS-LGraf landscape generator in order to increase accessibility for potential users. While the model is in general applicable to a wide range of use cases, we will provide guides and examples that demonstrate the general value of EFForTS-LGraf for the scientific community. Creation of landscape mosaics of European agriculturally dominated landscapes could be one such use case.

The nlrx package will be updated continuously to ensure functionality with later versions of $\mathrm{R}$ and NetLogo. All our tools are hosted on publicly available code repositories that allow documentation of feedback from other users. We will continue to incorporate this feedback in order to improve our tools further.

With our analyses we demonstrated the potential of EFForTS-ABM. EFForTSLGraf and $n l r x$ as a modelling toolkit to investigate socio-economic and ecological trade-offs in smallholder landscapes in Jambi province. We are confident, that future additions and refinements will increase our understanding of the complex interactions between socio-economic processes and ecosystem functioning of the landscape. These insights are highly needed in order to develop and guide policy recommendations that lead to a more sustainable land-use in smallholder dominated landscapes of Indonesia. 
Appendices 


\section{Appendix A}

\section{Supplementary Material: EFForTS-LGraf (Chapter 2)}

\section{A.1 Model Details}

\section{A.1.1 Details on road creation and household placement}

EFForTS-LGraf offers three options for road creation: (1) roads can be read in from an existing road map (option: real.shapefile); (2) a road network is artificially created based on a random elevation model (option: artificial.perlin); (3) a road network is created based on the straight road creation algorithm of the G-Raffe landscape generator (option: artificial.graffe).

To upload an existing real road map, one needs to store the respective shapefile of the roads, the projection file and a second shapefile that only includes the extent of the map. After loading the shapefile, the world is re-sized if necessary. All cells that have a road intersecting are identified as road cells.

The Perlin algorithm mimics situations in which roads are created depending on elevation gradients. First, a simple perlin noise elevation model is created by adding several random noise grids with decreasing weight (perlin parameters $p 1_{\text {r,perl }}, p 2_{\text {r,perl }}, p 3_{\text {r,perl }}$ ) (EBERT et al., 2003, PERLIN et al., 1985). The first road is then created by connecting two random locations in the landscape. First, a road-building-agent is created on one of these two random locations. For each neighboring cell, the road-building-agent calculates the distance to the destination cell (second random location) and the elevation difference to the agents' ${ }^{6}$ current location. The total score of each cell is then determined by weighting the distance and elevation criterion depending on the continuous parameter $p 4_{\mathrm{r}, \mathrm{perl}}(€[0,1])$. The road-building-agent then moves to the cell with the highest score, establishes a road-cell there and continues to move and create road-cells until it reaches the final destination. Thus, by adjusting the parameter $p 4_{\mathrm{r}, \mathrm{perl}}$, the algorithm gives a higher weight to the distance (values near 1) of the connection allowing for straight roads or to the elevation gradient (values near 0) of the connection allowing for wiggling roads. If the $n_{\mathrm{r}, \text { art }}$ is not reached yet, another road is created by selecting one random point on an already established road and another location in the landscape that is at least $m_{\mathrm{r}, \text { art }}$ cells away from any other road. 
Under the G-RaFFe algorithm all roads are straight and start along the left or lower edge of the simulation area and are directed either vertically, horizontally or diagonally within the landscape. Road length is drawn randomly within the interval $\left[1, \sqrt{w_{s}^{2}+h_{s}^{2}}\right]$. The parameter $m_{\mathrm{r}, \text { art }}$ determines the minimum parallel distance in cells between two roads. Roads are created until the number of road cells reaches $n_{\mathrm{r}, \text { art }}$. This road creation option is in most parts adopted from the road creation algorithm of the G-RaFFe model (PE'ER et al., 2013).

\section{A.1.2 Details on field establishment}

During the EFForTS-LGraf field establishment procedure, households attempt to establish a field in three steps: first deciding on the field size, second moving to a potential location and third making sure there is enough space to establish a field of the desired size in this location.

Step one: The size $f$ of the field is drawn randomly from the field size frequency distribution. Step two: Move to an 'others' start cell using one of four search strategies, which can change during the model run:

1. Random walk to an 'others' cell starting from the home base (s1.homebase)

2. Random walk to an 'others' cell starting from one of the fields of this household (s2.field)

3. Determine an 'others' cell within a defined radius from the home base (s3.nearby)

4. Determine the closest 'others' cell which is surrounded only by 'others' cells (s4.avoid)

The selection and order of these search strategies can be defined on the model interface. At the start cell, the household turns in a random compass direction (north, east, south or west) and starts with the field establishment procedure by trying to establish a first row of cells that will belong to the field. The household agent moves forward cell by cell until it either meets a cell which is already a field or a home base or an inaccessible area cell. To ensure reasonable field shapes, the minimum length $l$ of this first row needs to be the side length of the smallest square that fits into the field size. The maximum length of this first row is then set to be the side length of the next larger square that fits into the field size. Because this algorithm restricts field sizes to rather quadratic shapes, the maximum length can be further modified by the parameter $s_{f}$ which allows to proportionally increase the length of the first row. This results in narrower field shapes. 
If the establishment of the first row is not successful, the other possible compass directions for the first row are tested. Once a first field row is established, the farmer tries to expand the field to the left or right of this row until the field reaches its predefined size $f$. If expansion to one side of the first row did not result in the designated field size, the field is extended also to the other side. If also this expansion does not yield the designated field size, all so far added field patches are removed, the household moves back to the start cell and starts over again with the first field row in a different direction. If all possible four compass directions do not lead to a successful field establishment, the farmer selects a new random start cell and tries again to establish a field of the designated field size $f$. The parameter $n_{\text {strat }}$ defines in how many locations a household tries to establish fields before it switches the search strategy to the next strategy. If the household failed to establish fields for all selected strategies, the model will stop and report a warning message that field establishment was not successful. In such cases, the resulting landscape is incomplete because not all households reached their final size. This might especially happen under certain model parameterizations where households and field sizes tend to be very large without adjusting the total dimensions of the landscape.

\section{A.1.3 Details on EFForTS-LGraf spatial output}

The spatial information of generated landscapes can be exported as * asc raster files in order to allow exchange to other model applications. EFForTS-LGraf contains export functions for the following raster files:

- Road-raster: 0 for non-road cells, 1 for cells that have a road intersecting

- Homebase-raster: -1 for non-home base cells, household identity number ( $p \_$homebase_id) for home base cells. Multiple raster files are written if $n_{\mathrm{s}, \mathrm{c}}>1$.

- Ownership-raster: -1 for cells that are not owned, household identity number ( $p$ _owner) for cells that are owned by a household. Note: inaccessible areas do not show up in this output.

- Land-use-type-raster: 0 for 'others' and road cells (i.e. also home bases), 1, 2, 3, 4, 5 for the different crop types, 1000 for inaccessible areas

- Patch-id-raster: -1 for cells that are not smallholder fields (also inaccessible areas), patch identity number $\left(p \_i d\right)$ for smallholder fields 


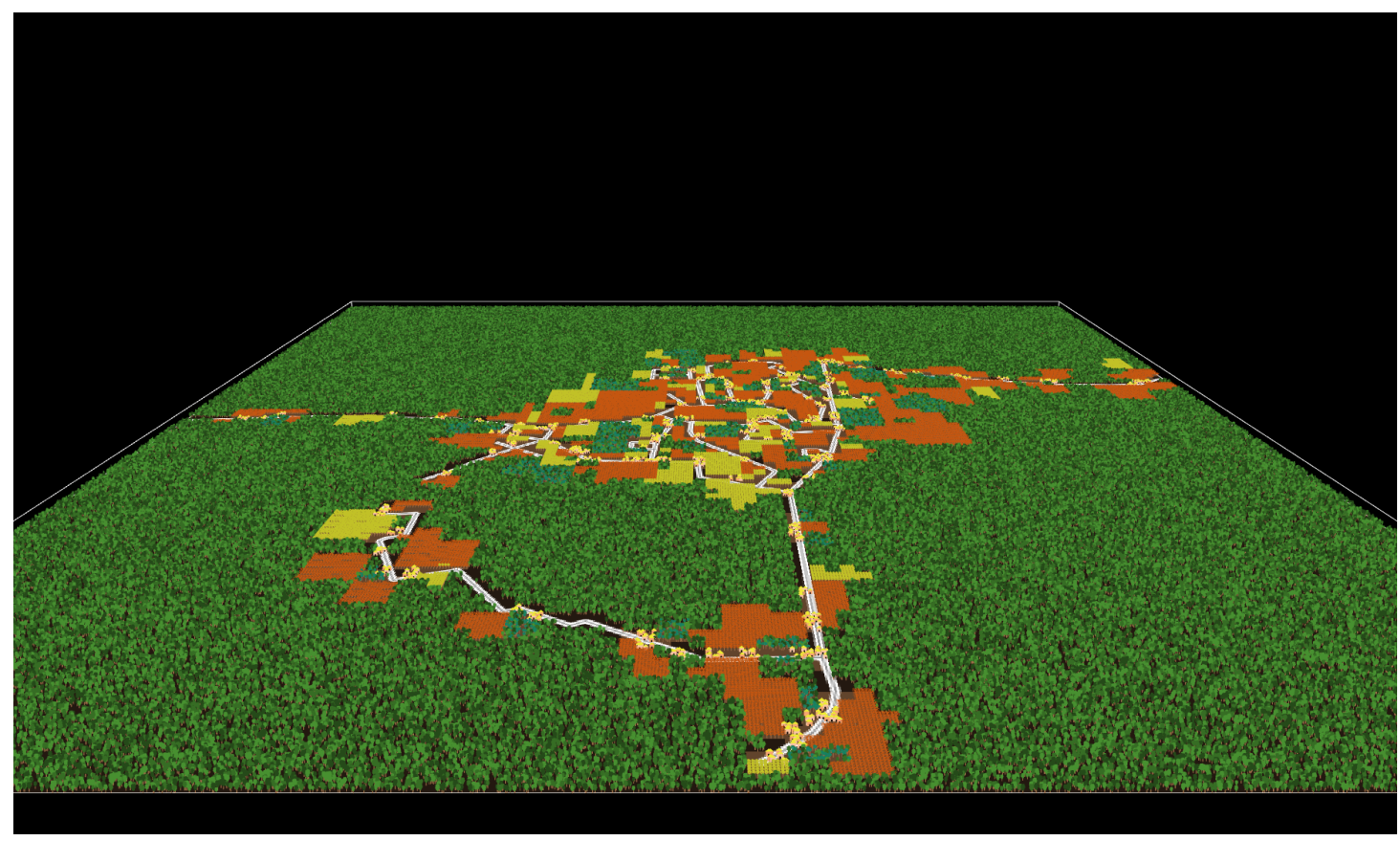

Figure A.1: 3D rendered snapshot of EFForTS-LGraf. White lines represent the real road polylines derived from GIS data. 'Others' cells are illustrated as green shaded tree shapes. Oil palm plantations are illustrated as orange colored palm rows. Rubber plantations are illustrated as yellow colored tree rows. Agroforestry cells are illustrated as mixed rows and trees in blue and green color. Settlements are illustrated by small house symbols.

- Matrix-patch-raster: -1 for cells that have a road intersecting and that are not 'others' cells, 'others' patch identity number ( $p$ _matrixcluster_id) for 'others' cells.

Besides raster output, the write-road-shapefiles procedure creates a polylineshapefile from the current road network, which is useful if one of the artificial road creation algorithms has been used.

Additionally, EFForTS-LGraf offers an output function that utilizes the 3D renderer of NetLogo, to create a three dimensional illustration of the generated landscape using trees, palms and houses to visualize the different crop types (Fig. A.1). With little code adjustments, this feature could in general be used to display other crop types as well. 


\section{A.2 Analysis Details}

\section{A.2.1 Approach 1: Sobol sensitivity analysis}

Table A.1: Sobol sensitivity analysis parameter ranges

\begin{tabular}{|c|c|c|c|}
\hline id & Name on GUI & variation & value \\
\hline$t_{\mathrm{s}}$ & setup-type & constant & "area" \\
\hline$n_{\mathrm{s}, \mathrm{h}}$ & number-of-farmers & not in use & - \\
\hline$n_{\mathrm{s}, \mathrm{v}}$ & number-of-villages & not in use & - \\
\hline$n_{\mathrm{s}, \mathrm{a}}$ & prop-agricultural-area & uniform & $\min =0.05, \max =0.75$ \\
\hline$n_{\mathrm{s}, \mathrm{c}}$ & households-per-cell & uniform (integer) & $\min =3, \max =6$ \\
\hline seed $_{\mathrm{s}}$ & rnd-seed & set externally & - \\
\hline$r e p_{\mathrm{s}}$ & reproducable? & constant & true \\
\hline$w_{\mathrm{s}}$ & width & constant & 100 \\
\hline$h_{\mathrm{s}}$ & height & constant & 100 \\
\hline$c_{\mathrm{s}}$ & cell-length-meter & constant & 50 \\
\hline$t_{\mathrm{r}}$ & road-type & constant & "artificial.perlin" \\
\hline$i_{\mathrm{r}, \mathrm{shp}}$ & road-map-nr & not in use & - \\
\hline$n_{\mathrm{r}, \text { art }}$ & total-road-length & uniform & $\min =500, \max =1000$ \\
\hline$m_{\mathrm{r}, \text { art }}$ & min-dist-roads & constant & 5 \\
\hline$p 1_{\mathrm{r}, \text { perl }}$ & perlin-octaves & uniform & $\min =2, \max =12$ \\
\hline$p 2_{\mathrm{r}, \text { perl }}$ & perlin-persistence & uniform & $\min =0.1, \max =0.9$ \\
\hline$p 3_{\mathrm{r}, \text { perl }}$ & cone-angle & uniform & $\min =90, \max =180$ \\
\hline$p 4_{\mathrm{r}, \mathrm{perl}}$ & dist-weight & uniform & $\min =0, \max =1$ \\
\hline$d_{\mathrm{v}}$ & vlg-size-distribution & constant & "uniform" \\
\hline$\mu_{\mathrm{v}}$ & vlg-size-mean_ha & uniform & $\min =10, \max =20$ \\
\hline$\sigma_{\mathrm{v}}$ & vlg-size-sd_ha & uniform & $\min =2, \max =10$ \\
\hline$d_{\mathrm{v}}$ & vlg-min-distance & uniform & $\min =1, \max =10$ \\
\hline$d_{\mathrm{h}}$ & hh-area-distribution & constant & "log-normal" \\
\hline$\mu_{\mathrm{h}}$ & hh-area-mean_ha & uniform & $\min =0.25, \max =3$ \\
\hline$\sigma_{\mathrm{h}}$ & hh-area-sd_ha & uniform & $\min =0.25, \max =1$ \\
\hline$n_{\mathrm{i}}$ & inaccessible-area-fraction & constant & 0 \\
\hline$l_{\mathrm{i}}$ & inaccessible-area-location & not in use & - \\
\hline$d_{\mathrm{i}}$ & $\begin{array}{l}\text { inaccessible-area- } \\
\text { distribution }\end{array}$ & not in use & - \\
\hline$\mu_{\mathrm{i}}$ & inaccessible-area-mean & not in use & - \\
\hline$\sigma_{\mathrm{i}}$ & inaccessible-area-sd & not in use & - \\
\hline$t_{\mathrm{f}}$ & field-type & constant & "percentage" \\
\hline$d_{\mathrm{f}}$ & field-size-distribution & constant & "normal" \\
\hline$\mu_{\mathrm{f}}$ & field_size_mean_ha & not in use & $\begin{array}{l}\text { derived as percentage from } \\
\text { hh-area-mean_ha }\end{array}$ \\
\hline$\sigma_{\mathrm{f}}$ & field_size_sd_ha & uniform & $\min =0.25, \max =2$ \\
\hline$p_{\mathrm{f}}$ & field-size-percentage & uniform & $\min =0.1, \max =0.9$ \\
\hline$s_{\mathrm{f}}$ & field-shape-factor & uniform & $\min =0.7, \max =2$ \\
\hline$t_{\text {strat }}$ & strategies-type & constant & "id" \\
\hline$s 1_{\text {strat }}$ & s1.homebase & not in use & $\begin{array}{l}\text { derived from field-strategies- } \\
\text { id }\end{array}$ \\
\hline
\end{tabular}




\begin{tabular}{|c|c|c|c|}
\hline$s 2_{\text {strat }}$ & s2.fields & not in use & $\begin{array}{l}\text { derived from field-strategies- } \\
\text { id }\end{array}$ \\
\hline$s 3_{\text {strat }}$ & s3.nearby & not in use & $\begin{array}{l}\text { derived from field-strategies- } \\
\text { id }\end{array}$ \\
\hline$s 4_{\text {strat }}$ & s4.avoid & not in use & $\begin{array}{l}\text { derived from field-strategies- } \\
\text { id }\end{array}$ \\
\hline$n_{\text {strat }}$ & change-strategy & uniform & $\min =5, \max =20$ \\
\hline$i_{\text {strat }}$ & field-strategies-id & uniform (integer) & $\min =1, \max =9$ \\
\hline$t_{1}$ & land-use-assignment & constant & "landscape-level-fraction" \\
\hline$i d_{l}$ & LUT-l-name $(\mathrm{l}=1,2,3,4,5)$ & constant & $l=1$ : "fields"; $1>1$ not in use \\
\hline$f r_{1}$ & LUT-l-fraction $(\mathrm{l}=1,2,3,4,5)$ & constant & $\mathrm{l}=1: 1 ; \mathrm{l}>1$ not in use \\
\hline$f r_{1, \mathrm{spec}}$ & LUT-l-specialize $(\mathrm{l}=1,2,3,4,5)$ & not in use & - \\
\hline$f_{1}$ & LUT-fill-up & constant & "LUT-1-fraction" \\
\hline
\end{tabular}

We created a parameter input matrix in order to calculate Sobol Sensitivity Indices for model parameters on different outputs (here: landscape metrics). The parameter matrix was created by variation of parameters in defined ranges (Table A.1). The parameter matrix was created with 500 samples and 10 bootstrapping replicates which results in 9500 simulations. For calculating sensitivity indices we used the optimized Sobol estimator proposed by Jansen (CHAN et al., 2000; JANSEN, 1999 SAltelli et al., 2010; SobOL, 1990).

\section{A.2.2 Approach 2: Validation}

To study the range of landscape characteristics that EFForTS-LGraf can create, we performed a second validation approach in addition to the genetic algorithm validation approach (see Approach 2, in Chapter 2). From the reclassified land-cover map, that was used for the genetic algorithm validation approach, we sampled 100 randomly placed landscapes, $100 \times 100$ cells in size (landscapes may overlap), and calculated the five landscape metrics for each of these sampled landscapes and each land-cover type (fields and other). We compared the landscape characteristics (landscape metrics) of these landscapes to the 9500 artificially generated landscapes from the Sobol sensitivity analysis (approach 1). To allow comparability, all agricultural crop types within the generated landscapes were aggregated to one class (fields) and the remaining area was classified as class 'others'.

Large heterogeneity was found in landscape metrics from 100 randomly placed sample landscapes $(100 \times 100$ cells $)$ within the classified land-cover map (point distributions in Fig. A.2). Landscape metrics were calculated as a function of 'others' cells area, because most indices are very sensitive to class proportions. The landscape shape index (LSI) quantifies the spatial aggregation of patches for each land-cover type. Compared to our generated landscapes, the sampled landscapes covered a relatively small range of aggregation levels (Fig. A.2). For landscapes with small 'others' area, our generated landscapes had higher LSI than 

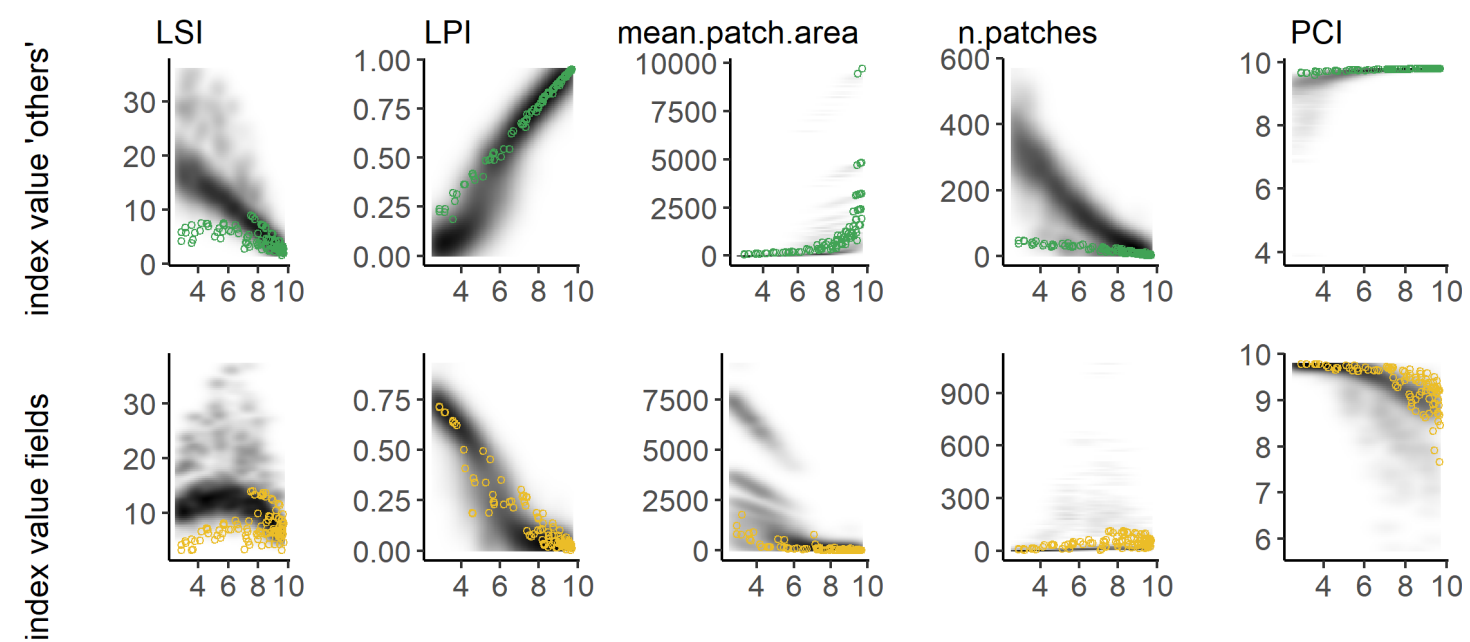

'others' area [1000 cells]

Figure A.2: Points indicate distributions of landscape metrics from 100 landscape samples $(100 \times 100$ cells $)$ from the re-classified satellite image of the Harapan region. Background shading indicates distributions of landscape metrics from 9500 generated landscapes of the same size and resolution (Sobol sensitivity analysis, approach 1). The darker the shading, the more often a landscape with the corresponding index value has been generated. Index distributions of 'others' cells and patches are presented in the upper row (green points, 'others'), whereas index distributions of field cells and patches are presented in the bottom row (yellow points, fields). 
the sampled landscapes. The largest patch index was almost linearly correlated with the 'others' area (negative for agricultural patches, positive for 'others' patches). With increasing 'others' area, the mean patch area was exponentially increasing for 'others' patches in both, the generated and the sampled landscapes. For fields, the mean patch area was almost constant at a very low level. Compared to our generated landscapes, the number of 'others' patches was relatively low, especially for landscapes with small 'others' area. The patch cohesion index (PCI) quantifies the shape complexity and perimeter density of patches and showed a decreasing trend for agricultural patches with increasing 'others' area. For 'others' patches, the patch cohesion index was almost constant across the 100 sampled landscapes.

Comparing the 9500 landscapes that were generated within the Sobol sensitivity analysis approach (approach 1) with the 100 realistic landscapes, many characteristics found in the sampled landscapes (point distributions in Fig. A.2 were covered by our generated landscapes (background shading in Fig. A.2). The generated landscapes covered a wide range of landscape shape index (LSI) values. However, generated landscapes with small 'others' area showed systematically higher LSI values. The largest patch index (LPI) distribution was matched very accurately and all sampled landscapes lay within the boundaries of the 9500 generated landscapes. EFForTS-LGraf was also able to reproduce a wide range of mean patch area although the observed heterogeneity in the sampled landscapes was significantly lower. The variety of the total number of patches was reproduced for field patches, but did not fit well for 'others' patches, especially when 'others' area was small. For the patch cohesion index all sampled landscapes lay within the boundaries of our generated landscapes.

In order to visualize the similarity between sampled and generated land-cover maps, we selected three different example landscapes with different 'others' cells area from the 100 samples of the Harapan land-cover map and three example landscapes from the 9500 generated artificial landscapes with matching 'others' area (Fig. A.3). By visual comparison, the resulting landscapes from EFForTSLGraf showed similar spatial clustering of patches and patch sizes although the landscapes from the Harapan land-cover map contained slightly more small field patches that were slightly more scattered across the 'others' area. This matched the observation from the landscape metrics comparison, where the sampled landscapes from the classified land-use map had a significantly greater number of field patches compared to our generated landscapes (Fig. A.3, n patches). 
(a)

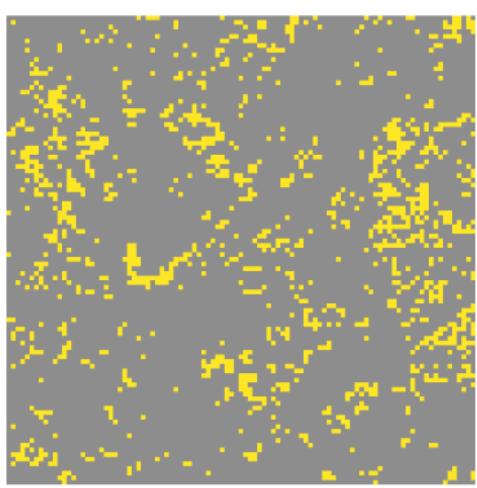

(d)

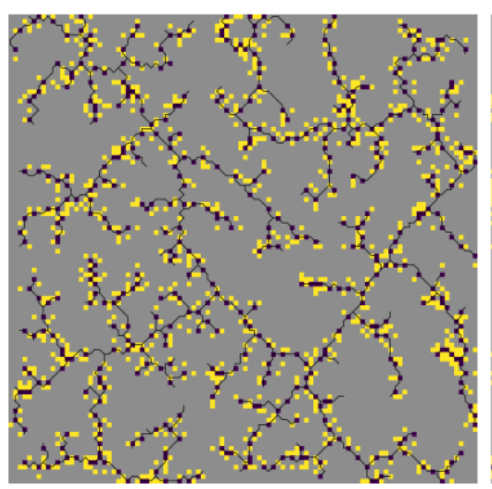

(b)

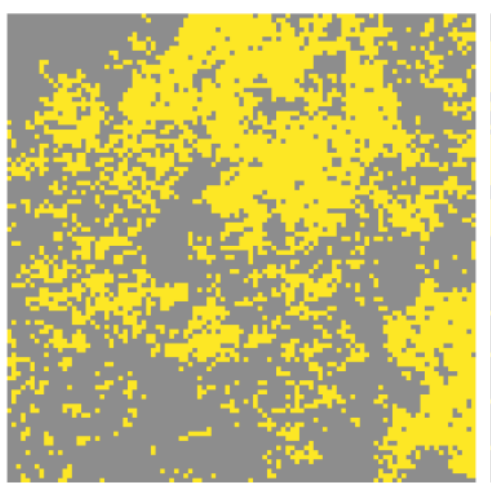

(e)

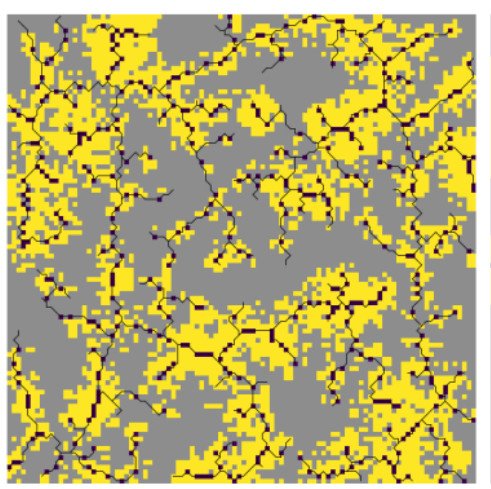

(c)

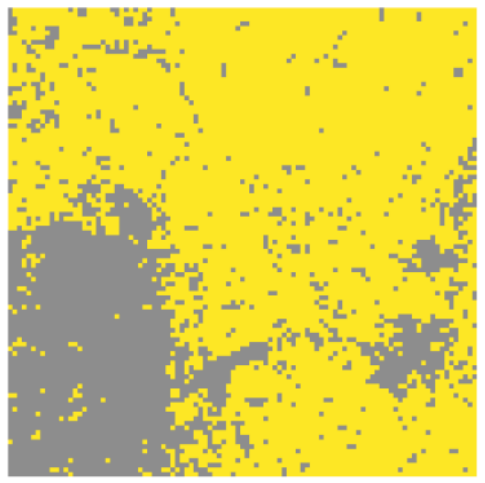

(f)

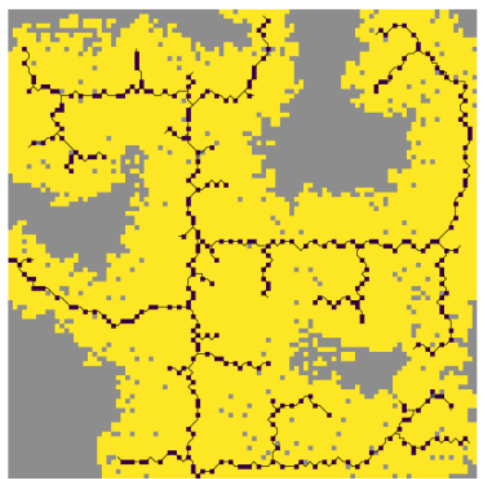

Figure A.3: Three of the 100 sampled landscapes from the re-classified satellite image (a, b, c) and three generated EFForTS-LGraf landscapes from the Sobol sensitivity analysis (d, e, f). Grey cells indicate 'others' cells and yellow cells indicate fields. For the EFForTS-LGraf landscapes, black cells indicate household home bases and lines indicate artificially generated roads. 


\section{A.2.3 Approach 3: Applied case study}

Table A.2: Applied case study parameter ranges

\begin{tabular}{|c|c|c|c|}
\hline id & Name on GUI & variation & value \\
\hline$t_{\mathrm{s}}$ & setup-type & constant & "area" \\
\hline$n_{\mathrm{s}, \mathrm{h}}$ & number-of-farmers & not in use & - \\
\hline$n_{\mathrm{s}, \mathrm{v}}$ & number-of-villages & not in use & - \\
\hline$n_{\mathrm{s}, \mathrm{a}}$ & prop-agricultural-area & constant & 0.5 \\
\hline$n_{\mathrm{s}, \mathrm{c}}$ & households-per-cell & constant & 1 \\
\hline seed $_{\mathrm{s}}$ & rnd-seed & set externally & - \\
\hline$r e p_{\mathrm{s}}$ & reproducable? & constant & true \\
\hline$w_{\mathrm{s}}$ & width & constant & 100 \\
\hline$h_{\mathrm{s}}$ & height & constant & 100 \\
\hline$c_{\mathrm{s}}$ & cell-length-meter & constant & 50 \\
\hline$t_{\mathrm{r}}$ & road-type & constant & "real.shapefile" \\
\hline$i_{\mathrm{r}, \mathrm{shp}}$ & road-map-nr & constant & 3 \\
\hline$n_{\mathrm{r}, \text { art }}$ & total-road-length & not in use & - \\
\hline$m_{\mathrm{r}, \text { art }}$ & min-dist-roads & not in use & - \\
\hline$p 1_{\mathrm{r}, \text { perl }}$ & perlin-octaves & not in use & - \\
\hline$p 2_{\mathrm{r}, \text { perl }}$ & perlin-persistence & not in use & - \\
\hline$p 3_{\mathrm{r}, \text { perl }}$ & cone-angle & not in use & - \\
\hline$p 4_{\mathrm{r}, \text { perl }}$ & dist-weight & not in use & - \\
\hline$d_{\mathrm{v}}$ & vlg-size-distribution & constant & "uniform" \\
\hline$\mu_{\mathrm{v}}$ & vlg-size-mean_ha & constant & 15 \\
\hline$\sigma_{\mathrm{v}}$ & vlg-size-sd_ha & constant & 6 \\
\hline$d_{\mathrm{v}}$ & vlg-min-distance & constant & 10 \\
\hline$d_{\mathrm{h}}$ & hh-area-distribution & constant & "log-normal" \\
\hline$\mu_{\mathrm{h}}$ & hh-area-mean_ha & uniform & $\min =1, \max =3$ \\
\hline$\sigma_{\mathrm{h}}$ & hh-area-sd_ha & constant & 0.91 \\
\hline$n_{\mathrm{i}}$ & inaccessible-area-fraction & constant & 0 \\
\hline$l_{\mathrm{i}}$ & inaccessible-area-location & not in use & - \\
\hline$d_{\mathrm{i}}$ & $\begin{array}{l}\text { inaccessible-area- } \\
\text { distribution }\end{array}$ & not in use & - \\
\hline$\mu_{\mathrm{i}}$ & inaccessible-area-mean & not in use & - \\
\hline$\sigma_{\mathrm{i}}$ & inaccessible-area-sd & not in use & - \\
\hline$t_{\mathrm{f}}$ & field-type & constant & "distribution" \\
\hline$d_{\mathrm{f}}$ & field-size-distribution & constant & "log-normal" \\
\hline$\mu_{\mathrm{f}}$ & field_size_mean_ha & constant & 0.49 \\
\hline$\sigma_{\mathrm{f}}$ & field_size_sd_ha & constant & 0.77 \\
\hline$p_{\mathrm{f}}$ & field-size-percentage & not in use & - \\
\hline$s_{\mathrm{f}}$ & field-shape-factor & constant & 1 \\
\hline$t_{\text {strat }}$ & strategies-type & constant & "id" \\
\hline$s 1_{\text {strat }}$ & s1.homebase & not in use & $\begin{array}{l}\text { derived from field-strategies- } \\
\text { id }\end{array}$ \\
\hline$s 2_{\text {strat }}$ & s2.fields & not in use & $\begin{array}{l}\text { derived from field-strategies- } \\
\text { id }\end{array}$ \\
\hline$s 3_{\text {strat }}$ & s3.nearby & not in use & $\begin{array}{l}\text { derived from field-strategies- } \\
\text { id }\end{array}$ \\
\hline
\end{tabular}




\begin{tabular}{|c|c|c|c|}
\hline$s 4_{\text {strat }}$ & s4.avoid & not in use & $\begin{array}{l}\text { derived from field-strategies- } \\
\text { id }\end{array}$ \\
\hline$n_{\text {strat }}$ & change-strategy & constant & 10 \\
\hline$i_{\text {strat }}$ & field-strategies-id & constant & 1 \\
\hline$t_{1}$ & land-use-assignment & constant & $\begin{array}{l}\text { "household-level- } \\
\text { specialization" }\end{array}$ \\
\hline$i d_{l}$ & LUT-l-name $(\mathrm{l}=1,2,3,4,5)$ & constant & $\begin{array}{l}l=1: \text { "oilpalm"; } 1=2: \text { "rubber"; } \\
\text { l>2 not in use }\end{array}$ \\
\hline$f r_{1}$ & LUT-l-fraction $(\mathrm{l}=1,2,3,4,5)$ & constant & $\begin{array}{l}\mathrm{l}=1: 0.5 ; \mathrm{l}=2: 0.5 ; \mathrm{l}>2 \text { not in } \\
\text { use }\end{array}$ \\
\hline$f r_{1, \mathrm{spec}}$ & LUT-l-specialize $(\mathrm{l}=1,2,3,4,5)$ & uniform/constant & $\begin{array}{l}l=1: \min =0, \max =1 ; l=2: 0, \\
l>2 \text { not in use }\end{array}$ \\
\hline$f_{1}$ & LUT-fill-up & constant & "LUT-2-fraction" \\
\hline
\end{tabular}

We created a parameter input matrix in order to calculate effects of household consolidation and household level specialization on different outputs (here: landscape metrics). The parameter matrix was created by variation of the two parameters household-area-mean_ha and LUT-1-specialize (Table A.2). We generated the parameter matrix by using a Latin Hypercube sampling design with 500 samples (MCKAY et al., 1979). We simulated three repetitions of the parameter matrix to account for stochastic effects. We analyzed the resulting landscapes via the five selected landscape metrics from previous approaches. We calculated linear regression models for each landscape metric and crop type combination and calculated standardized regression coefficients to estimate parameter and interaction effects on landscape metrics of the generated landscapes (coefficient results, see Approach 3 in Chapter 21. Additionally, we investigated the raw data by plotting landscape metrics as a function of specialization level, grouped by household size (see Fig. A.4. 


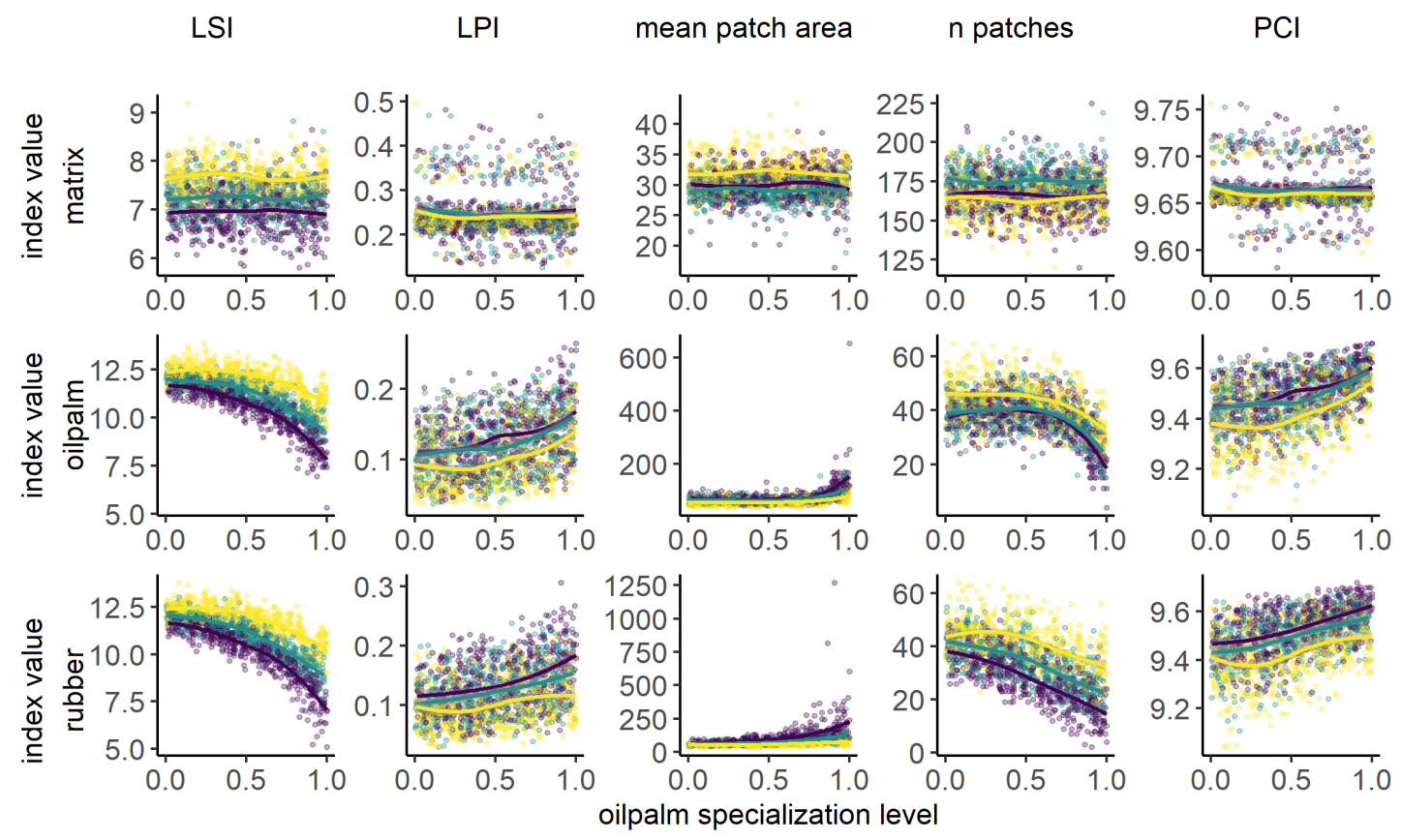

Figure A.4: Five selected landscape metrics, for two crop types (oil palm and rubber) and 'others' patches (matrix) calculated for land-cover maps generated by the model using a latin hypercube sampling approach. Plots show the value of the landscape metrics versus household specialization level on oil palm. Differences in household size distributions are shown by colours with darker colors indicating larger household size. These are grouped into small (1 - 1.65 ha, yellow), medium (1.66 - 2.32 ha, green) and large (2.32 - 3 ha, purple). Lines show smoothed trends and standard error using the locally weighted scatterplot smoothing (LOESS) method. 


\section{Appendix B}

\section{Supplementary Material: EFForTS-ABM (Chapter 3)}

\section{B.1 EFForTS-ABM: Model details}

The land-use change model is implemented in the open source modeling platform NetLogo 5.3.1. The model is still under further development. For questions please contact jsaleck@gwdg.de.

\section{B.1.1 Initialization}

The most important parts of the initialization are the initial spatial distribution of the different land uses, the location of farming households and the ownership of fields. All these state variables are determined using the landscape generator EFForTS-LGraf which was developed specifically for this purpose (see Chapter 2). The outputs of the landscape generator are different raster maps which are read into the land-use change model at the beginning of each simulation run. All raster maps used in the model have a $50 \mathrm{~m} \times 50 \mathrm{~m}$ resolution. The following grid-based maps are used as inputs:

- Forest/nonforest patches

- Land-use-types

- Roads

- Household home-base locations

- Field identity number

- Ownership of cells (connects households to fields)

Exemplary maps which were used for the initialization of the presented model runs are shown in Figure 3.1 in Chapter 3. Apart from these initial maps, the following state variables are initialized as follows: 
- Initial household wealth is drawn from a log-normal distribution with parameters given in Table B.3 (see also Section B.2.4). The resulting values for initial wealth are sorted and assigned to households in a way that households owning larger areas have a higher initial wealth.

- Factors for crop-specific inefficiencies are drawn for each household from gamma distributions (see Section B.2.3). The inefficiency factor reduces potential yields due to lack of expertise or site-specific conditions (see Equation B.2.

- If learning is turned on, households initialize their social networks based on the spatial proximity to their neighbors (see Section B.1.3.1).

- The initial age of agricultural fields is drawn from a uniform distribution with typical age ranges of oil palm and rubber plantations (see Table B.1).

- The initial carbon contents of fields are set according to their initial ages (see Figure B.1).

- Initial prices for oil palm fresh fruit bunches (FFB) and rubber as given in Table B.2 (for details see Section B.2.5).

Initial values to variables are summarized in Table B.1; model parameters are presented in Table B.2 and Table B.3. Note that distributions are based on household data (EULER et al., 2016b).

\section{B.1.2 Input data}

As external input for model initialization, EFForTS-ABM uses maps which are produced by the landscape generator EFForTS-LGraf. Apart from that, the only external variables are the yield prices. Different price functions are implemented (see Section B.2.5), two of which are used in simulations shown in this paper (see Section 3.3.

\section{B.1.3 Submodels}

The dynamic land-use change model comprises two main sub-models: the economic household submodel that models land-use decisions by rural households and the ecological submodel that simulates ecosystem functions on different spatial scales. In this section we describe the details of these submodels and their parameterization. 
Table B.1: Initial household parameter values

\begin{tabular}{|c|c|c|c|}
\hline Initialization & Unit & Value & Justification \\
\hline Number of households & {$[-]$} & 50 & \\
\hline $\begin{array}{l}\text { Household area } \mu \text { (log-normal distribu- } \\
\text { tion) }\end{array}$ & [ha] & 1.02 & Derived from household data \\
\hline Household area $\sigma$ & [ha] & 0.91 & Derived from household data \\
\hline Field size $\mu$ (log-normal distribution) & [ha] & 0.49 & Derived from household data \\
\hline Field size $\sigma$ & [ha] & 0.77 & Derived from Household data \\
\hline $\begin{array}{l}\text { Household wealth } \mu \text { (log-normal distri- } \\
\text { bution) }\end{array}$ & [USD] & 7 & Derived from household data \\
\hline Household wealth $\sigma$ & [USD] & 1 & Derived from household data \\
\hline Household wealth scaling factor & {$[-]$} & 10 & Estimated \\
\hline $\begin{array}{l}\text { Household inefficiency oilpalm } \quad \alpha \\
\text { (gamma distribution) }\end{array}$ & {$[-]$} & 3.168 & Estimated from household data \\
\hline $\begin{array}{l}\text { Household inefficiency } \\
\text { (gamma distribution) }\end{array}$ & {$[-]$} & 0.069 & Estimated from household data \\
\hline $\begin{array}{l}\text { Household inefficiency rubber } \alpha \text { (gamma } \\
\text { distribution) }\end{array}$ & {$[-]$} & 3.445 & Estimated from household data \\
\hline $\begin{array}{l}\text { Household inefficiency rubber } \lambda \text { (gamma } \\
\text { distribution) }\end{array}$ & {$[-]$} & 0.093 & Estimated from household data \\
\hline Social network median kernel distance & {$[\mathrm{km}]$} & 1 & Estimated \\
\hline Social network maximum kernel distance & {$[\mathrm{km}]$} & 2.5 & Estimated \\
\hline Learning diffusion rate & {$[-]$} & 0.5 & Estimated \\
\hline $\begin{array}{l}\text { Age range of oil palm plantations (uni- } \\
\text { form distribution) }\end{array}$ & [year] & {$[0,30]$} & Estimated from household data \\
\hline $\begin{array}{l}\text { Age range of rubber plantations (uni- } \\
\text { form distribution) }\end{array}$ & [year] & {$[0,40]$} & Estimated from household data \\
\hline $\begin{array}{l}\text { Fraction of agricultural area under oil } \\
\text { palm and rubber }\end{array}$ & {$[-]$} & $0.5: 0.5$ & \\
\hline
\end{tabular}

\section{B.1.3.1 Household model}

The economic household model consists of submodels dealing with household production and capital accumulation (see Paragraph Production function, cash flows and capital accumulation) as well as the corresponding land-use change decisions (see Paragraph Decision on land-use change and production and Reduction of factor inputs). In short, the economic household model includes the following processes (see Fig. 3.3. . At the beginning of each time step, if "learning" is turned on, households simultaneously improve their productivity by decreasing their inefficiencies (see Paragraph Household inefficiency 86 learning). Then household wealth is reduced by its planned consumption (box Consumption I in Fig. 3.3). Each household then decides on land management (box Land management in Fig. 3.3) including the decision on factor inputs and land-use change. This decision is based on the expected cash flows from different land use options over a certain time horizon (e.g. 10 years). We assume that households are credit constrained. This means 
that households might not be able to realize the most profitable land-use option, as they might, for example, not be able to mobilize the capital necessary for initial investment. Following the land management decision, annual yields (Yield in Fig. 3.3) of all household cells are calculated. Yields are affected by the age of plantations, factor inputs and household inefficiency, reflecting inefficient knowledge and site-specific conditions. Given current output prices (Output prices) the realized annual revenue (Revenue) is derived. Given current factor prices (Factor prices), costs (Costs) for agricultural production are calculated and subtracted from the revenue, resulting in the annual cash flow (Cash flow) of the household. In the case of positive annual cash flow, a part of the cash flow is consumed (Consumption II). The household's wealth (Wealth/Savings) is updated by adding the remaining cash flow and external income. The updated household wealth influences which land-use options are feasible for the household in the next time step.

\section{Production function, cash flows and capital accumulation}

For each household cell j we apply a Leontief production function (DIEWERT, 1971). This implies that factors cannot be substituted and production is determined by the input factor which is applied in the smallest relative amount. Thus, production is calculated as

$$
\hat{y}_{j, l, n}(L, K, T I, \overline{L A})=\min \left\{y_{n}^{*} \frac{L}{L_{n}^{*}}, y_{n}^{*} \frac{K}{K_{n}^{*}}, y_{n}^{*} \frac{T I}{T I_{n}^{*}}, y_{n}^{*} \frac{\overline{L A}}{\overline{L A}}\right\}
$$

with

$\hat{y}_{j, l, n}$ : production [ton] from crop $l$ of age $n$ on cell $j$ under the factor inputs labor $L$, capital $K$, technical inputs $T I$ and land $\overline{L A}$

$y_{n}^{*}$ : production [ton] of a plantation of age $n$ on one cell with optimal factor inputs (see Section B.2.1 for the derivation of the optimal production)

$L_{n}^{*}$ : the optimal factor input of labor [hour] for a plantation of age $n$

$K_{n}^{*}$ : the optimal capital stock [US\$] for a plantation of age $n$

$T I_{n}^{*}$ : the optimal factor input of technical input [US\$] for a plantation of age $n$

$\overline{L A}$ : Land [ha], which is fixed to the size of one cell.

The Leontief production function defines the potential production given a certain age of a plantation and certain levels of inputs (for oil palm plantations, yield is calculated in tons of fresh fruit bunches per hectare and year; rubber yield is calculated in tons of rubber per hectare and year). However, due to varying experience of farmers in the cultivation of different land uses, incomplete knowledge, e.g. about ideal timing of fertilization or harvesting, as well as variation in sitespecific conditions, this potential production might not be realized by a household. 
We incorporate the gap between potential and realized yield by introducing an inefficiency factor $\delta_{i, l}$ for each household $i$ and land-use type $l$. The realized production from cell $j$ which is owned by household $i$ is therefore

$$
y_{j, l, n}(L, K, T I, \overline{L A}):=\delta_{i, l} \cdot \hat{y}_{j, l, n}(L, K, T I, \overline{L A}) .
$$

Based on the assumption that input factors are the same for all cells belonging to one field, the production for a field consisting of $m$ cells of crop $l$ of age $n$ is given by

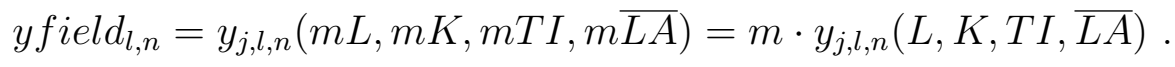

The revenue [US\$] from cell $j$ in year $t$ is

$$
\operatorname{Rcell}_{j, t}=y_{j, l, n_{t}}(L, K, T I, \overline{L A}) \cdot p_{l, t}
$$

with

$n_{t}$ : the age [year] of the plantation in cell $j$ at time $t$

$p_{l, t}:$ price $[\mathrm{US} \$ /$ ton] of the product of land use $l$ at year $t$.

The total revenue [US\$] from agricultural land use of household $i$ in year $t$ is thus given by

$$
R_{i, t}=\sum_{\text {household cells } j} \text { Rcell }_{j, t}
$$

The net cash flow [US\$] from cell $j$ in year $t$ is

$$
\Pi c e l l_{j, t}=\operatorname{Rcell}_{j, t}-\operatorname{rcost}_{j, l, n_{t}}(L, K, T I, \overline{L A})-i \operatorname{cost}_{j, l, n_{t}}
$$

with

rcost $_{j, l, n_{t}}$ : recurrent costs [US\$] on cell $j$ under crop $l$ in year $t$, depending on factor inputs of labor $L$, capital $K$, technical inputs $T I$ and land $\overline{L A}$ $i_{\text {cost }}{ }_{j, l, n_{t}}$ : investment costs on cell $j$ for agricultural production of crop $l$ in period $t$.

The net cash flow [US\$] from agricultural land use for household $i$ in year $t$ is thus given by 


$$
\Pi_{i, t}=\sum_{\text {household cells } j} \Pi_{j} \text { cell } l_{j, t}
$$

The recurrent costs for cell $j$ are calculated as

$$
\operatorname{rcost}_{j, l, n_{t}}(L, K, T I, \overline{L A})=\left\{\begin{array}{l}
r_{K, t} K+r_{L, t} \overline{L A}, \text { if } n_{t}<n_{m} \\
w_{l, t} L+r_{K, t} K+p_{T I, l, t} T I+r_{L, t} \overline{L A} \text { if } n_{t} \geq n_{m}
\end{array}\right.
$$

with

$n_{t}$ : the age of the plantation on cell $j$ at time $t$

$n_{m}$ : the maturation age of the plantation, i.e. the first year with non-zero yields

$r_{K, t}$ : rental rate of capital in year $t$

$K$ : the current capital stock [US\$] on cell $j$

$r_{L, t}$ : rental rate of land [US $\$ /$ ha] in year $t$ (independent of what crop is on the cell)

$w_{l, t}$ : wage for one hour of work $[\mathrm{US} \$ / \mathrm{h}]$ in crop $l$ in year $\mathrm{t}$

$L$ : input of labor [hour] on cell $j$ in year $t$

$p_{T I, l, t}:$ price for one unit of technical input $[\mathrm{US} \$ / \mathrm{kg}]$ in crop $l$ at time $\mathbb{1}^{1}$

$T I$ : technical input $[\mathrm{kg}]$ on cell $j$ in year $t$.

We assume that investment costs occur only within the immature phase of a plantation life cycle, i.e. as long as yields are zero. The total investment costs icost_total $l_{j, l}$ for a plantation of crop $l$ in one cell $j$ are therefore

$$
i c o s t \_ \text {total }_{j, l}=\sum_{k=0}^{n_{m}-1} i \operatorname{cost}_{j, l, k}
$$

These investment costs include non-recurrent costs, e.g. for buying seedlings, as well as all costs for labor and technical input in the immature phase. For establishing oil palms, for example, labor is needed for lining, the transportation of seedlings, and digging holes. Land is already owned by the household, i.e. part of its initial endowments, and we only consider the opportunity costs of holding this asset. During the immature period, the capital stock is built up and we assume that no further investment costs occur once positive yields are produced. From this point onwards all labor and input costs are classified as recurrent costs. We acknowledge that some of these recurrent costs could similarly be conceptualized as maintenance, i.e. reinvestment costs, but our simplification facilitates modeling of the crop choice

\footnotetext{
${ }^{1}$ Both wages and prices for technical input as well as rental rates for capital and land can vary with time. However, in our current model version, we keep them fixed and therefore omit the index $t$ in the remainder of the model description.
} 
decision later on.

Each household cell $j$ has a capital stock $K_{j, t}$, representing the resale value of the capital stock embodied in rubber trees or oil palms on the cell at time $t$ (see Eq. (B.1) and (B.8)). The capital stock is calculated as the cumulative investment costs in this cell minus depreciation

$$
K_{j, t}=\left(1-d_{l}\left(n_{t}\right)\right) \cdot K_{j, t-1}+i \operatorname{cost}_{j, l, n_{t}}
$$

with depreciation rate $d_{l}\left(n_{t}\right)$. The depreciation rate, which captures the natural productivity of the plantation, depends on the plantation age $n_{t}$ : for young plantations, $d$ is negative, for older ones positive. This is because productivity generally increases in young plantations and decreases in old plantations; the productivity inflection point is crop-specific. The total capital stock of household $i$ in year $t$ is accordingly

$$
K_{\text {tot }}{ }_{i, t}=\sum_{\text {household cells } j} K_{j, t}
$$

\section{Decision on land-use change and production}

The decision on land management and production, i.e. land-use change and the corresponding factor inputs, is determined by the profitability of land use options, as well as wealth (and consumption) of the household. Let $W_{i, t-1}$ be the wealth of household $i$ at the end of year $t-1$, i.e. the wealth available at the beginning of year $t$. For simplicity we assume, that, apart from the profit-based component of household consumption, all expenditures occurring in year t need to be disbursed by the household, i.e. paid before the income from agricultural production and external sources in the year $\mathrm{t}$ is available. Household consumption is calculated in a two-step process, partly before and partly after net cash flow realization of that time step. The planned household consumption of household $i, C \_p l a n_{i, t}$ consists of a fixed base consumption $\bar{C}_{i}$ representing the subsistence level, and a variable additional consumption depending on the actual wealth $W_{i, t-1}$.

Thus the planned consumption of household $i$ in year $t$ is

$$
C \_\operatorname{plan}_{i, t}=\bar{C}_{i}+C_{W} \cdot W_{i, t-1}
$$

with $C_{W}$ the fraction of wealth that is additionally consumed.

The actually realized consumption $C_{i, t}$ can increase by a profit-based component, if a positive net cash flow in this year permits additional consumption (see Table B.3 
for parameter values of consumption). Thus, after the calculation of the net cash flow $\Pi_{i, t}$, household consumption is updated according to

$$
C_{i, t}=\left\{\begin{array}{ll}
C \_\operatorname{plan}_{i, t}+C_{\pi} \cdot \Pi_{i, t} & , \text { if } \Pi_{i, t}>0 \\
C_{\text {plan }}>\operatorname{pla}_{i, t} & \text {, if } \Pi_{i, t} \leq 0
\end{array} .\right.
$$

The wealth after planned consumption is available to cover investment and recurrent costs of agricultural production. We define a minimum wealth level $W_{\min }$ that is always available to a household, assuming that the household can, if necessary, cover costs for consumption from a safety net (family, friends, etc. as a short term credit). Therefore the available resources for factor inputs and land-use change in year $t$ are

$$
W_{i, t e m p}:= \begin{cases}W_{i, t-1}-C \_ \text {plan }_{i, t} & , \text { if } W_{i, t-1}-C \_ \text {plan }_{i, t} \geq W_{\text {min }} \\ W_{\text {min }} & \text {, else }\end{cases}
$$

If the actual household wealth does not cover the planned consumption, the household temporarily takes up debts $D_{i, t, t e m p}$ of the amount

$$
D_{i, t, t e m p}:=C \_p_{\text {lan }}, t+W_{\text {min }}-W_{i, t-1} \quad .
$$

In each period $t$ each household decides on management of its household fields after reducing the wealth by the annual household's planned consumption (see Eq. B.14). This decision includes the decisions on factor inputs and land-use changes, which are taken simultaneously. It depends on the available capital for agricultural production $W_{i, t e m p}$.

Since we consider two possible land-use types (oil palm and rubber plantation), there are three possible options for each household field: to continue the actual land-use, to replant the actual land-use type or to change to the alternative land use. If a household has $u$ fields, the number of possible options is thus $3^{u}$. As the calculation of expected cash flows from different land-use options is the most time-consuming part of the model, we implemented two versions of this process: the "all-fields"-option, which allows the full number of options, i.e. in principal a change of land use in all fields of a household within one year, and a "one-fieldper-year"-option in which each household can change only one field per year. The latter reduces the number from $3^{u}$ to $3 u$. The option can be chosen on the GUI. For this paper, we apply the one-field-per-year option.

From the set of all options, only those are potentially possible, for which total investment costs (i.e. investment costs from all household fields within the next 
three years) as well as unavoidable recurrent costs in the current year can be covered by the actual wealth $W_{i, t e m p}$ (see Eq. B.17) while not falling under the minimum wealth level.

Let $o$ be an arbitrary option, $p_{k}$ the fields of the household $(k=1, \ldots g)$ and let $l_{k}$ be the intended land uses on these fields under option $o$. Let furthermore $m_{k}$ be the field sizes (i.e. number of cells in the field). The discounted total investment costs under the option $o$ within the next three years are

$$
{ }^{o} \text { Itot }_{i}:=\sum_{\text {household fields } p_{k}}\left(m_{p_{k}} \cdot \sum_{n=0}^{2} i \operatorname{cost}_{j_{p_{k}}, l_{p_{k}}, n_{t}+n} \cdot(1+r)^{n}\right),
$$

with $j_{p_{k}}$ a representative cell of field $p_{k}, l_{p_{k}}$ the intended land use on field $p_{k}, n_{t}$ the age of field $p_{k}$ at time $t$ and discount rate $r$.

Therefore, if

$$
W_{i, \text { temp }} \geq^{o} \text { Itot }_{i}+\underbrace{\sum_{\text {household cells } j}\left(r_{K} K_{n_{t, j}}^{*}+r_{L} \overline{L A}\right)}_{\text {unavoidable recurrent costs }}+W_{\text {min }},
$$

option $o$ can potentially be afforded by the household. This is a simplifying assumption as it neglects that a household could potentially cover the investment costs of the second and third year by the income in these years from other fields. If no option is affordable, the household chooses the "no change" option, i.e. all land uses remain the same and no replanting takes place.

The following steps are executed for each affordable option with the goal to choose the most profitable one.

In the current year $t$, investment costs due to the implementation of option $o$ are

$$
\sum_{\text {household fields } p_{k}} m_{p_{k}} \cdot \text { icost }_{j_{p_{k}}, l_{p_{k}}, n_{t}} .
$$

Therefore, if option $o$ is implemented, the remaining capital available for factor inputs in year $t$ is

$$
{ }^{o} W_{i, \text { rest }}:=W_{i, \text { temp }}-\sum_{\text {household fields } p_{k}} m_{p_{k}} \cdot i \operatorname{cost}_{j_{p_{k}}, l_{p_{k}}, n_{t}} \geq 0 .
$$


If the remaining capital ${ }^{o} W_{i, r e s t}$ is sufficient for optimal factor input on all fields, i.e. if

$$
{ }^{o} W_{i, \text { rest }} \geq \sum_{\text {household fields } p_{k}} m_{p_{k}} \cdot \operatorname{rcost}_{j_{p_{k}}, l_{p_{k}}, n_{t}}\left(L_{n_{t}}^{*}, K_{n_{t}}^{*}, T I_{n_{t}}^{*}, \overline{L A}\right)
$$

and no additional external constraints are existent, the household will apply optimal factor inputs to maximize production and profit from agricultural land use. If the remaining capital is not sufficient for optimal factor inputs, i.e.

$$
{ }^{o} W_{i, \text { rest }}<\sum_{\text {household fields } p_{k}} m_{p_{k}} \cdot \operatorname{rcost}_{j_{p_{k}}, l_{p_{k}}, n_{t}}\left(L_{n_{t}}^{*}, K_{n_{t}}^{*}, T I_{n_{t}}^{*}, \overline{L A}\right)
$$

factor inputs are reduced (see Paragraph Reduction of factor inputs). Net cash flow ${ }^{o} \Pi_{i, t}$ under option $o$ and actual factor inputs is calculated. The fictive household wealth under application of option $o$ is updated to

$$
{ }^{o} W_{i, t}=W_{i, t e m p}+{ }^{o} \Pi_{i, t}+\tilde{Y}
$$

with external household income $\tilde{Y}$.

To decide which of the affordable options should be chosen by the household, we calculate the expected cash flow from agricultural use within a certain time horizon $h$ for each potential option $o$. For this we also need to calculate the expected factor inputs during that time. As optimal factor inputs vary with plantation age and actual factor inputs depend on wealth, we need to simulate the wealth development of the household over the given time horizon. For this we assume, that within this period of $h$ years no more land-use changes occur.

Prices for input, output and labor are assumed to stay constant within the considered time horizon and at the level of prices in period $t$. Also the external income is assumed to stay the same as in year $t$. Household consumption for each year is calculated based on the expected wealth in the respective year. Let ${ }^{o} \Pi_{i, t}, \ldots,{ }^{o} \Pi_{i, t+h}$ be the expected net cash flows from agricultural use under option $o$ within the time horizon $h$. For each option $o$ the discounted accumulated expected cash flow is calculated as

$$
{ }^{o} \Pi \_ \text {expected }_{i}:=\sum_{j=0}^{h} \frac{{ }^{o} \Pi_{i, t+j}}{(1+r)^{j}},
$$

with discount rate $r$. The option with the maximal expected cash flow is then implemented. 


\section{Reduction of factor inputs}

In the case of Equation B.21 the household cannot afford optimal factor inputs if option $o$ is implemented. Therefore, factor inputs need to be reduced. However, Equation B.17 assures that the unavoidable rental costs for capital and land can be covered as

$$
{ }^{o} W_{i, \text { rest }} \geq \sum_{\text {household cells } j}\left(r_{K} K_{n_{t, j}}^{*}+r_{L} \overline{L A}\right)+W_{\text {min }} .
$$

We assume that costs for capital and land are fixed and only the input factors labor $L$ and technical input $T I$ can be reduced. The amount of available resources for factor input is

$$
{ }^{o} W_{i, F I}:={ }^{o} W_{i, r e s t}-\sum_{\text {household cells } j}\left(r_{K} K_{n_{t, j}}^{*}+r_{L} \overline{L A}\right)
$$

To determine on which fields factor inputs are reduced, the marginal loss for a representative cell $j_{m}$ of each household field $m$ is calculated. Factor inputs are reduced on the fields with lowest marginal losses, until all remaining capital is used.

The production of one unit of output less involves less labor and technical input and thus reduces the costs by an amount of cost_red. Since we apply a Leontief production function, each unit of production in a plantation of age $n$ involves factor inputs of $L_{n}^{*} / y_{n}^{*}$ of labor and $T I_{n}^{*} / y_{n}^{*}$ of technical input, where $L_{n}^{*}$ and $T I_{n}^{*}$ are the optimal factor inputs to produce the maximum output $y_{n}^{*}$ in a plantation of age $n$. Therefore, the optimal factor input for the production of $y_{n}^{*}-1$ output units on one cell is

$$
\left.\left(L_{n}^{*}-\frac{L_{n}^{*}}{y_{n}^{*}}, K_{n}^{*}, T I_{n}^{*}-\frac{T I_{n}^{*}}{y_{n}^{*}}, \overline{L A}\right)\right) .
$$

The cost reduction involved in producing one unit of output less on one cell is thus

$$
\begin{aligned}
\text { cost_red } & \left.=\operatorname{rcost}\left(L_{n}^{*}, K_{n}^{*}, T I_{n}^{*}, \overline{L A}\right)-\operatorname{rcost}\left(L_{n}^{*}-\frac{L_{n}^{*}}{y_{n}^{*}}, K_{n}^{*}, T I_{n}^{*}-\frac{T I_{n}^{*}}{y_{n}^{*}}, \overline{L A}\right)\right) \\
& =w \cdot \frac{L_{n}^{*}}{y_{n}^{*}}+p_{T I} \cdot \frac{T I_{n}^{*}}{y_{n}^{*}}
\end{aligned}
$$

with

$w$ : wage for one hour of work [US\$/h]

$p_{T I}$ : price for one unit of technical input [US\$ $/ \mathrm{kg}$ ]. 
The marginal loss (mloss) in net cash flow from cell $j$ under land use $l$ is thus

$$
\begin{aligned}
\text { mloss } & =\Pi c e l l_{j, t}\left(L_{n}^{*}, K_{n}^{*}, T I_{n}^{*}, \overline{L A}\right)-\Pi c e l l_{j, t}\left(L_{n}^{*}-\frac{L_{n}^{*}}{y_{n}^{*}}, K^{*}, T I_{n}^{*}-\frac{T I_{n}^{*}}{y_{n}^{*}}, \overline{L A}\right) \\
& =p_{l, t}-\text { cost_red }
\end{aligned}
$$

with

$p_{l, t}$ the revenue for one unit of production (= price [US\$/ton] of product of land use $l$ in year $t$.).

Those fields with high marginal losses should receive optimal factor input, if possible. Therefore factor inputs are determined starting with the field with the highest marginal loss. Let $p$ be the field with the highest marginal loss, $m$ be the number of cells in $p$ and $n_{p}$ the age of the plantation in field $p$.

If the remaining resources for factor inputs ${ }^{o} W_{i, F I}$ cover the costs for optimal input of labor and technical input on field $p$, i.e.

$$
{ }^{o} W_{i, F I} \geq m \cdot\left(w L_{n_{p}}^{*}+p_{T I} T I_{n_{p}}^{*}\right)
$$

this field will receive optimal factor input and ${ }^{o} W_{i, F I}$ is reduced by these costs:

$$
{ }^{o} W_{i, F I}:={ }^{o} W_{i, F I}-m \cdot\left(w L_{n_{p}}^{*}+p_{T I} T I_{n_{p}}^{*}\right) .
$$

This process is continued for the other household fields with decreasing marginal loss until the field is reached at which the remaining resources ${ }^{o} W_{i, F I}$ are not sufficient anymore to cover optimal factor inputs.

Let $q$ be this field of size $m_{q}$ and age $n_{q}$, where

$$
{ }^{o} W_{i, F I}<m_{q} \cdot\left(w L_{n_{q}}^{*}+p_{T I} T I_{n_{q}}^{*}\right) .
$$

As each unit of production involves labor and technical input costs of

$$
w \cdot \frac{L_{n_{q}}^{*}}{y_{n_{q}}^{*}}+p_{T I} \cdot \frac{T I_{n_{q}}^{*}}{y_{n_{q}}^{*}}
$$

the household can afford a production of

$$
f:={ }^{o} W_{i, F I} /\left(w \cdot \frac{L_{n_{q}}^{*}}{y_{n_{q}}^{*}}+p_{T I} \cdot \frac{T I_{n_{q}}^{*}}{y_{n_{q}}^{*}}\right)
$$


units. The factor inputs for labor and technical input on this field are thus

$$
f \cdot \frac{L_{n_{q}}^{*}}{y_{n_{q}}^{*}} \quad \text { and } \quad f \cdot \frac{T I_{n_{q}}^{*}}{y_{n_{q}}^{*}} .
$$

The remaining fields do not receive inputs of labor or technical inputs in this year.

At the end of this step, factor inputs for each household cell are known. Thus the profit from land use under option $o$ with these factor inputs can be calculated for each household cell and household wealth can be updated according to Equation B.22,

\section{Implementation of the land management decision}

Now it is clear which of the affordable options is implemented and also the factor inputs are known. Let $o$ be the chosen option, then the unavoidable costs in this year are potential investment costs as well as the recurrent costs for capital and land

$$
{ }^{o} \text { cost }_{u}:=\sum_{\text {household cellj }}\left({ }^{o} \text { icost }_{j}+r_{t} K_{j}+r_{L, t} \overline{L A}\right) .
$$

Similar to Equation B.14, these unavoidable costs are subtracted from the current wealth, respecting the minimum wealth level

$$
W_{i, \text { temp } 2}:= \begin{cases}W_{i, t e m p}-{ }^{o} \operatorname{cost} s_{u} & , \text { if } W_{i, t e m p}-{ }^{o} \operatorname{cost} s_{u} \geq W_{\min } \\ W_{\min } & , \text { else. }\end{cases}
$$

If the household needs to take up debts to assure the minimum wealth level, these debts amount to

$$
D_{i, t, t e m p 2}:={ }^{o} \operatorname{cost}_{j}+W_{\min }-W_{i, t e m p 2}
$$

Finally, the factor inputs of labor and technical inputs under option $o$ reduce the wealth

$$
W_{i, t e m p 3}:=W_{i, t e m p 2}-\left({ }^{o} \operatorname{cost}_{L, t}+{ }^{o} \operatorname{cost}_{T I, t}\right)
$$

with

${ }^{o} \operatorname{cost}_{L, t}$ costs for labor in year $t$ under option $o$,

${ }^{o} \operatorname{cost}_{T I, t}$ costs for technical inputs in year $t$ under option $o$.

Any debts a household gets into in the current year, e.g. due to consumption or due to unavoidable costs (see Eq. B.15 and B.37), are added to the potentially 
remaining debts from the previous year, and if possible, payed off at the end of the period, when cash flows are realized. Household debts in period $t$ before pay off are therefore

$$
D_{i, t e m p 3}:=D_{i, t-1}+D_{i, t, t e m p}+D_{i, t, t e m p 2}
$$

with

$D_{i, t-1}$ debts after pay off in period $t-1$.

Now the cash flow from the realized option $o$ as well as the external income are added to the household wealth and the cash flow dependent part of consumption is accounted for

$$
W_{i, t e m p 4}:=\left\{\begin{array}{l}
W_{i, t e m p 3}+(1-\beta)^{o} \Pi_{i, t}+\tilde{Y}_{i}, \text { if }{ }^{o} \Pi_{i, t}>0 \\
W_{i, t e m p 3}+{ }^{o} \Pi_{i, t}+\tilde{Y}_{i}, \text { if }{ }^{o} \Pi_{i, t} \leq 0
\end{array}\right.
$$

with

${ }^{o} \prod_{i, t}$ the cash flow in this year,

$\tilde{Y}_{i}$ : external income in year $t$,

$\beta$ the cash flow dependent fraction of consumption (see Eq. B.13).

Finally, the household pays off debts but respects the minimum wealth level. Therefore the household wealth which is available for the next year is

$$
W_{i, t}:=\left\{\begin{array}{l}
W_{i, t e m p 4}-D_{i, t, t e m p} \quad, \text { if } W_{i, t e m p 4}-D_{i, t, t e m p 3}>W_{m i n} \\
W_{m i n}, \text { if } W_{i, t e m p 4}-D_{i, t, t e m p 3} \leq W_{\min }
\end{array}\right.
$$

The household debts are updated accordingly to

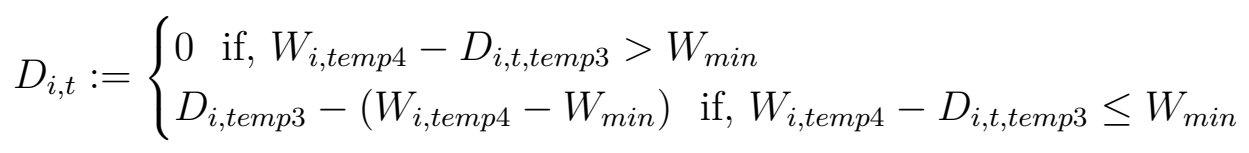

Households which do not manage to pay back debts within a certain period, i.e. $D_{i, t}>0$ for $D_{\max }$ consecutive years (see Table B.2), are assumed to be incapable of acting and are frozen in the model.

\section{Household inefficiency \& learning}

Depending on the parameterization of the model, households can have crop-specific heterogeneous inefficiency values for oilpalm and rubber (see Section B.2.3). The 
higher the inefficiency value of a specific land use type is, the lower is the realized yield, compared to the optimal production function (see Eq. B.2).

If "learning" is turned off, households inefficiency values do not change over time, assuming no diffusion of knowledge or spillover effects. However, if "learning" is turned on, households can improve their productivity by decreasing their inefficiency values over time. This follows the assumption, that social networks and interactions between households lead to improvements in farming efficiency. The creation of the social network is executed once during the initialization of the model. In the current model version, this social network is a static network and does not change over time. The model offers four options to create the social networks of households. (1) The network is created by connecting each household with its n-nearest-neighbors based on the road distances. This approach is deterministic and assuming all households are connected via the same road network, each household has the same number of connected households. However, the diffusion of information inside the network can still differ depending on the initial distribution of inefficiencies. (2) The network is created by connecting each household, with every household that can be reached within a specified road distance. This approach is deterministic and households are likely to be heterogeneous in numbers of connected households, depending on the spatial proximity to other households. (3) The network is created by using a negative exponential function, that serves to calculate household distance connectivity probabilities. The probability function is scaled to an estimated median household connectivity distance. Then, for each pair of two households that is connected via roads, the geographic distance via the road network is calculated. The two households are then connected, based on the distance specific connection probability, derived from the negative exponential household distance probability function. This approach is non-deterministic and households are likely to be heterogeneous in numbers of connected households. (4) The network is created by using the negative exponential function (3) in combination with a maximum distance bound (2).

Learning takes place at the beginning of each simulation step (see Fig. 3.2). Households are only allowed to improve inefficiencies for crops they currently cultivate. Furthermore, they can only learn from connected households that cultivate this crop as well. For each specific crop, each household calculates the mean of crop inefficiencies of connected households that fit the given requirements. The mean inefficiency of connected households for this crop type, represents the mean inefficiency of the households social network. If the household inefficiency for a specific crop type is higher than the mean inefficiency of its social network, the household can improve its inefficiency for that crop type. The level of improvement is calculated by multiplying the difference of household inefficiency and its social network inefficiency with the parameter "learning-diffusion-rate", that defines the 


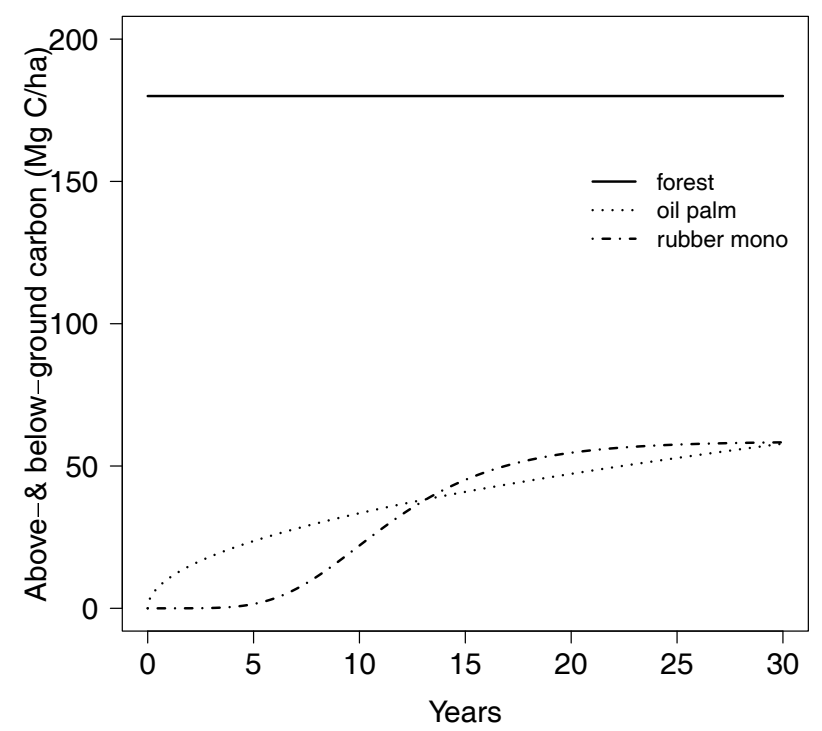

Figure B.1: Carbon stocks of different land-use types

speed of household adjustment, i.e. diffusion rate of the social network. If "learningdiffusion-rate" is set to 1 , all households immediately adjust to the mean inefficiency level of their social networks.

\section{B.1.3.2 Ecological model}

\section{Carbon storage}

For the calculation of carbon stored in the vegetation of oil palm plantations, we use a function of (GERMER and SAUERBORN, 2008), that estimates aboveground biomass (AGB) of oil palm plantations as a function of plantation age

$$
A G B_{\text {oilpalm }}(\text { age })\left[M g h a^{-1}\right]=18.95 * a g e^{0.5}
$$

Assuming a carbon content of $41.3 \%$ and a constant root-shoot ratio of 0.35 , i.e. $74 \%$ of total carbon is aboveground and $26 \%$ is below ground (SYAHRINUDin, 2005), we arrive at a vegetative carbon stock of

$$
\text { carbon }_{\text {oilpalm }}(\text { age })\left[M g h a^{-1}\right]=\left(18.95 * a g e^{0.5} \cdot 0.413\right) \cdot 1.35
$$

For rubber monoculture we apply the function for rubber trees in the Mato Grosso, Brazil from (WAUTERs et al., 2008)

$$
\operatorname{carbon}_{\text {rubbermono }}(\operatorname{age})\left[M g h a^{-1}\right]=58.609 * \exp (-13.696 * \exp (-0.264 * a g e))
$$


For forest we assign a constant carbon content (we do not consider the option of converting plantations into forest yet). A mean carbon stock value is derived from estimations of total biomass from plot data (KотоwsKA et al., 2015), applying a carbon content of $0.47 \%$ (default value for insular Asian tropical rainforests (IPCC, 2006).

$$
\text { carbon }_{\text {forest }}\left[M g h a^{-1}\right]=389 \cdot 0.47 \approx 180
$$

The resulting carbon stocks are shown in Figure B.1.

\section{B.2 Parameterization of the household submodel}

For the implementation of the Leontief production function, we consider the following economic functions: optimal production, optimal labor use, optimal amount of technical inputs, optimal capital stock, and the use of land. Apart from land, all economic functions depend on the age of the respective plantation. To derive these functions and their parameters we used data from a household survey in the province of Jambi, Sumatra (EulER et al., 2012, FAust et al., 2013). Jambi is the focus of the Collaborative Research Center EFForTS (Ecological and Socioeconomic Functions of Tropical Lowland Rainforest Transformation Systems (Sumatra, Indonesia)) which has started in 2012. Interdisciplinary research on social and economic dynamics has provided a household survey of 701 households, which include information such as households' land holdings, agricultural and non-agricultural activity, endowments and household composition (for more details see Euler et al., 2016b; Euler et al., 2017; Krishna et al., 2014; KrishnA et al., 2015). The survey represents a random sample out of 40 villages which in return are randomly chosen out of 5 regencies within the province of Jambi. The respective sample sizes per village are chosen proportionally to village size. Out of the household sample, we use information on the production of 246 oil palm farmers cultivating 385 oil palm fields and 579 rubber farmers cultivating 962 rubber fields. Drawing on the reported ages of plantations, the oil palm fields of oil palm farmers are between 0 and 23 years old and the rubber fields have an age between 0 and 45 years. This enables a data-based parametrization of the economic functions for these time spans. Since we do not assume a maximum plantation age in our model, we also need to extrapolate economic functions for plantation ages beyond the data. To derive the production function, we estimate optimal yield, labor and technical inputs. For the estimation of optimal yields we selected the $30 \%$ highest yielding fields per plantation age $(N=105$ for oil palm and $N=244$ for rubber $)$ (see Fig. B.2 (a) and (b)). Assuming that these fields are optimally managed, they were also used to derive model functions and parameters for optimal labor and technical input. 


\section{B.2.1 Production functions for oil palm and rubber}

\section{B.2.1.1 Optimal production}

Yields of the $30 \%$ highest yielding oil palm and rubber fields is presented in Figure B.2 (a,b). As an estimation of the optimal, i.e. maximal potential fresh fruit bunch production over palm age, we derived a function which reproduces the bunch production of the process-based PALMSIM model, which was validated against 13 sites in Indonesia and Malaysia (Hoffmann et al., 2014, see Fig. B.2 c). After the immature phase of three years, in which yield is zero, this function has a roughly exponential increasing phase, which is followed by a plateau and a decreasing yield phase. The applied function is

$$
\text { production }_{\text {oil palm }}(x)=\left\{\begin{array}{l}
0, \text { if } x \leq 2 \\
p_{o 1} \cdot \exp \left(p_{o 2} \cdot x\right), \text { if } 2<x \leq 7 \\
p_{o 3}, \text { if } 7<x \leq 11 \\
\max \left\{0, p_{o 4} \cdot x+p_{o 5}\right\}, \text { if } x>11
\end{array}\right.
$$

with parameters shown in Table B.2. As we do not assume a maximum plantation age in our model, this function is also used to extrapolate production for plantation ages beyond the data (see Fig. B.2 e).

For rubber, we estimated the potential yield from our data and used a parabola which reflects the limited life span of tapped rubber trees. As we are interested in the maximal possible yields, we require rather an envelope function above the data than a fit. Therefore, we shift the fitted function upwards so that $95 \%$ of the data from high yielding fields are under the curve (Fig. B.2 (d)). We fix the production of rubber in the first five years to zero. The resulting optimal production function for rubber is shown in Figure B.2 (f). The applied optimal production function for rubber is therefore

$$
\text { production }_{\text {rubber }}(x)=\left\{\begin{array}{l}
0, \text { if } x \leq 4 \\
\max \left\{0, p_{r 1} \cdot x^{2}+p_{r 2} \cdot x+p_{r 3}\right\}, \text { if } x>4
\end{array}\right.
$$

with parameters shown in Table B.2.

\section{B.2.1.2 Optimal labor input}

To estimate optimal labor use we draw on the labor data from the same $30 \%$ highest yielding fields per plantation age, but exclude data from the first three years for 

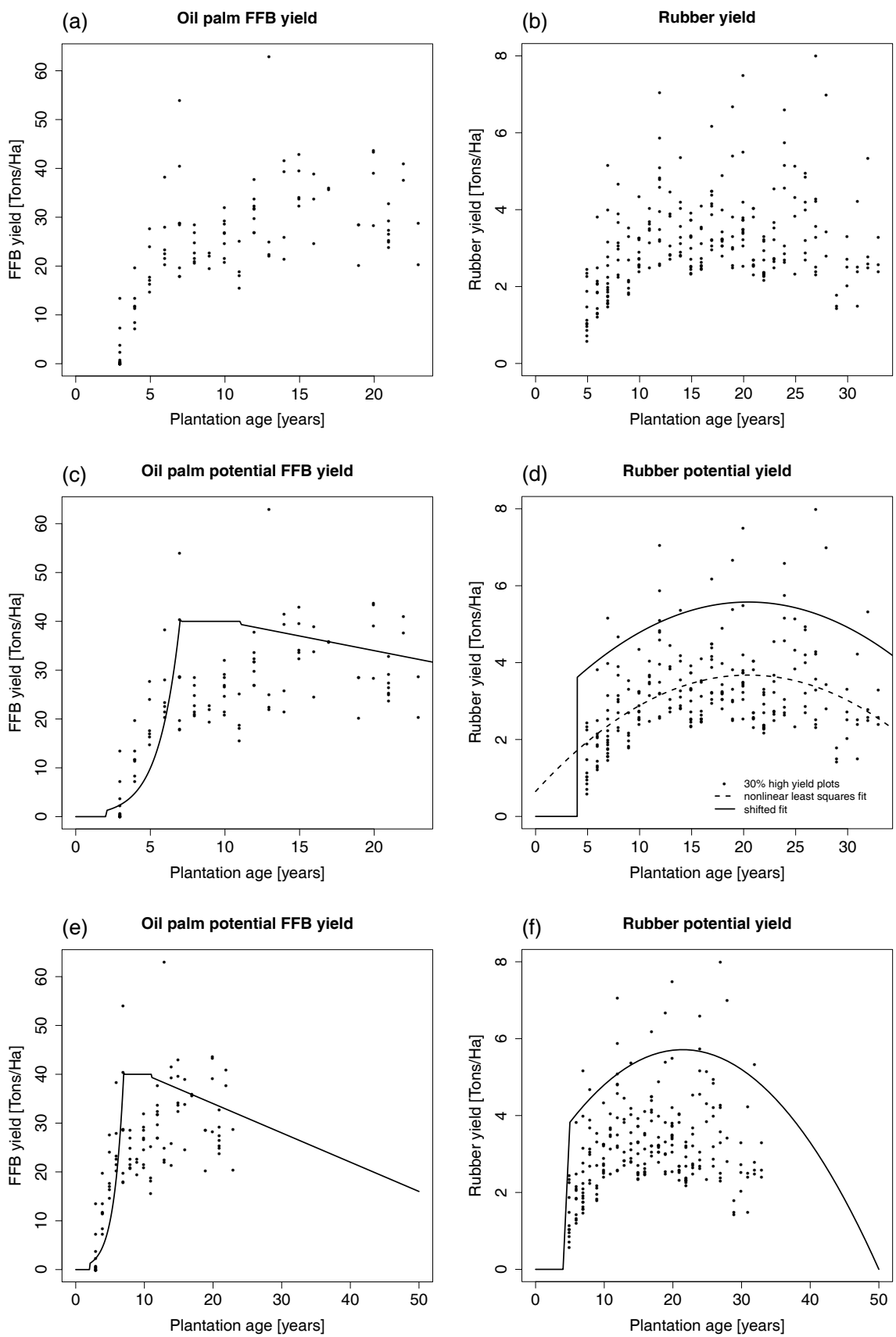

Figure B.2: (a) Production of oil palm fresh fruit bunches $[\mathrm{T} / \mathrm{Ha}]$ of the $30 \%$ highest yielding fields per plantation age. (b) Rubber production $[\mathrm{T} / \mathrm{Ha}]$ of the $30 \%$ highest yielding fields per plantation age. (c), (d) nonlinear least square fit to oil palm and rubber data, respectively, (dotted line) and upwards shifted fit (95\% of data under the curve). (e), (f) Optimal yield functions applied in the model (parameter values were rounded). 
Table B.2: Parameters of the economic household model related to the Leontief production function and costs.

\begin{tabular}{|c|c|c|c|c|c|c|}
\hline Category & $\begin{array}{l}\text { Land-use } \\
\text { type }\end{array}$ & Parameter & Unit & Meaning & Value & $\begin{array}{l}\text { Reference/ } \\
\text { Justifica- } \\
\text { tion }\end{array}$ \\
\hline \multirow[t]{10}{*}{ Production } & Oil palm & $p_{o 1}$ & {$[-]$} & $\begin{array}{lll}\begin{array}{l}\text { Scaling } \\
\text { phase) }\end{array} & \text { (exponential growth } \\
\end{array}$ & 0.3 & \\
\hline & & $p_{o 2}$ & {$[-]$} & $\begin{array}{l}\text { Exponent (exponential growth } \\
\text { phase) }\end{array}$ & 0.7 & \\
\hline & & $p_{o 3}$ & {$[\mathrm{~T}]$} & Plateau value (plateau phase) & 40 & $\begin{array}{l}\text { HOFFMANN et } \\
\text { al., } 2014\end{array}$ \\
\hline & & $p_{o 4}$ & {$[-]$} & Slope (decreasing phase) & -0.6 & \\
\hline & & $p_{o 5}$ & {$[\mathrm{~T}]$} & Intercept (decreasing phase) & 46 & \\
\hline & & $p_{o}$ & {$[\mathrm{USD} / \mathrm{ton}]$} & Price fresh fruit bunches & 90 & $\begin{array}{l}\text { Household } \\
\text { data }\end{array}$ \\
\hline & Rubber & $p_{r 1}$ & {$[-]$} & Quadratic parameter of parabola & -0.007 & $\begin{array}{l}\text { Household } \\
\text { data }\end{array}$ \\
\hline & & $p_{r 2}$ & {$[\mathrm{~T}]$} & Linear parameter of parabola & 0.3 & $\begin{array}{l}\text { Derived from } \\
\text { household } \\
\text { data }\end{array}$ \\
\hline & & $p_{r 3}$ & {$[-]$} & Constant parameter of parabola & 2.5 & \\
\hline & & $p_{r}$ & [USD/ton] & Price rubber & 1100 & $\begin{array}{l}\text { Household } \\
\text { data }\end{array}$ \\
\hline \multirow[t]{12}{*}{ Labour } & Oil palm & $l_{o 1}$ & {$[\mathrm{y}]$} & Breakpoint 1 & 5 & \\
\hline & & $l_{o 2}$ & [year] & Breakpoint 2 & 7 & \\
\hline & & $l_{o 3}$ & [year] & Breakpoint 3 & 25 & \\
\hline & & $l_{o 4}$ & [h/year] & Slope segment 1 & 100 & \\
\hline & & $l_{05}$ & [h/year] & Slope segment 2 & -80 & $\begin{array}{l}\text { Derived from } \\
\text { household } \\
\text { data }\end{array}$ \\
\hline & & $l_{o 6}$ & {$[\mathrm{~h} /$ year $]$} & Slope segment 3 & -0.8 & \\
\hline & & $l_{07}$ & [h] & Intercept segment 1 & -230 & \\
\hline & & $l_{08}$ & [h] & Intercept segment 2 & 690 & \\
\hline & & $l_{o 9}$ & [h] & Intercept segment 3 & 120 & \\
\hline & & $l_{o 10}$ & {$[\mathrm{~h}]$} & Plateau value (old plantations) & 1400 & Calibrated \\
\hline & Rubber & $l_{r 1}$ & [h/(ha year)] & $\begin{array}{l}\text { Labour input (plantation age }> \\
4)\end{array}$ & 700 & $\begin{array}{l}\text { Derived from } \\
\text { household } \\
\text { data }\end{array}$ \\
\hline & $\begin{array}{l}\text { All land- } \\
\text { use } \\
l\end{array}$ & $w_{l}$ & [USD/hour] & Wage & 1.6 & $\begin{array}{l}\text { Household } \\
\text { data }\end{array}$ \\
\hline \multirow[t]{3}{*}{$\begin{array}{l}\text { Technical } \\
\text { input }\end{array}$} & Oil palm & $t_{o 1}$ & $\begin{array}{l}{[\mathrm{kg} /(\mathrm{ha}} \\
\text { year })]\end{array}$ & Constant input mature phase & 740 & $\begin{array}{l}\text { Household } \\
\text { data }\end{array}$ \\
\hline & Rubber & $t_{r 1}$ & $\begin{array}{l}{[\mathrm{kg} /(\mathrm{ha}} \\
\text { year })]\end{array}$ & Constant input mature phase & 150 & $\begin{array}{l}\text { Household } \\
\text { data }\end{array}$ \\
\hline & $\begin{array}{l}\text { All land- } \\
\text { use types } \\
l\end{array}$ & $p_{T I}$ & {$[\mathrm{USD} / \mathrm{kg}]$} & Price technical input & 0.5 & $\begin{array}{l}\text { Household } \\
\text { data }\end{array}$ \\
\hline \multirow[t]{9}{*}{ Capital } & Oil palm & icost_totalo & {$[\mathrm{USD} / \mathrm{ha}]$} & $\begin{array}{lll}\text { Investment } & \text { costs } & \text { immature } \\
\text { phase } m & & \end{array}$ & $\begin{array}{ll}600 & 200 \\
150] & \end{array}$ & $\begin{array}{l}\text { Household } \\
\text { data }\end{array}$ \\
\hline & & $d_{o 2}$ & {$[-]$} & $\begin{array}{l}\text { Depreciation rate young planta- } \\
\text { tions }\end{array}$ & -0.1 & \\
\hline & & $d_{o 3}$ & {$[-]$} & Depreciation rate old plantations & 0.1 & Estimated \\
\hline & & $c_{o 4}$ & [year] & $\begin{array}{l}\text { Age in which depreciation rate } \\
\text { switches }\end{array}$ & 10 & \\
\hline & Rubber & icost_total $_{r}$ & {$[\mathrm{USD} / \mathrm{ha}]$} & $\begin{array}{l}\text { Investment } \quad \text { costs } \quad \text { immature } \\
\text { phase } m\end{array}$ & $\begin{array}{l}{\left[\begin{array}{lll}200 & 70 & 70 \\
70 & 70]\end{array}\right.}\end{array}$ & $\begin{array}{l}\text { Household } \\
\text { data }\end{array}$ \\
\hline & & $d_{r 2}$ & {$[-]$} & $\begin{array}{l}\text { Depreciation rate young planta- } \\
\text { tions }\end{array}$ & -0.05 & \\
\hline & & $d_{r 3}$ & {$[-]$} & Depreciation rate old plantations & 0.05 & Estimated \\
\hline & & $c_{r 4}$ & [year] & $\begin{array}{l}\text { Age in which depreciation rate } \\
\text { switches }\end{array}$ & 15 & \\
\hline & $\begin{array}{l}\text { All land- } \\
\text { use types }\end{array}$ & $r_{K}$ & {$[-]$} & Rental rate of capital & 0.1 & Estimated \\
\hline \multirow[t]{2}{*}{ Land } & $\begin{array}{l}\text { All land- } \\
\text { use types } \\
l\end{array}$ & $r_{L}$ & {$[-]$} & Rental rate of land & 0.1 & Estimated \\
\hline & & $p_{L}$ & {$[\mathrm{USD} / \mathrm{ha}]$} & Land price & 750 & $\begin{array}{l}\text { Household } \\
\text { data }\end{array}$ \\
\hline Debts & $\begin{array}{ll}\text { All } & \text { land- } \\
\text { use } & \text { types } \\
l & \end{array}$ & $D_{\max }$ & {$[-]$} & $\begin{array}{l}\text { Number of consecutive years } \\
\text { households in debt are frozen }\end{array}$ & 5 & Estimated \\
\hline
\end{tabular}

oil palm, and respectively the first five years for rubber, as we consider input of labor during this period as part of the investment. The data on labor comprise 
Table B.3: Parameters of the economic household model related to household wealth and consumption.

\begin{tabular}{llll}
\hline Parameter & Unit & Meaning & Value \\
\hline$W_{\min }$ & {$[\$]$} & Minimum wealth level & 30 \\
$D_{\max }$ & {$[$ year] } & Maximum number of consecutive debt years & 5 \\
$\tilde{Y}$ & {$[\$]$} & External annual household income (constant) & 500 \\
$\bar{C}$ & {$[\$]$} & Base consumption (subsistence level) & 1000 \\
$C_{W}$ & {$[-]$} & Consumption fraction of wealth & 0.05 \\
$C_{\pi}$ & {$[-]$} & Consumption fraction of net cash flow & 0.1 \\
\hline
\end{tabular}

operations such as land clearing, pits taking, seedling transportation, planting and replanting, manure and fertilizer application, chemical and manual weeding, harvesting, pruning and marketing. Working hours per hectare are accumulated for each best performing field. The data are very scattered for both land uses (see Fig. B.3 (a) and (b)). For oil palm an increase in labor after the plantation establishment phase followed by a slight decrease in labor input is apparent. We tested different relationships: a hump-shaped function

$$
l a b(x)=l_{1}+\frac{x}{l_{2}} \exp ^{-\frac{x}{l_{2}}},
$$

and a segmented linear regression with one and two breakpoints (Fig. B.3 (c)). An AIC comparison of the three fits resulted in the lowest AIC for the segmented linear regression with two breakpoints. We therefore apply this function in the model and set the optimal labor input for the first three years to zero. One critical aspect is the extrapolation of labor inputs beyond the age where data were available. Apparently one reason why oil palm plantations generally have a lifespan of $25-30$ years is that after that period, yields decrease and harvesting becomes very difficult as the trees reach a height in which the fruit bunches are difficult to harvest with the conventional pole method. Therefore, we assume a steep increase in labor costs when palms reach a height after which the conventional harvesting method with long sticks is not possible anymore (see also Corley and Tinker, $2008 \mathrm{p}$. 303 ff. and p. 318). As plantation cycles in our data end after about 25 years, we assume, that at this time, labor costs increase and result in plantations being unprofitable. We calibrate the amount of labor needed by assuming that at this point, the net cash flow is approximately zero, given optimal inputs and observed input and output prices. 
The optimal labor input function is therefore

$$
\text { labor }_{\text {oilpalm }}(x)=\left\{\begin{array}{l}
0, \text { if } x \leq 2 \\
l_{o 4} \cdot x+l_{o 7}, \text { if } x>2 \text { and } x \leq l_{o 1} \\
l_{o 5} \cdot x+l_{o 8}, \text { if } x>l_{o 1} \text { and } x \leq l_{o 2} \\
l_{o 6} \cdot x+l_{o 9}, \text { if } x>l_{o 2} \text { and } x \leq l_{o 3} \\
l_{o 10}, \text { if } x>l_{o 3}
\end{array}\right.
$$

with parameters shown in Table B.2 (see Fig. B.3 (e)).

For rubber, we tested a constant, linear and hump-shaped function (see Eq. B.49), with the AIC suggesting the hump-shaped curve (Fig. B.3 (d)). However, since there was no large difference between the fits and labor input in rubber plantations seems to be rather steady over the years (regular tapping, harvesting and weeding), we decided to choose the constant function for optimal labor input. Therefore the optimal labor input for rubber is

$$
\text { labor }_{\text {rubber }}(x)=\left\{\begin{array}{l}
0, \text { if } x \leq 4 \\
l_{r 1}, \text { if } x>4
\end{array}\right.
$$

with parameter in Table B.2 (see also Fig. B.3 (f)).

\section{B.2.1.3 Optimal technical input}

To estimate optimal technical input for both land uses, we use the data on technical inputs from the 30\% highest yielding fields per plantation age (see Fig. B.4 (a) and (b)). As for labor, technical input in the immature phase of the plantation are considered as part of the investment. The data on technical inputs refer to seedlings, plant and animal waste, soil amendments, fertilizer, herbicides, machinery and input and output transportation (measured in fuel). Except seedlings, quantities of inputs are generally measured in liters per hectare and are also accumulated for each best performing field. Seedlings are plausibly assumed to have a weight of 1 kilogram. The data on technical inputs are very scattered for both land uses. For oil palm, the data suggest an increase in technical inputs over time, while the inputs for rubber seem quite uniform. For both land-use types we tested a linear and a constant relationship.

The resulting fits are shown in Figure B.4 (c,d). For oil palm, although the AIC comparison suggests the linear increase, we decide for the constant relationship as the linear fit results in unrealistically high technical input when extrapolated for old plantations. Also fertilizer recommendations for oil palm plantations typically 

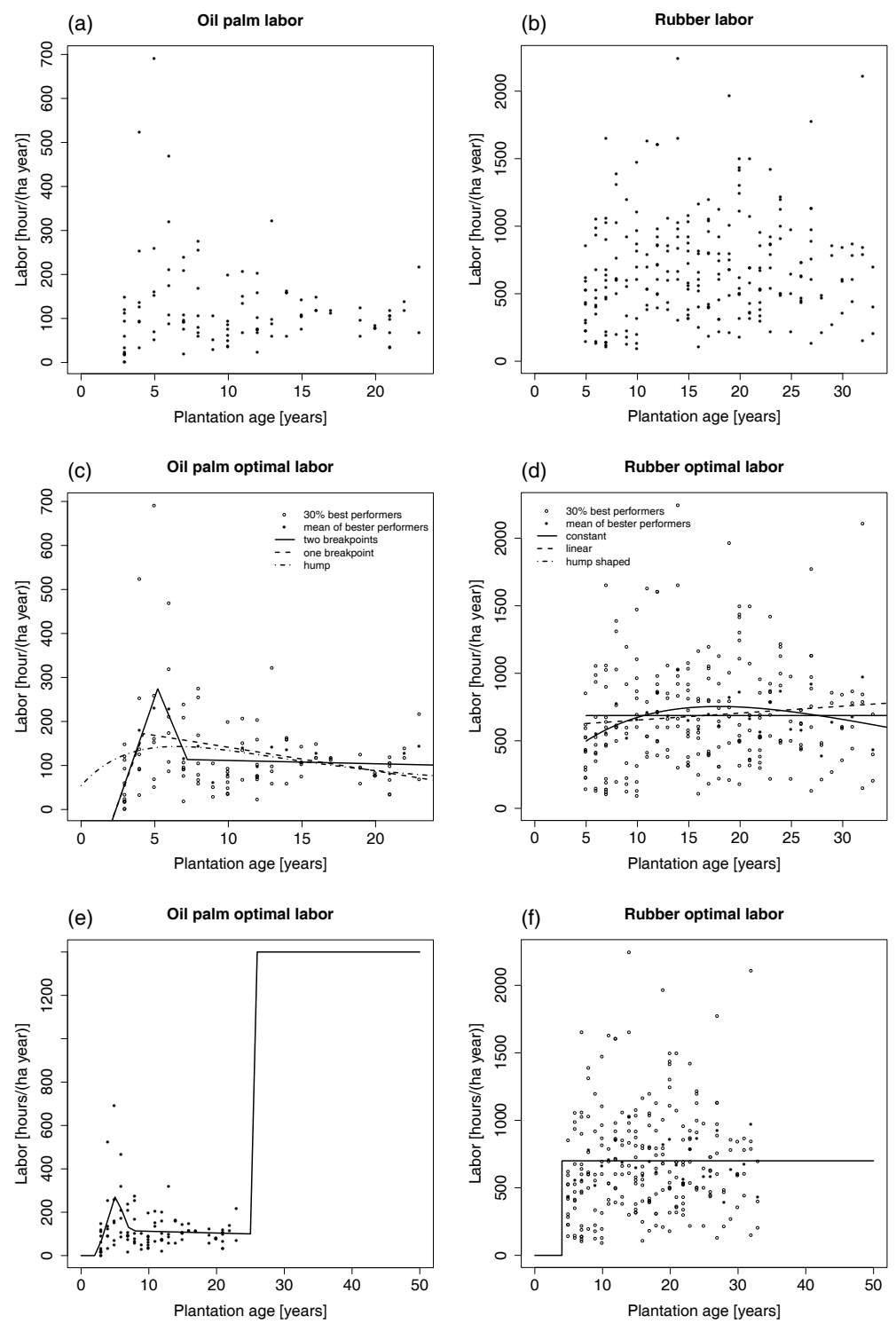

Figure B.3: (a) Labor input for oil palm [h/(Ha year)] of the $30 \%$ highest production fields per plantation age. (b) Labor input for rubber [h/(Ha year)] of the $30 \%$ highest production fields per plantation age. (c) Different fits to the data: Segmented linear regressions with one and two breakpoints and a hump-shaped function of the form Equation B.49. AIC results: 1257.5 (two breakpoints) < 1264.2 (one breakpoint) < 1271.5 (humped shape). (d) Different fits to the data: Constant labor input, linear regression and a hump-shaped function of the form Equation B.49. AIC results: 3596.9 (hump shaped) < 3600.9 (linear) < 3601.4 (constant). (e), (f) optimal labor function applied in the model (parameter values were rounded). 
suggest a two-level fertilization scheme and differentiate only between immature and mature plantation phase (COMTE et al., 2012). Figure B.4 (e) shows the applied relationship for optimal technical inputs, where inputs for the first three years are set to zero. The optimal technical input function is therefore

$$
\text { tinput }_{\text {oilpalm }}(x)=\left\{\begin{array}{l}
0, \text { if } x \leq 2 \\
t_{o 1}, \text { if } x>2
\end{array}\right.
$$

with parameters shown in Table B.2.

For rubber we compared a linear regression with constant technical inputs and decide for the constant function which is also suggested by AIC. The applied relationship for optimal technical inputs in rubber is therefore

$$
\text { tinput }_{\text {rubber }}(x)=\left\{\begin{array}{l}
0, \text { if } x \leq 4 \\
t_{r 1}, \text { if } x>4
\end{array}\right.
$$

with parameter in Table B.2 (see also Fig. B.4 (f)).

\section{B.2.1.4 Optimal capital input}

The optimal capital input over time represents the capital stock of an oil palm or rubber plantation, i.e. the accumulated, discounted investment costs (see Paragraph Production function, cash flows and capital accumulation in Section B.1.3.1). During the immature period $m$ of plantations we regard all labor costs and costs for technical inputs as investment costs. The accumulated value of costs for labor and technical inputs in this period are considered as total establishing costs of the plantation. All costs have been also derived from the household survey.

capstock $_{\text {oilpalm }}(x)=\left\{\begin{array}{l}\text { capstock }_{\text {oilpalm }, x-1 *\left(1+d_{o 2}\right)+\text { icost_total }_{o_{x, m}},}, \text { if } x \leq c_{o 4} \\ \text { capstock }_{\text {oilpalm, } x-1} *\left(1+d_{o 3}\right)+\text { icost_total }_{o_{x, m}}, \text { if } x>c_{o 4}\end{array}\right.$

capstock $_{r u b b e r}(x)=\left\{\begin{array}{l}\text { capstock }_{r u b b e r, x-1} *\left(1+d_{r 2}\right)+i \text { cost_total } \\ \text { capstock }_{r_{x u b b e r, x-1}} *\left(1+d_{r 3}\right)+i \text { if } x \leq c_{r 4} \\ \text { total } l_{r_{x, m}}, \text { if } x>c_{r 4}\end{array}\right.$

As investment costs for labor we include costs for the operations land clearing, pits taking, seedling transportation, planting and replanting, manure and fertilizer application, chemical and manual weeding, harvesting, pruning and marketing. Due 

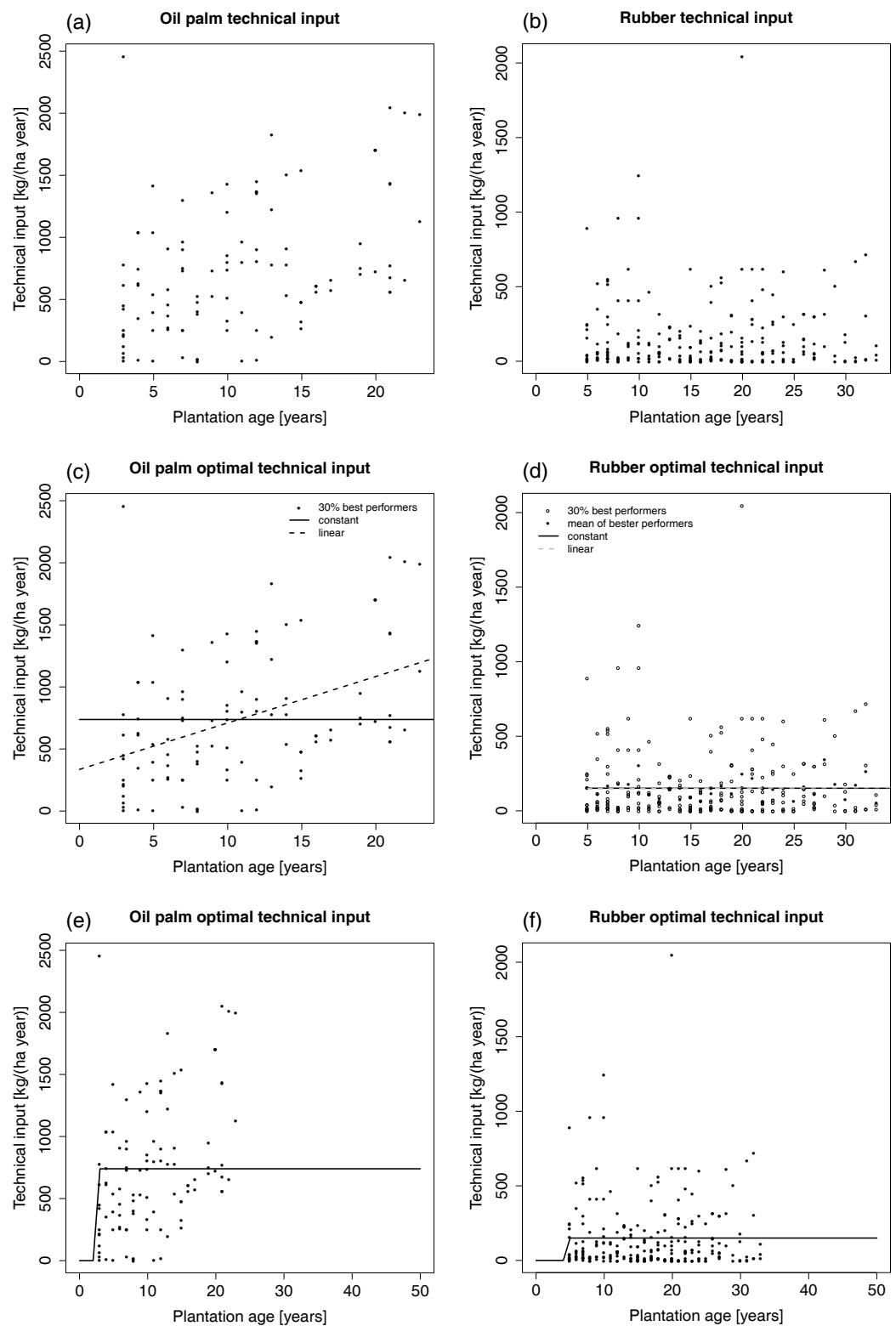

Figure B.4: (a) Technical input in oil palm plantations $[\mathrm{Kg} /(\mathrm{Ha}$ Year $)]$ of the $30 \%$ highest production fields per plantation age. (b) Technical input in rubber plantations $[\mathrm{Kg} /(\mathrm{Ha}$ Year $)]$ of the $30 \%$ highest production fields per plantation age.(c) Different fits: exponential increase (continuous line), linear (dashed) and power law (dotted). AIC comparison: 1600.2 (exponential) $<1601.3$ (linear) $<$ 1602.9 (power law). (d) Different fits: constant function (continuous line) and linear regression (dashed). AIC comparison: 3358.7 (constant) < 3360.7 (linear). (e), (f) optimal technical input function applied in the model (parameter values were rounded). 

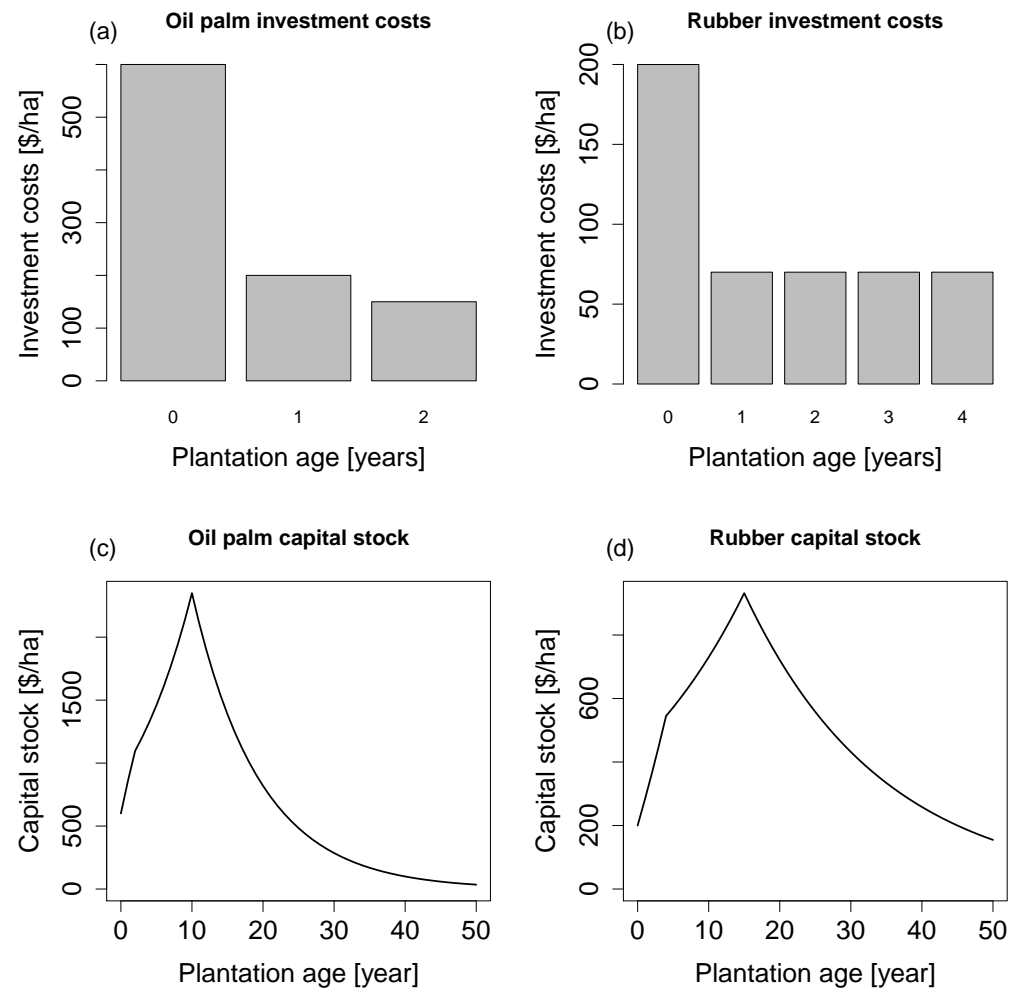

Figure B.5: (a) Investment costs $[\$ / \mathrm{Ha}]$ for the first three years of an oil palm plantation. (b) Investment costs $[\$ / \mathrm{Ha}]$ for the first five years of a rubber plantation. As there was no large difference between the years 1 and 4, we apply the average of these years. (c), (d) Capital stocks over time.

to the high variance within the data on labor use, all labor costs per operation are calculated in multiplying the median hours of work per operation with the mean value of wages per operation. We also include costs for out-contracted labor. The costs for technical inputs are calculated in multiplying the idiosyncratic prices of inputs with the respective quantities of inputs. The respective inputs are seedlings, plant and animal waste, soil amendments, fertilizer, herbicides, machinery and input and output transportation. The resulting investment costs during the immature phase are shown in Figure B.5 (a) and (b). As described in Paragraph Production function, cash flows and capital accumulation in Section B.1.3.1, we assume a positive depreciation rate, i.e. increasing capital stocks in young plantations, and afterwards a negative depreciation rate, i.e. decreasing capital stocks. All parameters concerning capital costs in oil palm and rubber plantations are given in Table B.2. The resulting optimal capital inputs for the Leontief production function are shown in Figure B.5 (c) and (d). 


\section{B.2.1.5 Optimal land input}

Since we always calculate the Leontief production function based on a cell, the input for land is fixed to the cell size, in this case to $0.25 \mathrm{ha}$.

\section{B.2.2 Costs, revenue \& Cash flow}

(a) Labor costs

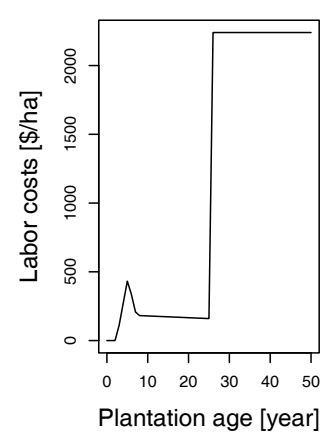

(d) Capital costs

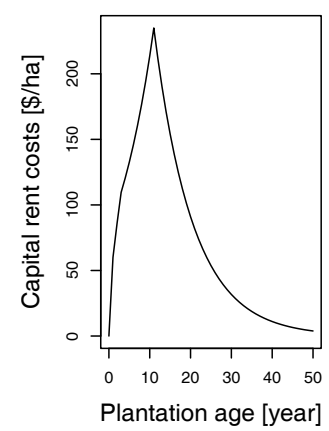

(b) Technical input

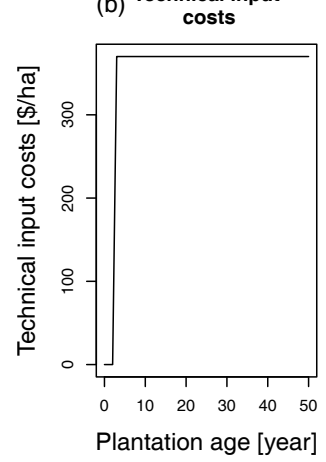

(e) Land rental cost

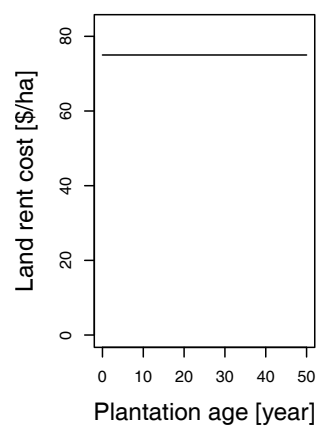

(c) Investment

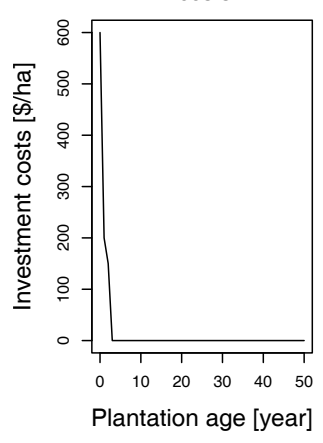

(f) Recurrent costs

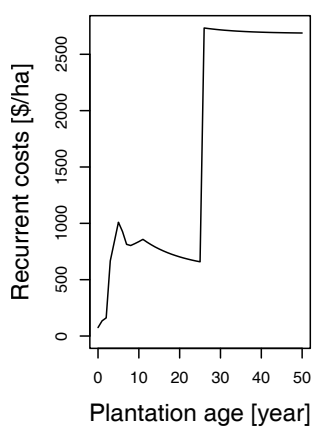

Figure B.6: Overview of the different cost functions for oil palm over plantation age under optimal production inputs. Recurrent costs are the sum of labor, technical input, capital and land rental costs.

For the calculation of the different costs occurring in plantation agriculture over time, we use the household data to derive mean values for wages, prices of technical inputs and prices of land. We also include a price for capital, which captures the opportunity costs of capital referring to a rental rate of capital. Prices of fresh oil palm fruit bunches and rubber are also derived from the household survey (see Table B.2). 
All data are calculated as mean values over all fields considering only the mature period after the first three or five years for oil palm and rubber, respectively. To receive the final mean value for wage measured in hours, we first calculate the average wage per day (per operation), which is divided by the average numbers of working hours (per operation). The kinds of operation we considered are land clearing, pits taking, seedling transport, replanting, manure and fertilizer application, chemical and manual weeding, harvesting, cutting leaves, marketing, intercultural operations and irrigation. From all mean wages per operations we took a final mean. For calculating the overall mean price of technical inputs, we consider only the most applied and widely representative technical inputs used in the survey, which are fertilizer and herbicides. For each input the mean price and quantity is calculated. To generate a final price and quantity, we weight the final quantities of fertilizer and herbicides with the respective mean price and divide them by the sum of both quantities.

(a) Labor costs

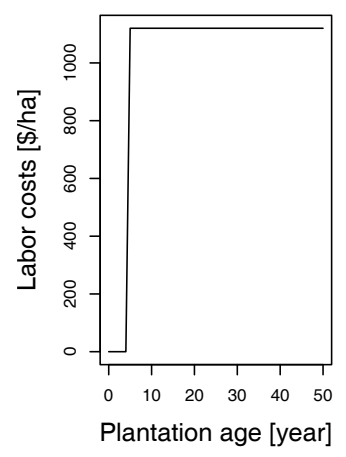

(d) Capital costs

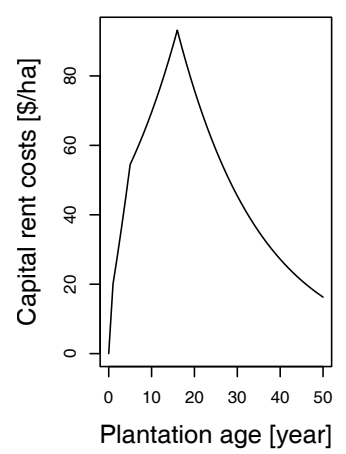

(b) Technical input

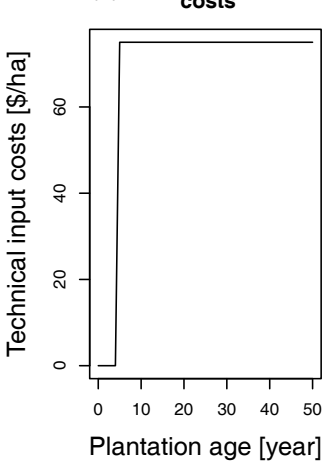

(e) Land rental cost

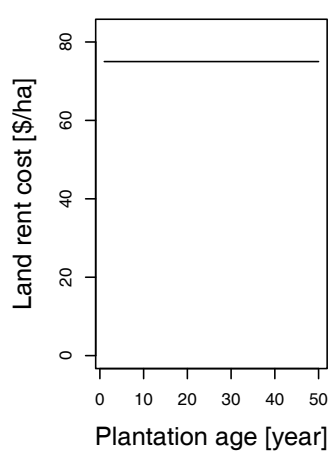

(c) Investment

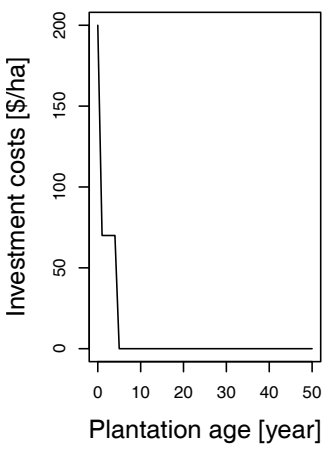

(f) Recurrent costs

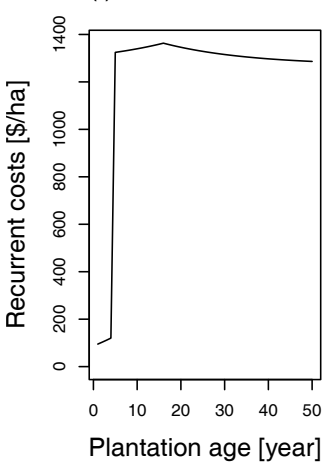

Figure B.7: Overview of the different cost functions for rubber over plantation age under optimal production inputs. Recurrent costs are the sum of labor, technical input, capital and land rental costs. 
The rental rates for capital $\left(r_{K}\right)$ and land $\left(r_{l}\right)$ (see Table B.2) are calculated as the average interest rate for informal and formal credits reported in the household survey. The price for land $\left(p_{l}\right)$ captures the average price for land per hectare, which has been sold between 2009 to 2012 (see Table B.2). Applying theses factors to the optimal factor inputs derived in Section B.2.1, we arrive at costs over the plantation lifetime presented in Figure B.6 (oil palm) and Figure B.7 (rubber).

(a)

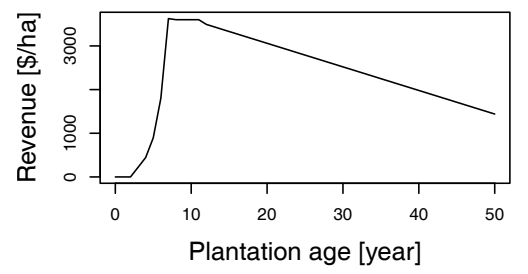

(c) Expected accumulated cash flow

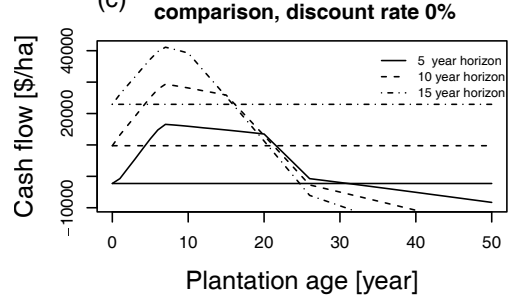

(e) Expected accumulated cash flow

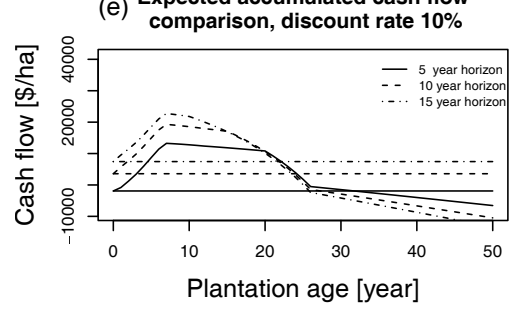

(b) Net cash flow

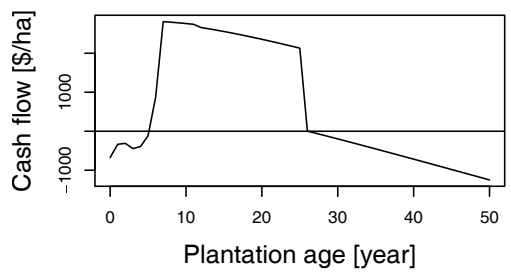

(d) Expected accumulated cash flow

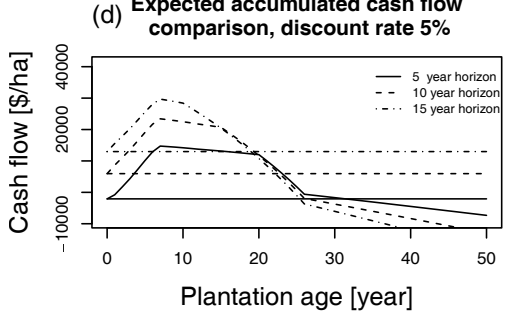

Figure B.8: (a, b) Annual revenue and net cash flow of an oil palm plantation under optimal production inputs. (c), (d) and (e) Comparison of expected net cash flow of existing plantations (curves) with expected net cash flows from a newly established plantation (straight lines) under different planning horizons $(5,10,15$ years). Different fields represent different levels of discount rates $(0,0.05$ and 0.1 , respectively). The second intersection of each pair of lines marks the plantation age, in which replanting becomes the more profitable option.

Applying the average farm-gate prices as an example, we arrive at revenues and net cash flows shown in Figure B.8 (a,b) and Figure B.9 (a,b). Finally, Figure B.8 (c,d,e) and Figure B.9 (c,d,e) depict expected cash flows over the plantation lifetime (curves), as well as the expected cash flow for newly established plantations (straight 
lines). These expected cash flows are used in the model to compare different landuse change options (see Paragraph Decision on land-use change and production in Section B.1.3.1).
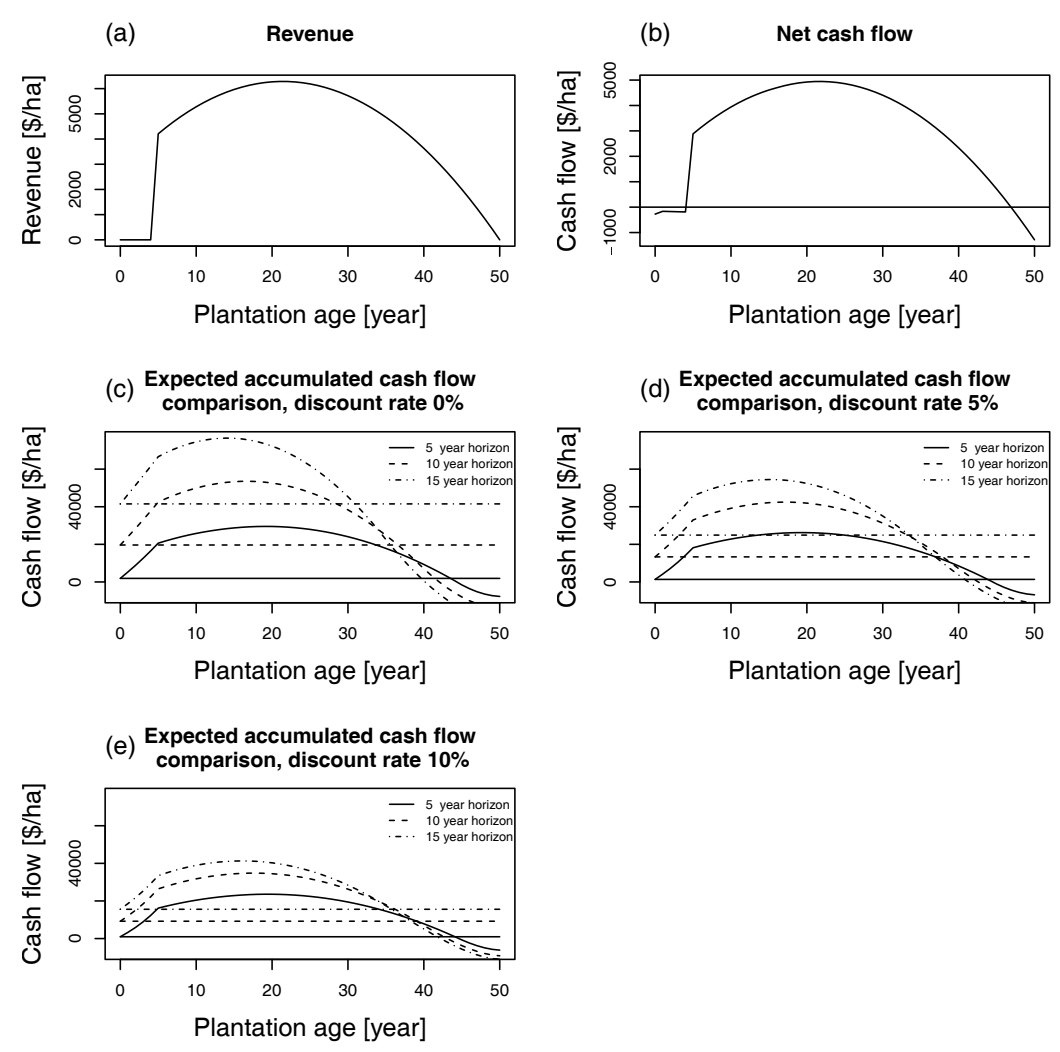

Figure B.9: $(\mathrm{a}, \mathrm{b})$ Annual revenue and net cash flow of a rubber plantation under optimal production inputs. (c), (d) and (e) Comparison of expected net cash flow of existing plantations (curves) with expected net cash flows from a newly established plantation (straight lines) under different planning horizons $(5,10,15$ years). Different fields represent different levels of discount rates $(0,0.05$ and 0.1 , respectively). The second intersection of each pair of lines marks the plantation age, in which replanting becomes the more profitable option.

The accumulated expected net cash flow for newly established plantations over different time horizons and different price scenarios is shown in Figure B.10. With the applied prices for oil palm fresh fruit bunches and rubber, rubber is the more profitable option, independent of the time horizon considered (Fig. B.10 (a)). However, if the price relation between oil palm and rubber changes, e.g. with considerably lower prices for rubber, the profitability can depend on the considered time horizon (Fig. B.10 (b)). 

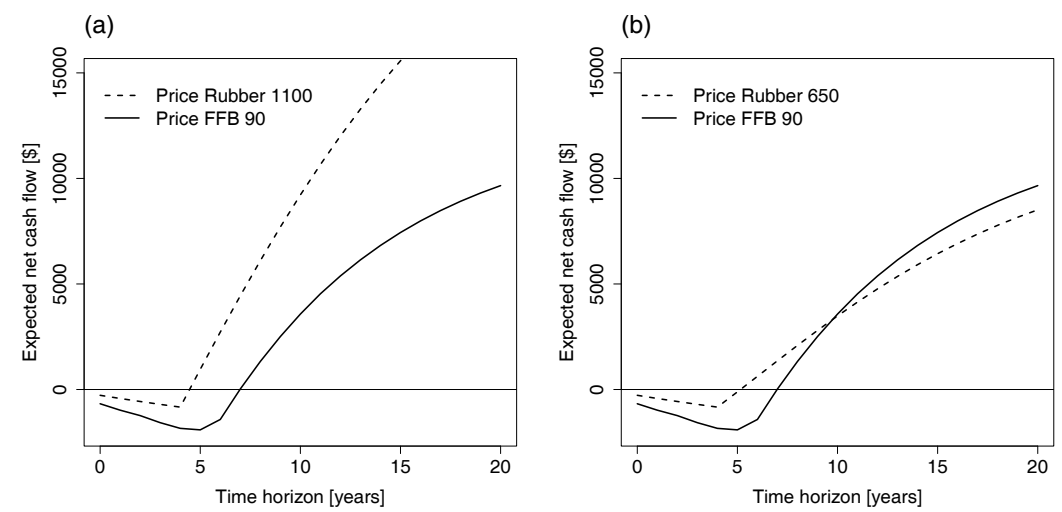

Figure B.10: Accumulated expected net cash flows with discount rate of 0.1 for newly established oil palm and rubber plantations under different time horizons.

(a) Prices for fresh fruit bunches FFB and rubber as derived from household data.

(b) Hypothetical lower price for rubber.

\section{B.2.3 Initial household inefficiency distribution}
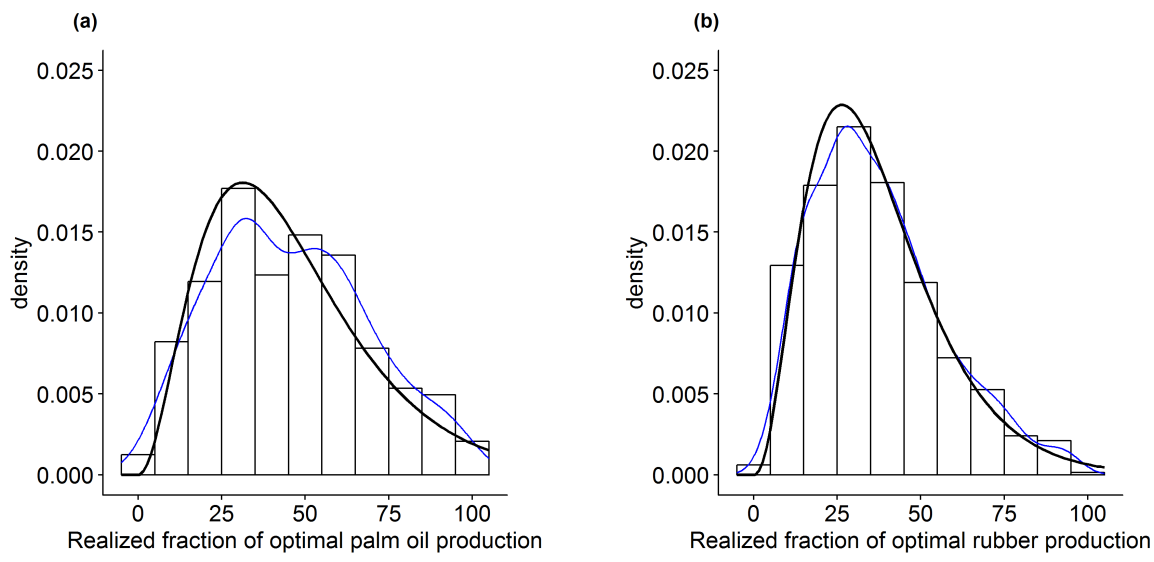

Figure B.11: Oilpalm (a) and Rubber (b) efficiency distribution of survey households, calculated as realized fraction of optimal production. Bars show densities of efficiency classes, the blue line shows the density function, the black line shows the gamma distribution fit used for model initialization. The gamma distribution fit parameters are $\alpha=3.168$ and $\lambda=0.069$ for oilpalm efficiencies (a) and $\alpha=3.445$ and $\lambda=0.093$ for rubber efficiencies (b).

Yield data from the household survey were used to initialize the crop-specific inefficiencies of all households in the model (Fig. B.2). The unrealized fractions of the optimal production functions (yield gaps) of each household and crop-type 
were calculated. In order to distribute these inefficiencies to the model households, different distribution functions were fitted against these inefficiency distributions of household survey data. The histogram of resulting inefficiencies of households was slightly left-skewed, which resulted in a bad fit for the normal distribution. The issue was resolved by inverting the inefficiencies to efficiencies $\left(1-\delta_{i, l}\right)$ which resulted in a right-skewed distribution, and performing a gamma distribution fit (see Fig. B.11). These gamma distributions were then implemented in the model to distribute initial inefficiencies for oil palm and rubber by drawing random numbers from the corresponding distribution and inverting these values back to inefficiencies. Because the initial model households do already own differing numbers of oil palm and rubber fields, we additionally coupled the distribution of these two crop inefficiencies to prevent households from heaving a higher inefficiency for the crop type they currently cultivate at a larger proportion. To this end, during model initialization, each model household draws one inefficiency value from each gamma distribution. These values are only taken, if the crop type of the distribution with the lower inefficiency corresponds to the crop type the households cultivates at a larger proportion. Otherwise, a new pair of inefficiencies is drawn until these requirements are fulfilled. Households with equal proportions of both crop types draw inefficiencies from the gamma distribution without the need to fulfill any of these requirements.

\section{B.2.4 Initial household wealth}

For the estimation of initial household wealth we use data on assets purchased by households between 2000 and 2012 from the household survey. Asset categories included for example cellphones, television, satellite dishes, motorbikes and cars, fridges and washing machines. Figure B.12 shows the histogram of the cumulative value of purchased assets to which we fitted a log-normal distribution. We use this distribution as a proxy for household wealth. Since these purchased assets represent only a fraction of household wealth, we multiply the drawn values with a scaling factor (in this case 10), to obtain the initial values for household wealth.

\section{B.2.5 Price dynamics}

All farmers are assumed to receive the same price for the same crop. These prices are related to world market prices of the respective crops, but additionally we used information on price transmission from survey data. Farm-gate prices are considerably lower than world market prices mainly because of trade and transport margins. Average farm gate prices received by smallholders were $885 \mathrm{IDR} / \mathrm{kg}$ (about USD 0.09) of fresh fruit bunches for oil palm and $10412 \mathrm{IDR} / \mathrm{kg}$ (about USD 1.10) for rubber in the final quarter of 2012 (with an exchange rate of 9500 


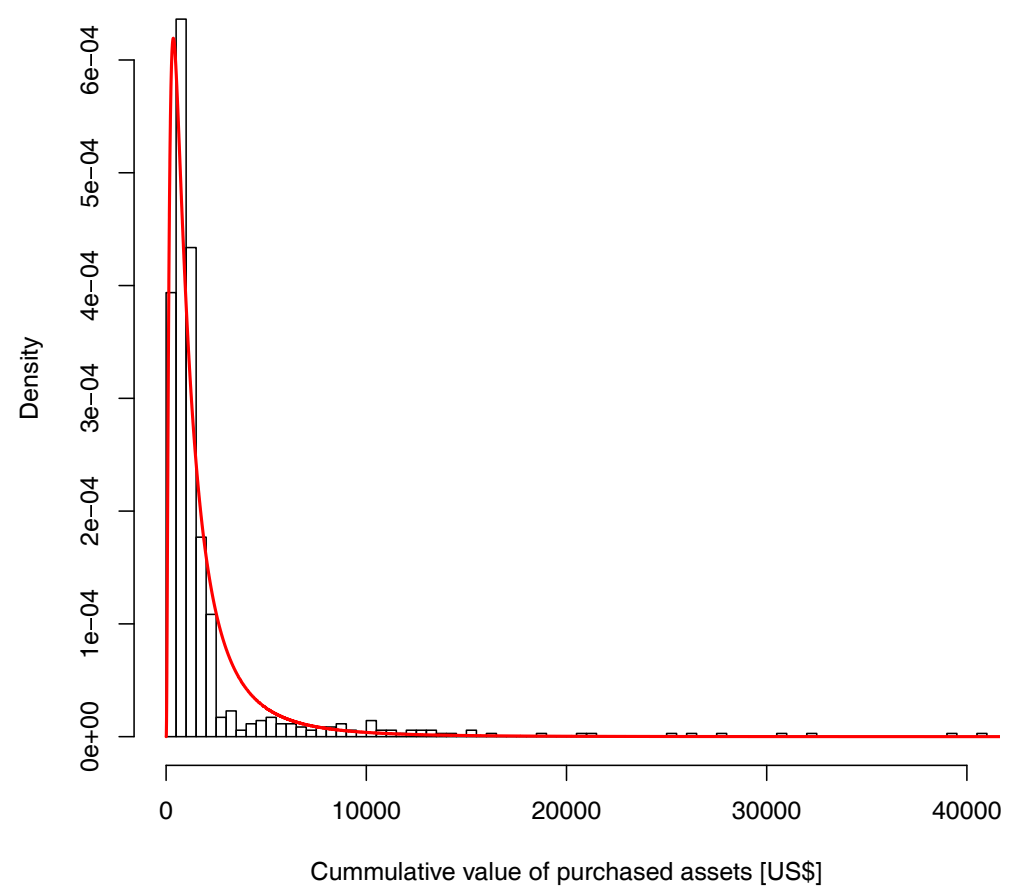

Figure B.12: Histogram of cumulative value of purchased assets by households between 2000 and 2012 .

IDR/USD) see (EULER et al., 2016b). The world market price for rubber at that time was about $3.20 \mathrm{USD} / \mathrm{kg}$; in April 2015 it had declined to $1.71 \mathrm{USD} / \mathrm{kg}$. For palm oil, the prices of which cannot be readily compared to the price for fresh fruit bunches, prices also declined, but the decline was less pronounced; from 768 USD/metric ton in 10/2012 to 592 USD/metric ton in 04/2015 (all international price data from the World Bank).

Different options for price dynamics are implemented in the model and can be chosen from the GUI. Prices can be kept constant, or variable around the initial prices with a specifiable range of variation ("price-fluctuation-\%"). In the latter case, the annual price variation is drawn from a uniform distribution. Prices can also be chosen as correlated, again with a specifiable variation. In this case the price for the next year is calculated based on the current price with the variation again drawn from a uniform distribution. Fourth, prices can be chosen to follow a Gaussian random walk with crop-specific mean and standard deviation. For example, if $p_{n}$ is the price per harvested ton fresh fruit bunches in year $n$, the price for the following year is determined as

$$
p_{n+1}=p_{n}+r(\mu, \sigma)
$$




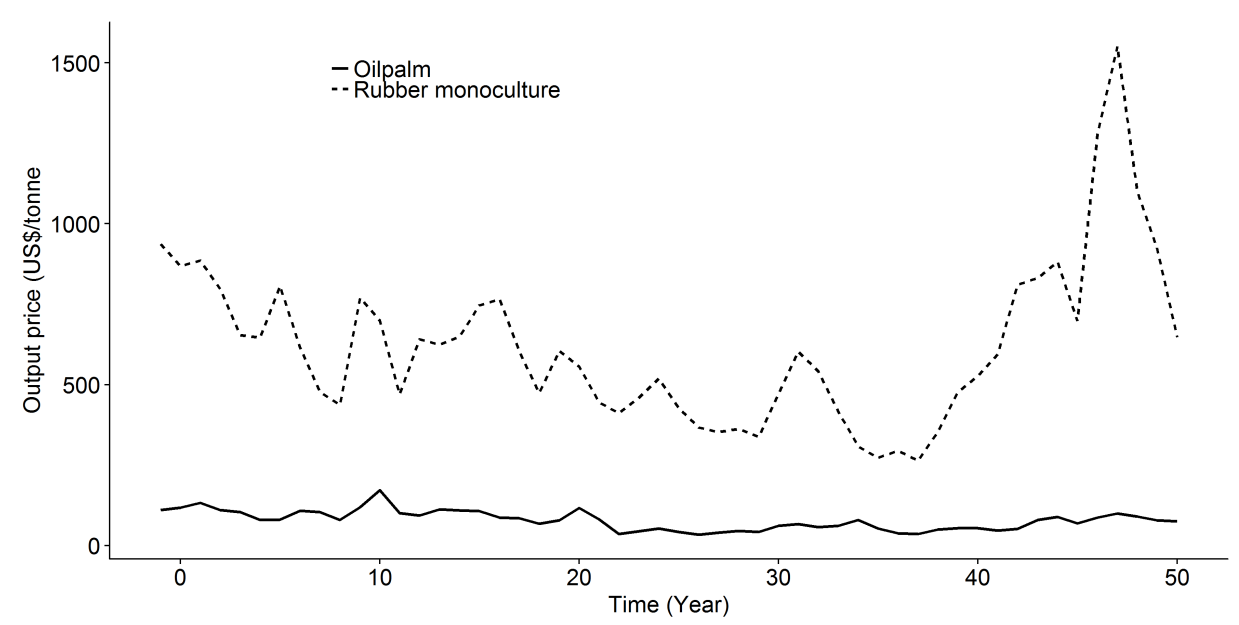

Figure B.13: Prices for rubber and oil palm for each simulation year when running the model with historical price trends. The values for years 0-50 are adjusted from World Bank data for the corresponding years in the range 1963-2013.

where $r$ is a normally distributed random variable with mean $\mu$ and standard deviation $\sigma$. While $\mu$ determines the expected slope of the price function, $\sigma$ determines price volatility. Finally, prices can be set to follow trends based on nominal annual prices in the World Bank Commodity Price Data, using "Palm oil" for oil palm produce and "Rubber, TSR20" for rubber produce. The prices are adjusted using a land-use-specific multiplication factor so that the prices for 2012 match the farm-gate prices actually observed (and also used in the constant price scenario; see Table B.2 and Figure B.13.

The first analyses in this paper focus on basic model dynamics, so we apply the constant price option. In the second set of analyses we are interested in simulating real trends, and hence we choose the historical trends option.

\section{B.3 EFForTS-LGraf: Landscape generator}

The landscape generator EFForTS-LGraf is an extended version of the simple process-based landscape generator G-RaFFe (PE'ER et al., 2013), which originally simulates the extension of fields from roads and creates binary maps with forest- and non-forest cells. For our purpose we added different land uses and households as an intermediate level between fields and landscape (Details, see Chapter 2). Households can own several fields of different sizes with different land uses. Household locations are always close to roads. For the creation of maps for model initialization, we used a section of a real road map from the Jambi region. Main input parameters 
for the landscape generator are the density of farming households, the distribution of household sizes, the distribution of field sizes, and the fraction of the different land uses.

\section{B.3.1 Parametrization of EFForTS-LGraf}

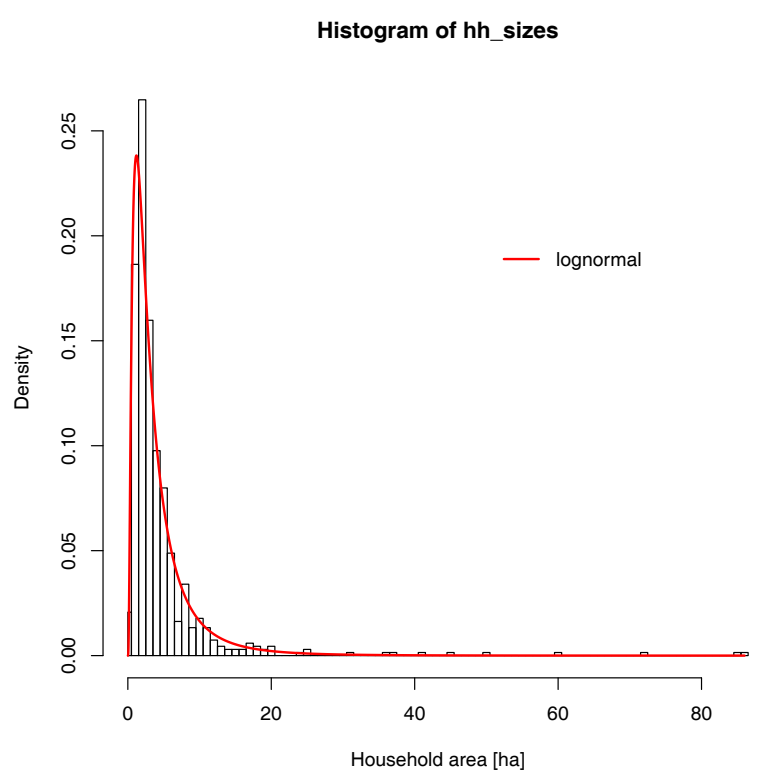

Figure B.14: Histogram of household sizes with maximum likelihood fit of the log-normal distribution.

\section{B.3.1.1 Household sizes}

We use data from a household survey (701 households, (EulER et al., 2012; FAUsT et al., 2013)) to determine the distribution of household sizes (= total area available for agricultural use). We scaled the histogram of household sizes to $[0,1]$ and fitted the density functions of a log-normal distribution to the data (see Fig. B.14) using maximum likelihood fitting (function fitdistr of the package MASS in the statistics software R). The resulting parameters for mean and standard deviation of household area are presented in Table B.1. Within the landscape generator, household sizes are determined by drawing a random number from the log-normal density function and rounding for the cell resolution (0.25 ha). 


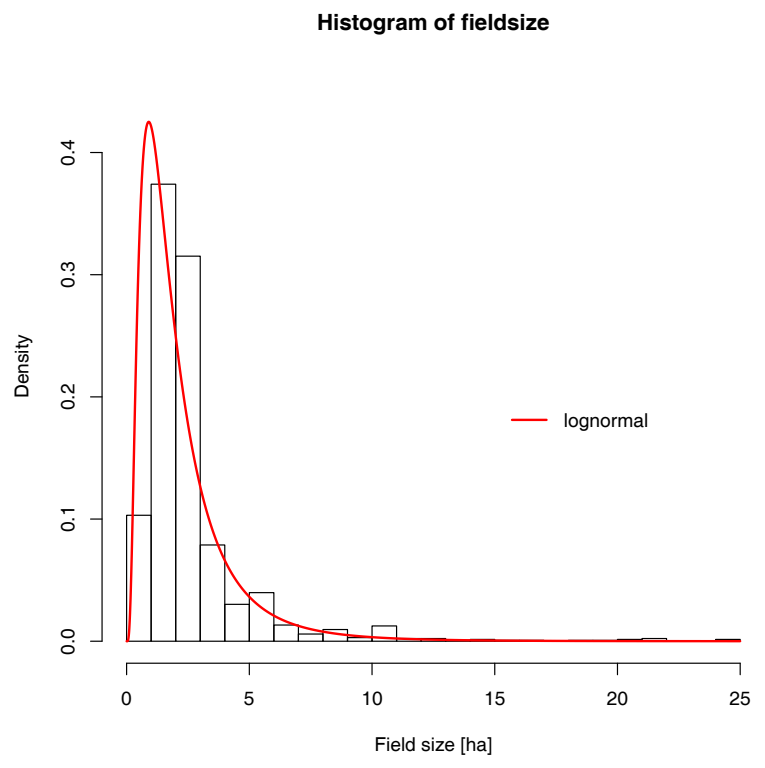

Figure B.15: Histogram of field sizes with maximum likelihood fit of the log-normal distribution.

\section{B.3.1.2 Field sizes}

In the same manner as for household sizes, we use data from a household survey to determine the distribution of field sizes. We again fitted a log-normal distribution to the data (see Fig. B.15). The resulting parameters for mean and standard deviation of field sizes are presented in Table B.1.

\section{B.4 Conversion of plantation plots under differ- ent land uses}

Field studies show that a moderate proportion of oil palm was converted to other crops in the study area, while for rubber the respective conversion was much lower (overall, $14.47 \%$ vs. $0.99 \%$; see Table B.4). The low proportion of rubber suggests that conversion of fields of rubber plantations to oil palm does not generally occur. Evidence from the field also indicates that during times of low rubber output prices, fields are left to fallow until prices are profitable again (V. Krisha, personal communication). 
Table B.4: Share of plantation plots under different land uses at the time of

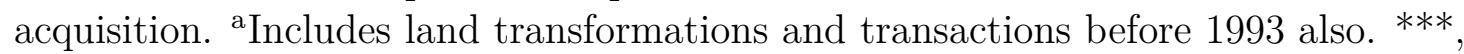
**, *: The difference in the proportions of oil palm and village plots developed from a given type of land use is statistically significant at 0.10, 0.05 and 0.10 levels, respectively. Source: Farm-household survey data (2013).

\begin{tabular}{|c|c|c|c|c|c|c|}
\hline & \multicolumn{2}{|c|}{ Overalla $^{\mathrm{a}}$} & \multicolumn{2}{|c|}{$1993-2002$} & \multicolumn{2}{|c|}{ 2003-2012 } \\
\hline & Oil palm & Rubber & Oil palm & Rubber & Oil palm & Rubber \\
\hline No conversion & 19.12 & $35.22^{* * *}$ & 25.60 & $40.52^{\text {wa* }}$ & 18.25 & $46.56^{* * * *}$ \\
\hline Other crops & 14.47 & $0.99^{* * * *}$ & 10.71 & $1.04^{* * *}$ & 14.29 & $1.62^{* * *}$ \\
\hline Primary forest & 13.95 & $32.54^{* * *}$ & 10.12 & $26.75^{* \infty * *}$ & 13.49 & $19.84^{*}$ \\
\hline $\begin{array}{l}\text { Secondary forest (bush } \\
\text { and grass lands) }\end{array}$ & 33.07 & $27.38^{* *}$ & 28.57 & 29.61 & 47.62 & $31.58^{* * *}$ \\
\hline No idea & 19.38 & $3.87^{* * *}$ & 25.00 & $2.08^{* * *}$ & 6.35 & $0.40^{* * *}$ \\
\hline Overall & 100.00 & 100.00 & 100.00 & 100.00 & 100.00 & 100.00 \\
\hline Number of plots & 387 & 1008 & 168 & 385 & 126 & 247 \\
\hline
\end{tabular}

\section{B.5 Additional model results}




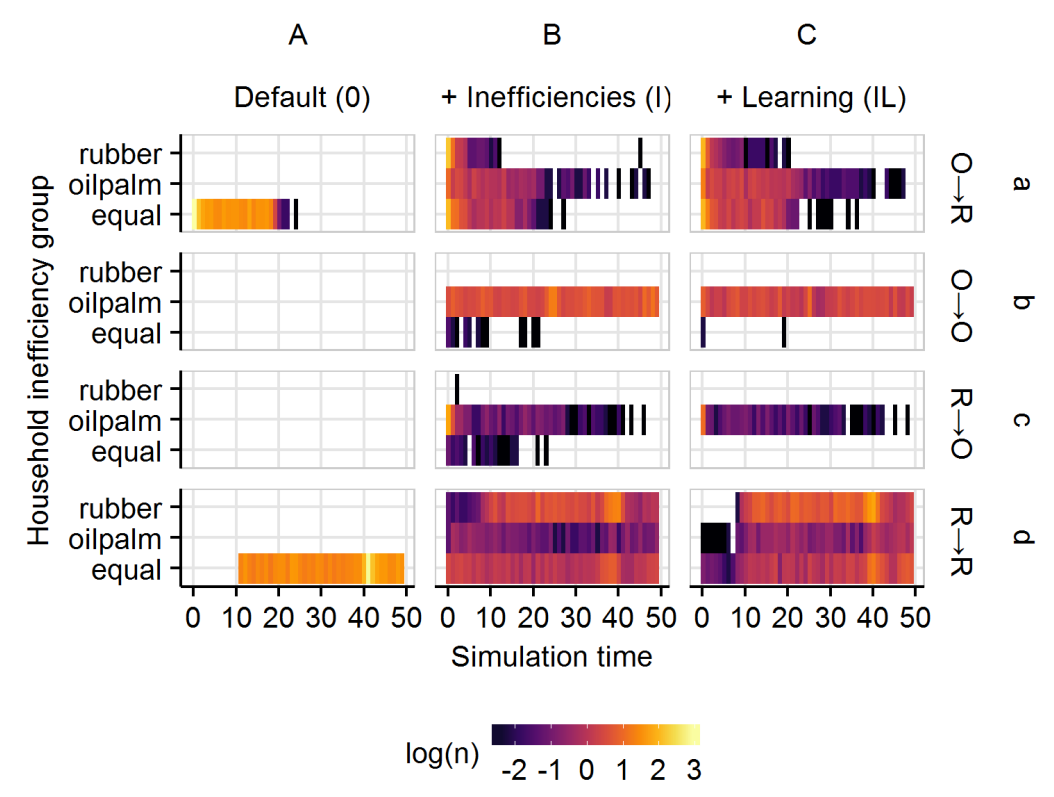

Figure B.16: Land-use change and replanting of fields under constant prices scenario for agents with no inefficiencies and no learning (A), heterogeneous inefficiencies and no learning (B) and heterogeneous inefficiencies and learning (C). Households have been segregated into three classes (y-axis) based on the difference in crop inefficiencies. Households with less then $10 \%$ difference between rubber and oilpalm inefficiency are classified as equal. Households with at least $10 \%$ lower rubber inefficiency than oilpalm inefficiency are classified as rubber experts. Households with at least $10 \%$ lower oilpalm inefficiency than rubber inefficiency are classified as oilpalm experts. The four columns show the four possible land-use change decisions that reset field age to zero: Land-use change from oilpalm to rubber (a), replanting of oilpalm fields (b), land-use change from rubber to oilpalm (c) and replanting of rubber fields (d). The colored strips show for each time step and household class the logarithmic mean number of fields (derived from 20 model replications) with land-use change of the respective land-use-change option. 


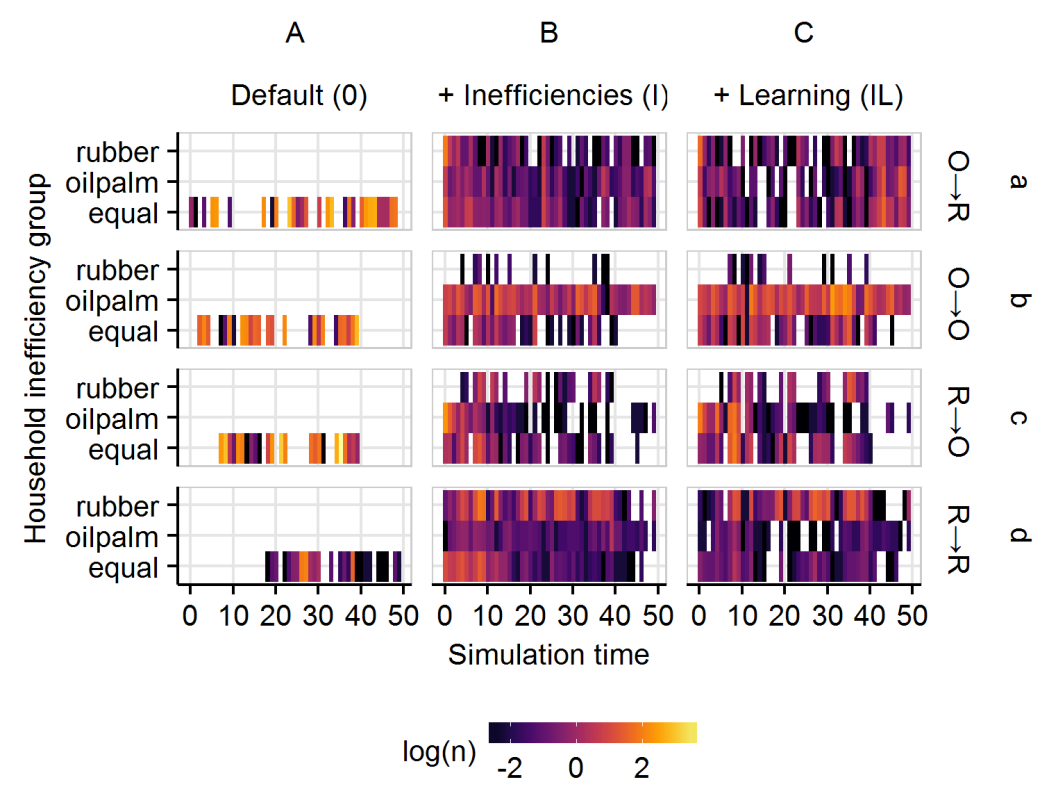

Figure B.17: Land-use change and replanting of fields under historical price trends scenario for agents with no inefficiencies and no learning (A), heterogeneous inefficiencies and no learning (B) and heterogeneous inefficiencies and learning (C). Households have been segregated into three classes (y-axis) based on the difference in crop inefficiencies. Households with less then $10 \%$ difference between rubber and oilpalm inefficiency are classified as equal. Households with at least 10\% lower rubber inefficiency than oilpalm inefficiency are classified as rubber experts. Households with at least $10 \%$ lower oilpalm inefficiency than rubber inefficiency are classified as oilpalm experts. The four columns show the four possible land-use change decisions that reset field age to zero: Land-use change from oilpalm to rubber (a), replanting of oilpalm fields (b), land-use change from rubber to oilpalm (c) and replanting of rubber fields (d). The colored strips show for each time step and household class the logarithmic mean number of fields (derived from 20 model replications) with land-use change of the respective land-use-change option. 


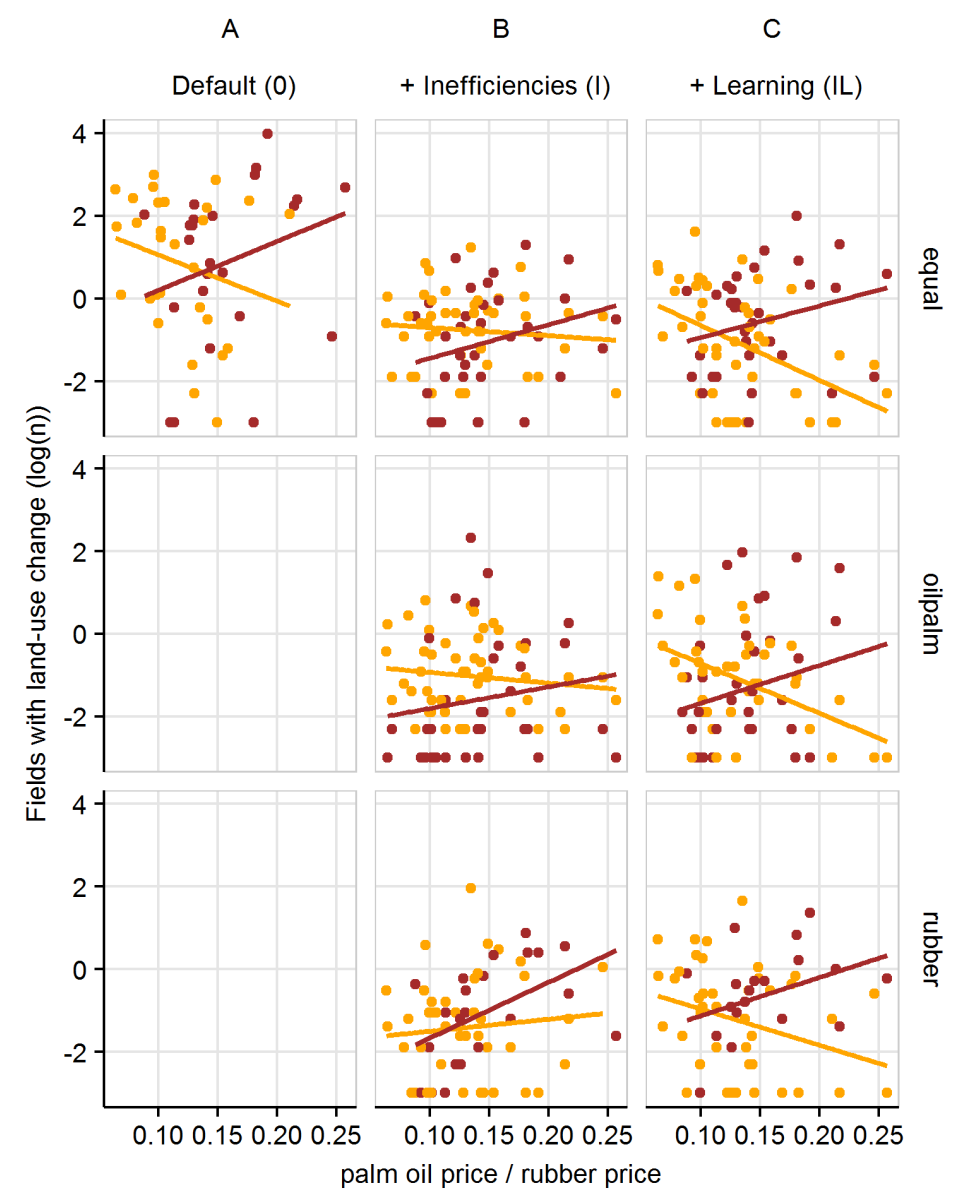

Figure B.18: Correlation of land-use change and output prices under historical price trends scenario for agents with no inefficiencies and no learning (A), heterogeneous inefficiencies and no learning (B) and heterogeneous inefficiencies and learning (C). Households have been segregated into three classes based on the difference in crop inefficiencies. Households with less then $10 \%$ difference between rubber and oilpalm inefficiency are classified as equal. Households with at least 10\% lower rubber inefficiency than oilpalm inefficiency are classified as rubber experts. Households with at least $10 \%$ lower oilpalm inefficiency than rubber inefficiency are classified as oilpalm experts. The colored points refer to the logarithmic mean number of fields (derived from 20 model replications) with land-use change from oilpalm to rubber (dark red points) and from rubber to oilpalm (dark yellow points) in dependence of the current price ratio (palm oil price / rubber price). The linear models show the general trend for each land-use change option. 


\section{Appendix C}

\section{Supplementary Material: From bacteria to birds: tropical land-use change causes variable responses in species turnover (Chapter 4)}

\section{C.1 Methods}

\section{C.1.1 Study region and study design}

The field research for this study was conducted in the province of Jambi on the island of Sumatra, Indonesia. This tropical lowland region has undergone massive changes in land use during the 20th century and is a showcase for smallholder agriculture in Indonesia (ClOugh et al., 2016). Two sample landscapes, 'Harapan' and 'Bukit Duabelas' (with loam and Acrisol soils, respectively), were selected within Jambi Province. In each landscape, we established four $50 \mathrm{~m} \times 50 \mathrm{~m}$ replicate plots in each of the four land-use systems common to the region: primary degraded lowland rainforest (MARGONO et al., 2014), jungle rubber (a traditional agroforestry system), monoculture rubber plantation and monoculture oil palm plantation, resulting in a total number of 32 plots. At the time of site selection in 2012 , the monoculture rubber plantation varied between 7-16 years in age and the oil palm plantation between $8-15$ years. This number of replicates is typical for ecological studies in tropical lowland forests (MALHI et al., 2004). The forest plots were located in the Bukit Duabelas National Park and the Harapan Rainforest Restoration concession (PT REKI). All other plots were owned and managed by smallholders. Within each plot, five permanent $5 \mathrm{~m} \times 5 \mathrm{~m}$ subplots were established. More information on the study region, study design, land-use systems and management practices of the smallholder systems are published elsewhere (Clough et al., 2016, Drescher et al., 2016).

\section{C.1.2 Species data}

Overall we used species matrices of 14 different taxonomic groups, namely canopy ants, canopy parasitic wasps, butterflies, birds, understorey plants, leaf litter ants, 
Table C.1: Summary of species data that have been used within this study.

\begin{tabular}{|c|c|c|}
\hline Taxon & Methods & Citations \\
\hline Canopy ants & Canopy fogging & DRESCHER et al., 2016 \\
\hline $\begin{array}{l}\text { Canopy parasitic } \\
\text { wasps }\end{array}$ & Canopy fogging & DRESCHER et al., $\overline{2016}$ \\
\hline Butterflies & Sweep netting, identification & - \\
\hline Birds & Point counts and sound recordings & PRABOWO et al., 2016 \\
\hline $\begin{array}{l}\text { Understorey } \\
\text { plants }\end{array}$ & Plant identification & REMBOLD et al., 2017 \\
\hline Leaf litter ants & Leaf litter samples, sieving, identification & Mumme et al., 2015 \\
\hline Spiders & Leaf litter samples, sieving, identification & MuMmE et al., 2015 \\
\hline Fungi & $\begin{array}{l}\text { Extraction of soil DNA, identification to } \\
\text { OTUs }\end{array}$ & SAHNER et al., 2015 \\
\hline Oribatida & $\begin{array}{l}\text { Soil samples, heat extraction, identification } \\
\text { to morphospecies }\end{array}$ & KLARNER et al., 2017 \\
\hline Mesostigmata & $\begin{array}{l}\text { Soil samples, heat extraction, identification } \\
\text { to morphospecies }\end{array}$ & KLARNER et al., 2017 \\
\hline Testate amoebae & $\begin{array}{l}\text { Soil samples, washing, filtration, identifica- } \\
\text { tion to morphospecies }\end{array}$ & KRASHEVSKA et al., 2016 \\
\hline Archaea & $\begin{array}{l}\text { Extraction of soil DNA, identification to } \\
\text { OTUs }\end{array}$ & SCHNEIDER et al., 2015 \\
\hline Bacteria & $\begin{array}{l}\text { Extraction of soil DNA, identification to } \\
\text { OTUs }\end{array}$ & SCHNEIDER et al., 2015 \\
\hline Protists & $\begin{array}{l}\text { Extraction of soil DNA, identification to } \\
\text { OTUs }\end{array}$ & ScHULZ et al., 2019 \\
\hline
\end{tabular}

spiders, fungi, oribatida, mesostigmata, testate amoebae, archaea, bacteria and protists (see Table C.1).

\section{C.1.2.1 Canopy ants \& Canopy parasitic wasps}

Canopy ants (Formicidae) and canopy parasitoid wasps (Braconidae, Ceraphronidae, Encyrtidae, Eulophidae, Platygastridae, Scelionidae) were collected by canopy fogging. Details are described in DrEscher et al., 2016.

\section{C.1.2.2 Butterflies}

We obtained abundance data for butterflies (Lepidoptera: Papilionidae, Pieridae, Lycaneidae, Nymphalidae) from all 32 study plots between August and October 2017. Butterflies were collected using sweep netting (exception: Troides amphrysus CRAMER 1779, identified on sight) on three parallel transects per plot, with two transects located on the outer borders of the plots, and the third transect located through the center. Sweep netting was conducted twice per day per plot, in the morning (8:00 - 11:00 am) and afternoon hours (13:00 - 16:00 pm). All butterfly 
individuals were released after identification in the evenings of the sampling day, with the exception of up to two dried/mounted individuals and five individuals in $99 \%$ EtOH p.A. per species, which were kept for species ID and further analysis. Our data is based on 6653 caught and/or observed butterfly individuals that we identified to 209 species, using standard taxonomic literature.

\section{C.1.2.3 Birds}

Birds were sampled with point counts as well as automated sound recordings from May-July 2013. Details are described in Prabowo et al., 2016.

\section{C.1.2.4 Understorey plants}

All vascular plant individuals growing within the five $5 \mathrm{~m} \times 5 \mathrm{~m}$ subplots were identified, including terrestrial plants (herbs, shrubs, and young trees), climbers and epiphytes up to $3 \mathrm{~m}$ height. Details are described in REmBold et al., 2017.

\section{C.1.2.5 Leaf litter ants \& Spiders}

Leaf litter samples were derived from three randomly placed $5 \mathrm{~m} \times 5 \mathrm{~m}$ subplots within each of the study plots. $1 \mathrm{~m}^{2}$ of leaf litter was sieved using a coarse 2 $\mathrm{cm}$ mesh width. Macro-invertebrates were hand-collected from the litter sieves, stored in $75 \%$ ethanol and transported to the laboratory for identification and trait measurements. Details are described in Mumme et al., 2015.

\section{C.1.2.6 Fungi}

Soil samples were taken from each study plot and were processed (sieving, freezeddrying and milling) for DNA extraction of soil fungal communities. Details are described in SAHNER et al., 2015.

\section{C.1.2.7 Oribatida \& Mesostigmata}

Three soil cores were taken during October-November 2013 from each study plot. Soil cores measured $16 \mathrm{~cm} \times 16 \mathrm{~cm}$ and comprised the litter layer and the underlying mineral soil layer to a depth of $5 \mathrm{~cm}$. Animals were extracted by heat KEMPSON et al., 1963, collected in dimethyleneglycol-water solution (1:1) and thereafter transferred into 70\% ethanol. More details are described in KLARNER et al., 2017.

\section{C.1.2.8 Testate amoebae}

Litter and upper mineral soil samples (to a depth of $50 \mathrm{~mm}$ ) were taken in October and November 2013, using a corer of $50 \mathrm{~mm}$ in diameter. Testate amoebae were 
extracted from the samples by washing $1 \mathrm{~g}$ dry weight litter sample over a filter of $500 \mu \mathrm{m}$ mesh and back-sieving the filtrate through $10 \mu \mathrm{m}$ mesh. More details are described in KRASHEvsKa et al., 2016.

\section{C.1.2.9 Archaea \& Bacteria}

Soil DNA samples were used to assess bacterial and archaeal community compositions. Details are described in SchNeIDER et al., 2015.

\section{C.1.2.10 Protists}

Soil samples were taken from each study plot and were processed (sieving, freezeddrying and milling) for DNA extraction of Protist communities. Details are described in ScHulz et al., 2019.

\section{C.1.3 Environmental data}

Table C.2: Summary of environmental data that have been used within this study.

\begin{tabular}{|c|c|c|}
\hline Variables & Methods & Citations \\
\hline Air \& soil temperatures & meteorological stations & DRESCHER et al., 2016 \\
\hline Humidity & soil sensors & DRESCHER et al., $\overline{2016}$ \\
\hline $\begin{array}{l}\text { Soil organic carbon \& soil fer- } \\
\text { tility indicators }\end{array}$ & soil samples & - \\
\hline $\begin{array}{l}\text { Soil respiration \& soil green- } \\
\text { house gas fluxes }\end{array}$ & static chambers & $\begin{array}{l}\text { HASSLER et al., 2017; KUR- } \\
\text { NIAWAN et al., } 2018\end{array}$ \\
\hline Nutrient leaching fluxes & cup lysimeters & KURNIAWAN et al., 2018 \\
\hline Structural complexity & $\begin{array}{l}\text { Terrestrial laser scans and } \\
\text { photographs }\end{array}$ & $\begin{array}{l}\text { DRESCHER et al., 2016 ZEMP } \\
\text { et al., } 2019 \mathrm{a}\end{array}$ \\
\hline Litterfall & Litter traps & DRESCHER et al., 2016 \\
\hline
\end{tabular}

Overall we used 24 different environmental predictors including climatic conditions, soil organic carbon and soil fertility indicators, soil respiration and soil greenhouse gas fluxes, nutrient leaching fluxes, tree structural variables and litterfall (see Table C.2).

\section{C.1.3.1 Climatic conditions}

Meteorological stations have been set up within each core plot to measure hourly below-canopy air temperature and relative humidity. Additionally, soil sensors have been used to assess soil temperatures and soil moistures at $0.3 \mathrm{~m}$ depth. Details are described in DRESCHER et al., 2016. 


\section{C.1.3.2 Soil organic carbon and soil fertility indicators}

In 2013, soil samples were collected at three depth intervals $(0.0-0.1 \mathrm{~m}, 0.1-0.3 \mathrm{~m}$, $0.3-0.5 \mathrm{~m}$ ) in each of the five randomly selected subplots per plot, and further three depth intervals $(0.5-1.0 \mathrm{~m}, 1.0-1.5 \mathrm{~m}$ and $1.5-2.0 \mathrm{~m})$ at two of the five subplots. The mean of the five or two subplots represented the value for each replicate plot. Soil organic carbon for the 0.0-0.5 m and 0.5-2.0 $\mathrm{m}$ depths were cumulative stocks of the three depth intervals. For the soil fertility indicators (net $\mathrm{N}$ mineralization rate, extractable $\mathrm{P}$, and exchangeable $\mathrm{Ca}, \mathrm{K}, \mathrm{Mg}$ and $\mathrm{Na}$ ), we used the measurements in the top $0.10 \mathrm{~m}$ depth. Soil organic C concentrations were analyzed from air-dried, ground soils using a CN analyzer (Vario EL Cube, Elementar Analysis Systems GmbH, Hanau, Germany). Net N mineralization was measured using an in-situ buried bag method of intact soil cores. Extractable $\mathrm{P}$ was determined from air-dried, $2 \mathrm{~mm}$ sieved soils using the Bray 2 method. Exchangeable cations were determined by percolating air-dried, $2 \mathrm{~mm}$ sieved soils with unbuffered $1 \mathrm{M} \mathrm{NH} 4 \mathrm{Cl}$ and cations were measured in percolates using an inductively coupled plasma-atomic emission spectrometer (ICP-AES; iCAP 6300 Duo VIEW ICP Spectrometer, Thermo Fischer Scientific GmbH, Dreieich, Germany).

\section{C.1.3.3 Soil respiration and soil greenhouse gas fluxes}

Soil CO2, CH4 and N2O fluxes were measured monthly for one year (2013) using vented, static chambers with permanently installed bases in four subplots per plot HASsler et al., 2017; KuRniawan et al., 2018. The mean of the four subplots represented the value for each replicate plot on each sampling period. During gas sampling, the chamber bases were closed and four gas samples (23 $\mathrm{mL}$ each) were taken at $1 \mathrm{~min}, 11 \mathrm{~min}, 21 \mathrm{~min}$, and $31 \mathrm{~min}$ after chamber closure. Gas samples were immediately injected into pre-evacuated $12 \mathrm{~mL}$ Labco Exetainers and were analyzed using a gas chromatograph with electron capture and flame ionization detector (GC 6000 Vega Series 2, Carlo Erba Instruments, Milan, Italy). Soil gas fluxes were calculated from the linear increase of concentration over time of chamber closure and adjusted for the measured air temperature and pressure at the time of sampling.

\section{C.1.3.4 Nutrient leaching fluxes}

Nutrient leaching was measured biweekly to monthly for one year (2013) using suction cup lysimeters (P80 ceramic, maximum pore size $1 \mu \mathrm{m}$; CeramTec AG, Marktredwitz, Germany), which were installed in two subplots per plot. These lysimeters were inserted into the soil down to $1.5 \mathrm{~m}$ depth. Soil water was withdrawn by applying a $40 \mathrm{kPa}$ vacuum on the sampling tube. The collected soil water samples were stored in $100 \mathrm{~mL}$ plastic bottles and immediately frozen upon arrival at the 
field laboratory. Frozen water samples were transported to Germany and were kept frozen until analysis. The total dissolved N (TDN), NH4+ and NO3 - were measured using continuous flow injection colorimetry (SEAL Analytical AA3, SEAL Analytical GmbH, Norderstedt, Germany) whereas dissolved organic C (DOC) was determined using a Total Organic Carbon Analyzer (TOC-Vwp, Shimadzu Europa GmbH, Duisburg, Germany). Dissolved $\mathrm{Na}, \mathrm{Ca}, \mathrm{Mg}$, total Al, total P and total S were analyzed using ICP-AES. Drainage water fluxes were estimated using a soil water model, parameterized with our measured site characteristics (climate data, leaf area index, rooting depth, soil water retention curve, texture and bulk density), as described in details in ref. KURNIAWAN et al., 2018, Nutrient leaching fluxes were calculated by multiplying the element concentrations from each of the two lysimeters per replicate plot with the total biweekly or monthly drainage water flux. The annual leaching flux was the sum of biweekly to monthly measured leaching fluxes, and the average of the two lysimeters per plot represents the value of each replicate plot.

\section{C.1.3.5 Structural complexity}

Different aspects of structural complexity have been measured using terrestrial laser scanning in each of the 32 core plots. Details on measurements and methods are described in ZEMP et al., 2019a. Additionally, hemispherical photographs were taken at $1.2 \mathrm{~m}$ above the ground from 32 positions within each core plot to derive canopy openness. Details are described in Drescher et al., 2016.

\section{C.1.3.6 Litterfall}

Leaf litterfall was assessed by placing 16 litter traps $(75 \times 75 \mathrm{~cm})$ in each core plot. Measurements were taken monthly from March 2013 to April 2014. Details are described in Drescher et al., 2016.

\section{C.1.4 Analysis}

\section{C.1.4.1 Data cleaning and selection}

Species matrices. All species matrices have been reformatted to the same format $($ column $=$ sites, rows $=$ species, cells $=$ presence/absence $)$. Species observations that were taken at a subplot level have been aggregated to plot level observations. All species matrices were then read into $\mathrm{R}$ for further analysis.

Environmental data. From the initial set of environmental variables, 38 have been selected for final GDM analysis. Envrionmental variables were distributed into 4 groups (soil variables, vegetation related variables (structural complexity), litter 

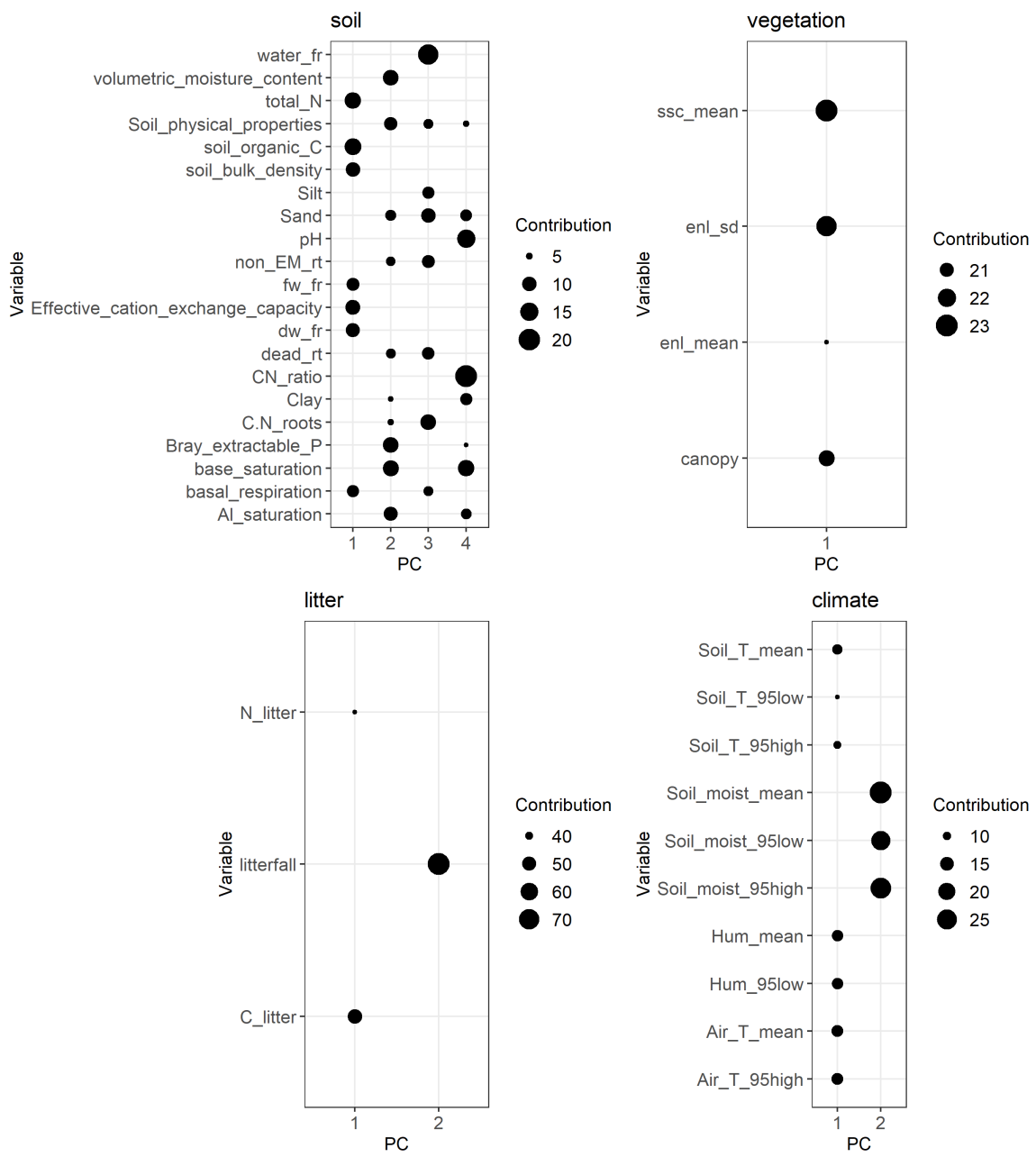

Figure C.1: Contributions (percentage) of environmental variables to principal components of the four variable groups soil, vegetation, litter and climate.

variables and climatic variables). We conducted a principal component analysis for each group and selected the first components until a cumulative explained variance of $70 \%$ was reached. Variable contributions of these selected principal components are displayed in Fig. C.1.

Rarefaction analysis In order to study undersampling effects, we calculated rarefaction curves for the 14 selected taxonomic groups at different levels of $\mathrm{q}[0,1$, 2]. We used the iNEXT R-package to calculate rarefaction curves for all taxa for which we received community data (see Figures C.2 to C.5) (CHAO et al., 2014; HsieH et al., 2016). Rarefaction results revealed undersampling issues for chilopoda, leaf litter Beetles and leaf litter Spiders datasets. Thus, we excluded these three 
datasets from the analysis. We observed saturated or nearly saturated rarefaction curves at all sites $(q=2)$ for 11 of the remaining taxa, including archaea, bacteria, butterflies, canopy ants, canopy parasitic wasps, fungi, leaf litter ants, oribatida, plants, protists and testate amoebae. For spiders, birds and mesostigmata, we observed undersampling in only some sites. These datasets were still included but results may be taken with caution.

\section{C.1.4.2 Species occurrence analysis}

Species occurrences were calculated separately for each taxonomic group. For each taxon we calculated the proportion of species present in each of the four land-uses forest, oil palm, rubber and jungle rubber and in each combination of these landuses. Land-use groups with more than one agricultural land-use (oil-palm, rubber, jungle rubber) were aggregated to the group agriculture. The species occurrences are displayed in Fig. 4.1 in Chapter 4.

\section{C.1.4.3 Turnover analysis}

Dissimilarity between pairwise observations were calculated separately for each taxon and land-use. Pairwise Morisita-Horn dissimilarity indices were calculated using the vegan R-package. Afterwards we aggregated the pairwise dissimilarities to a mean dissimilarity for each taxon and land-use. Finally, we calculated the percentage change of dissimilarity for each agricultural land-use in comparison to the observed forest dissimilarity. These dissimilarity changes are displayed in Fig. 4.2 in Chapter 4.

\section{C.1.4.4 Ordination}

We performed a non-metric multidimensional scaling (NMDS) analysis on calculated pairwise dissimilarities between each plot combination. Additionally, resulting coordinates of the core plots on the NMDS scale have been grouped by land uses. We used the envfit function from the $\mathrm{R}$ package vegan to fit environmental vectors onto the ordination of dissimilarities. For the purpose for easier visibility, we only displayed the 10 most correlated environmental variables which corresponds to a maximum $\mathrm{p}$ value of 0.29. NMDS results are displayed in Fig. 4.1 in Chapter 4.

\section{C.1.4.5 Turnover correlations}

We calculated Kendall's tau correlation indices for species richness and pairwise Morisita-Horn dissimilarity indices between each taxonomic group, irrespective of land uses. The correlations are displayed in Fig. 4.3 in Chapter 4 


\section{C.1.4.6 Generalized dissimilarity modelling (GDM)}

A generalized dissimilarity model was applied to each taxonomic group. We used the respective species matrix, the selected principal components of each environmental variables group (see Paragraph Environmental Data in Section C.1.4.1) and the geographic plot coordinates to run the model. Execution of the GDM was done by using the GDM R-package. Contribution of envrionmental variables (PCs) and distance was estimated by running a variance importance decomposition on the final models. These contributions are displayed in Fig. 4.4 4.5 in Chapter 4. 


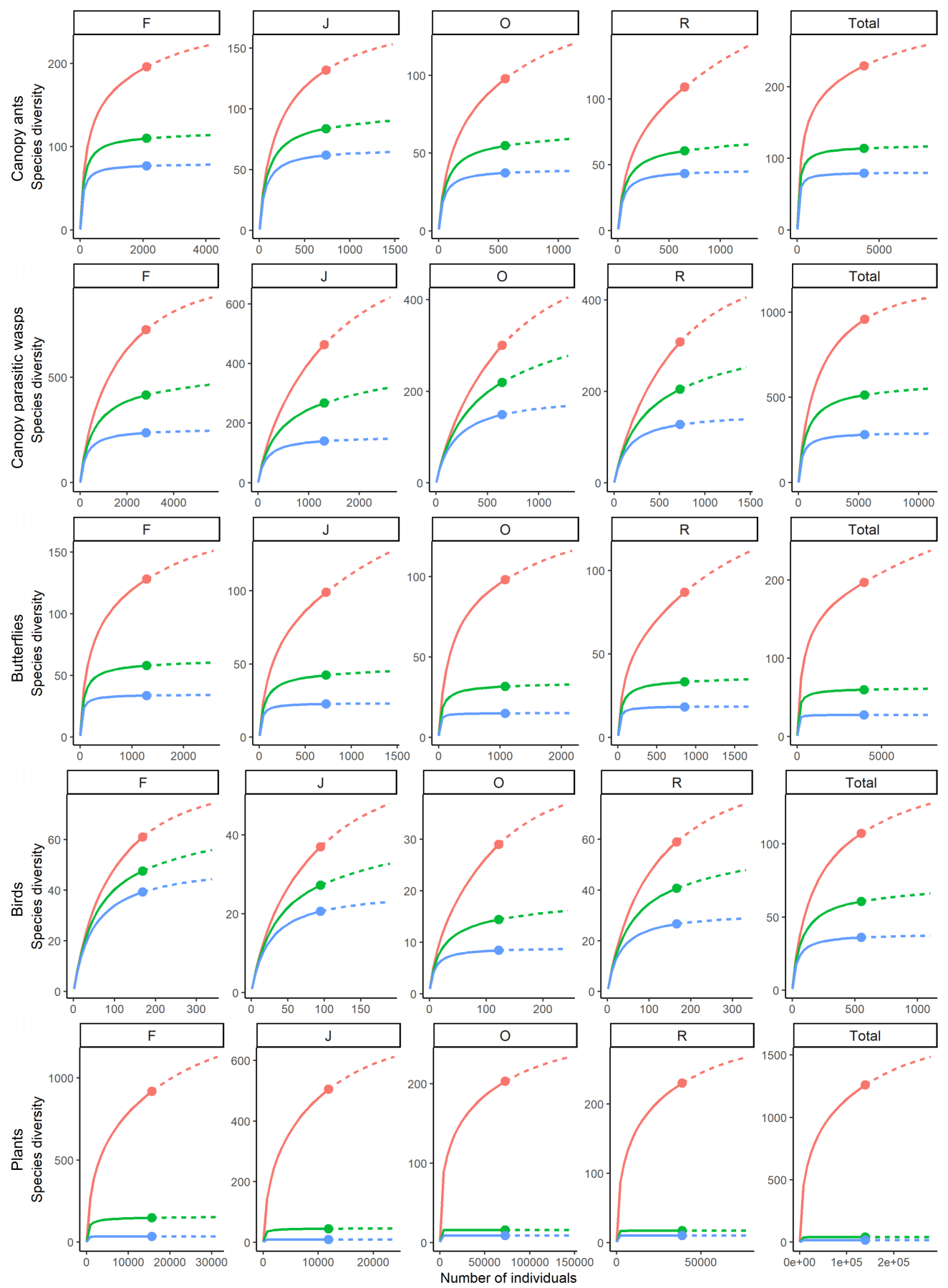

Figure C.2: Rarefaction curves for canopy ants, canopy parasitic wasps, butterflies, birds, and plants. Colors indicate hill numbers $\mathrm{q}=0$ (red), $\mathrm{q}=1$ (green), and $\mathrm{q}=2$ (blue). Panels represent land uses forest $(\mathrm{F})$, jungle rubber $(\mathrm{J})$, oil palm plantation $(\mathrm{O})$, rubber monoculture plantation $(\mathrm{R})$, and total across all land uses. 


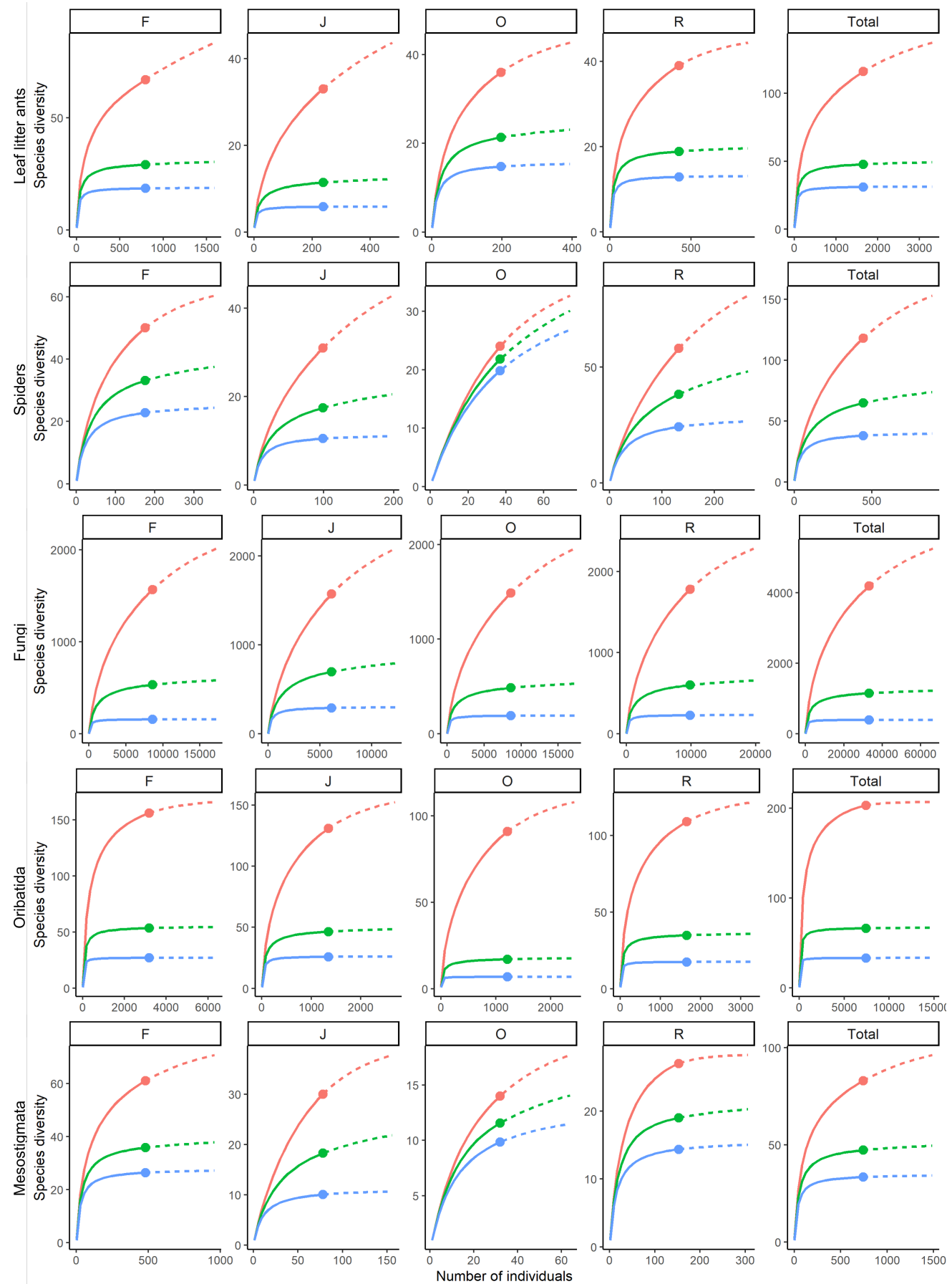

Figure C.3: Rarefaction curves for leaf litter ants, spiders, fungi, oribatida, and mesostigmata. Colors indicate hill numbers $q=0$ (red), $q=1$ (green), and $q=2$ (blue). Panels represent land uses forest $(\mathrm{F})$, jungle rubber $(\mathrm{J})$, oil palm plantation $(\mathrm{O})$, rubber monoculture plantation $(\mathrm{R})$, and total across all land uses. 


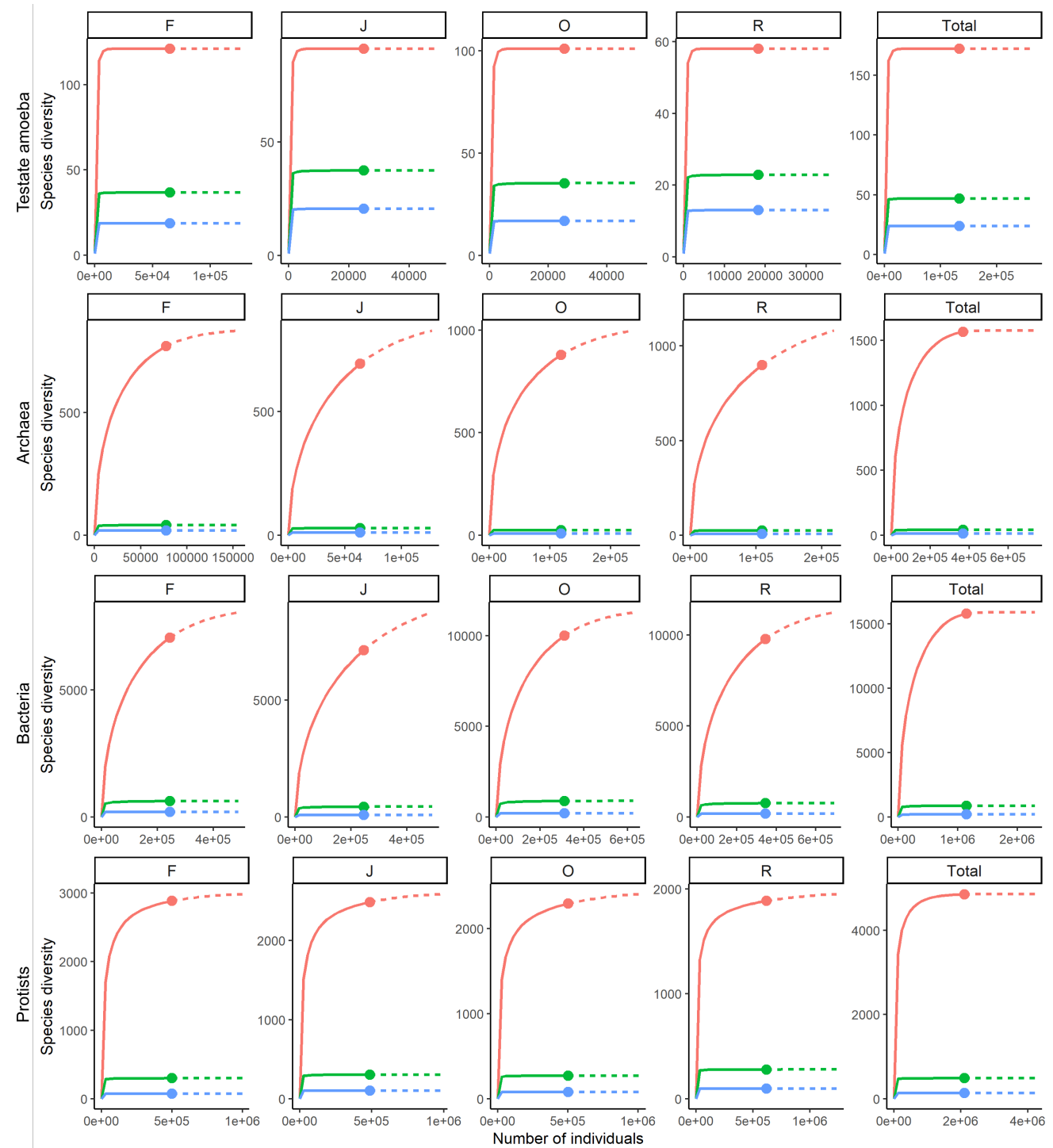

Figure C.4: Rarefaction curves for testate amoeba, archaea, bacteria, and protists. Colors indicate hill numbers $\mathrm{q}=0$ (red), $\mathrm{q}=1$ (green), and $\mathrm{q}=2$ (blue). Panels represent land uses forest $(\mathrm{F})$, jungle rubber $(\mathrm{J})$, oil palm plantation $(\mathrm{O})$, rubber monoculture plantation $(\mathrm{R})$, and total across all land uses. 

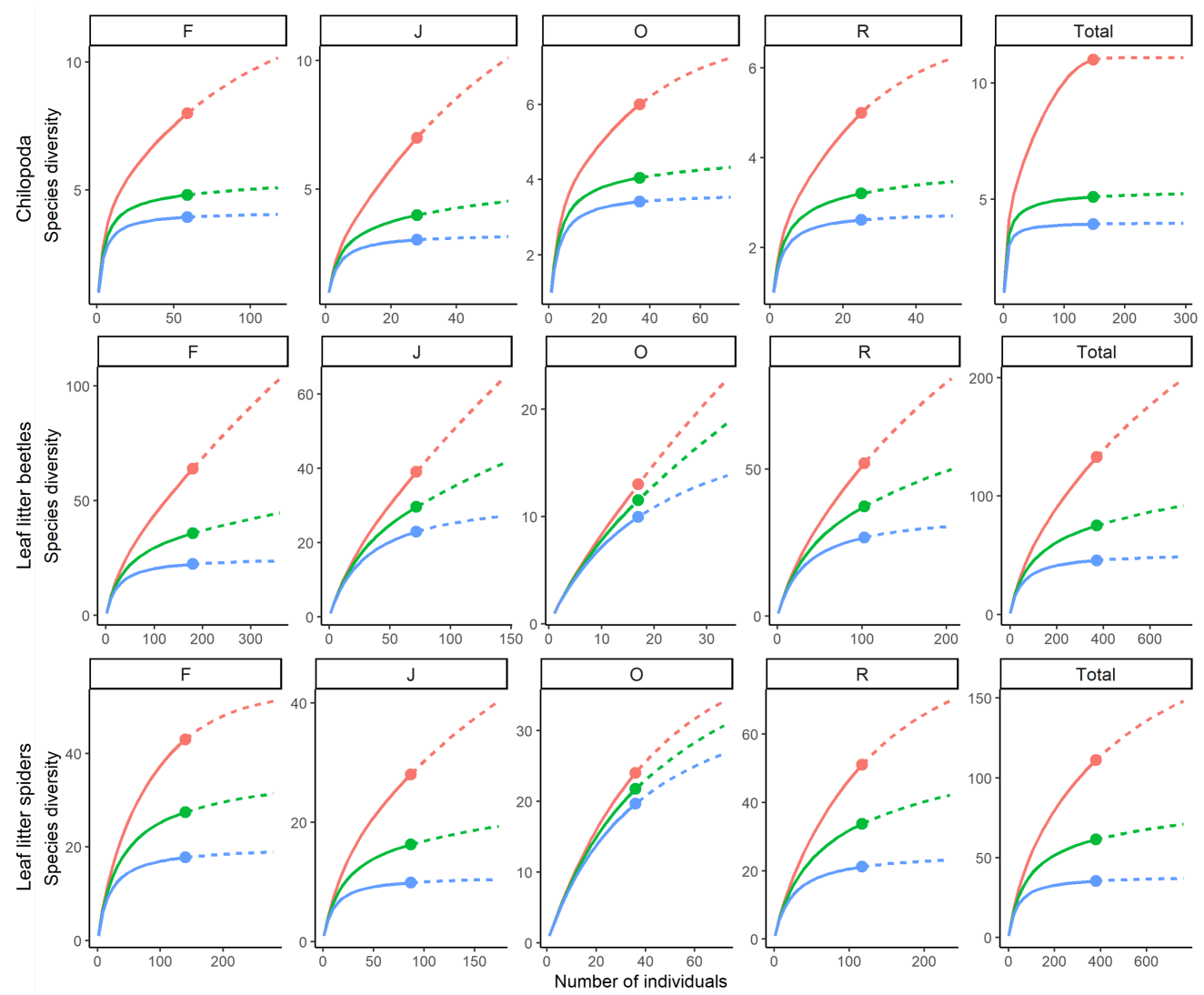

Figure C.5: Rarefaction curves for chilopoda, leaf litter beetles, and leaf litter spiders. Colors indicate hill numbers $\mathrm{q}=0$ (red), $\mathrm{q}=1$ (green), and $\mathrm{q}=2$ (blue). Panels represent land uses forest $(\mathrm{F})$, jungle rubber $(\mathrm{J})$, oil palm plantation $(\mathrm{O})$, rubber monoculture plantation $(\mathrm{R})$, and total across all land uses. 


\section{Appendix D}

\section{Supplementary Material: $n l r x$ package (Chapter 5)}

\section{D.1 Benchmark details}

We used the Wolf Sheep Predation model from the NetLogo models library to evaluate the performance of the nlrx package. We generated a Latin Hypercube sampling design with 100 samples of the seven numeric model parameters. Each simulation of the Latin Hypercube was performed for 500 ticks. We have taken model stochasticity into account by executing 8 replications of the Latin Hypercube parameter matrix with different random seeds. As performance comparison, we performed the same simulations with the package RNetLogo.

As performance indicators, we measured the execution time and the available system memory at three points during the simulations: before starting simulations, after finishing simulations and after manually executing the $\mathrm{R}$ garbage collection function $\mathrm{gc}$ () (for results, see Fig. 5.1 in Chapter 5). We performed the benchmarks on different systems with different specifications (see Tab. D.1). While we found working solutions for benchmarking RNetLogo and nlrx on Windows, we did not find a solution to do the same on Unix. There are a lot of problems connecting Java, Netlogo and R under Unix via RNetLogo, see https://github.com/NetLogo/ NetLogo/issues/1282.

Table D.1: System specifications of machines running benchmark simulations.

\begin{tabular}{|c|c|c|c|c|c|c|}
\hline ID & $\mathbf{R}$ version & $\overline{\mathrm{OS}}$ & system & CPU model & $\begin{array}{l}\text { CPU } \\
\text { cores }\end{array}$ & $\begin{array}{l}\text { system } \\
\text { RAM }\end{array}$ \\
\hline D1 & $\begin{array}{l}3.5 .0 \\
04-23)\end{array}$ & $\begin{array}{l}\text { Windows } \\
>=8 \times 64\end{array}$ & $\begin{array}{l}\text { x86_64, } \\
\text { mingw32 }\end{array}$ & $\begin{array}{l}\text { Intel(R) Core(TM) i7-8700 } \\
\text { CPU @ 3.20GHz }\end{array}$ & 12 & $32 \mathrm{~Gb}$ \\
\hline D2 & $\begin{array}{l}3.5 .1 \\
07-02)\end{array}(2018-$ & $\begin{array}{l}\text { Windows } 7 \\
\mathrm{x} 64 \text { SP } 1\end{array}$ & $\begin{array}{l}\text { x86_64, } \\
\text { mingw32 }\end{array}$ & $\begin{array}{l}\text { Intel(R) Core(TM) i5- } 4570 \\
\text { CPU @ 3.20GHz }\end{array}$ & 4 & $16 \mathrm{~Gb}$ \\
\hline N1 & $\begin{array}{l}3.5 .0 \\
04-23)\end{array}(2018-$ & $\begin{array}{l}\text { Windows } \\
>=8 \times 64\end{array}$ & $\begin{array}{l}\text { x86_64, } \\
\text { mingw32 }\end{array}$ & $\begin{array}{l}\text { Intel(R) Core }(\mathrm{TM}) \quad \text { i7- } \\
3720 \mathrm{QM} \mathrm{CPU} @ 2.60 \mathrm{GHz}\end{array}$ & 8 & $16 \mathrm{~Gb}$ \\
\hline $\mathrm{N} 2$ & $\begin{array}{l}3.5 .1 \\
07-02)\end{array}(2018-$ & $\begin{array}{l}\text { Windows } \\
>=8 \times 64\end{array}$ & $\begin{array}{l}\text { x86_64, } \\
\text { mingw32 }\end{array}$ & $\begin{array}{l}\text { Intel(R) Core(TM) i5-6200U } \\
\text { CPU @ } 2.30 \mathrm{GHz}\end{array}$ & 4 & $8 \mathrm{~Gb}$ \\
\hline N3 & $\begin{array}{l}3.5 .1 \\
07-02)\end{array}(2018-$ & $\begin{array}{l}\text { Windows } \\
>=8 \times 64\end{array}$ & $\begin{array}{l}\text { x86_64, } \\
\text { mingw32 }\end{array}$ & $\begin{array}{l}\text { Intel(R) Core(TM) i5-6200U } \\
\mathrm{CPU} @ 2.30 \mathrm{GHz}\end{array}$ & 4 & $8 \mathrm{~Gb}$ \\
\hline
\end{tabular}




\section{D.2 Ants parallel}

nlrx enables user to run simulation designs of NetLogo in a highly parallelized workflow. This can either be achieved on a local machine (see first example in List. 10), or on a high-perfomance cluster if the workload exceeds the capabilities of local machines (see second example in List. 10p. In order to run this example, the nl object needs to be setup first as explained in the use case "Sensitivity Analysis with nlrx" (see List. 1, 2, 3 in Chapter 5). 


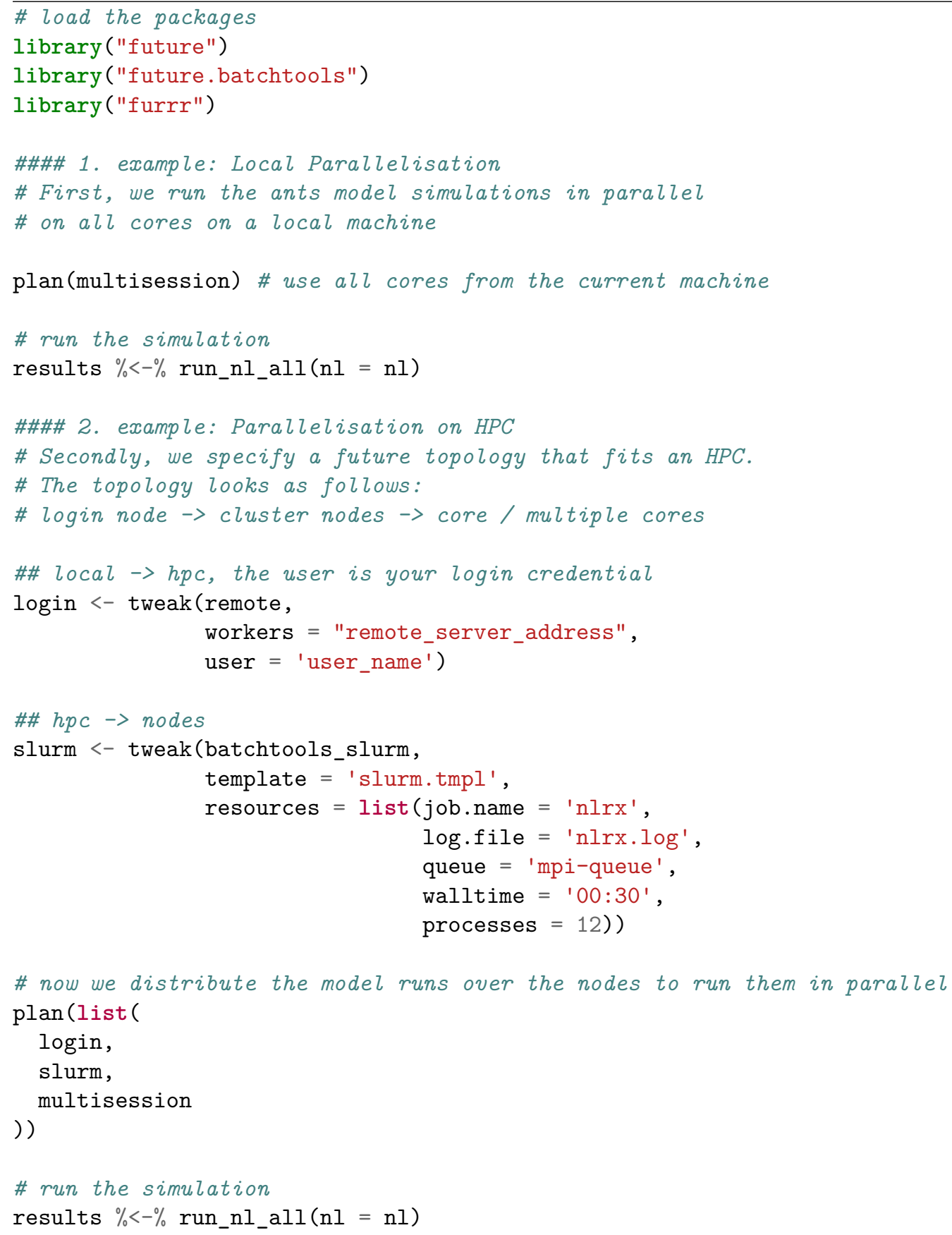

Listing 10: Example of the steps that are needed to run an experiment in parallel, either on a local machine or on a high-perfomance cluster (HPC). 


\section{D.3 nldoc}

\section{D.3.1 Documentation of NetLogo models with $n l r x$}

In order to support a fully reproducible NetLogo model analysis and documentation framework, nlrx also provides functions to generate documentation files from NetLogo models. We adapted the roxygen2 documentation standard for R-packages to allow NetLogo users to add model documentation markdown headers directly within the NetLogo model code. The nldoc() function of the nlrx package searches model code for these headers and creates a model documentation file. The documentation can be created in different formats (html, pdf, docx) and styles. In order to create NetLogo model documentations with nldoc, documentation tags need to be added to the NetLogo model. These tags are very similar to roxygen2 documentation tags and are called noxygen tags for the purpose of this package. Noxygen tags are organized in three main groups:

- General model information

- ‘@model Defines the title for the model documentation

- '@author Defines the author of the model (multiple author tags can be used to define several authors)

- Global definitions

- '@global Defines the name of a global definitions (e.g. globals, patchesowns, breeds, ...)

- '@details Further description of the global definition (multi line: each further line needs to start with details tag)

- '@code TRUE/FALSE if following code should be included in the documentation

- Procedures

- ‘@procedure Defines the name of a model procedure

- ‘@param Defines a parameter that needs to be provided for the function call

- ‘@return Description of the return value (in case of to-report functions)

- '@details Further description of the model procedure (multi line: each further line needs to start with details tag)

- '@code TRUE/FALSE if following code should be included in the documentation 
Using these tags, detailed information on model meta data, global variables or single procedures can be added as comments to any NetLogo model (see List. 11). While having this information within the NetLogo model code is already useful and beneficial, generating a model documentation with nlrx in *.html, *.docx or *.pdf format allows to share and distribute this information in a clean, readable format (see Documentation example of the Wolf Sheep Predation model, below).

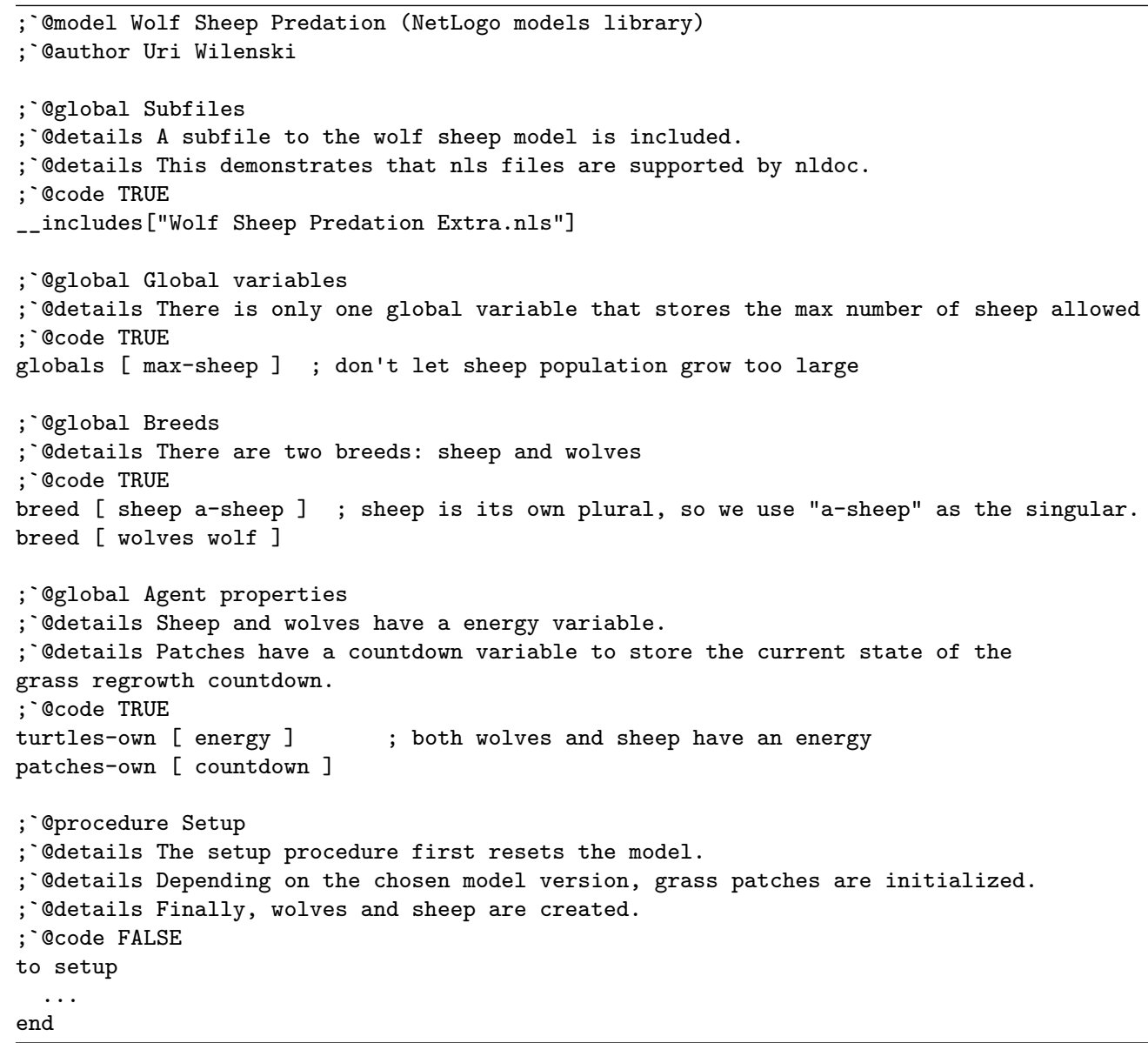

Listing 11: Example of added noxygen tags within the Wolf Sheep Predation model from the NetLogo models library. 


\title{
Wolf Sheep Predation (NetLogo models library)
}

\author{
Uri Wilenski
}

Mon Mar 25 10:49:43 2019

\section{Contents}

\begin{tabular}{|c|c|}
\hline \multicolumn{2}{|l|}{ Global } \\
\hline \multicolumn{2}{|l|}{ Subfiles } \\
\hline \multicolumn{2}{|l|}{ Global variables . } \\
\hline \multicolumn{2}{|r|}{$\cdots \cdots \cdots$} \\
\hline \multicolumn{2}{|r|}{$\ldots \ldots \ldots \ldots \ldots$} \\
\hline \multicolumn{2}{|l|}{ Procedures } \\
\hline \multicolumn{2}{|l|}{ Setup . } \\
\hline \multicolumn{2}{|r|}{$\ldots \ldots \ldots \ldots \ldots \ldots$} \\
\hline \multicolumn{2}{|r|}{$\ldots \ldots \ldots \ldots \ldots \ldots$} \\
\hline \multicolumn{2}{|c|}{ 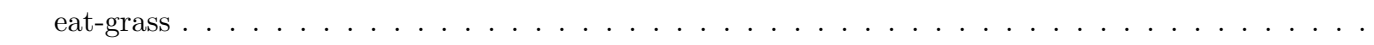 } \\
\hline \multicolumn{2}{|c|}{ 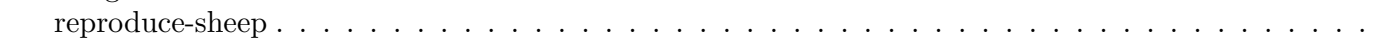 } \\
\hline \multicolumn{2}{|c|}{ 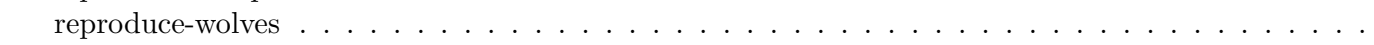 } \\
\hline \multicolumn{2}{|c|}{ 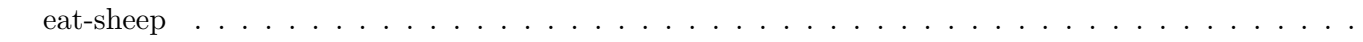 } \\
\hline \multicolumn{2}{|c|}{ 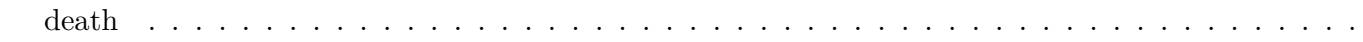 } \\
\hline \multicolumn{2}{|c|}{ 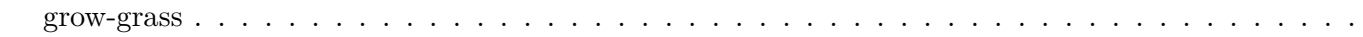 } \\
\hline \multicolumn{2}{|c|}{ 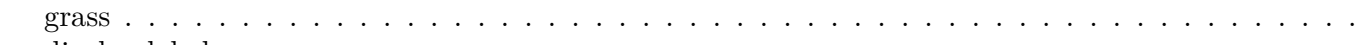 } \\
\hline \multicolumn{2}{|c|}{ display-labels $\ldots$. } \\
\hline \multicolumn{2}{|c|}{ 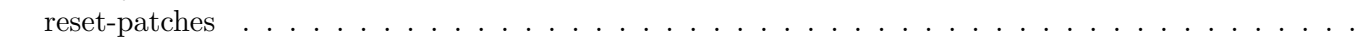 } \\
\hline \multirow{2}{*}{\multicolumn{2}{|c|}{$\begin{array}{l}\text { reset-turtles } \ldots \\
\text { calc-sum } \ldots \ldots\end{array}$}} \\
\hline & \\
\hline \multicolumn{2}{|l|}{ GUI elements } \\
\hline \multicolumn{2}{|l|}{ Info Tab } \\
\hline \multicolumn{2}{|l|}{ WHAT IS IT? } \\
\hline \multicolumn{2}{|l|}{ HOW IT WORKS } \\
\hline \multicolumn{2}{|l|}{ HOW TO USE IT } \\
\hline \multicolumn{2}{|l|}{ THINGS TO NOTICE . } \\
\hline \multicolumn{2}{|r|}{$\ldots \ldots \ldots \ldots \ldots \ldots \ldots$} \\
\hline \multicolumn{2}{|c|}{ 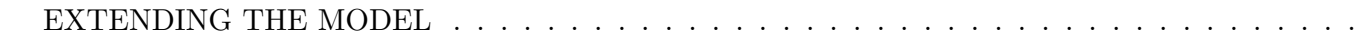 } \\
\hline \multicolumn{2}{|l|}{ NETLOGO FEATURES . } \\
\hline \multicolumn{2}{|l|}{ RELATED MODELS } \\
\hline \multicolumn{2}{|l|}{ CREDITS AND REFERENCES } \\
\hline \multicolumn{2}{|l|}{ HOW TO CITE } \\
\hline COPYRIGHT AND LICENSE . & $\ldots \ldots \ldots \ldots \ldots \ldots \ldots \ldots \ldots \ldots \ldots \ldots \ldots \ldots \ldots \ldots$ \\
\hline
\end{tabular}

\section{Global}

Subfiles

Description 
A subfile to the wolf sheep model is included. This demonstrates that nls files are supported by nldoc.

_-_includes["Wolf Sheep Predation Extra.nls"]

\section{Global variables}

\section{Description}

There is only one global variable that stores the max number of sheep allowed

globals [ max-sheep ] ; don't let sheep population grow too large

\section{Breeds}

\section{Description}

There are two breeds: sheep and wolves

breed [ sheep a-sheep ] ; sheep is its own plural, so we use "a-sheep" as the singular. breed [ wolves wolf]

\section{Agent properties}

\section{Description}

Sheep and wolves have a energy variable. Patches have a countdown variable to store the current state of the grass regrowth countdown.

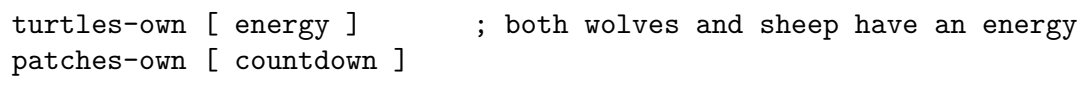

\section{Procedures}

\section{Setup}

\section{Description}

The setup procedure first resets the model. Depending on the chosen model version, grass patches are initialized. Finally, wolves and sheep are created.

Go

\section{Description}

This is the main procedure of the model. It iterates over sheep and wolve agents. These agents then move, forage and die if they dont have enough energy.

\section{Move}

\section{Description}

Turtles turn left and right at random and then move one patch forward.

to move ; turtle procedure

rt random 50 


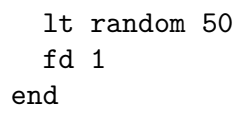

\section{eat-grass}

\section{Description}

If the current patch contains grass, the sheep eats it and gains energy. Then the patch color is set to brown

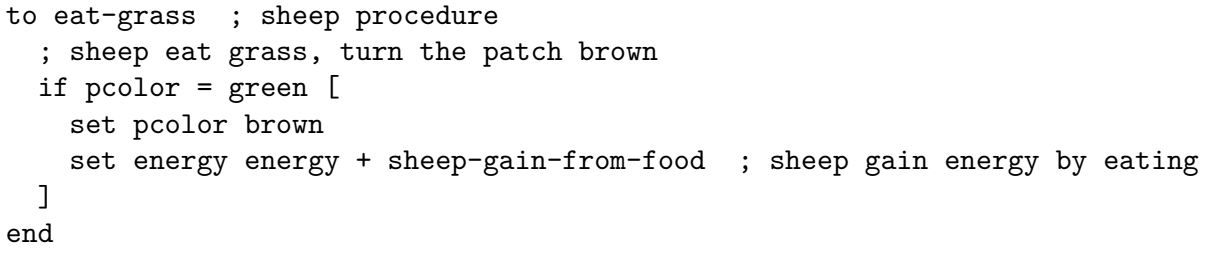

\section{reproduce-sheep}

\section{Description}

Under a defined probability, a sheep may hatch a new offspring and loses $50 \%$ of its energy.

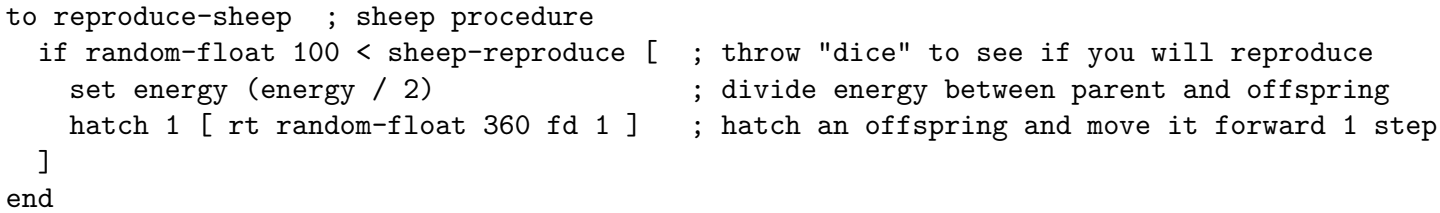

\section{reproduce-wolves}

\section{Description}

Under a defined probability, a wolf may hatch a new offspring and loses $50 \%$ of its energy.

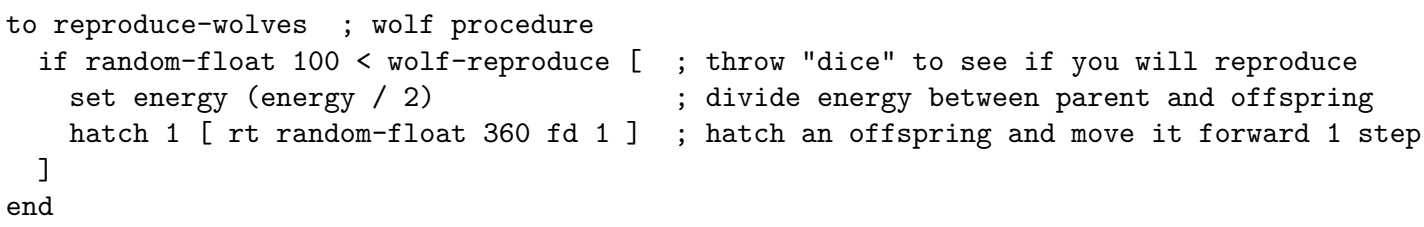

\section{eat-sheep}

\section{Description}

If a wolf meets a sheep, the sheep dies and the wolf gains energy.

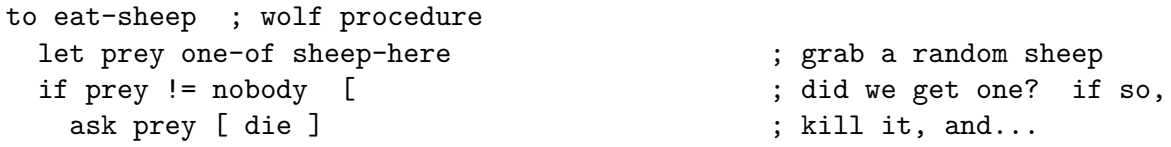




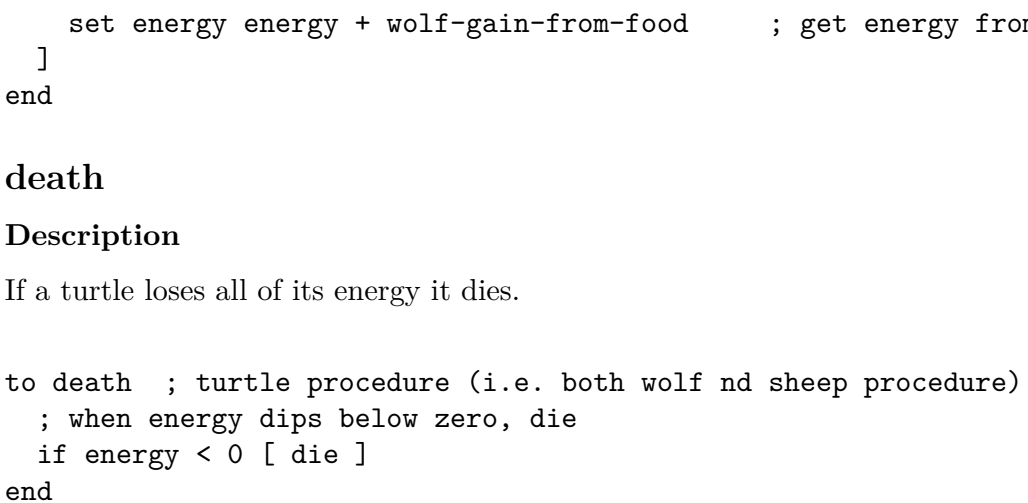

\section{grow-grass}

\section{Description}

The patch countdown timer is reduced for all brown patches. If the countdown of a brown patch is 0 , it turns green.

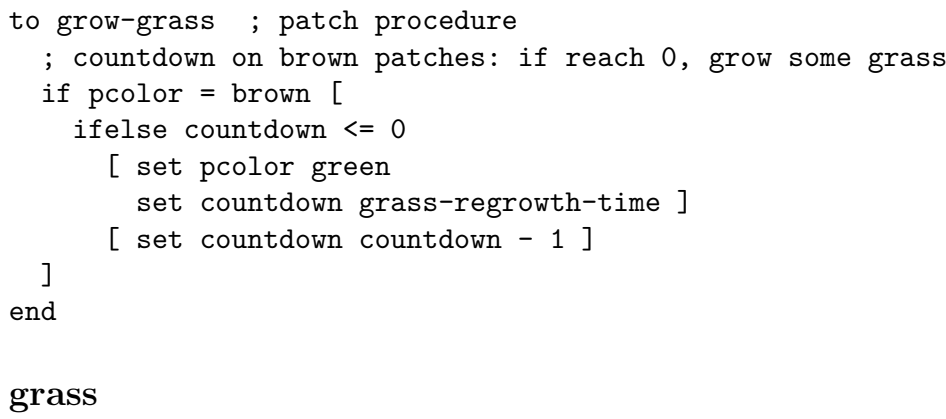

\section{Return}

number of green patches

\section{Description}

Reports the number of grass patches

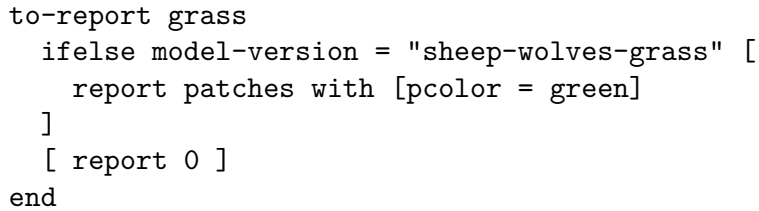

\section{display-labels}

\section{Description}

Sets energy levels as labels of sheep and wolves 


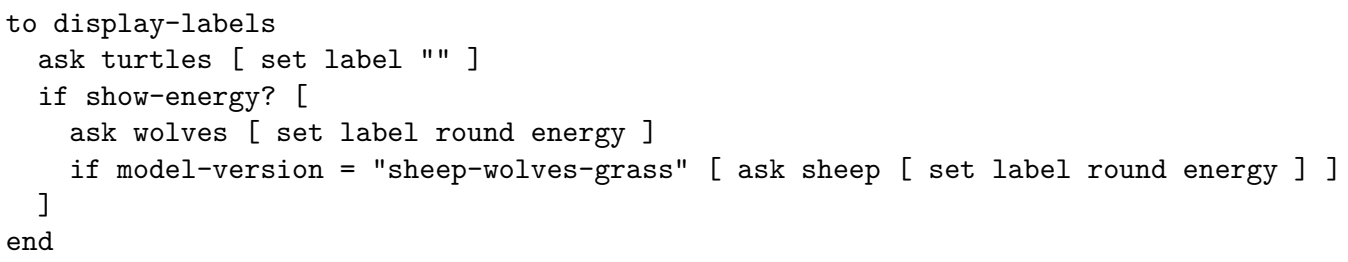

\section{reset-patches}

\section{Description}

This function just resets all patches to green color

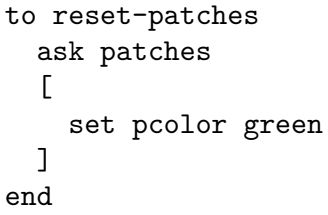

reset-turtles

\section{Description}

This function creates some turtles

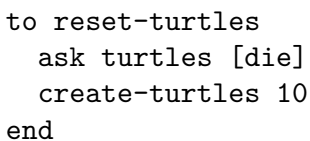

\section{calc-sum}

\section{Parameters}

a any number $b$ any number

\section{Return}

sum of $\mathrm{a}$ and $\mathrm{b}$

\section{Description}

This function calculates the sum of two provided numbers

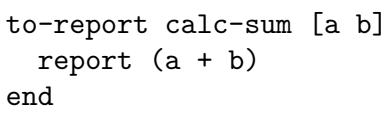

\section{GUI elements}




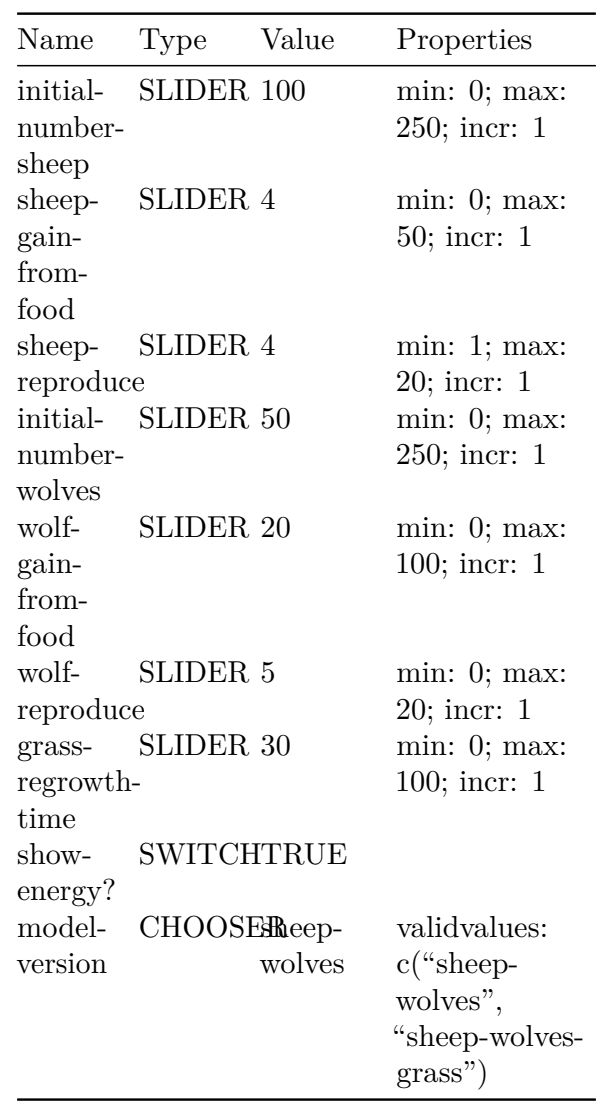

\section{Info Tab}

\section{WHAT IS IT?}

This model explores the stability of predator-prey ecosystems. Such a system is called unstable if it tends to result in extinction for one or more species involved. In contrast, a system is stable if it tends to maintain itself over time, despite fluctuations in population sizes.

\section{HOW IT WORKS}

There are two main variations to this model.

In the first variation, the "sheep-wolves" version, wolves and sheep wander randomly around the landscape, while the wolves look for sheep to prey on. Each step costs the wolves energy, and they must eat sheep in order to replenish their energy - when they run out of energy they die. To allow the population to continue, each wolf or sheep has a fixed probability of reproducing at each time step. In this variation, we model the grass as "infinite" so that sheep always have enough to eat, and we don't explicitly model the eating or growing of grass. As such, sheep don't either gain or lose energy by eating or moving. This variation produces interesting population dynamics, but is ultimately unstable. This variation of the model is particularly well-suited to interacting species in a rich nutrient environment, such as two strains of bacteria in a petri dish (Gause, 1934).

The second variation, the "sheep-wolves-grass" version explictly models grass (green) in addition to wolves and sheep. The behavior of the wolves is identical to the first variation, however this time the sheep must eat 
grass in order to maintain their energy - when they run out of energy they die. Once grass is eaten it will only regrow after a fixed amount of time. This variation is more complex than the first, but it is generally stable. It is a closer match to the classic Lotka Volterra population oscillation models. The classic LV models though assume the populations can take on real values, but in small populations these models underestimate extinctions and agent-based models such as the ones here, provide more realistic results. (See Wilensky \& Rand, 2015; chapter 4).

The construction of this model is described in two papers by Wilensky \& Reisman (1998; 2006) referenced below.

\section{HOW TO USE IT}

1. Set the model-version chooser to "sheep-wolves-grass" to include grass eating and growth in the model, or to "sheep-wolves" to only include wolves (black) and sheep (white).

2. Adjust the slider parameters (see below), or use the default settings.

3. Press the SETUP button.

4. Press the GO button to begin the simulation.

5. Look at the monitors to see the current population sizes

6. Look at the POPULATIONS plot to watch the populations fluctuate over time

Parameters: MODEL-VERSION: Whether we model sheep wolves and grass or just sheep and wolves INITIAL-NUMBER-SHEEP: The initial size of sheep population INITIAL-NUMBER-WOLVES: The initial size of wolf population SHEEP-GAIN-FROM-FOOD: The amount of energy sheep get for every grass patch eaten (Note this is not used in the sheep-wolves model version) WOLF-GAIN-FROM-FOOD: The amount of energy wolves get for every sheep eaten SHEEP-REPRODUCE: The probability of a sheep reproducing at each time step WOLF-REPRODUCE: The probability of a wolf reproducing at each time step GRASSREGROWTH-TIME: How long it takes for grass to regrow once it is eaten (Note this is not used in the sheep-wolves model version) SHOW-ENERGY?: Whether or not to show the energy of each animal as a number

Notes: - one unit of energy is deducted for every step a wolf takes - when running the sheep-wolves-grass model version, one unit of energy is deducted for every step a sheep takes

There are three monitors to show the populations of the wolves, sheep and grass and a populations plot to display the population values over time.

If there are no wolves left and too many sheep, the model run stops.

\section{THINGS TO NOTICE}

When running the sheep-wolves model variation, watch as the sheep and wolf populations fluctuate. Notice that increases and decreases in the sizes of each population are related. In what way are they related? What eventually happens?

In the sheep-wolves-grass model variation, notice the green line added to the population plot representing fluctuations in the amount of grass. How do the sizes of the three populations appear to relate now? What is the explanation for this?

Why do you suppose that some variations of the model might be stable while others are not?

\section{THINGS TO TRY}

Try adjusting the parameters under various settings. How sensitive is the stability of the model to the particular parameters?

Can you find any parameters that generate a stable ecosystem in the sheep-wolves model variation? 
Try running the sheep-wolves-grass model variation, but setting INITIAL-NUMBER-WOLVES to 0. This gives a stable ecosystem with only sheep and grass. Why might this be stable while the variation with only sheep and wolves is not?

Notice that under stable settings, the populations tend to fluctuate at a predictable pace. Can you find any parameters that will speed this up or slow it down?

\section{EXTENDING THE MODEL}

There are a number ways to alter the model so that it will be stable with only wolves and sheep (no grass). Some will require new elements to be coded in or existing behaviors to be changed. Can you develop such a version?

Try changing the reproduction rules - for example, what would happen if reproduction depended on energy rather than being determined by a fixed probability?

Can you modify the model so the sheep will flock?

Can you modify the model so that wolves actively chase sheep?

\section{NETLOGO FEATURES}

Note the use of breeds to model two different kinds of "turtles": wolves and sheep. Note the use of patches to model grass.

Note use of the ONE-OF agentset reporter to select a random sheep to be eaten by a wolf.

\section{RELATED MODELS}

Look at Rabbits Grass Weeds for another model of interacting populations with different rules.

\section{CREDITS AND REFERENCES}

Wilensky, U. \& Reisman, K. (1998). Connected Science: Learning Biology through Constructing and Testing Computational Theories - an Embodied Modeling Approach. International Journal of Complex Systems, M. 234, pp. 1 - 12. (The Wolf-Sheep-Predation model is a slightly extended version of the model described in the paper.)

Wilensky, U. \& Reisman, K. (2006). Thinking like a Wolf, a Sheep or a Firefly: Learning Biology through Constructing and Testing Computational Theories - an Embodied Modeling Approach. Cognition \& Instruction, 24(2), pp. 171-209. http://ccl.northwestern.edu/papers/wolfsheep.pdf .

Wilensky, U., \& Rand, W. (2015). An introduction to agent-based modeling: Modeling natural, social and engineered complex systems with NetLogo. Cambridge, MA: MIT Press.

Lotka, A. J. (1925). Elements of physical biology. New York: Dover.

Volterra, V. (1926, October 16). Fluctuations in the abundance of a species considered mathematically. Nature, $118,558 \hat{\text { €€ } " 560 .}$

Gause, G. F. (1934). The struggle for existence. Baltimore: Williams \& Wilkins.

\section{HOW TO CITE}

If you mention this model or the NetLogo software in a publication, we ask that you include the citations below.

For the model itself: 


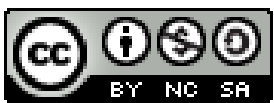

Figure 1: CC BY-NC-SA 3.0

- Wilensky, U. (1997). NetLogo Wolf Sheep Predation model. http://ccl.northwestern.edu/netlogo/ models/WolfSheepPredation. Center for Connected Learning and Computer-Based Modeling, Northwestern University, Evanston, IL.

Please cite the NetLogo software as:

- Wilensky, U. (1999). NetLogo. http://ccl.northwestern.edu/netlogo/. Center for Connected Learning and Computer-Based Modeling, Northwestern University, Evanston, IL.

\section{COPYRIGHT AND LICENSE}

Copyright 1997 Uri Wilensky.

This work is licensed under the Creative Commons Attribution-NonCommercial-ShareAlike 3.0 License. To view a copy of this license, visit https://creativecommons.org/licenses/by-nc-sa/3.0/ or send a letter to Creative Commons, 559 Nathan Abbott Way, Stanford, California 94305, USA.

Commercial licenses are also available. To inquire about commercial licenses, please contact Uri Wilensky at uri@northwestern.edu.

This model was created as part of the project: CONNECTED MATHEMATICS: MAKING SENSE OF COMPLEX PHENOMENA THROUGH BUILDING OBJECT-BASED PARALLEL MODELS (OBPML). The project gratefully acknowledges the support of the National Science Foundation (Applications of Advanced Technologies Program) - grant numbers RED \#9552950 and REC \#9632612.

This model was converted to NetLogo as part of the projects: PARTICIPATORY SIMULATIONS: NETWORK-BASED DESIGN FOR SYSTEMS LEARNING IN CLASSROOMS and/or INTEGRATED SIMULATION AND MODELING ENVIRONMENT. The project gratefully acknowledges the support of the National Science Foundation (REPP \& ROLE programs) - grant numbers REC \#9814682 and REC-0126227. Converted from StarLogoT to NetLogo, 2000.

\section{Behavior Space Experiments}

\section{wolf-sheep-experiment}

\section{Definitions}

\begin{tabular}{|c|c|c|c|c|c|c|c|}
\hline Setup & Go & Final & Time limit & Metrics & Measure each tick & repetitions & exit condition \\
\hline setup & go & ca & 500 & count sheep; count wolves; grass & true & 10 & not any? turtles \\
\hline
\end{tabular}

\section{Parameters}

\begin{tabular}{lll}
\hline Parameter & Type & Values \\
\hline show-energy? & constant & false \\
wolf-reproduce & enumerated & $3,5,7$ \\
initial-number-wolves & constant & 50 \\
initial-number-sheep & constant & 100 \\
model-version & enumerated & "sheep-wolves", "sheep-wolves-grass" \\
sheep-gain-from-food & constant & 4 \\
grass-regrowth-time & constant & 30 \\
sheep-reproduce & enumerated & $3,4,5$ \\
wolf-gain-from-food & sequence & 9 from: 10; to: 30; by: 5 \\
\hline
\end{tabular}




\section{D.3.2 Generate procedure networks of NetLogo models with $n l r x$}

Furthermore, complex NetLogo models often have a high number of model procedures, whose calls are nested into each other. This logical flow of NetLogo model can be seen as a complex network of procedures. Unfortunately, NetLogo does not provide tools to visualize the connections between different procedures. nlrx provides the function nldoc_network() that generates an igraph object from NetLogo model procedure calls. Analysing and visualizing this network may help to understand the logical connections in complex agent-based models (see Fig. D.1).

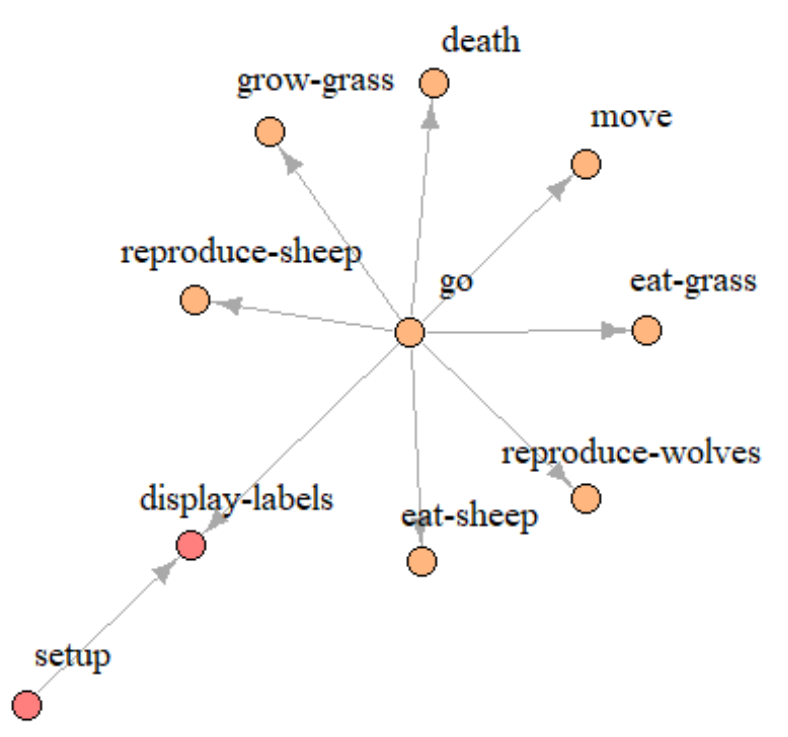

Figure D.1: Visualization of logical connections between model procedures within the Wolf Sheep Predation model from the NetLogo Models Library. The network was created by applying the nldoc_network() function of the nlrx package and visualized using the igraph package.

\section{D.4 Ants spatial}

nlrx captures metrics from NetLogo, either for agents, patches or links. Hence, all simulated properties from an agent-based model on the individual level can be 
further analysed in $\mathrm{R}$. This also leverages the vast geospatial analysis tools from $\mathrm{R}$ to ecologists dealing with NetLogo. In this example, we show a very simple analysis of attraction and repulsion of the ant agents during food collection.

First, we specify the relevant metrics we need to perform a spatial analysis (the coordinates of agents and further information that are needed to derive meaningful statistics). Here, we are interested in the spatial patterns of ants after at least one of the agents was able to collect a food resource. Hence, we store the metrics for coordinates and the color of agents in the experiment of the $\mathrm{nl}$ object. The color of the ant agents codes for individuals with and without an attached food resource, and is thus used in our spatial analysis as label. We simulate one parameterization of the Ants model without repetitions.

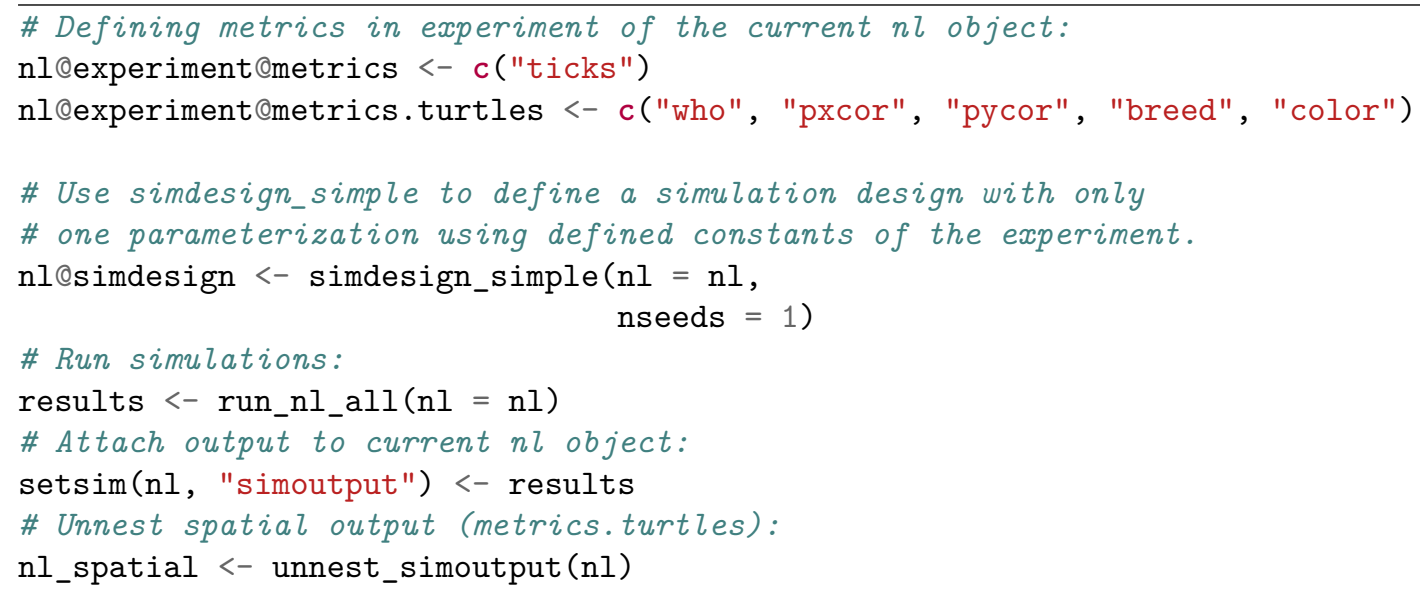

Listing 12: Run one simulation and measure agent metrics.

Secondly, after unnesting the metrics, the data are in a format that makes further post-processing (transforming to other $\mathrm{R}$ objects) straightforward. We coerce the data into a bivariate spatial point pattern with the spatstat package (BADDELEY et al., 2015). Given the chemical cues that are released by ants that carry a food resource, one would hypothesize that ants are more clustered at fine scales than on broader scales. Furthermore, we expect that this pattern has three peaks in time - for each of the food clusters the ants can find.

Thirdly, we test for this spatial pattern with the bivariate pair correlation function, assuming complete spatial randomness as null model. This statistic tests for spatial patterns that are segregated, random or clustered over spatial scales (for more details see WiEgand and Moloney, 2013). Spatial patterns in this functions carry two marks, where one mark is the center for the calculation and the other mark is tested for the spatial dispersion around the first mark. We calculate the pair correlation function for each step, with the ants carrying resource as one 
mark for the spatial pattern, and all other ants as the other mark. We find two distinct patterns in our data, a very strong clustering of ants around individuals with food resources at very early stages of a model run and a peak of clustering starting after 370 model steps (Fig. D.2). This indicates that the ants find the first location of food patches considerably fast, while the other two locations are only found and depleted with a time lag. 


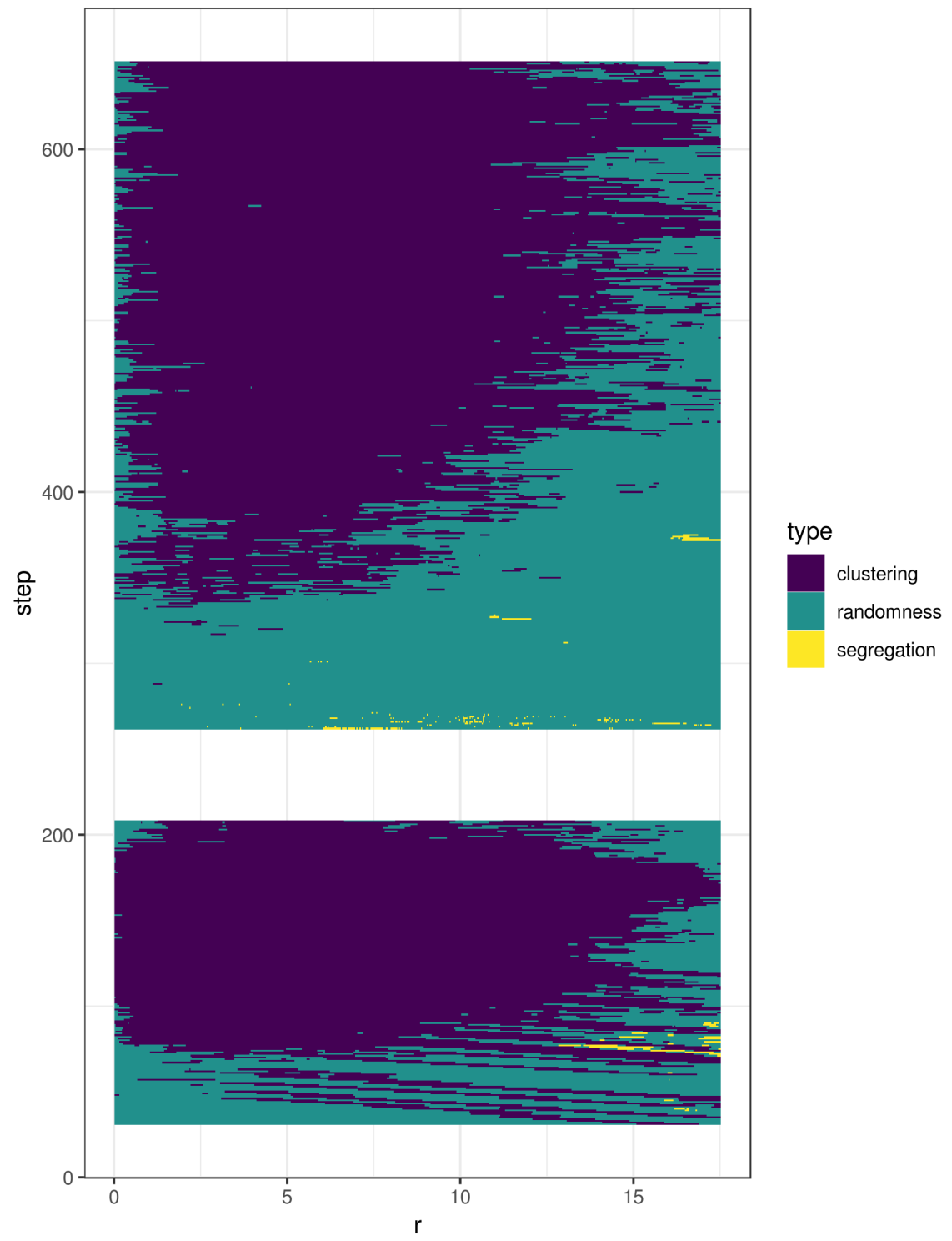

Figure D.2: Results from bivariate point pattern analysis. We measured positions of ants carrying food and compared the spatial pattern to positions of all other ants at each simulation tick. The gap between step 200 and 270 is caused by no ants finding any food resource. 


\section{References}

Abar, S., Theodoropoulos, G. K., Lemarinier, P., and O'Hare, G. M. (2017). "Agent Based Modelling and Simulation tools: A review of the state-ofart software". Computer Science Review 24, 13-33. DOI: 10.1016/J.COSREV 2017.03 .001 .

AN, L. (2012). "Modeling human decisions in coupled human and natural systems: Review of agent-based models". Ecological Modelling 229, 25-36. DOI: 10.1016/ j.ecolmodel.2011.07.010.

An, L., Linderman, M., QI, J., Shortridge, A., and LiU, J. (2005). "Exploring Complexity in a Human-Environment System: An Agent-Based Spatial Model for Multidisciplinary and Multiscale Integration". Annals of the Association of American Geographers 95.1, 54-79. DOI: 10.1111/j.1467-8306.2005.00450.x.

Ayllón, D., Railsback, S. F., Vincenzi, S., Groeneveld, J., and Almodóvar, A. (2016). "InSTREAM-Gen: Modelling eco-evolutionary dynamics of trout populations under anthropogenic environmental change". Ecological Modelling 326, 36-53. DOI: 10.1016/J .ECOLMODEL . 2015.07.026.

Baddeley, A., Rubak, E., and Turner, R. (2015). Spatial point patterns: methodology and applications with $R$. Boca Raton: Chapman and Hall/CRC.

Baldeck, C. A., Harms, K. E., Yavitt, J. B., John, R., Turner, B. L., Valencia, R., Navarrete, H., Bunyavejchewin, S., Kiratiprayoon, S., Yaacob, A., Supardi, M. N. N., Davies, S. J., Hubbell, S. P., Chuyong, G. B., Kenfack, D., Thomas, D. W., and Dalling, J. W. (2013). "Habitat filtering across tree life stages in tropical forest communities". Proceedings of the Royal Society B: Biological Sciences 280.1766, 20130548. DOI: 10.1098/ rspb.2013.0548.

Barlow, J., Franca, F., Gardner, T., Hicks, C., Lennox, G., Berenguer, E., Castello, L., Economo, E., Ferreira, J., Guénard, B., Leal, C., Victoria, I., Lees, A., Parr, C., Wilson, S., Young, P., and Graham, N. (2018). "The future of hyperdiverse tropical ecosystems". Nature 559, 517-526. DOI: $10.1038 / \mathrm{s} 41586-018-0301-1$.

Barnes, A. D., Jochum, M., Mumme, S., Haneda, N. F., Farajallah, A., Widarto, T. H., and Brose, U. (2014). "Consequences of tropical land use for multitrophic biodiversity and ecosystem functioning". Nature Communications 5, 5351. DOI: $10.1038 /$ ncomms6351. 
Beck, J., Holloway, J. D., and Schwanghart, W. (2013). "Undersampling and the measurement of beta diversity". Methods in Ecology and Evolution 4.4, 370-382. DOI: $10.1111 / 2041-210 x .12023$.

Bell, A, Parkhurst, G, Droppelmann, K, and Benton, T. (2016). "Scaling up pro-environmental agricultural practice using agglomeration payments: Proof of concept from an agent-based model". Ecological Economics 126, 32-41.

Berger, T. (2001). "Agent-based spatial models applied to agriculture: a simulation tool for technology diffusion, resource use changes and policy analysis". Agricultural Economics 25.2-3, 245-260. DOI: $10.1111 /$ j.1574-0862. 2001 tb00205.x.

Berkes, F., Folke, C., and Colding, J. (1998). Linking social and ecological systems : management practices and social mechanisms for building resilience. Cambridge: Cambridge University Press, 459.

Bruch, E. and Atwell, J. (2015). "Agent-Based Models in Empirical Social Research". Sociological Methods \& Research 44.2, 186-221. DOI: $10.1177 /$ 0049124113506405 .

Cabral, J. S., Valente, L., and Hartig, F. (2017). "Mechanistic simulation models in macroecology and biogeography: state-of-art and prospects". Ecography $40.2,267-280$.

Cartwright, S. J., Bowgen, K. M., Collop, C., Hyder, K., Nabe-Nielsen, J., Stafford, R., Stillman, R. A., Thorpe, R. B., and Sibly, R. M. (2016). "Communicating complex ecological models to non-scientist end users". Ecological Modelling 338, 51-59. DOI: 10.1016/j.ecolmodel.2016.07.012.

Chan, K., Tarantola, S., Saltelli, A., and Sobol, I. M. (2000). "VarianceBased Methods". Sensitivity Analysis. Ed. by A. SAltelli, K. Chan, and E. Scotт. Chichester: Wiley, 167-197.

Chao, A., Colwell, R. K., Gotelli, N. J., Hsieh, T. C., Sander, E. L., Ma, K. H., Colwell, R. K., and Ellison, A. M. (2014). "Rarefaction and extrapolation with Hill numbers : A framework for sampling and estimation in species diversity studies". Ecological Monographs 84.1, 45-67. DOI: 10.1890/130133.1.

Clough, Y., Barkmann, J., Juhrbandt, J., Kessler, M., Wanger, T. C., Anshary, A., Buchori, D., Cicuzza, D., Darras, K., Putra, D. D., Erasmi, S., Pitopang, R., Schmidt, C., Schulze, C. H., Seidel, D., SteffanDewenter, I., Stenchly, K., Vidal, S., Weist, M., Wielgoss, A. C., and TscharntKe, T. (2011). "Combining high biodiversity with high yields in 
tropical agroforests". Proceedings of the National Academy of Sciences 108.20, 8311-8316. DOI: 10.1073/pnas.1016799108.

Clough, Y., Krishna, V. V., Corre, M. D., Darras, K., Denmead, L. H., MeiJide, A., Moser, S., Musshoff, O., Steinebach, S., Veldkamp, E., Allen, K., Barnes, A. D., Breidenbach, N., Brose, U., Buchori, D., Daniel, R., Finkeldey, R., Harahap, I., Hertel, D., Holtkamp, A. M., Hörandl, E., Irawan, B., Jaya, I. N. S., Jochum, M., Klarner, B., Knohl, A., Kotowska, M. M., Krashevska, V., Kreft, H., Kurniawan, S., Leuschner, C., Maraun, M., Melati, D. N., Opfermann, N., Pérez-Cruzado, C., Prabowo, W. E., Rembold, K., Rizali, A., Rubiana, R., Schneider, D., Tuitrosoedirdjo, S. S., TuoA, A., Tscharntke, T., and Scheu, S. (2016). "Land-use choices follow profitability at the expense of ecological functions in Indonesian smallholder landscapes". Nature Communications 7, 13137. DOI: 10.1038/ncomms 13137 .

Comte, I., Colin, F., Whalen, J. K., Grunberger, O., and Caliman, J. P. (2012). "Chapter three - Agricultural Practices in Oil Palm Plantations and Their Impact on Hydrological Changes, Nutrient Fluxes and Water Quality in Indonesia: A Review". Advances in Agronomy 116, 71-124. DOI: 10.1016/B9780-12-394277-7.00003-8.

Condit, R., Pitman, N., Leigh, E. G., Chave, J., Terborgh, J., Foster, R. B., Núñez, P., Aguilar, S., Valencia, R., Villa, G., Muller-Landau, H. C., Losos, E., and Hubbell, S. P. (2002). "Beta-Diversity in Tropical Forest Trees". Science 295.5555, 666-669. DOI: 10.1126/science.1066854.

Corley, R. H. V. and Tinker, P. B. H. (2008). The Oil Palm. Chichester: John Wiley \& Sons.

DeAngelis, D. L. and Grimm, V. (2014). "Individual-based models in ecology after four decades". F1000Prime Reports 6. DOI: 10.12703/P6-39.

Diewert, W. E. (1971). "An Application of the Shephard Duality Theorem: A Generalized Leontief Production Function". Journal of Political Economy 79.3, 481-507.

Dislich, C., Keyel, A. C., Salecker, J., Kisel, Y., Meyer, K. M., Auliya, M., Barnes, A. D., Corre, M. D., Darras, K., Faust, H., Hess, B., Klasen, S., Knohl, A., Kreft, H., Meijide, A., Nurdiansyah, F., Otten, F., Pe'er, G., Steinebach, S., Tarigan, S., Tölle, M. H., Tscharntke, T., and WiEgand, K. (2017). "A review of the ecosystem functions in oil palm plantations, using forests as a reference system". Biological Reviews 92.3, 15391569. DOI: $10.1111 / \mathrm{brv} .12295$. 
Dislich, C., Hettig, E., Salecker, J., Heinonen, J., Lay, J., Meyer, K. M., WiEgand, K., and TARigan, S. (2018). "Land-use change in oil palm dominated tropical landscapes - An agent-based model to explore ecological and socioeconomic trade-offs". PLOS ONE 13.1, e0190506. DOI: 10.1371/journal.pone 0190506

Drescher, J., Rembold, K., Allen, K., Beckschäfer, P., Buchori, D., Clough, Y., Faust, H., Fauzi, A. M., Gunawan, D., Hertel, D., Irawan, B., Jaya, I. N. S., Klarner, B., Kleinn, C., Knohl, A., Kotowska, M. M., Krashevska, V., Krishna, V., Leuschner, C., Lorenz, W., Meijide, A., Melati, D., Nomura, M., Pérez-Cruzado, C., Qaim, M., Siregar, I. Z., Steinebach, S., TuoA, A., Tscharntke, T., Wick, B., Wiegand, K., Kreft, H., and Scheu, S. (2016). "Ecological and socio-economic functions across tropical land use systems after rainforest conversion". Philosophical Transactions of the Royal Society B 371.1694, 20150275. DOI: 10.1098/rstb 2015.0275.

Ebert, D. S., Musgrave, F. K., Peachey, D., Perlin, K., Worley, S., Mark, W. R., and HART, J. C. (2003). Texturing \& modeling : a procedural approach. San Francisco: Morgan Kaufmann, 687.

Edwards, D. P., Magrach, A., Woodcock, P., Ji, Y., Lim, N. T.-L., Edwards, F. A., Larsen, T. H., Hsu, W. W., Benedick, S., Khen, C. V., Chung, A. Y. C., Reynolds, G., Fisher, B., Laurance, W. F., Wilcove, D. S., Hamer, K. C., and YU, D. W. (2014). "Selective-logging and oil palm: multitaxon impacts, biodiversity indicators, and trade-offs for conservation planning". Ecological Applications 24.8, 2029-2049. DOI: 10.1890/14-0010.1.

Euler, M., Krishna, V., Fathoni, Z., Hermanto, S., Schwarze, S., and QAIM, M. (2012). "Ecological and Socioeconomic Functions of Tropical Lowland Rainforest Transformation Systems (Sumatra, Indonesia), Household Survey 2012". Göttingen, Germany; Jambi, Indonesia; Bogor, Indonesia. Georg-August University of Goettingen, Bogor Agricultural University, and University of Jambi (datasets).

Euler, M., Hoffmann, M. P., Fathoni, Z., and Schwarze, S. (2016a). "Exploring yield gaps in smallholder oil palm production systems in eastern Sumatra, Indonesia". Agricultural Systems 146, 111-119. DOI: 10.1016/j .agsy . 2016 04.007 .

Euler, M., Schwarze, S., Siregar, H., and Qaim, M. (2016b). "Oil Palm Expansion among Smallholder Farmers in Sumatra, Indonesia". Journal of Agricultural Economics 67.3, 658-676. DOI: 10.1111/1477-9552.12163. 
Euler, M., Krishna, V., Schwarze, S., Siregar, H., and Qaim, M. (2017). "Oil Palm Adoption, Household Welfare, and Nutrition Among Smallholder Farmers in Indonesia". World Development 93, 219-235. DOI: 10.1016/j.worlddev. 2016.12.019.

Evans, M. R., Grimm, V., Johst, K., Knuuttila, T., Langhe, R. de, LesSells, C. M., Merz, M., O’Malley, M. A., Orzack, S. H., Weisberg, M., Wilkinson, D. J., Wolkenhauer, O., and Benton, T. G. (2013). "Do simple models lead to generality in ecology?" Trends in Ecology $\& 5$ Evolution 28.10, 578-583. DOI: $10.1016 / \mathrm{j}$. tree.2013.05.022.

Faust, H., Schwarze, S., Beckert, B., Brümmer, B., Dittrich, C., Euler, M., Gatto, M., Hauser-Schäublin, B., Hein, J., Holtkamp, A. M., IbanezDiaz, M., Klasen, S., Kopp, T., Krishna, V., Kunz, Y., Lay, J., Musshoff, O., Qaim, M., Steinebach, S., and Vorlaufer, M. (2013). "Assessment of socio-economic functions of tropical lowland transformation systems in Indonesia - sampling framework and methodological approach". EFForTS Discussion Paper Series 1, University of Goettingen.

Feintrenie, L., Schwarze, S., and Levang, P. (2010). "Are Local People Conservationists? Analysis of Transition Dynamics from Agroforests to Monoculture Plantations in Indonesia". Ecology and Society 15.4. DOI: 10.5751/ES-03870150437.

Ferrier, S., Manion, G., Elith, J., and Richardson, K. (2007). "Using generalized dissimilarity modelling to analyse and predict patterns of beta diversity in regional biodiversity assessment". Diversity and Distributions 13.3, 252-264. DOI: $10.1111 / \mathrm{j} .1472-4642.2007 .00341 . \mathrm{x}$.

Fischer, R., Bohn, F., Paula, M. Dantas de, Dislich, C., Groeneveld, J., Gutiérrez, A. G., Kazmierczak, M., Knapp, N., Lehmann, S., Paulick, S., Pütz, S., Rödig, E., Taubert, F., Köhler, P., and Huth, A. (2016). "Lessons learned from applying a forest gap model to understand ecosystem and carbon dynamics of complex tropical forests". Ecological Modelling. Next generation ecological modelling, concepts, and theory: structural realism, emergence, and predictions 326, 124-133. DOI: $10.1016 / \mathrm{j}$. ecolmodel.2015.11.018.

Flynn, D. F. B., Gogol-Prokurat, M., Nogeire, T., Molinari, N., Richers, B. T., Lin, B. B., Simpson, N., Mayfield, M. M., and DeClerck, F. (2009). "Loss of functional diversity under land use intensification across multiple taxa". Ecology Letters 12.1, 22-33. DOI: 10.1111/j.1461-0248.2008.01255.x.

Foley, J. A., Defries, R., Asner, G. P., Barford, C., Bonan, G., Carpenter, S. R., Chapin, F. S., Coe, M. T., Daily, G. C., Gibbs, H. K., Helkowski, 
J. H., Holloway, T., Howard, E. A., Kucharik, C. J., Monfreda, C., Patz, J. A., Prentice, I. C., Ramankutty, N., and Snyder, P. K. (2005). "Global consequences of land use." Science (New York, N.Y.) 309.5734, 570-4. DOI: $10.1126 /$ science. 1111772 .

Frishkoff, L., Gabot, E., Sandler, G., Marte, C., and Mahler, D. (Apr. 2019). "Elevation shapes the reassembly of Anthropocene lizard communities". Nature Ecology \&6 Evolution 3, 1. DOI: 10.1038/s41559-019-0819-0.

Gardner, R. H., Milne, B. T., Turnei, M. G., and O’Neill, R. V. (1987). "Neutral models for the analysis of broad-scale landscape pattern". Landscape Ecology 1.1, 19-28. DOI: $10.1007 /$ BF02275262.

Gatto, M., Wollni, M., and QAim, M. (2015). "Oil palm boom and land-use dynamics in Indonesia: The role of policies and socioeconomic factors". Land Use Policy 46, 292-303. DOI: 10.1016/j.landusepol.2015.03.001.

Gaucherel, C., Giboire, N., Viaud, V., Houet, T., Baudry, J., and Burel, F. (2006). "A domain-specific language for patchy landscape modelling: The Brittany agricultural mosaic as a case study". Ecological Modelling 194.1-3, 233-243. DOI: $10.1016 /$ J.ECOLMODEL . 2005.10.026.

Germer, J. and Sauerborn, J. (2008). "Estimation of the impact of oil palm plantation establishment on greenhouse gas balance". Environment, Development and Sustainability 10.6, 697-716. DOI: 10.1007/s10668-006-9080-1.

Grimm, V and Railsback, S. F. (2005). Individual-Based Modeling and Ecology. Princeton: Princeton University Press.

Grimm, V, Berger, U, Bastiansen, F, Eliassen, S, Ginot, V, Giske, J, GossCustard, J, Grand, T, Heinz, S. K., Huse, G, Huth, A, Jepsen, J. U., Jorgensen, C, Mooij, W. M., Müller, B, Pe'er, G, Piou, C, Railsback, S. F., Robbins, A. M., Robbins, M. M., Rossmanith, E, Rüger, N, Strand, E, Souissi, S, Stillman, R. A., Vabo, R, Visser, U, and DeAngelis, D (2006a). "A standard protocol for describing individual-based and agent-based models". Ecological Modelling 198, 115-126. DOI: 10.1016/j.ecolmodel.2006. 04.023.

Grimm, V. and Berger, U. (2016). "Structural realism, emergence, and predictions in next-generation ecological modelling: Synthesis from a special issue". Ecological Modelling 326, 177-187. DOI: 10.1016/J.ECOLMODEL.2016.01.001.

Grimm, V., Berger, U., Bastiansen, F., Eliassen, S., Ginot, V., Giske, J., Goss-Custard, J., Grand, T., Heinz, S. K., Huse, G., Huth, A., Jepsen, J. U., Jørgensen, C., Mooij, W. M., Müller, B., Pe’er, G., Piou, C., 
Railsback, S. F., Robbins, A. M., Robbins, M. M., Rossmanith, E., RüGer, N., Strand, E., Souissi, S., Stillman, R. A., Vabø, R., Visser, U., and DeAngelis, D. L. (2006b). "A standard protocol for describing individualbased and agent-based models". Ecological Modelling 198.1-2, 115-126. DOI: $10.1016 / \mathrm{j}$.ecolmodel.2006.04.023.

Grimm, V., Berger, U., DeAngelis, D. L., Polhill, J. G., Giske, J., and RAILsBaCK, S. F. (2010). "The ODD protocol: A review and first update". Ecological Modelling 221.23, 2760-2768. DOI: 10.1016/j.ecolmodel.2010.08. 019.

Grimm, V., Augusiak, J., Focks, A., Frank, B. M., Gabsi, F., Johnston, A. S., Liu, C., Martin, B. T., Meli, M., Radchuk, V., Thorbek, P., and RAILsBaCK, S. F. (2014). "Towards better modelling and decision support: Documenting model development, testing, and analysis using TRACE". Ecological Modelling 280, 129-139. DOI: 10.1016/j.ecolmodel.2014.01.018.

Hassler, E., Corre, M. D., Kurniawan, S., and Veldkamp, E. (2017). "Soil nitrogen oxide fluxes from lowland forests converted to smallholder rubber and oil palm plantations in Sumatra, Indonesia". Biogeosciences 14.11, 2781-2798. DOI: $10.5194 / \mathrm{bg}-14-2781-2017$.

Hettig, E., Lay, J., and Sipangule, K. (2016). "Drivers of Households' Land-Use Decisions: A Critical Review of Micro-Level Studies in Tropical Regions". Land 5.4, 32. DOI: $10.3390 /$ land5040032.

Hoffmann, M. P., Castaneda Vera, A., Wijk, M. T. van, Giller, K. E., Oberthür, T., Donough, C., and Whitbread, A. M. (2014). "Simulating potential growth and yield of oil palm (Elaeis guineensis) with PALMSIM: Model description, evaluation and application". Agricultural Systems 131, 1-10. DOI: $10.1016 / \mathrm{j}$.agsy.2014.07.006.

Holdo, R. M., Galvin, K. A., Knapp, E., Polasky, S., Hilborn, R., and Holt, R. D. (2010). "Responses to alternative rainfall regimes and antipoaching in a migratory system". Ecological Applications: A Publication of the Ecological Society of America 20.2, 381-397.

Holland, J. H. (1992). Adaptation in Natural and Artificial Systems: An Introductory Analysis with Applications to Biology, Control and Artificial Intelligence. Cambridge, MA, USA: MIT Press.

Hsieh, T. C., MA, K. H., and ChaO, A. (2016). "iNEXT: an R package for rarefaction and extrapolation of species diversity (Hill numbers)". Methods in Ecology and Evolution 7.12, 1451-1456. DOI: 10.1111/2041-210X.12613. 
Ibisch, P. L., Hoffmann, M. T., Kreft, S., Pe'er, G., Kati, V., BiberFreudenberger, L., DellaSala, D. A., Vale, M. M., Hobson, P. R., and SELva, N. (2016). "A global map of roadless areas and their conservation status." Science (New York, N.Y.) 354.6318, 1423-1427. DOI: 10.1126/science. aaf7166.

IPCC (2006). "2006 IPCC Guidelines for National Greenhouse Gas Inventories". Vol. 4. IGES. Chap. 4: Forest Land, 4.1-4.83.

Jansen, M. J. (1999). "Analysis of variance designs for model output". Computer Physics Communications 117.1-2, 35-43. DOI: 10.1016/S0010-4655(98)001544.

Janssen, M. A. (2017). "The Practice of Archiving Model Code of Agent-Based Models". Journal of Artificial Societies and Social Simulation 20.1, 2. DOI: $10.18564 /$ jasss. 3317

Jeltsch, F., Blaum, N., Brose, U., Chipperfield, J. D., Clough, Y., Farwig, N., Geissler, K., Graham, C. H., Grimm, V., Hickler, T., Huth, A., May, F., Meyer, K. M., Pagel, J., Reineking, B., Rillig, M. C., Shea, K., Schurr, F. M., Schröder, B., Tielbörger, K., Weiss, L., Wiegand, K., Wiegand, T., Wirth, C., and Zurell, D. (2013). "How can we bring together empiricists and modellers in functional biodiversity research?" Basic and Applied Ecology 14.2, 93-101. Dor: 10.1016/j.baae.2013.01.001.

Karp, D. S., Rominger, A. J., Zook, J., Ranganathan, J., Ehrlich, P. R., and DAILY, G. C. (2012). "Intensive agriculture erodes $\beta$-diversity at large scales". Ecology Letters 15.9, 963-970. DOI: 10.1111/j.1461-0248.2012.01815.x.

Kelley, H. and Evans, T. (2011). "The relative influences of land-owner and landscape heterogeneity in an agent-based model of land-use". Ecological Economics 70.6, 1075 -1087. DOI: 10.1016/j .ecolecon.2010.12.009.

Kelly (Letcher), R. A., Jakeman, A. J., Barreteau, O., Borsuk, M. E., ElSawah, S., Hamilton, S. H., Henriksen, H. J., Kuikka, S., Maier, H. R., Rizzoli, A. E., Delden, H. van, and Voinov, A. A. (2013). "Selecting among five common modelling approaches for integrated environmental assessment and management". Environmental Modelling \& Software 47, 159-181. DOI: $10.1016 / j$.envsoft.2013.05.005.

Kempson, D. A., Lloyd, M., and Ghelardi, R. J. (1963). "A new extractor for woodland litter". Pedobiologia. Vol. 3. 1. Jena, Germany, 1-21.

Kiesling, E., Günther, M., Stummer, C., and Wakolbinger, L. M. (2012). "Agent-based simulation of innovation diffusion: a review". Central European 
Journal of Operations Research 20.2, 183-230. DOI: 10.1007/s10100-0110210-y

Kirby, K. R., Laurance, W. F., Albernaz, A. K., Schroth, G., Fearnside, P. M., Bergen, S., Venticinque, E. M., and Costa, C. da (2006). "The future of deforestation in the Brazilian Amazon". Futures 38.4, 432-453. DOI: 10.1016/J .FUTURES .2005.07.011.

Kirkpatrick, S., Gelatt, C. D., and Vecchi, M. P. (1983). "Optimization by Simulated Annealing". Science 220.4598, 671-680. DOI: 10.1126/science.220 4598.671 .

Klarner, B., Winkelmann, H., Krashevska, V., Maraun, M., Widyastuti, R., and Scheu, S. (2017). "Trophic niches, diversity and community composition of invertebrate top predators (Chilopoda) as affected by conversion of tropical lowland rainforest in Sumatra (Indonesia)". PLOS ONE 12.8, 1-17. DOI: 10 1371/journal.pone.0180915.

Klasen, S., Priebe, J., and Rudolf, R. (2013). "Cash crop choice and income dynamics in rural areas: evidence for post-crisis Indonesia". Agricultural Economics 44.3, 349-364. DOI: 10.1111 /agec. 12015 .

Klasen, S., Meyer, K. M., Dislich, C., Euler, M., Faust, H., Gatto, M., Hettig, E., Melati, D. N., Jaya, I. N. S., Otten, F., Pérez-Cruzado, C., Steinebach, S., Tarigan, S., and Wiegand, K. (2016). Economic and ecological trade-offs of agricultural specialization at different spatial scales. DOI: $10.1016 / \mathrm{j}$.ecolecon.2016.01.001.

KoH, L. P. (2011). "Balancing societies' priorities: An ecologist's perspective on sustainable development". Basic and Applied Ecology 12.5, 389-393. DOI: 10.1016/J.BAAE. 2011.05.004.

Koh, L. P., Levang, P., and Ghazoul, J. (2009). "Designer landscapes for sustainable biofuels". Trends in Ecology \&6 Evolution 24.8, 431-438. DOI: 10. 1016/j.tree.2009.03.012.

Kotowska, M. M., Leuschner, C., Triadiati, T., Meriem, S., and Hertel, D. (2015). "Quantifying above- and belowground biomass carbon loss with forest conversion in tropical lowlands of Sumatra (Indonesia)". Global Change Biology 21.10, 3620-3634. DOI: 10.1111/gcb.12979.

Krashevska, V., Klarner, B., Widyastuti, R., Maraun, M., and Scheu, S. (2015). "Impact of tropical lowland rainforest conversion into rubber and oil palm plantations on soil microbial communities". Biology and Fertility of Soils 51.6, 697-705. DOI: 10.1007/s00374-015-1021-4. 
Krashevska, V., Klarner, B., Widyastuti, R., Maraun, M., and Scheu, S. (2016). "Changes in Structure and Functioning of Protist (Testate Amoebae) Communities Due to Conversion of Lowland Rainforest into Rubber and Oil Palm Plantations". PLOS ONE 11.7, 1-15. DOI: 10.1371/ journal . pone 0160179

Krishna, V., Euler, M., Siregar, H., and Qaim, M. (2017). "Differential livelihood impacts of oil palm expansion in Indonesia". Agricultural Economics 48.5, 639-653. DOI: 10.1111 /agec. 12363 .

Krishna, V. V., Pascual, U., and QAim, M. (2014). "Do emerging land markets promote forestland appropriation? Evidence from Indonesia". EFForTS Discussion Paper Series 7, University of Goettingen.

Krishna, V. V., Euler, M., Siregar, H., Fathoni, Z., and QAim, M. (2015). "Farmer heterogeneity and differential livelihood impacts of oil palm expansion among smallholders in Sumatra, Indonesia". EFForTS Discussion Paper Series 13, University of Goettingen.

Kumar, M., Husian, M., Upreti, N., and Gupta, D. (2010). "Genetic Algorithm: Review and Application". International Journal of Information Technology and Knowledge Management 2.2, 451-454.

Kunz, Y., Steinebach, S., Dittrich, C., Hauser-Schäublin, B., Rosyani, I., Soetarto, E., and Faust, H. (2017). "The fridge in the forest': Historical trajectories of land tenure regulations fostering landscape transformation in Jambi Province, Sumatra, Indonesia". Forest Policy and Economics 81, 1-9. DOI: $10.1016 / \mathrm{j}$.forpol.2017.04.005.

Kurniawan, S., Corre, M. D., Matson, A. L., Schulte-Bisping, H., Utami, S. R., Straaten, O. van, and Veldkamp, E. (2018). "Conversion of tropical forests to smallholder rubber and oil palm plantations impacts nutrient leaching losses and nutrient retention efficiency in highly weathered soils". Biogeosciences 15.16, 5131-5154. DOI: 10.5194/bg-15-5131-2018.

Lai, J., Lortie, C. J., Muenchen, R. A., Yang, J., and MA, K. (2019). "Evaluating the popularity of R in ecology". Ecosphere 10.1, e02567.

Lambin, E. F., Turner, B., Geist, H. J., Agbola, S. B., Angelsen, A., Bruce, J. W., Coomes, O. T., Dirzo, R., Fischer, G., Folke, C., George, P., Homewood, K., Imbernon, J., Leemans, R., Li, X., Moran, E. F., Mortimore, M., Ramakrishnan, P., Richards, J. F., Skånes, H., Steffen, W., Stone, G. D., Svedin, U., Veldkamp, T. A., Vogel, C., and Xu, J. (2001). "The causes of land-use and land-cover change: moving beyond the 
myths". Global Environmental Change 11.4, 261-269. DOI: 10.1016/S09593780(01) 00007-3.

Langhammer, M., Thober, J., Lange, M., Frank, K., and Grimm, V. (2019). "Agricultural landscape generators for simulation models: A review of existing solutions and an outline of future directions". Ecological Modelling 393, 135-151. DOI: $10.1016 /$ J .ECOLMODEL . 2018.12.010.

Laniak, G. F., Olchin, G., Goodall, J., Voinov, A., Hill, M., Glynn, P., Whelan, G., Geller, G., Quinn, N., Blind, M., Peckham, S., Reaney, S., Gaber, N., Kennedy, R., and Hughes, A. (2013). "Integrated environmental modeling: A vision and roadmap for the future". Environmental Modelling 86 Software. Thematic Issue on the Future of Integrated Modeling Science and Technology 39, 3-23. DOI: $10.1016 / \mathrm{j}$.envsoft.2012.09.006.

Laurance, W. F., Goosem, M., and Laurance, S. G. (2009). "Impacts of roads and linear clearings on tropical forests". Trends in Ecology \& Evolution 24.12, 659-669. DOI: 10.1016/J . TREE. 2009.06.009.

Laurance, W. F., Sayer, J., and Cassman, K. G. (2014). "Agricultural expansion and its impacts on tropical nature". Trends in Ecology $\&$ Evolution 29.2, $107-$ 116. DOI: $10.1016 / \mathrm{J}$. TREE.2013.12.001.

Lawton, J., Bignell, D., Bolton, B, Bloemers, G., Eggleton, P., Hammond, P., Hodda, M., Holt, R., Larsen, T., and Mawdsley, N. (1998). "Biodiversity inventories, indicator taxa and effects of habitat modification in tropical forest". Nature 391, 72-76. DOI: 10.1038/34166.

Le, Q. B., Park, S. J., Vlek, P. L. G., and Cremers, A. B. (2008). "LandUse Dynamic Simulator (LUDAS): A multi-agent system model for simulating spatio-temporal dynamics of coupled human-landscape system. I. Structure and theoretical specification". Ecological Informatics 3.2, 135-153. DOI: $10.1016 / \mathrm{j}$. ecoinf.2008.04.003.

Le, Q. B., Park, S. J., and Vlek, P. L. G. (2010). "Land Use Dynamic Simulator (LUDAS): A multi-agent system model for simulating spatio-temporal dynamics of coupled human-landscape system: 2. Scenario-based application for impact assessment of land-use policies". Ecological Informatics 5.3, 203-221. DOI: 10. 1016/j.ecoinf.2010.02.001.

Legendre, P., Borcard, D., and Peres-Neto, P. R. (2005). "Analyzing Beta Diversity: Partitioning the Spatial Variation of Community Composition Data". Ecological Monographs 75.4, 435-450. DOI: 10.1890/05-0549. 
Malhi, Y., Phillips, O. L., Lewis, S. L., Phillips, O. L., Baker, T. R., Lloyd, J., Malhi, Y., Almeída, S., Higuchi, N., Laurance, W. F., Neill, D. A., Silva, J. N. M., Terborgh, J., Torres lezama, A., Vásquez Martinez, R., Brown, S., Chave, J., Kuebler, C., Núñez Vargas, P., and Vinceti, B. (2004). "Concerted changes in tropical forest structure and dynamics: evidence from 50 South American long-term plots". Philosophical Transactions of the Royal Society of London. Series B: Biological Sciences 359.1443, 421-436. DOI: 10.1098/rstb.2003.1431.

Margono, B., Potapov, P., Turubanova, S., Stolle, F., and Hansen, M. (2014). "Primary forest cover loss in Indonesia over 2000-2012". Nature Climate Change 4, 730-735. DOI: 10.1038/nclimate2277.

Matthews, R. B., Gilbert, N. G., Roach, A., Polhill, J. G., and Gotts, N. M. (2007). "Agent-based land-use models: a review of applications". Landscape Ecology 22.10, 1447-1459. DOI: 10.1007/s10980-007-9135-1.

McGarigal, K., Cushman, S., and Ene, E. (2012). FRAGSTATS v4: Spatial Pattern Analysis Program for Categorical and Continuous Maps. Amherst.

McKay, M. D., Beckman, R. J., and Conover, W. J. (1979). "A Comparison of Three Methods for Selecting Values of Input Variables in the Analysis of Output from a Computer Code". Technometrics 21.2, 239. DOI: 10.2307/1268522.

Melati, D. (2017). "The use of remote sensing data to monitor land use systems and forest variables of the tropical rainforest landscape under transformation in Jambi Province, Sumatra, Indonesia". Dissertation. Georg-August-Universität Göttingen, 126.

Mendenhall, C. D., Shields-Estrada, A., Krishnaswami, A. J., and Daily, G. C. (2016). "Quantifying and sustaining biodiversity in tropical agricultural landscapes". Proceedings of the National Academy of Sciences 113.51, 1454414551. DOI: $10.1073 /$ pnas. 1604981113 .

Mokany, K., Harwood, T. D., Overton, J. M., Barker, G. M., and Ferrier, S. (2011). "Combining $\alpha$ - and $\beta$-diversity models to fill gaps in our knowledge of biodiversity". Ecology Letters 14.10, 1043-1051. DOI: 10 .1111/ j . 1461 0248.2011.01675.x.

MorRIs, M. D. (1991). "Factorial sampling plans for preliminary computational experiments". Technometrics 33, 161-174.

Müller, B., Bohn, F., Dressler, G., Groeneveld, J., Klassert, C., Martin, R., Schlüter, M., Schulze, J., Weise, H., and Schwarz, N. (2013). "Describing human decisions in agent-based models - ODD + D, an extension 
of the ODD protocol". Environmental Modelling \& Software 48, 37-48. DOI: 10.1016/J.ENVSOFT.2013.06.003.

Mumme, S., Jochum, M., Brose, U., Haneda, N. F., and Barnes, A. D. (2015). "Functional diversity and stability of litter-invertebrate communities following land-use change in Sumatra, Indonesia". Biological Conservation 191, 750-758. DOI: $10.1016 / \mathrm{j}$.biocon.2015.08.033.

Myers, N., Mittermeier, R., Mittermeier, C., Fonseca, G., and Kent, J. (2000). "Biodiversity hotspot for conservation priorities". Nature 403, 853-8. DOI: $10.1038 / 35002501$.

Müller, B., Bohn, F., Dressler, G., Groeneveld, J., Klassert, C., Martin, R., Schlüter, M., Schulze, J., Weise, H., and Schwarz, N. (2013). "Describing human decisions in agent-based models - ODD + D, an extension of the ODD protocol". Environmental Modelling \& Software 48, 37-48. DOI: $10.1016 / j$.envsoft.2013.06.003.

Müller, K. and Wickham, H. (2018). tibble: Simple Data Frames. R package version 1.4.2.

Nelson, E., Mendoza, G., Regetz, J., Polasky, S., Tallis, H., Cameron, D., Chan, K. M., Daily, G. C., Goldstein, J., Kareiva, P. M., Lonsdorf, E., Naidoo, R., Ricketts, T. H., and Shaw, M. (2009). "Modeling multiple ecosystem services, biodiversity conservation, commodity production, and tradeoffs at landscape scales". Frontiers in Ecology and the Environment 7.1, 4-11. DOI: $10.1890 / 080023$.

Newbold, T., Hudson, L. N., Hill, S. L. L., Contu, S., Lysenko, I., Senior, R. A., Börger, L., Bennett, D. J., Choimes, A., Collen, B., Day, J., De Palma, A., Díaz, S., Echeverria-Londoño, S., Edgar, M. J., Feldman, A., Garon, M., Harrison, M. L. K., Alhusseini, T., Ingram, D. J., Itescu, Y., Kattge, J., Kemp, V., Kirkpatrick, L., Kleyer, M., Correia, D. L. P., Martin, C. D., Meiri, S., Novosolov, M., Pan, Y., Phillips, H. R. P., Purves, D. W., Robinson, A., Simpson, J., Tuck, S. L., Weiher, E., White, H. J., Ewers, R. M., Mace, G. M., Scharlemann, J. P. W., and Purvis, A. (2015). "Global effects of land use on local terrestrial biodiversity". Nature 520.7545, 45-50. DOI: 10.1038/nature14324.

Parker, D. C., Manson, S. M., Janssen, M. A., Hoffmann, M. J., and Deadman, P. (2003). "Multi-Agent Systems for the Simulation of Land-Use and Land-Cover Change: A Review". Annals of the Association of American Geographers 93.2, 314-337. DOI: 10.1111/1467-8306.9302004. 
Pe'er, G., Dicks, L. V., Visconti, P., Arlettaz, R., Baldi, A., Benton, T. G., Collins, S., Dieterich, M., Gregory, R. D., Hartig, F., Henle, K., Hobson, P. R., Kleijn, D., Neumann, R. K., Robijns, T., Schmidt, J., Shwartz, A., Sutherland, W. J., Turbe, A., Wulf, F., and Scott, A. V. (2014). "EU agricultural reform fails on biodiversity". Science 344.6188, 1090-1092. DOI: $10.1126 /$ science. 1253425

Pe'er, G., Zurita, G. A., Schober, L., Bellocq, M. I., Strer, M., Müller, M., and PÜTZ, S. (2013). "Simple Process-Based Simulators for Generating Spatial Patterns of Habitat Loss and Fragmentation: A Review and Introduction to the G-RaFFe Model". PLOS ONE 8.5, e64968. DOI: 10.1371/journal .pone. 0064968

Pe'er, G., Lakner, S., Passoni, G., Azam, C., Berger, J., Hartmann, L., Schueler, S., Müller, R., Meyer-Höfer, M. von, and Zinngrebe, Y. (2017). Is the CAP Fit for purpose? An evidence-based, rapid fitness-check assessment. Tech. rep. Leipzig: German Centre for Integrative Biodiversity Research (iDiv) Halle-Jena-Leipzig.

Peng, R. D. (2011). "Reproducible Research in Computational Science". Science 334.6060, 1226-1227. DOI: 10.1126/science.1213847.

Perlin, K., Ken, Perlin, and Ken (1985). "An image synthesizer". Proceedings of the 12th annual conference on Computer graphics and interactive techniques - SIGGRAPH '85. Vol. 19. 3. New York, USA: ACM Press, 287-296. DOI: $10.1145 / 325334.325247$.

Phalan, B., Onial, M., Balmford, A., and Green, R. E. (2011). "Reconciling Food Production and Biodiversity Conservation: Land Sharing and Land Sparing Compared". Science 333.6047, 1289-1291. DOI: 10.1126/science.1208742.

Polasky, S., Nelson, E., Camm, J., Csuti, B., Fackler, P., Lonsdorf, E., Montgomery, C., White, D., Arthur, J., Garber-Yonts, B., Haight, R., Kagan, J., Starfield, A., and Tobalske, C. (2008). "Where to put things? Spatial land management to sustain biodiversity and economic returns". Biological Conservation 141.6, 1505-1524. DOI: 10.1016/j.biocon.2008.03 022.

Powell, L. L., Wolfe, J. D., Johnson, E. I., Hines, J. E., Nichols, J. D., and Stouffer, P. C. (2015). "Heterogeneous movement of insectivorous Amazonian birds through primary and secondary forest: A case study using multistate models with radiotelemetry data". Biological Conservation. Special Issue: Ecology and Conservation of Avian Insectivores of the Rainforest Understory: A Pan-Tropical Perspective 188, 100-108. DOI: 10.1016/j.biocon.2015.01.028. 
Prabowo, W. E., Darras, K., Clough, Y., Toledo-Hernandez, M., Arlettaz, R., Mulyani, Y. A., and Tscharntke, T. (2016). "Bird Responses to Lowland Rainforest Conversion in Sumatran Smallholder Landscapes, Indonesia". PLOS ONE 11.5, e0154876. DOI: 10.1371/journal.pone.0154876.

R Core Team (2018). R: A Language and Environment for Statistical Computing. $\mathrm{R}$ Foundation for Statistical Computing. Vienna, Austria.

Railsback, S., Ayllón, D., Berger, U., Grimm, V., Lytinen, S., Sheppard, C., and Thiele, J. (2017). "Improving execution speed of models implemented in Netlogo". Jasss 20.1, 3. DOI: 10.18564/jasss. 3282

Railsback, S. F. and Grimm, V. (2012). Agent-Based and Individual-Based Modeling: A Practical Introduction. 59468th edition. Princeton: Princeton University Press.

Rembold, K., Mangopo, H., Tuttrosoedirdjo, S. S., and Kreft, H. (2017). "Plant diversity, forest dependency, and alien plant invasions in tropical agricultural landscapes." Biological Conservation 213.Part A, 234-242.

Sahner, J., Budi, S. W., Barus, H., Edy, N., Meyer, M., Corre, M. D., and Polle, A. (2015). "Degradation of Root Community Traits as Indicator for Transformation of Tropical Lowland Rain Forests into Oil Palm and Rubber Plantations". PLOS ONE 10.9, 1-19. DOI: 10.1371/journal.pone.0138077.

Salecker, J and Sciaini, M (2018). nlrx: Setup, Run and Analyze NetLogo Model Simulations from $R$ via $X M L$. $\mathrm{R}$ package version 0.2.0.

Saltelli, A., Tarantola, S., and Chan, K.-S. (1999). "A Quantitative ModelIndependent Method for Global Sensitivity Analysis of Model Output". Technometrics 41.1, 39-56. DOI: 10.1080/00401706.1999.10485594.

Saltelli, A., Ratto, M., Andres, T., Campolongo, F., Cariboni, J., Gatelli, D., Saisana, M., and Tarantola, S. (2008). Global sensitivity analysis: the primer. Chichester: John Wiley \& Sons.

Saltelli, A., Annoni, P., Azzini, I., Campolongo, F., Ratto, M., and TaranTOLA, S. (2010). "Variance based sensitivity analysis of model output. Design and estimator for the total sensitivity index". Computer Physics Communications 181.2, 259-270. DOI: 10.1016/J.CPC.2009.09.018.

Sandve, G. K., Nekrutenko, A., Taylor, J., and Hovig, E. (2013). "Ten Simple Rules for Reproducible Computational Research". PLOS Computational Biology 9.10, 1-4. DOI: 10.1371/journal.pcbi.1003285. 
Sayer, J., Ghazoul, J., Nelson, P., and Klintuni Boedhihartono, A. (2012). "Oil palm expansion transforms tropical landscapes and livelihoods". Global Food Security 1.2, 114-119. DOI: 10.1016/j.gfs.2012.10.003.

Schneider, D., Engelhaupt, M., Allen, K., Kurniawan, S., Krashevska, V., Heinemann, M., Nacke, H., Wijayanti, M., Meryandini, A., Corre, M. D., Scheu, S., and Daniel, R. (2015). "Impact of Lowland Rainforest Transformation on Diversity and Composition of Soil Prokaryotic Communities in Sumatra (Indonesia)". Frontiers in Microbiology 6, 1339. DOI: 10.3389/ fmicb.2015.01339.

Schouten, M., Verwaart, T., and Heijman, W. (2014). "Comparing two sensitivity analysis approaches for two scenarios with a spatially explicit rural agent-based model". Environmental Modelling E Software 54, 196-210. DOI: $10.1016 / \mathrm{j}$.envsoft.2014.01.003.

Schröder, B. and Seppelt, R. (2006). "Analysis of pattern-process interactions based on landscape models - Overview, general concepts, and methodological issues". Ecological Modelling 199.4, 505-516. DOI: 10.1016/J.ECOLMODEL. 2006 05.036 .

Schulz, G., Schneider, D., Brinkmann, N., Edy, N., Daniel, R., Polle, A., Scheu, S., and Krashevska, V. (2019). "Changes in Trophic Groups of Protists With Conversion of Rainforest Into Rubber and Oil Palm Plantations". Frontiers in Microbiology 10, 240. DOI: 10.3389/fmicb.2019.00240.

Schulze, C. H., Waltert, M., Kessler, P. J. A., Pitopang, R., Veddeler, D., Mühlenberg, M., Gradstein, S. R., Leuschner, C., Steffan-Dewenter, I., and Tscharntke, T. (2004). "Biodiversity indicator groups of tropical land-use systems: comparing plants, birds, and insects". Ecological Applications 14.5, 1321-1333. DOI: $10.1890 / 02-5409$.

Schulze, J., Müller, B., Groeneveld, J., and Grimm, V. (2017). "Agent-Based Modelling of Social-Ecological Systems: Achievements, Challenges, and a Way Forward". Journal of Artificial Societies and Social Simulation 20.2, 8. DOI: 10.18564/jasss. 3423

Sciaini, M., Fritsch, M., Scherer, C., and Simpkins, C. E. (2018). "NLMR and landscapetools: An integrated environment for simulating and modifying neutral landscape models in R". Methods in Ecology and Evolution 9.11, 2240-2248. DOI: $10.1111 / 2041-210 \mathrm{X} .13076$. 
Singh, I., Squire, L., Strauss, J., et al. (1986). Agricultural Household Models: Extensions, Applications, and Policy. Baltimore: The Johns Hopkins University Press.

Soares-Filho, B. S., Assunção, R. M., and Pantuzzo, A. E. (2001). "Modeling the Spatial Transition Probabilities of Landscape Dynamics in an Amazonian Colonization FrontierTransition probability maps indicate where changes may occur in the landscape, thus enabling better evaluation of the ecological consequences of lands". BioScience 51.12, 1059-1067. DOI: $10.1641 / 0006-$ 3568(2001)051[1059:mtstpo]2.0.co;2.

Sobol, I. M. (1990). "Sensitivity analysis for nonlinear mathematical models". Matematicheskoe Modelirovanie 2.1, 112-118. DoI: 10.18287/0134-2452-201539-4-459-461.

Solar, R. R. d. C., Barlow, J., Ferreira, J., Berenguer, E., Lees, A. C., Thomson, J. R., Louzada, J., Maués, M., Moura, N. G., Oliveira, V. H. F., Chaul, J. C. M., Schoereder, J. H., Vieira, I. C. G., Mac Nally, R., and GARDNER, T. A. (2015). "How pervasive is biotic homogenization in humanmodified tropical forest landscapes?" Ecology Letters 18.10, 1108-1118. DOI: 10.1111/ele.12494.

SyAhrinudin (2005). "The potential of oil palm and forest plantations for carbon sequestration on degraded land in Indonesia". Ecology and Development Series $28,1-107$.

Tabarelli, M., Peres, C. A., and Melo, F. P. (2012). "The 'few winners and many losers' paradigm revisited: Emerging prospects for tropical forest biodiversity". Biological Conservation 155, 136-140. DOI: 10.1016/j.biocon 2012.06.020.

TAylor, J. E. and Adelman, I. (2003). "Agricultural Household Models: Genesis, Evolution, and Extensions". Review of Economics of the Household 1.1-2, 33-58. DOI: $10.1023 / \mathrm{A}: 1021847430758$.

Thiele, J. C., Kurth, W., and Grimm, V. (2012). "RNetLogo: An R package for running and exploring individual-based models implemented in NetLogo". Methods in Ecology and Evolution 3.3, 480-483. DOI: 10.1111/j.2041-210X. $2011.00180 . \mathrm{x}$.

Thiele, J. C., Kurth, W., and Grimm, V. (2014). "Facilitating Parameter Estimation and Sensitivity Analysis of Agent-Based Models : A Cookbook Using NetLogo and R". Journal of Artificial Societies and Social Simulation 17.3, 11. DOI: $10.18564 /$ jasss. 2503 . 
Tietjen, B. (2016). "Same rainfall amount different vegetation-How environmental conditions and their interactions influence savanna dynamics". Ecological Modelling 326, 13-22. DOI: 10.1016/J.ECOLMODEL.2015.06.013.

Valbuena, D., Verburg, P. H., Bregt, A. K., and Ligtenberg, A. (2010). "An agent-based approach to model land-use change at a regional scale". Landscape Ecology 25.2, 185-199. DOI: 10.1007/s10980-009-9380-6.

VanderWal, J., Falconi, L., Januchowski, S., Shoo, L., and Storlie, C. (2014). SDMTools: Species Distribution Modelling Tools: Tools for processing data associated with species distribution modelling exercises. $\mathrm{R}$ package version 1.1-221.

Villamor, G. B., Le, Q. B., Djanibekov, U., Noordwijk, M. van, and Vlek, P. L. G. (2014). "Biodiversity in rubber agroforests, carbon emissions, and rural livelihoods: An agent-based model of land-use dynamics in lowland Sumatra". Environmental Modelling \& Software 61, 151-165. DOI: $10.1016 / \mathrm{j}$.envsoft 2014.07 .013 .

VinCENOt, C. E. (2018). "How new concepts become universal scientific approaches: insights from citation network analysis of agent-based complex systems science." Proceedings. Biological sciences 285.1874, 20172360. DOI: 10.1098/rspb. 2017 2360.

Watson, J., Dudley, N., Segan, D., and Hockings, M. (Nov. 2014). "The performance and potential of protected areas". Nature 515, 67-73. DOI: 10 1038/nature13947.

Wauters, J. B., Coudert, S., Grallien, E., Jonard, M., and Ponette, Q. (2008). "Carbon stock in rubber tree plantations in Western Ghana and Mato Grosso (Brazil)". Forest Ecology and Management. Large-scale experimentation and oak regeneration 255.7, 2347-2361. DOI: $10.1016 / \mathrm{j}$.foreco.2007.12.038

Wickham, H. (2014). "Tidy Data”. Journal of Statistical Software, Articles 59.10, $1-23$.

Wiegand, T. and Moloney, K. A. (2013). Handbook of spatial point-pattern analysis in ecology. Boca Raton: Chapman and Hall/CRC.

Wilensky, U. (1999). NetLogo. Evanston, IL: Center for Connected Learning and Computer-Based Modeling, Northwestern University.

Willighagen, E and Ballings, M (2015). genalg: $R$ based Genetic Algorithm. $\mathrm{R}$ package version 0.2.0. 
With, K. A. (1997). "The Application of Neutral Landscape Models in Conservation Biology. Aplicacion de Modelos de Paisaje Neutros en la Biologia de la Conservacion". Conservation Biology 11.5, 1069-1080. DOI: 10.1046/j.15231739.1997.96210.x.

Zemp, D. C., Ehbrecht, M., Seidel, D., Ammer, C., Craven, D., Erkelenz, J., Irawan, B., Sundawati, L., Hölscher, D., and Kreft, H. (2019a). "Mixedspecies tree plantings enhance structural complexity in oil palm plantations". Agriculture, Ecosystems \& Environment 283, 106564. DOI: 10.1016/j.agee 2019.06 .003 .

Zemp, D. C., Gérard, A., Hölscher, D., Ammer, C., Irawan, B., Sundawati, L., Teuscher, M., and Kreft, H. (2019b). "Tree performance in a biodiversity enrichment experiment in an oil palm landscape". Journal of Applied Ecology 56.10, 2340-2352. DOI: 10.1111/1365-2664.13460.

Zhang, H. and Vorobeychik, Y. (2016). "Empirically Grounded Agent-Based Models of Innovation Diffusion: A Critical Review". arXiv:1608.08517 [physics]. 


\section{Acknowledgments}

This thesis would not have been possible without the continuous support and guidance from many people. Firstly, I would like to express my sincere gratitude to my supervisor Prof. Dr. Kerstin Wiegand for the continuous support during my studies. Her guidance helped me in all the time of research and writing of this thesis. Many thanks also to my co-supervisor Dr. Katrin M. Meyer who encouraged me to apply for a PhD grant and supported my work with fruitful discussions and guidance. Many thanks to all members of the Ecosystem Modelling group in Goettingen, for being great colleagues, friends and supporters of my research. Your valuable comments on my talks, posters and manuscripts were a great resource for improving my work and scientific skills. Special thanks go to Claudia Dislich, who supported me early on in my scientific career and encouraged me to work in the EFForTS project. Without her expertise, support and guidance this work would not have been possible. Special thanks also go to Marco Sciaini, who encouraged me to develop my first R-package and always supported me, as a colleague and a friend. Special thanks also go to Craig Simpkins, Matthias Fritsch and Daniel Esser, who were always open to listen to my ideas and supported me with their expertise. Huge thanks go to Ilona Watteler-Spang for her endless effort in getting the formal things done and her patience and persistence in stressful moments. Special thanks go to all my colleagues from the EFForTS project. Without the hard and excellent work of these researchers, our models would miss the excellent data basis that allows us to take our ideas to the next level.

I would also like to thank the Deutsche Bundesstiftung Umwelt (DBU), who supported my work during the first three years of my $\mathrm{PhD}$ and encouraged me to start a scientific career. I gratefully acknowledge the funding I received from the collaborative research centre 990, EFForTS.

I would like to thank my parents, my brother, and my family for all their patience, help and support throughout this challenging work. I thank my beloved wife for her patience, support and understanding and for accompanying me through this intense time. I would like to thank my dear friend Henrik Ziegenhagen for all his support, open ears, and for juicing up my work-life balance. I would like to thank all my faithful friends from the scout association Großer Jäger. Thank you for being loyal, even in times I became scarce. Last, but not least, I would like to thank the music for being my companion through all stages of this work. Without the power of music I would not have been able to refresh my mind sustainably. 


\section{Doktoranden-Erklärung der Georg-August-Universität Göttingen}

Name: Jan Salecker

Anschrift: Buesgenweg 4, 37077 Göttingen

Ich habe eine Dissertation zum Thema: Landscape-level assessment of ecological and socioeconomic functions of rainforest transformation systems in Sumatra (Indonesia) an der Georg-August-Universität Göttingen angefertigt. Dabei wurde ich von Frau Prof. Dr. Kerstin Wiegand betreut.

Ich gebe folgende Erklärung ab:

1. Die Gelegenheit zum vorliegenden Promotionsvorhaben ist mir nicht kommerziell vermittelt worden. Insbesondere habe ich keine Organisation eingeschaltet, die gegen Entgelt Betreuerinnen und Betreuer für die Anfertigung von Dissertationen sucht oder die mir obliegenden Pflichten hinsichtlich der Prüfungsleistungen für mich ganz oder teilweise erledigt.

2. Hilfe Dritter wurde bis jetzt und wird auch künftig nur in wissenschaftlich vertretbarem und prüfungsrechtlich zulässigem Ausmaß in Anspruch genommen. Insbesondere sind alle Teile der Dissertation selbst angefertigt; fremde Hilfe habe ich dazu weder unentgeltlich noch entgeltlich entgegengenommen und werde dies auch zukünftig so halten. Die Kapitel 2 f5 dieser Dissertation basieren auf Manuskripten, die in wissenschaftlichen Zeitschriften publiziert wurden (Kapitel 2, 3, 5), oder zur Veröffentlichung in ebensolchen Zeitschriften eingereicht werden sollen (Kapitel 4). Die Schaffung dieser Kapitel wurden im typischen wissenschaftlichen Rahmen durch die angegebenen Mitautoren, gerade mit Blick auf Aufbau und Sprache, unterstützt.

Des Weiteren ist mir bekannt, dass Unwahrhaftigkeiten hinsichtlich der vorstehenden Erklärung die Zulassung zur Promotion ausschließen bzw. später zum Verfahrensabbruch oder zur Rücknahme des erlangten Grades berechtigen.

Göttingen, 24.02.2020 